DERLI DIAS DO AMARAL JUNIOR

\title{
PROJETO DE UMA TURBINA AXIAL PARA MICRO APROVEITAMENTOS HIDRÁULICOS COM ÊNFASE NO CÁLCULO DOS PERFIS DO ROTOR E DISTRIBUIDOR
}

Dissertação apresentada à Escola Politécnica da Universidade de São Paulo para obtenção do Título de Mestre em Engenharia. 
DERLI DIAS DO AMARAL JUNIOR

PROJETO DE UMA TURBINA AXIAL PARA MICRO APROVEITAMENTOS HIDRÁULICOS COM ÊNFASE NO CÁLCULO DOS PERFIS DO ROTOR E DISTRIBUIDOR

Dissertação apresentada à Escola Politécnica da Universidade de São Paulo para obtenção do Título de Mestre em Engenharia.

Área de Concentração:

Engenharia Mecânica

Orientador:

Prof. Dr. Fabio Saltara 


\begin{tabular}{|l|} 
Este exemplar foi revisado e corrigido em relação à versão original, sob \\
responsabilidade única do autor e com a anuência de seu orientador. \\
São Paulo, 27 de janeiro de 2014. \\
Assinatura do autor \\
Assinatura do orientador
\end{tabular}

FICHA CATALOGRÁFICA

Amaral Junior, Derli Dias do

Projeto de uma turbina axial para micro aproveitamentos hidráulicos com ênfase no cálculo dos perfis do rotor e distribuidor / D.D. do Amaral Junior. -- versão corr. -- São Paulo, 2014. $112 \mathrm{p}$.

Dissertação (Mestrado) - Escola Politécnica da Universidade de São Paulo. Departamento de Engenharia Mecânica.

1. Turbinas hidráulicas 2. Cascatas 3 . Rotor 4. Teoria de campos I. Universidade de São Paulo. Escola Politécnica. Departamento de Engenharia Mecânica II. t. 


\section{DEDICATÓRIA}

Aos meus pais Derly e Dalva, meu irmão Ricardo e minha esposa Tatiane pelo carinho, paciência e incentivo. 


\section{AGRADECIMENTOS}

Agradeço a Deus primeiramente por me guiar no caminho correto da felicidade que passa essencialmente pela busca de conhecimento.

À Universidade Estadual Paulista (UNESP) e a Escola Politécnica da Universidade de São Paulo que despertaram em mim o interesse acadêmico e me formaram Engenheiro Mecânico e Mestre em engenharia.

À minha família, meu pai Derly Dias, minha mãe Dalva Dias, minha esposa Tatiane Matheus e meu irmão Ricardo Leandro que deram estrutura financeira, carinho e incentivo para conclusão deste trabalho.

Ao consultor e Prof. Dr. Paulo Cesar Leone que teve papel central no desenvolvimento deste trabalho através da sua vasta experiência, ajuda e paciência durante a preparação e finalização do estudo.

Ao meu orientador Prof. Dr. Fabio Saltara, pela confiança, orientação e puxões de orelha em momentos decisivos do estudo.

À empresa Hydrel que através de seu fundador, Almirante Othon Luiz Pinheiro da Silva, me forneceu subsídios e confiança para a conclusão deste estudo.

Aos amigos de trabalho Bruce Gazzola, Henrique Lourenço, Antonio Pereira, Wesley Monteiro, Shintaro Jonen, Carlos Mello e Fabrizio Stocco que em deram apoio durante o desenvolvimento deste estudo. 


\section{RESUMO}

O proposito deste trabalho é apresentar uma metodologia para projeto de uma turbina axial para micro aproveitamentos hidráulicos com ênfase no projeto das geometrias do rotor e distribuidor, incluindo os resultados analíticos e numéricos através do método dos painéis. Comparações do projeto analítico com testes de campo são também apresentadas. A metodologia analítica utilizada foi a teoria do escoamento não-viscoso de Wenig que avalia os fatores de interferência para modelar o quando as característica de sustentação e arrasto de uma cascata de perfis são relacionadas com as de um perfil isolado. Foi verificado que a teoria de Wenig fornece uma boa previsão do fator de interferência se o ângulo de ataque for relativamente baixo e a espessura das pás for relativamente pequena quando comparada com a distância entre as pás. A metodologia numérica usando o método de vorticidade superficial proposto por Martensen para uma cascata de perfis e para um perfil isolado foi utilizada para se ter uma comparação com os coeficientes analíticos de sustentação e arrasto. Testes de campo foram realizados em um protótipo de $20 \mathrm{~kW}$ de acordo com a norma IEC-60041 e sua comparação com o método analítico e por consequência o método numérico validou o método empregado para confecção das pás do rotor e distribuidor.

Palavras Chave: Turbina Axial, Cascata de Perfis, Método dos Painéis, Ensaios de Campo. 


\begin{abstract}
The purpose of this work is to present a methodology to design a small axial hydraulic turbine with emphasis on the project of the profiles of the runner and wicket gate, including both analytical and numerical results from a cascade panel method. Comparisons with field test measurements of a prototype are also presented. The analytical methodology used is the Wenig's inviscid flow theory which requires the evaluation of interference factors to model how lift and drag characteristics of the turbine cascade of blades are related to those of a single isolated airfoil. It is found that the Wenig's theory provides a reasonable prediction of the lift interference factor if both the angle of attack is relatively low and the thickness of the blades is relatively small when compared to the distance between the blades. The numerical methodology that relies the Hess and Smith's 2-D panel method for a cascade of blades and for an isolated airfoil was used in order to have a comparison with the analytical lift and drag. Prototype field test measurements of the turbine power output, in agreement with IEC-60041 standards, were carried out to evaluate the results using the analytical and numerical methods.
\end{abstract}

Keywords: Hydraulic turbine, cascades, runner, field theory. 


\section{LISTA DE SÍMBOLOS}

\section{SÍMBOLOS LATINOS}

\begin{tabular}{|c|c|c|}
\hline$a$ & Designação da Linha Média & [un] \\
\hline$(r h s)_{m}$ & Termo do lado direito da Matriz dos Coeficientes dos Painéis & {$[\mathrm{m} / \mathrm{s}]$} \\
\hline$a_{0}$ & Inclinação da Curva de Sustentação & {$\left[{ }^{\circ}\right]$} \\
\hline$A_{1}$ & Área de Entrada da Turbina & {$\left[\mathrm{m}^{2}\right]$} \\
\hline$A_{2}$ & Área de Saída da Turbina & {$\left[\mathrm{m}^{2}\right]$} \\
\hline$a_{n}$ & Coeficientes do Polinômio do Coef. de Arrasto & [un] \\
\hline$b$ & Largura da Crista & [m] \\
\hline$c$ & Corda do Perfil & [mm] \\
\hline$C_{1}$ & Constante do Tipo de Distribuição de Espessura & [un] \\
\hline$C_{2}$ & Constante de Arqueamento do Perfil & [un] \\
\hline$C_{B A}$ & Distância da Linha de Referência & [mm] \\
\hline$C_{D}$ & Coeficiente de Arrasto & [un] \\
\hline$C_{F r}$ & Coeficiente de Força Radial & [un] \\
\hline$C_{F t}$ & Coeficiente de Força Tangencial & [un] \\
\hline$C_{L}$ & Coeficiente de Sustentação & [un] \\
\hline Clisolado & Coeficiente de Sustentação Perfil Isolado & [un] \\
\hline$C_{L O}$ & Coeficiente de Sustentação da Cascata de Perfis & [un] \\
\hline$C_{P}$ & Coeficiente de Pressão & [un] \\
\hline$C_{T}$ & Coeficiente de Torque de uma Pá & [un] \\
\hline$C_{T R}$ & Coeficiente de Torque de um Perfil & [un] \\
\hline$C_{z}$ & Componente de Força perpendicular ao Perfil & {$[\mathrm{N}]$} \\
\hline$D$ & Arrasto & {$[\mathrm{N}]$} \\
\hline$D_{R}$ & Raio do Rotor & [mm] \\
\hline$D_{X}$ & Espaçamento Radial & [un] \\
\hline$F$ & Força & {$[\mathrm{N}]$} \\
\hline$f$ & Estimativa para Iteração de $\beta$ & [un] \\
\hline$f_{0}$ & Ordenada Máxima da Linha Média & [mm] \\
\hline$F_{a}$ & Força Axial nas Pás & {$[\mathrm{N}]$} \\
\hline$F_{i t}$ & Função de Iteração do Ângulo $\beta$ & [un] \\
\hline$F_{t}$ & Força Tangencial nas Pás & {$[\mathrm{N}]$} \\
\hline$g$ & Aceleração da Gravidade Local & {$\left[\mathrm{m} / \mathrm{s}^{2}\right]$} \\
\hline$h$ & Espaçamento dos Perfis entre Cordas & [mm] \\
\hline
\end{tabular}




\begin{tabular}{|c|c|c|}
\hline$h_{a}$ & Afogamento da Hélice & {$[\mathrm{m}]$} \\
\hline$h_{c}$ & Altura da Crista (Método dos Vertedouros) & [m] \\
\hline$H_{g}$ & Queda Bruta & {$[\mathrm{m}]$} \\
\hline$H_{l}$ & Queda Líquida & [m] \\
\hline$H_{l n}$ & Queda Líquida Nominal & {$[\mathrm{m}]$} \\
\hline$k$ & Parâmetro da Relação Espaçamento-Corda & [un] \\
\hline$k\left(s_{m}, s_{n}\right)$ & Coeficiente de Acoplamento & [un] \\
\hline$k_{w m}$ & Termo de Correção de Espessura & [un] \\
\hline$L$ & Sustentação & {$[\mathrm{N}]$} \\
\hline$m$ & Relação do Coeficiente de Sustentação da Cascata & [un] \\
\hline M & Número de Pontos Centrais (Método dos Painéis) & [un] \\
\hline$m_{2}$ & Coeficiente para NACA $66 \mathrm{a}=0,8$ & [un] \\
\hline$m_{3}$ & Coeficiente para NACA $66 \mathrm{a}=0,8$ & [un] \\
\hline$m_{5}$ & Coeficiente para NACA $66 \mathrm{a}=0,8$ & [un] \\
\hline$m_{p}$ & Painel & [un] \\
\hline$M_{t}$ & Torque Hidráulico no Rotor & \\
\hline$n$ & Expoente & [un] \\
\hline$n_{n}$ & Rotação Nominal & {$[\mathrm{rpm}]$} \\
\hline$n_{q}$ & Rotação Especifica & [un] \\
\hline$p$ & Pressão & {$[\mathrm{Pa}]$} \\
\hline$p^{-}$ & Perda de Pressão Total & {$[\mathrm{Pa}]$} \\
\hline$p_{0}$ & Pressão Atmosférica & {$[\mathrm{Pa}]$} \\
\hline$p_{0 \text { epp }}$ & Pressão a Montante do Perfil & {$[\mathrm{Pa}]$} \\
\hline$p_{1}$ & Pressão de Entrada nas Pás e da Turbina & {$[\mathrm{Pa}]$} \\
\hline$p_{2}$ & Pressão de Saída nas Pás e da Turbina & {$[\mathrm{Pa}]$} \\
\hline$p_{\infty}$ & Pressão do Escoamento Livre & {$[\mathrm{Pa}]$} \\
\hline$P_{f}$ & Potência dissipada nos Mancais & {$[\mathrm{W}]$} \\
\hline$P_{g}$ & Potência do Gerador & {$[\mathrm{W}]$} \\
\hline$P_{R}$ & Coeficiente de Carregamento & [un] \\
\hline$P_{t}$ & Potência da Turbina & {$[\mathrm{W}]$} \\
\hline$p_{v}$ & Pressão de Vapor d'água & {$[\mathrm{Pa}]$} \\
\hline$Q$ & Vazão da Turbina & {$\left[\mathrm{m}^{3} / \mathrm{s}\right]$} \\
\hline$q_{m n}$ & Velocidade Induzida em $s_{m}$ & {$[\mathrm{~m} / \mathrm{s}]$} \\
\hline$Q_{n}$ & Vazão Nominal & {$\left[\mathrm{m}^{3} / \mathrm{s}\right]$} \\
\hline$r$ & Raio & [mm] \\
\hline
\end{tabular}




\begin{tabular}{|c|c|c|}
\hline$R_{B}$ & Raio do Cubo & {$[\mathrm{mm}]$} \\
\hline$R_{e}$ & Número de Reynolds & [un] \\
\hline$r_{m n}$ & Distância entre dois Painéis & [m] \\
\hline$R_{R}$ & Raio do Rotor & {$[\mathrm{mm}]$} \\
\hline$S$ & Área & {$\left[\mathrm{m}^{2}\right]$} \\
\hline$s$ & Perímetro do Perfil & [m] \\
\hline$S_{c}$ & Solidez da Cascata de Perfis & [un] \\
\hline$S_{c a v}$ & Margem de Segurança para o início de Cavitação & [un] \\
\hline$S_{m}$ & Comprimento do Painel $\mathrm{m}$ & [m] \\
\hline$s_{n}$ & Elemento de Vorticidade & [un] \\
\hline Ste & Elemento do Bordo de Fuga (Método dos Painéis) & [m] \\
\hline$T$ & Torque & {$[\mathrm{Nm}]$} \\
\hline$t$ & Espessura do Perfil & {$[\mathrm{mm}]$} \\
\hline$t_{0}$ & Espessura Máxima do Perfil & [mm] \\
\hline$u$ & Coeficiente dos Ângulos da Cascata & [un] \\
\hline$U_{\infty}$ & Velocidade Axial em relação ao Painel $m$ & {$[\mathrm{~m} / \mathrm{s}]$} \\
\hline$U_{m n}$ & Componente Axial da Velocidade $W_{m n}$ & {$[\mathrm{~m} / \mathrm{s}]$} \\
\hline$V$ & Velocidade & {$[\mathrm{m} / \mathrm{s}]$} \\
\hline$V_{0}$ & Velocidade de Entrada na Máquina & {$[\mathrm{m} / \mathrm{s}]$} \\
\hline$v_{1}$ & Velocidade de Entrada nas Pás e da Turbina & {$[\mathrm{m} / \mathrm{s}]$} \\
\hline$V_{1}$ & Velocidade de Circulação na Cascata de Painéis (horário) & {$[\mathrm{m} / \mathrm{s}]$} \\
\hline$v_{2}$ & Velocidade de Saída nas Pás e da Turbina & {$[\mathrm{m} / \mathrm{s}]$} \\
\hline$V_{2}$ & Velocidade de Circulação na Cascata de Painéis (anti-horário) & {$[\mathrm{m} / \mathrm{s}]$} \\
\hline$V_{\infty}$ & Velocidade Tangencial ao Painel $m$ & {$[\mathrm{~m} / \mathrm{s}]$} \\
\hline$v_{\infty}$ & Velocidade do Escoamento Livre & {$[\mathrm{m} / \mathrm{s}]$} \\
\hline$v_{a}$ & Velocidade Axial & {$[\mathrm{m} / \mathrm{s}]$} \\
\hline$V_{m}$ & Velocidade Média na Entrada do Distribuidor & {$[\mathrm{m} / \mathrm{s}]$} \\
\hline$V_{m n}$ & Componente Tangencial da Velocidade $W_{m n}$ & {$[\mathrm{~m} / \mathrm{s}]$} \\
\hline$v_{t}$ & Velocidade Tangencial & {$[\mathrm{m} / \mathrm{s}]$} \\
\hline$W_{1}$ & Velocidade de Incidência no Rotor & {$[\mathrm{m} / \mathrm{s}]$} \\
\hline$W_{2}$ & Velocidade de Saída do Rotor & {$[\mathrm{m} / \mathrm{s}]$} \\
\hline$W_{\infty}$ & Velocidade Média na Cascata (Método dos Painéis) & {$[\mathrm{m} / \mathrm{s}]$} \\
\hline$W_{\infty}$ & Velocidade de Corrente Uniforme Incidente ao Painel m & {$[\mathrm{m} / \mathrm{s}]$} \\
\hline$W_{e}$ & Velocidade de Incidência na Cascata (Método dos Painéis) & {$[\mathrm{m} / \mathrm{s}]$} \\
\hline$W_{m}$ & Velocidade Média no Rotor & {$[\mathrm{m} / \mathrm{s}]$} \\
\hline$W_{m n}$ & Velocidade Induzida dos Painéis & {$[\mathrm{m} / \mathrm{s}]$} \\
\hline
\end{tabular}




$\begin{array}{llr}W_{s} & \text { Velocidade de Saída na Cascata (Método dos Painéis) } & {[\mathrm{m} / \mathrm{s}]} \\ W_{t} & \text { Velocidade Tangencia ao Rotor } & {[\mathrm{m} / \mathrm{s}]} \\ x_{C} & \text { Abscissa do Corda } & {[\mathrm{mm}]} \\ x_{D} & \text { Abscissa do Dorso } & {[\mathrm{mm}]} \\ x_{F} & \text { Abscissa da Face } & {[\mathrm{mm}]} \\ X_{n} & \text { Abscissa dos Pontos dos Painéis } & {[\mathrm{m}]} \\ x_{n} & \text { Abscissa dos Pontos dos Pivôs dos Painéis } & {[\mathrm{m}]} \\ Y^{*} & \text { Ordenada Planificada } & {[\mathrm{mm}]} \\ y_{c} & \text { Ordenada em função da Corda } & {[\mathrm{mm}]} \\ y_{D} & \text { Ordenada do Dorso } & {[\mathrm{mm}]} \\ y_{F} & \text { Ordenada da Face } & {[\mathrm{mm}]} \\ Y_{n} & \text { Ordenada dos Pontos dos Painéis } & {[\mathrm{m}]} \\ y_{n} & \text { Ordenada dos Pontos dos Pivôs dos Painéis } & {[\mathrm{m}]} \\ y_{t} & \text { Ordenada da Linha Média } & {[\mathrm{mm}]} \\ Z & \text { Número de Pás } & {[\mathrm{un}]} \\ Z_{\mathrm{D}} & \text { Coordenada do Dorso } & {[\mathrm{mm}]} \\ Z e l & \text { Distancia Vertical entre os Sensores de Entrada e Saída da Turbina } & {[\mathrm{m}]} \\ Z_{\mathrm{F}} & \text { Coordenada da Face } & {[\mathrm{mm}]}\end{array}$

\section{SÍMBOLOS GREGOS}

$\begin{array}{lll}\alpha_{1} & \text { Ângulo de Entrada nas Pás } & {\left[{ }^{\circ}\right]} \\ \alpha_{2} & \text { Ângulo de Saída nas Pás } & {\left[{ }^{\circ}\right]} \\ \alpha_{1 R} & \text { Ângulo de Incidência relativo a } W_{1} & {\left[{ }^{\circ}\right]} \\ \alpha_{2 D} & \text { Ângulo de Incidência relativo a } V_{1} & {\left[{ }^{\circ}\right]} \\ \alpha_{2 R} & \text { Ângulo de Incidência relativo a } W_{2} & {\left[{ }^{\circ}\right]} \\ \alpha_{i d} & \text { Ângulo de Ataque Ideal } & {\left[{ }^{\circ}\right]} \\ \alpha_{i n c} & \text { Ângulo de Incidência } & {\left[{ }^{\circ}\right]} \\ \alpha_{m} & \text { Ângulo Médio entre } \alpha_{1} \text { e } \alpha_{2} & {\left[{ }^{\circ}\right]} \\ \alpha_{m R} & \text { Ângulo Médio de Incidência no Rotor } & {\left[{ }^{\circ}\right]} \\ \alpha_{m e} & \text { Ângulo Médio de Incidência no Distribuidor } & {\left[{ }^{\circ}\right]} \\ \alpha_{z l} & \text { Ângulo Incidência para Sustentação Nula } & {\left[{ }^{\circ}\right]} \\ \alpha_{\infty} & \text { Ângulo Incidência do Escoamento Livre (Painéis) } & {\left[{ }^{\circ}\right]} \\ \beta & \text { Ângulo de Sustentação Nula } & {\left[{ }^{\circ}\right]} \\ \beta_{e} & \text { Ângulo Relativo } W_{e} & {\left[{ }^{\circ}\right]} \\ \beta_{s} & \text { Ângulo Relativo } W_{s} & {\left[{ }^{\circ}\right]}\end{array}$




\begin{tabular}{|c|c|c|}
\hline$\beta_{\infty}$ & Ângulo Relativo $W_{\infty}$ & {$\left[{ }^{\circ}\right]$} \\
\hline$\beta_{m}$ & Inclinação do Perfil do Painel $m$ & {$\left[{ }^{\circ}\right]$} \\
\hline$\beta_{n}$ & Inclinação do par vizinho de Elementos $n$ & {$\left[^{\circ}\right]$} \\
\hline$\beta_{z l}$ & Ângulo de Sustentação Nula & {$\left[{ }^{\circ}\right]$} \\
\hline$\beta_{c o}$ & Inclinação da Corda do Perfil & {$\left[^{\circ}\right]$} \\
\hline$\Gamma$ & Circulação & {$\left[\mathrm{m}^{2} / \mathrm{s}\right]$} \\
\hline$\Delta h_{\text {viscosa }}$ & Perdas Viscosas na Turbina & [m] \\
\hline$\Delta h_{u ́ t i l}$ & Queda Útil do Rotor & [m] \\
\hline$\Delta h_{\text {suç̧ão }}$ & Perda de Carga na Sucção & [m] \\
\hline$\Delta h_{\text {total }}$ & Queda Útil Total & [m] \\
\hline$\gamma$ & Vorticidade & [un] \\
\hline$\varepsilon$ & Relação de Arrasto do Perfil & [un] \\
\hline$\eta_{\text {geno }}$ & Rendimento do Gerador & [un] \\
\hline$\eta_{G}$ & Eficiência Global & {$[\%]$} \\
\hline$\eta_{H}$ & Eficiência Hidráulica do Rotor & {$[\%]$} \\
\hline$\Theta_{F}$ & Ângulo Polar da Face & {$\left[{ }^{\circ}\right]$} \\
\hline$\Theta_{D}$ & Ângulo Polar do Dorso & {$\left[{ }^{\circ}\right]$} \\
\hline$\theta$ & Ângulo Polar em relação ao Eixo x & {$\left[{ }^{\circ}\right]$} \\
\hline$\theta_{c}$ & Ângulo Relativo a Cascata & [rad] \\
\hline$\theta_{c o}$ & Ângulo da Corda & {$\left[{ }^{\circ}\right]$} \\
\hline$\theta_{D}$ & Ângulo do Dorso & {$\left[{ }^{\circ}\right]$} \\
\hline$\theta_{F}$ & Ângulo da Face & {$\left[{ }^{\circ}\right]$} \\
\hline$\mu$ & Raio do Plano Complexo YX & {$[\mathrm{m}]$} \\
\hline$\mu_{v}$ & Coeficiente de Cascata (Método dos Vertedouros) & [un] \\
\hline$v$ & Viscosidade Cinemática & {$\left[\mathrm{m}^{2} / \mathrm{s}\right]$} \\
\hline$\rho$ & Densidade da Água & {$\left[\mathrm{kg} / \mathrm{m}^{3}\right]$} \\
\hline$\sigma_{0}$ & Número de Cavitação Local & [un] \\
\hline$\sigma_{x}$ & Número Local de Cavitação & [un] \\
\hline$\phi_{m n}$ & Inclinação de $r_{m n}$ & {$\left[{ }^{\circ}\right]$} \\
\hline$\Phi$ & Ângulo do Passo & {$\left[{ }^{\circ}\right]$} \\
\hline$\chi$ & Raio Adimensional & [un] \\
\hline$\chi_{b}$ & Raio Adimensional do Cubo do Rotor & [un] \\
\hline$\Omega$ & Rotação & [rpm] \\
\hline$\omega$ & Velocidade Angular & {$[\mathrm{rad} / \mathrm{s}]$} \\
\hline
\end{tabular}




\section{SUMÁRIO}

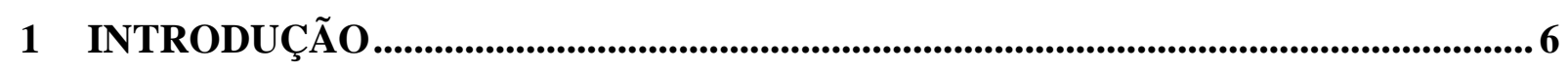

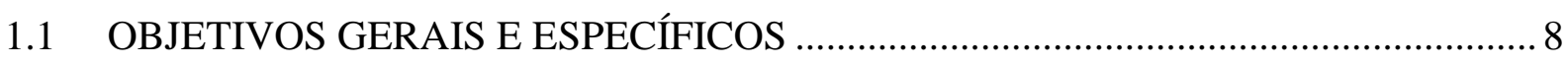

2 REVISÃO DA BIBLIOGRAFIA........................................................................9

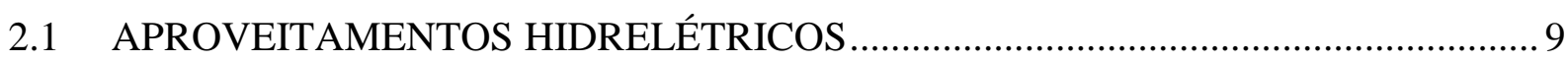

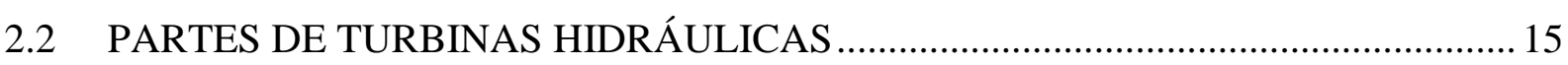

2.3 CONCEITOS LIGADOS A TURBINAS HIDRÁULICAS AXIAIS ………………....... 17

2.3.1 Esquema de Turbina Axial em Análise..................................................................... 17

2.4 DEFINIÇÃO DAS VARIÁVEIS IMPORTANTES DE PROJETO................................. 18

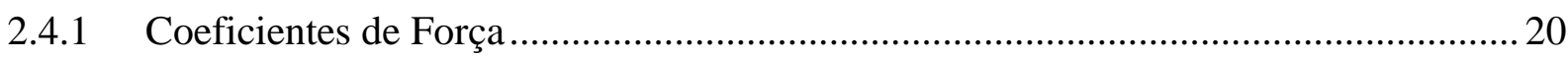

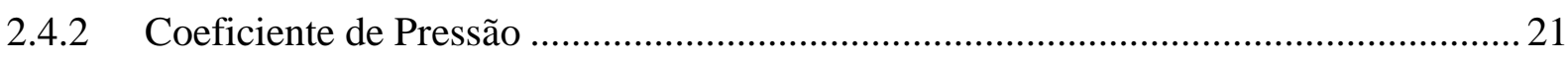

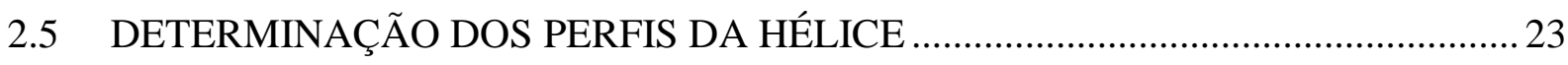

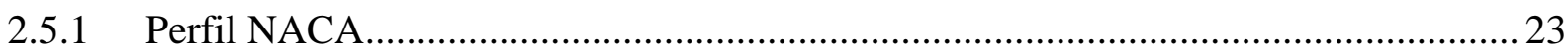

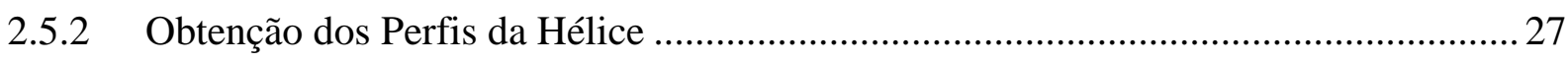

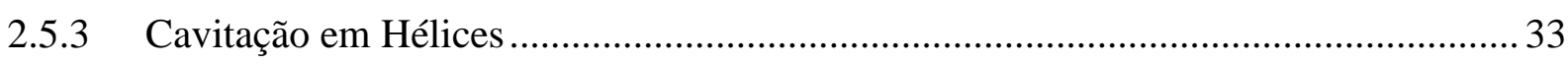

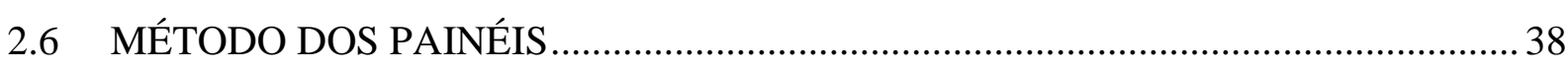

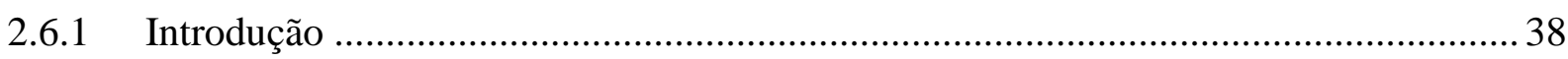

2.6.2 Modelo de Vorticidade Superficial para Escoamentos planos bidimensionais ...........38

2.6.3 Esquema computacional para análise da Vorticidade Superficial .............................. 42

2.6.4 Método da Vorticidade Superficial para Perfis Isolados (Aerofólios) .......................... 44

2.6.5 Método dos Painéis para perfis em cascata............................................................... 46

3 DESENVOLVIMENTO ................................................................................................50

3.1 OBTENÇÃO DOS PERFIS DO ROTOR E DISTRIBUIDOR …………………….......50

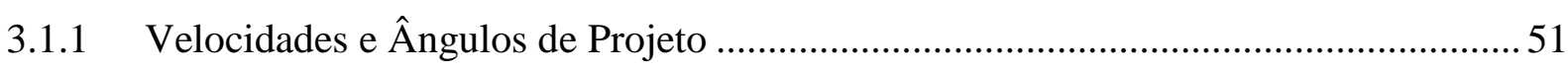

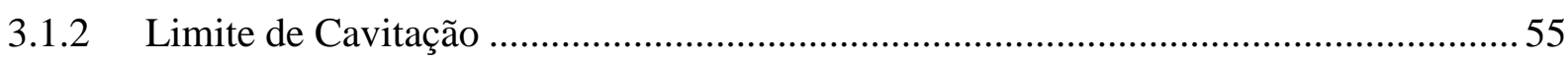

3.1.3 Ajuste de Cascata ........................................................................................ 57

3.1.4 Coeficiente de Sustentação e Potência da Unidade Geradora......................................... 60

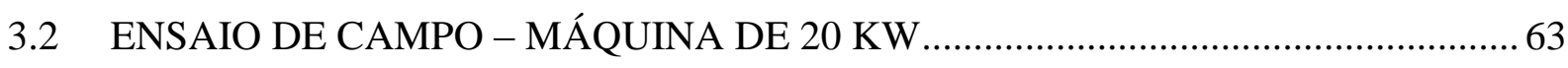

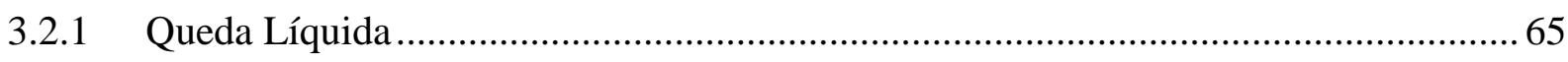

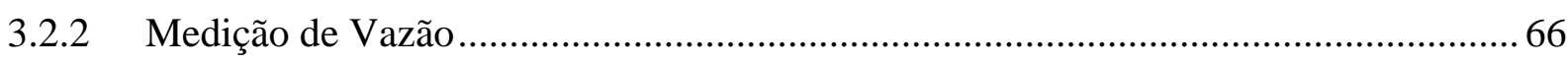

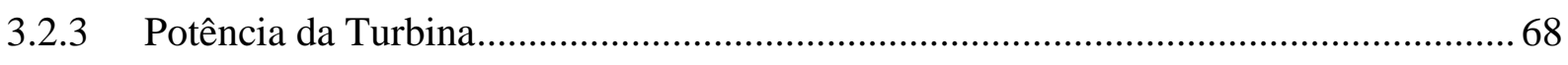

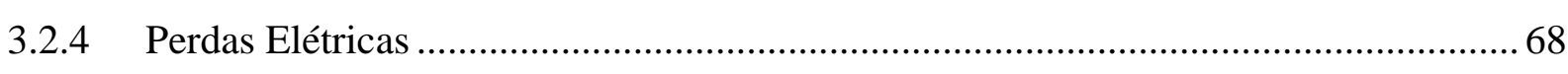

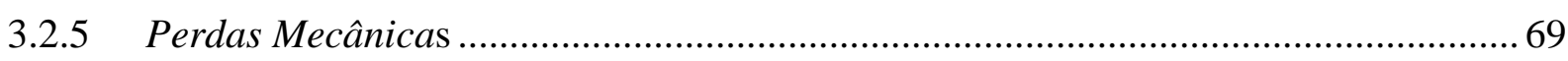

4 RESULTADOS E DISCUSSÕES....................................................................... 
4.1 DETERMINAÇÃO DOS PERFIS DA HÉLICE (MÉTODO ANALÍTICO)................ 71

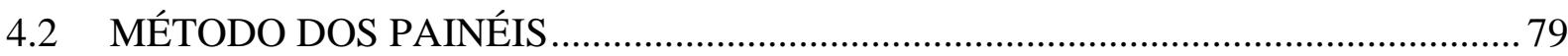

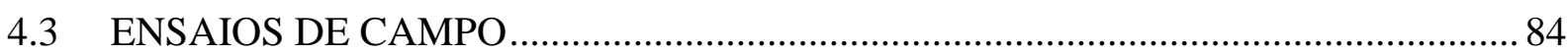

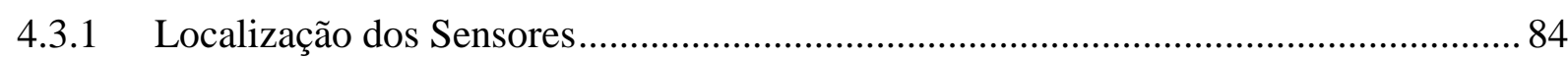

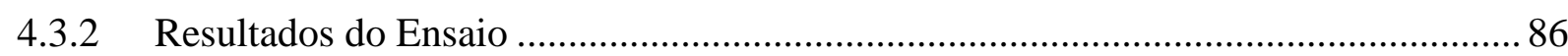

5 CONCLUSÕES E RECOMENDAÇÕES................................................................91 


\section{Lista de Figuras}

FIGURA 1.1. MÁQUINA DE $20 \mathrm{KW}$ EM TESTES NO CTH DA USP E NA FAZENDA IPANEMA

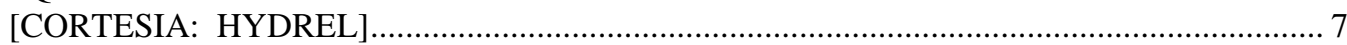

FIGURA 1.2. CORTE ESQUEMÁTICO DA MÁQUINA DE 20 KW [CORTESIA: HYDREL] ......................... 7

FIGURA 2.1. FAIXA OPERACIONAL DOS DIVERSOS TIPOS DE TURBINAS HIDRÁULICAS. FIGURA EXTRAÍDA DE VOITH (2004).

FIGURA 2.2. GRÁFICO PARA ESCOLHA DOS TIPOS PADRONIZADOS DE TURBINAS HIDRÁULICAS. [CORTESIA: HYDREL].

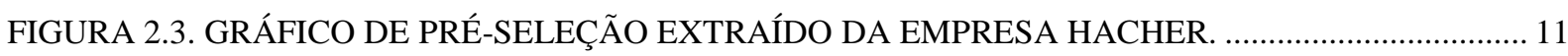

FIGURA 2.4. EXEMPLO DE TURBINA BULBO. FIGURA EXTRAÍDA DE VOITH (2004)........................... 12

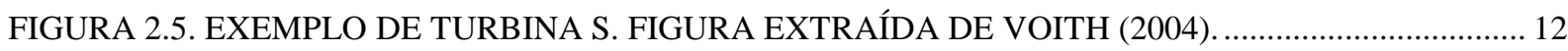

FIGURA 2.6 EXEMPLO DE TURBINA FRANCIS. FIGURA EXTRAÍDA DE VOITH (2004). ...................... 13

FIGURA 2.7 EXEMPLO DE TURBINA KAPLAN. FIGURA EXTRAÍDA DE VOITH (2004) ......................... 13

FIGURA 2.8 EXEMPLO DE TURBINA TIPO STRAFLO. FIGURA EXTRAÍDA DE SOUZA (1999)_........... 14

FIGURA 2.9 TURBINA AXIAL THB DE 20 KW [CORTESIA: HYDREL] ............................................... 15

FIGURA 2.10 PRINCIPAIS ELEMENTOS DE UMA TURBINA. FIGURA EXTRAÍDA DE VOITH (2004). 16 FIGURA 2.11 ESQUEMA DA TURBINA AXIAL EM ANALISE. [CORTESIA: HYDREL] .......................... 17

FIGURA 2.12 GEOMETRIA DE UMA SEÇÃO DE UM AEROFÓLIO TÍPICO. FIGURA EXTRAIIDA DE

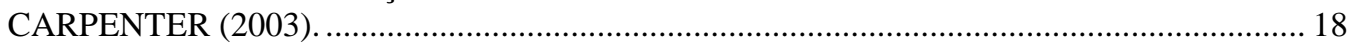

FIGURA 2.13 COEFICIENTE DE SUSTENTAÇÃO EM FUNÇÃO DO ÂNGULO DE ATAQUE. FIGURA

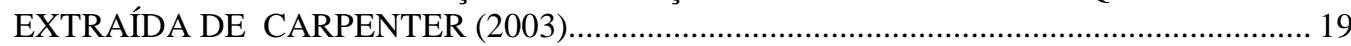

FIGURA 2.14 DISTRIBUIÇÃO TÍPICA DE PRESSÃO EM UMA SEÇÃO DE UM AEROFÓLIO. FIGURA

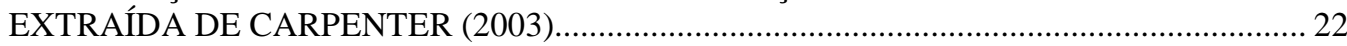

FIGURA 2.15 COEFICIENTE DE PRESSÃO SOBRE UM AEROFÓLIO. DIREITA: EM FUNÇÃO DA VELOCIDADE (FIGURA EXTRAÍDA E ADAPTADA DE CARPENTER, 2003); ESQUERDA: EM FUNÇÃO DE $C_{P}$ (FIGURA EXTRAÍDA E ADAPTADA DE ABBOTT, 1958).

FIGURA 2.16 COEFICIENTE DE CARREGAMENTO PARA DUAS LINHAS MÉDIAS. DIREITA: A=0.8; ESQUERDA: A=0. FIGURA EXTRAÍDA DE ABBOTT (1958)........................................... 25

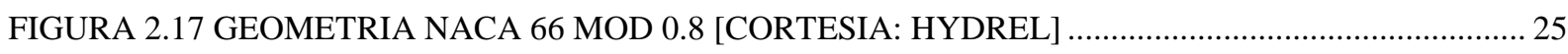

FIGURA 2.18 NOMENCLATURA DO PERFIL EXPANDIDO NO PLANO [CORTESIA: HYDREL]........... 26 FIGURA 2.19 SEÇÃO OBTIDA DOS DADOS DO PERFIL NACA 66 [CORTESIA: HYDREL] .................... 26 FIGURA 2.20. TRAÇO DAS SUPERFÍCIES DE REFERENCIA DOS PERFIS [CORTESIA: HYDREL] ..... 27 FIGURA 2.21. TRAÇO DAS SUPERFÍCIES DE REFERENCIAS NO PLANO Z; Y*= R $\theta$ RESULTANTE DA PLANIFICAÇÃO DO CILINDRO DE RAIO R [CORTESIA: HYDREL] ......................... 28

FIGURA 2.22 ESQUEMA DE NOTAÇÃO PARA DEFINIR O COEFICIENTE DE ARRASTO E SUSTENTAÇÃO SOBRE UMA CASCATA BIDIMENSIONAL [CORTESIA: HYDREL].. 29

FIGURA 2.23. EFEITO DO ÂNGULO DE SUSTENTAÇÃO ZERO E DA RELAÇÃO ESPAÇAMENTO CORDA NO COEFICIENTE DE SUSTENTAÇÃO. FIGURA EXTRAIIDA DE TWHAITES (1987).

FIGURA 2.24 ROTOR AFOGADO - NÚMERO DE CAVITAÇÃO. FIGURA EXTRAÍDA DE KRUPPA (1969).

FIGURA 2.25 SEÇÕES PARA CÁLCULO DO CRITÉRIO DE CAVITAÇÃO EM UMA SEÇÃO QUALQUER [CORTESIA: HYDREL].

FIGURA 2.26 MODELO DE VORTICIDADE PARA UM CORPO BIDIMENSIONAL; EM CIMA: VELOCIDADE INDUZIDA PELO ELEMENTO SUPERFICIAL EM $s n$; EM BAIXO: REPRESENTAÇÃO DA SUPERFÍCIE DO CORPO POR ELEMENTOS DE LINHA RETILÍNEOS. FIGURA EXTRAÍDA DE LEWIS (1991).

FIGURA 2.27 ARCO CIRCULAR RELACIONADO AO USO DO ELEMENTOS DE LINHA RETA. FIGURA EXTRAÍDA DE LEWIS (1991). 
FIGURA 2.28 PERFIL ISOLADO - ESQUEMA DE IMPLEMENTAÇÃO. FIGURA EXTRAÍDA DE LEWIS

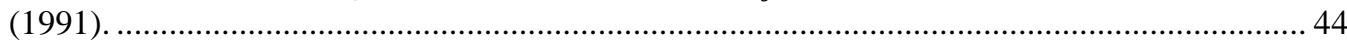

FIGURA 2.29 GEOMETRIA EM CASCATA E SEUS TRIÂNGULOS DE VELOCIDADE. FIGURA

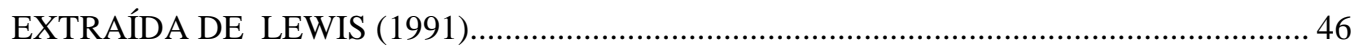

FIGURA 2.30 TRANSFORMAÇÃO DO ARRANJO DE VÓRTICES NO PLANO Z PARA O PAR DE VÓRTICES NO PLANO Z. FIGURA EXTRAÍDA DE LEWIS (1991).................................... 47

FIGURA 2.31 DIAGRAMA DE FLUXO PARA O PROGRAMA "BLADE ROW”. FIGURA EXTRAÍDA DE LEWIS (1991).

FIGURA 3.1 ÂNGULOS DO PASSO E ÂNGULOS DE INCLINAÇÃO DAS CORDAS - DISTRIBUIDOR E

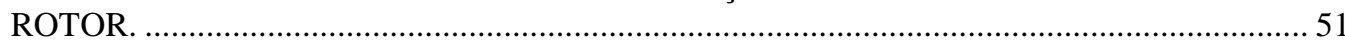

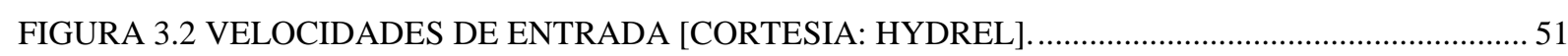

FIGURA 3.3 VELOCIDADES - GRADES DO DISTRIBUIDOR E ROTOR ..............................................52 FIGURA 3.4 ÂNGULOS PERTINENTES PARA O POSICIONAMENTO DOS PERFIS AO LONGO DO

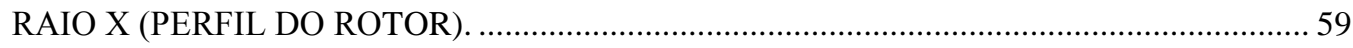

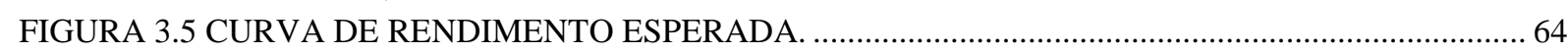

FIGURA 3.6 TURBINA DE REAÇÃO - EIXO HORIZONTAL - FIGURA EXTRAÍDA DA IEC 60041........ 66

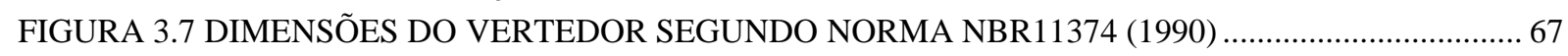

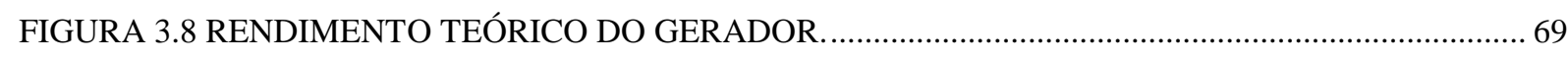

FIGURA 3.9 PERDA DE POTENCIA NOS MANCAIS (FONTE: MANUAL SKF) ....................................... 70

FIGURA 4.1 PÁ DO DISTRIBUIDOR - GEOMETRIA E ADEQUAÇÃO NO SERVO MECANISMO DE

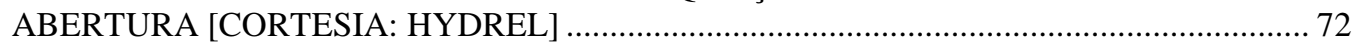

FIGURA 4.2 OBTENÇÃO DO PERFIL EXPANDIDO ATRAVÉS DA GEOMETRIA NACA 66.................... 72

FIGURA 4.3 PERFIL TRIDIMENSIONAL OBTIDO DO PERFIL EXPANDIDO........................................... 74

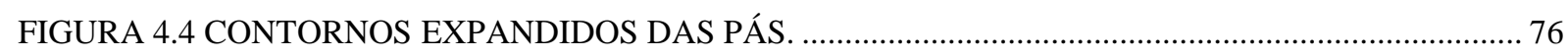

FIGURA 4.5 PÁS DO ROTOR E DISTRIBUIDOR FUNDIDAS [CORTESIA: HYDREL] ……………........... 77

FIGURA 4.6 COEFICIENTE DE ARRASTO PARA OS PERFIS DO ROTOR E DISTRIBUIDOR................. 78

FIGURA 4.7 COMPARAÇÃO DO COEFICIENTE DE SUSTENTAÇÃO - PERFIS ISOLADOS VERSUS

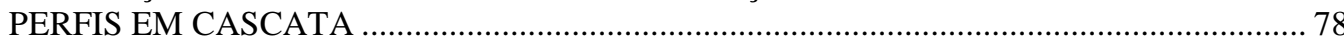

FIGURA 4.8 DISTRIBUIÇÕES DE PRESSÃO EM FUNÇÃO DA CORDA - PERFIS DO ROTOR................. 79 FIGURA 4.9 DISTRIBUIÇÕES DE PRESSÃO EM FUNÇÃO DA CORDA - PERFIS DO DISTRIBUIDOR 80 FIGURA 4.10 DISTRIBUIÇÕES DE PRESSÃO- PERFIS DO ROTOR - EXTREMIDADES ………………... 80 FIGURA 4.11 COEFICIENTE DE SUSTENTAÇÃO EM FUNÇÃO DO ÂNGULO DE ATAQUE - PERFIL

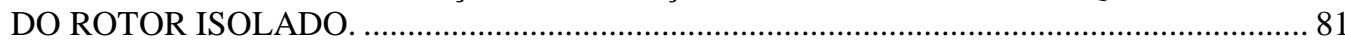

FIGURA 4.12 COEFICIENTE DE SUSTENTAÇÃO- PERFIL DO DISTRIBUIDOR ISOLADO. .................... 82 FIGURA 4.13 VETORES VELOCIDADE PARA DUAS SEÇÕES PLANIFICADAS DO ROTOR.................. 82 FIGURA 4.14 COMPARAÇÃO - MÉTODO DOS PAINÉIS VERSUS MÉTODO ANALÍTICO (TEÓRICO) -

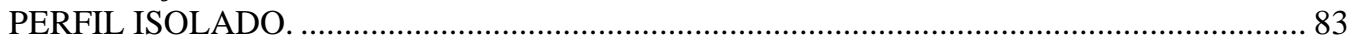

FIGURA 4.15 COMPARAÇÃO - MÉTODO DOS PAINÉIS VERSUS MÉTODO ANALÍTICO (TEÓRICO) -

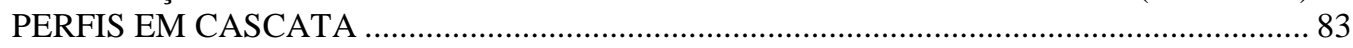

FIGURA 4.16 COMPORTAMENTO DA POTÊNCIA DA TURBINA EM FUNÇÃO DA VAZÃO E POSIÇÃO

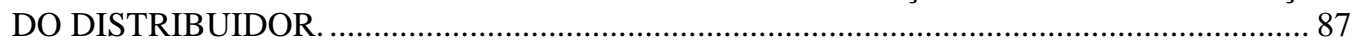

FIGURA 4.17 EFICIÊNCIA GLOBAL DA TURBINA VERSUS ABERTURA DO DISTRIBUIDOR. ............ 88

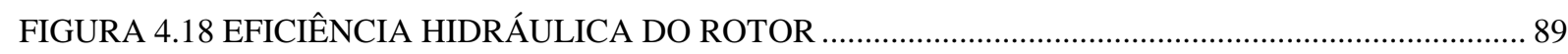
FIGURA 4.19 EFICIÊNCIA GLOBAL - COMPARAÇÃO COM PROJETO.................................................... 90 


\section{Lista de Tabelas}

TABELA 2.1 CARACTERÍSTICAS DAS SÉRIES NACA. TABELA EXTRAIIDA E TRADUZIDA DE

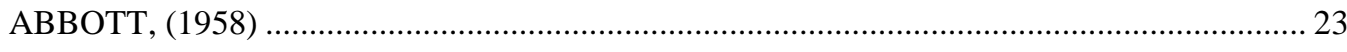

TABELA 2.2 VALORES DA CONSTANTE C1 PARA ALGUNS TIPOS DE PERFIS (KRUPPA, 1969)....... 34 TABELA 2.3 CONSTANTE C2 PARA PERFIS ARQUEADOS (KRUPPA, 1969) .......................................... 36

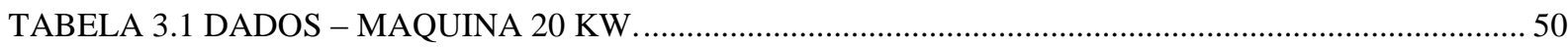

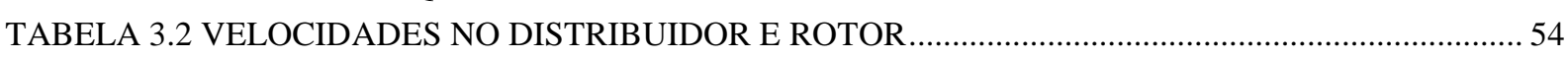

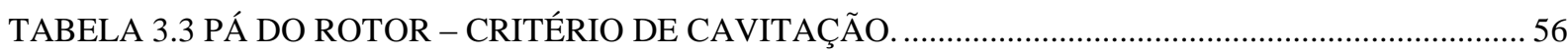

TABELA 3.4 PÁ DO DISTRIBUIDOR - CRITÉRIO DE CAVITAÇÃO. ..................................................... 57

TABELA 3.5 ESQUEMA DE DETERMINAÇÃO DO ÂNGULO DE SUSTENTAÇÃO NULA (EXEMPLO:

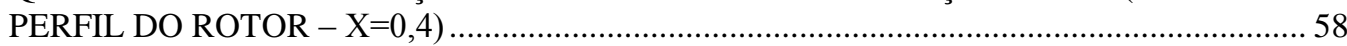

TABELA 3.6 RESULTADOS DOS ÂNGULOS DE POSICIONAMENTO DOS PERFIS DO ROTOR ............ 58

TABELA 3.7 RESULTADOS DOS ÂNGULOS DE POSICIONAMENTO DOS PERFIS DO DISTRIBUI..... 59

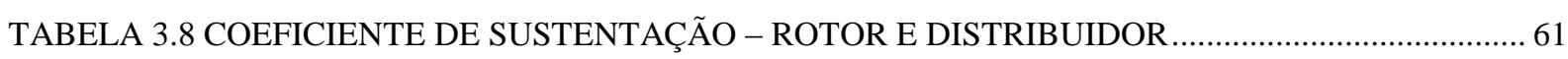

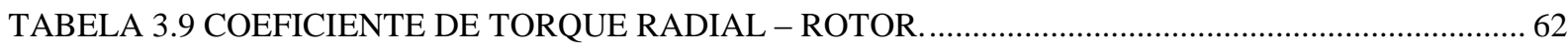

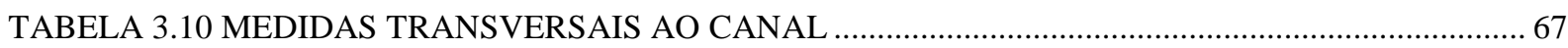

TABELA 4.1 TRANSFORMAÇÃO DO PERFIL NACA 66 EM UM PERFIL DO ROTOR - X=0,4

[CORTESIA: HYDREL] ............................................................................................... 73

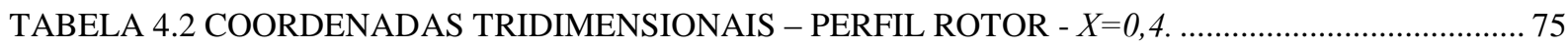

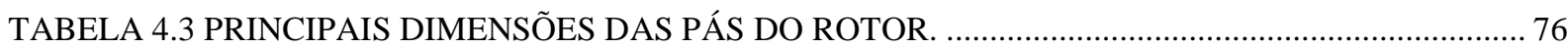

TABELA 4.4 PRINCIPAIS DIMENSÕES DAS PÁS DO DISTRIBUIDOR …………........................................ 77

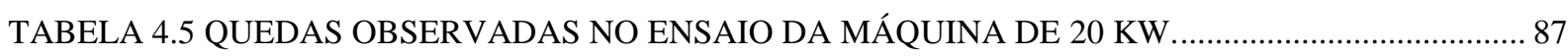

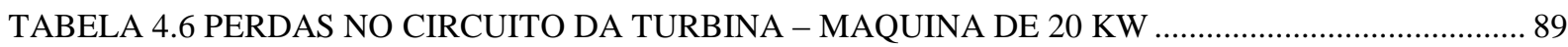

TABELA 4.7 CONVERSÃO DOS DADOS DE MEDIÇÃO PARA A QUEDA NOMINAL DE PROJETO

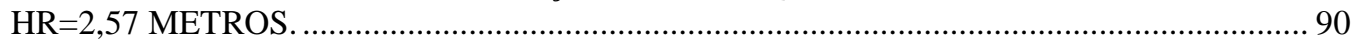




\section{INTRODUÇÃO}

As MCHs (Micro Centrais Hidrelétricas) estão classificadas, de acordo com o Manual da Eletrobrás dentro do conceito geral das Pequenas Centrais Hidrelétricas, identificadas de acordo com grandezas como potência de até $100 \mathrm{~kW}$, altura de queda menor que 3 metros, vazão inferior a $2 \mathrm{~m} 3 / \mathrm{s}$ e período de implantação máximo de seis meses.

Uma $\mathrm{MCH}$ é composta por dispositivos que captam e conduzem água do rio para uma casa de máquinas, onde ocorre a transformação de energia hidráulica em elétrica através da utilização de um conjunto turbina-gerador. A água utilizada é restituída ao rio ao final do processo. Os principais componentes de uma $\mathrm{MCH}$ são uma Barragem, uma Estrutura de Captação, um Canal ou Tubulação de Adução, um Canal de Fuga, Comportas, Turbinas Hidráulicas, Geradores Elétricos e equipamentos de proteção. A diferenciação da máquina a ser estudada das máquinas convencionais para esse tipo de queda se dá por dois principais aspectos:

- O rotor do gerador usa imãs permanentes de $\mathrm{Ni}-\mathrm{Fe}-\mathrm{Br}$ o que de um lado elimina a utilização do sistema de excitação, mas do outro insere um problema na montagem devido ao alto campo magnético destes imãs.

- A montagem do rotor do gerador fica no mesmo corpo do rotor da turbina o que corta custos de equipamentos como mancais e eixos entre outros. Entretanto, também insere um problema difícil de ser superado que é a vedação do estator.

Devido à necessidade de oferecer a máquina a baixo custo a ideia de se ter as pás do rotor móveis como em uma turbina Kaplan foi descartada. Embora se perca eficiência mecânica em cargas parciais transformando a turbina em uma "propeller" evitam-se o alto custo e alta complexidade da instalação de uma ogiva (cabeçote Kaplan).

A primeira máquina com esta configuração foi concedida e testada nas instalações do Centro Tecnológico de Hidráulica e Recursos Hídricos da USP (CTH) e hoje está instalada na Fazenda Ipanema, município de Iperó-SP, local este que pertencente ao ICMBIO (Instituto Chico Mendes de Conservação da Biodiversidade). A figura 1.1 mostra a máquina instalada no dia de testes no CTH e na Fazenda Ipanema. A unidade geradora foi testada, em ambos os casos, gerando energia que estava sendo dissipada em forma de calor através de resistências inseridas em uma caixa d'água. 

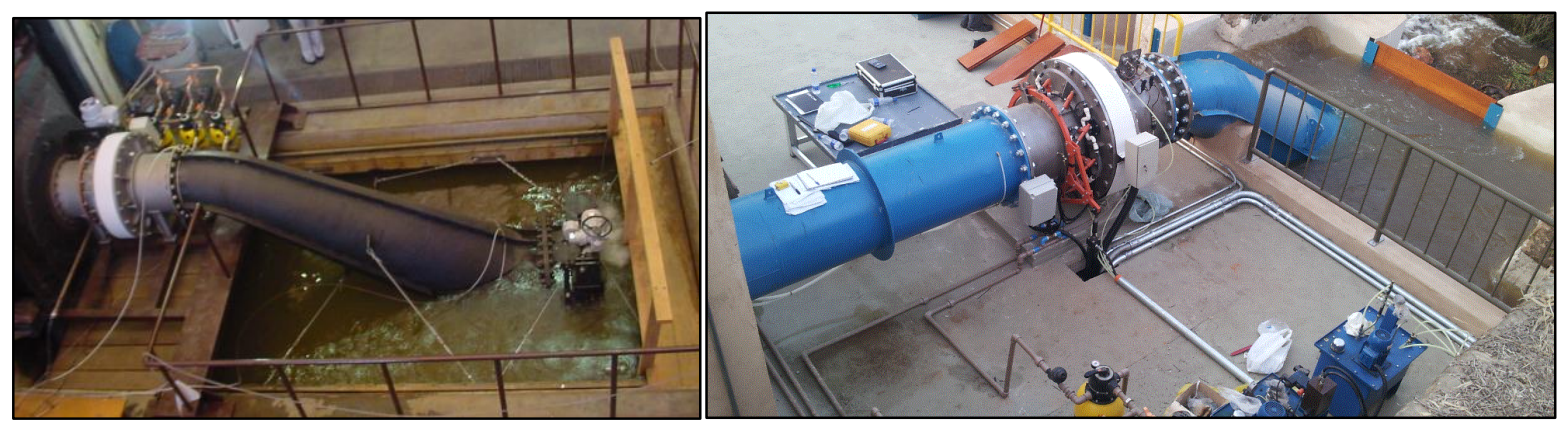

Figura 1.1. Máquina de $20 \mathrm{~kW}$ em testes no CTH da USP e na Fazenda Ipanema [Cortesia: Hydrel]

A figura 1.2 mostra um corte da máquina sendo possível visualizar a trajetória do fluxo de água através da turbina. Esse tipo de máquina não tem pré-distribuidor como nas máquinas convencionais por não contar com caixa espiral. O distribuidor é móvel e controlado por servomotor eletro-hidráulico, porém na operação da máquina ele trabalha fixo com as pás na posição de rendimento máximo, já que um controle de regulação de velocidade traria custos desnecessários para essa faixa de potência.

A figura 1.2 mostra um corte desta máquina com seus principais equipamentos, sem o conduto de adução e o tubo de sucção:

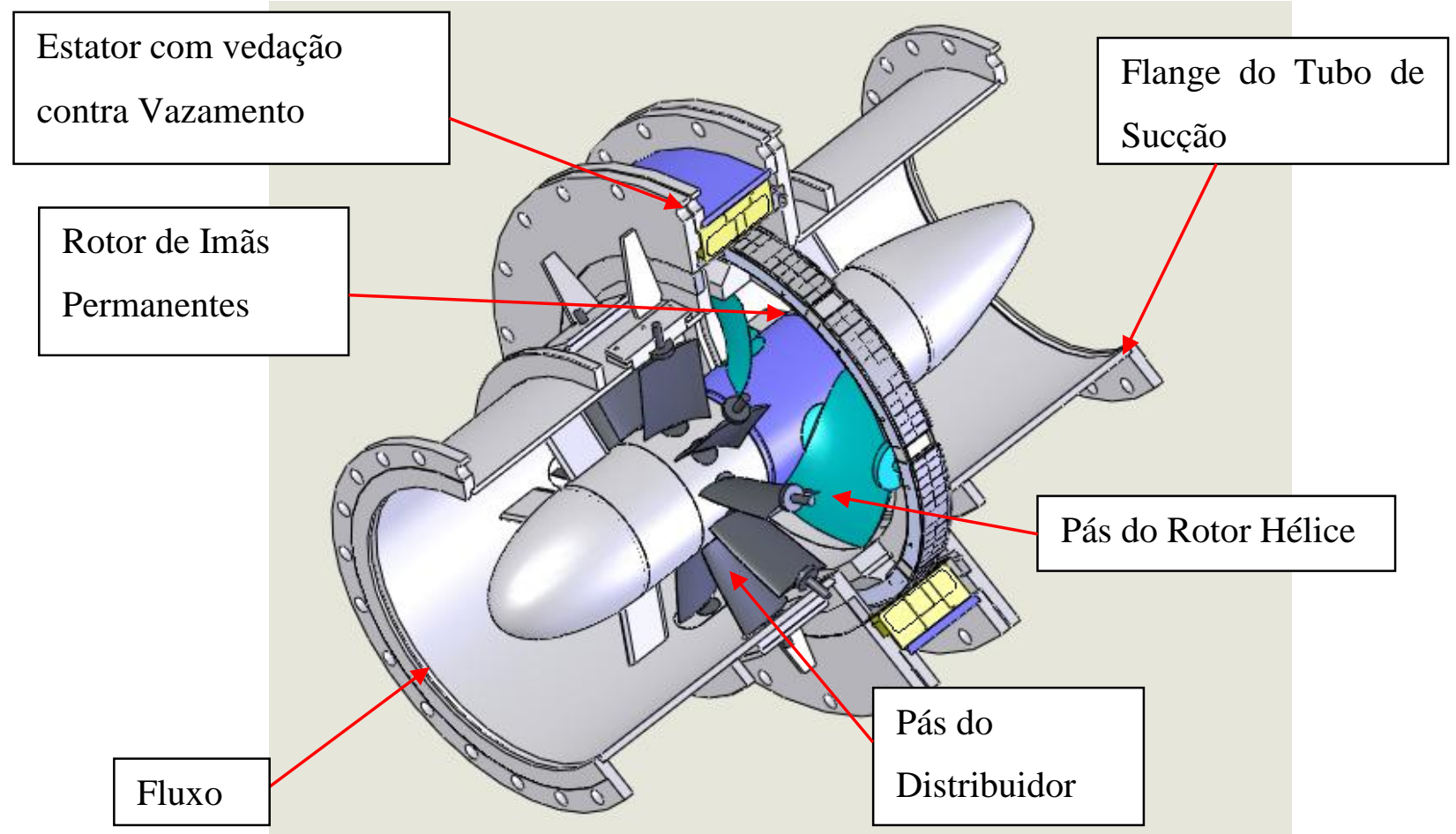

Figura 1.2. Corte esquemático da Máquina de $20 \mathrm{~kW}$ [Cortesia: Hydrel] 
O trabalho de conhecimento das técnicas de projeto hidráulico e mecânico e o potencial que as micro centrais hidráulicas têm no cenário energético brasileiro são as justificativas do trabalho.

\subsection{OBJETIVOS GERAIS E ESPECÍFICOS}

O objetivo central é estudar como se calcula uma turbina axial tipo hélice para um dado aproveitamento hidrelétrico, neste caso será um micro aproveitamento, concentrando-se no cálculo da geometria das pás do rotor e distribuidor levando-se em conta as variáveis hidráulicas da máquina.

Outro objetivo importante é a comparação do método analítico utilizado para determinação das geometrias das pás com um método numérico amplamente conhecido, que é o método dos painéis.

O trabalho também conta com uma parte experimental e o objetivo aqui é a verificação em campo do método analítico para cálculo da máquina respeitando-se todos os desvios e dificuldades que um ensaio de protótipo apresenta.

É também objetivo do estudo o conhecimento e aperfeiçoamento técnico realizado através da revisão bibliográfica e cálculo da unidade geradora. 


\section{REVISÃO DA BIBLIOGRAFIA}

O objetivo central deste capítulo é revisar a literatura que serve de base para as técnicas utilizadas para desenvolver:

- Cálculo do escoamento através da turbina axial em questão;

- Método dos painéis que foi utilizado como comparativo do cálculo analítico;

- Técnicas utilizadas no ensaio da turbina estudada em campo.

Além dos tópicos acima este capitulo visa introduzir o tipo de turbina estudada no cenário dos tipos de máquinas hidráulicas utilizadas nos mais diversos tipos de aproveitamentos.

\subsection{APROVEITAMENTOS HIDRELÉTRICOS}

Segundo (MAGNOLI, 2005) todas as turbinas hidráulicas possuem princípios de operação semelhantes, porém elas não são exatamente iguais e o tipo de rotor escolhido dá origem a diversos desenhos de máquina. Outras diferenças, menos aparentes, também podem existir e antes que se proceda ao cálculo de qualquer fenômeno físico presente no sistema, é indispensável conhecer os tipos de turbinas.

Com posse das características do aproveitamento hidráulico, como altura de queda, vazão e número de máquinas, um tipo diferente de perfil hidráulico pode ser empregado para o rotor. Dependendo também da altura de queda e da potência de cada unidade, define-se a orientação do eixo, vertical ou horizontal.

Segundo MAGNOLI (2005) o rotor pode ser Francis, Pelton, ou Kaplan. A escolha é baseada na queda e na rotação específica da máquina, definida por:

$$
n_{q}=\frac{n_{n} \sqrt{Q_{n}}}{H_{l n^{\frac{3}{4}}}}
$$

$$
\begin{array}{lll}
\mathrm{H}_{l n} & : \text { queda líquida nominal } & {[\mathrm{m}]} \\
\mathrm{n}_{\mathrm{n}} & : \text { rotação nominal da máquina } & {[\mathrm{rpm}]} \\
\mathrm{n}_{\mathrm{q}} & : \text { rotação específica } & {[\mathrm{rpm}]} \\
\mathrm{Q}_{\mathrm{n}} & : \text { Vazão Nominal } & {[\mathrm{m}]}
\end{array}
$$


Máquinas do tipo Pelton são indicadas para rotações específicas inferiores a $20 \mathrm{rpm}$ e quedas superiores a 200 m, já as Francis podem ser utilizadas na faixa de 20 a 100 rpm e 30 a 800 $\mathrm{m}$, enquanto que as Kaplan são utilizadas para valores superiores a $100 \mathrm{rpm}$ e quedas inferiores a 70 m. Estes limites não são fixos e há pequenas sobreposições entre eles, como visto na figura a seguir. Ainda conforme SIMONE (2000), para potências superiores a 15 MW, a escolha é por máquinas de eixo vertical, ao passo que para potências menores é comum optar-se pelo eixo horizontal.

Na configuração horizontal, as máquinas Kaplan geralmente assumem outras variantes que são as turbinas $\mathrm{S}$, bulbo e tubular.

Outra variação das turbinas Kaplan são as turbinas hélice, cuja única diferença são as pás do rotor que, em vez de se ajustarem ao fluxo, conforme a condição de operação, estas são mantidas fixas. Um último aspecto, quanto aos seus tipos, é que, a não ser pelas turbinas Pelton, que são turbinas de ação, todas as demais são turbinas de reação e podem ser projetadas para também atuarem como bombas. A figura 2.1 mostra um gráfico de seleção de maquinas para grandes aproveitamentos hidráulicos.

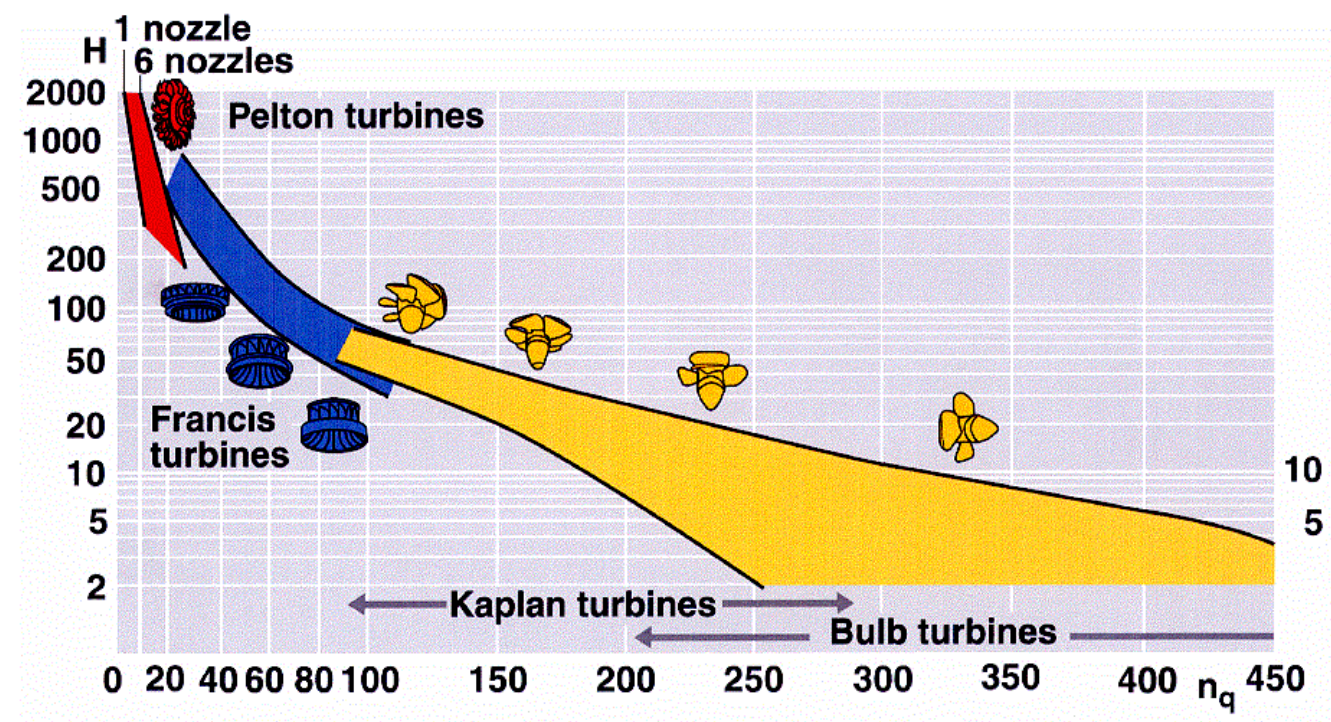

Figura 2.1. Faixa operacional dos diversos tipos de turbinas hidráulicas. Figura extraída de VOITH (2004).

A figura 2.2 mostra um gráfico de seleção para micro e pequenos aproveitamentos hidráulicos agora em função da vazão, a unidade geradora deste estudo se encontra nessa faixa. Os gráficos de seleção de turbinas hidráulicas não são semelhantes entre os fabricantes, um exemplo pode ser visto na figura 2.3 da empresa Hacher. 


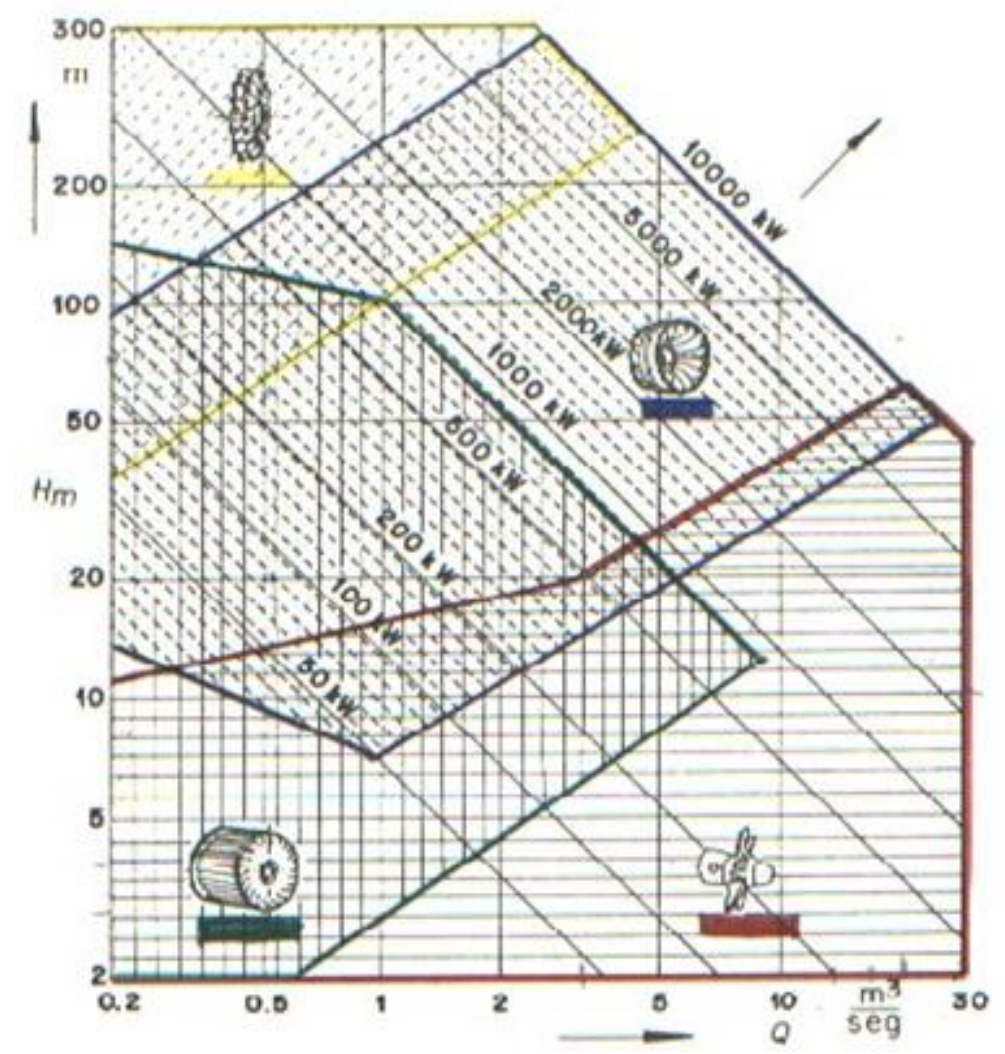

Figura 2.2. Gráfico para Escolha dos Tipos Padronizados de Turbinas Hidráulicas. [Cortesia: Hydrel].

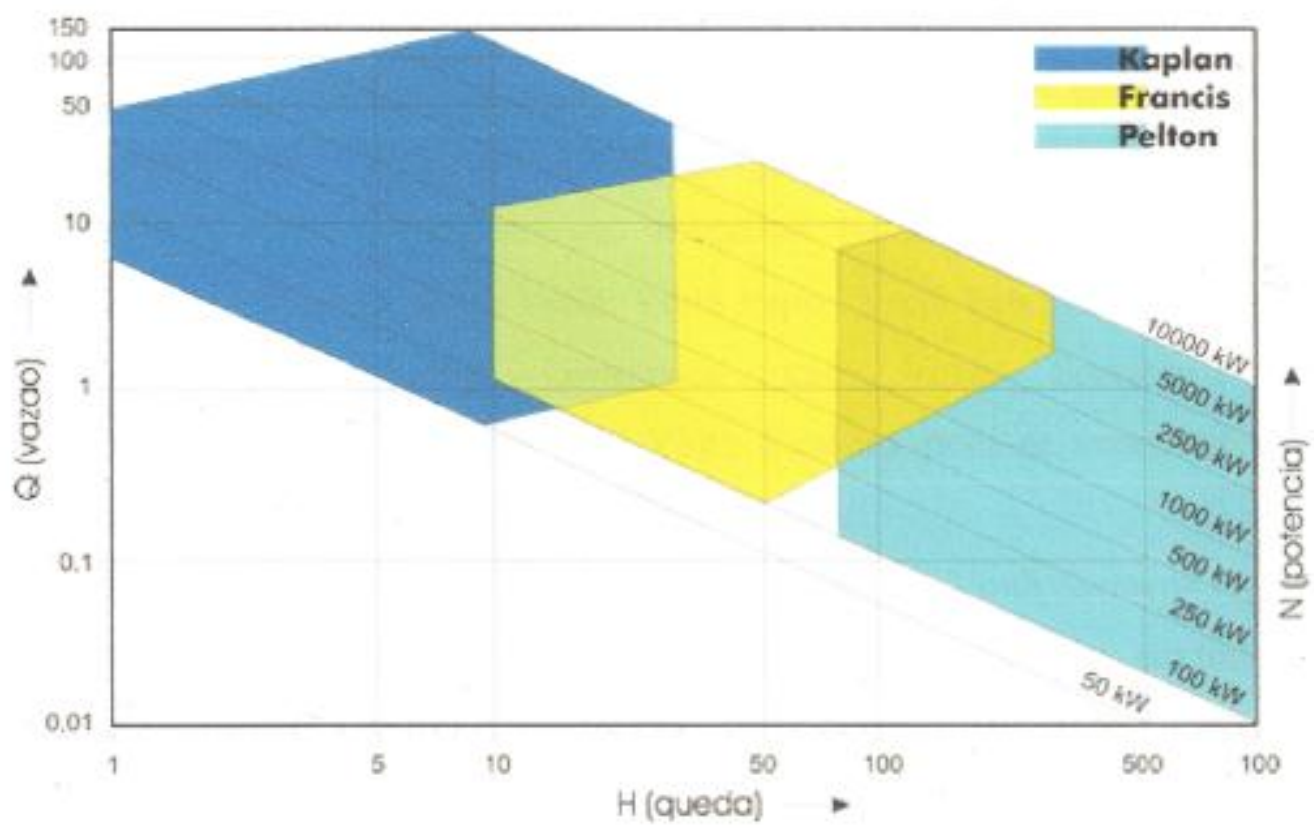

Figura 2.3. Gráfico de Pré-Seleção extraído da Empresa Hacher. 
As figuras 2.4, 2.5, 2.6 e 2.7 mostram os tipos de turbinas mais comuns empregadas em grandes aproveitamentos hidráulicos.

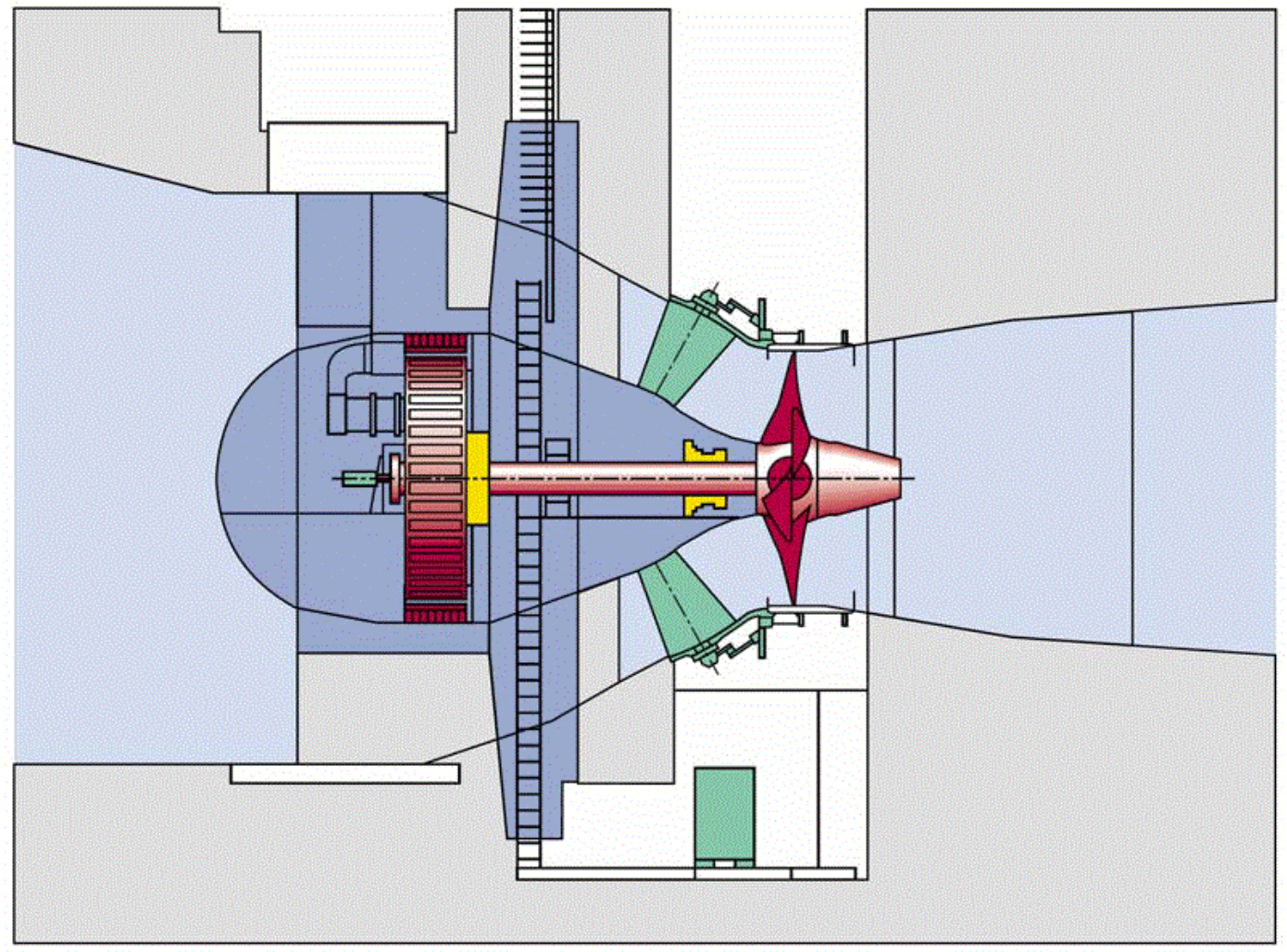

Figura 2.4. Exemplo de Turbina Bulbo. Figura extraída de VOITH (2004).

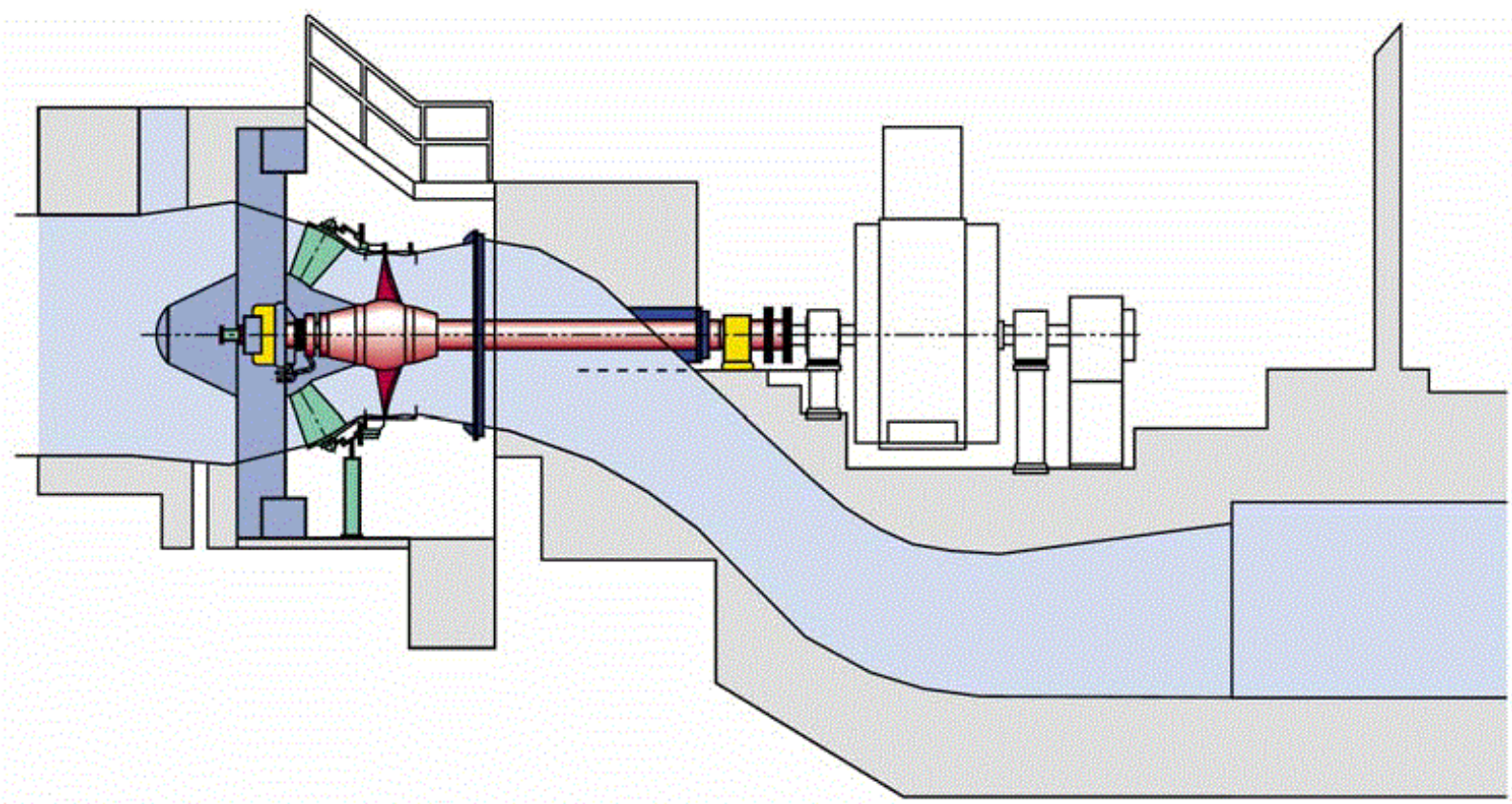

Figura 2.5. Exemplo de Turbina S. Figura extraída de VOITH (2004). 


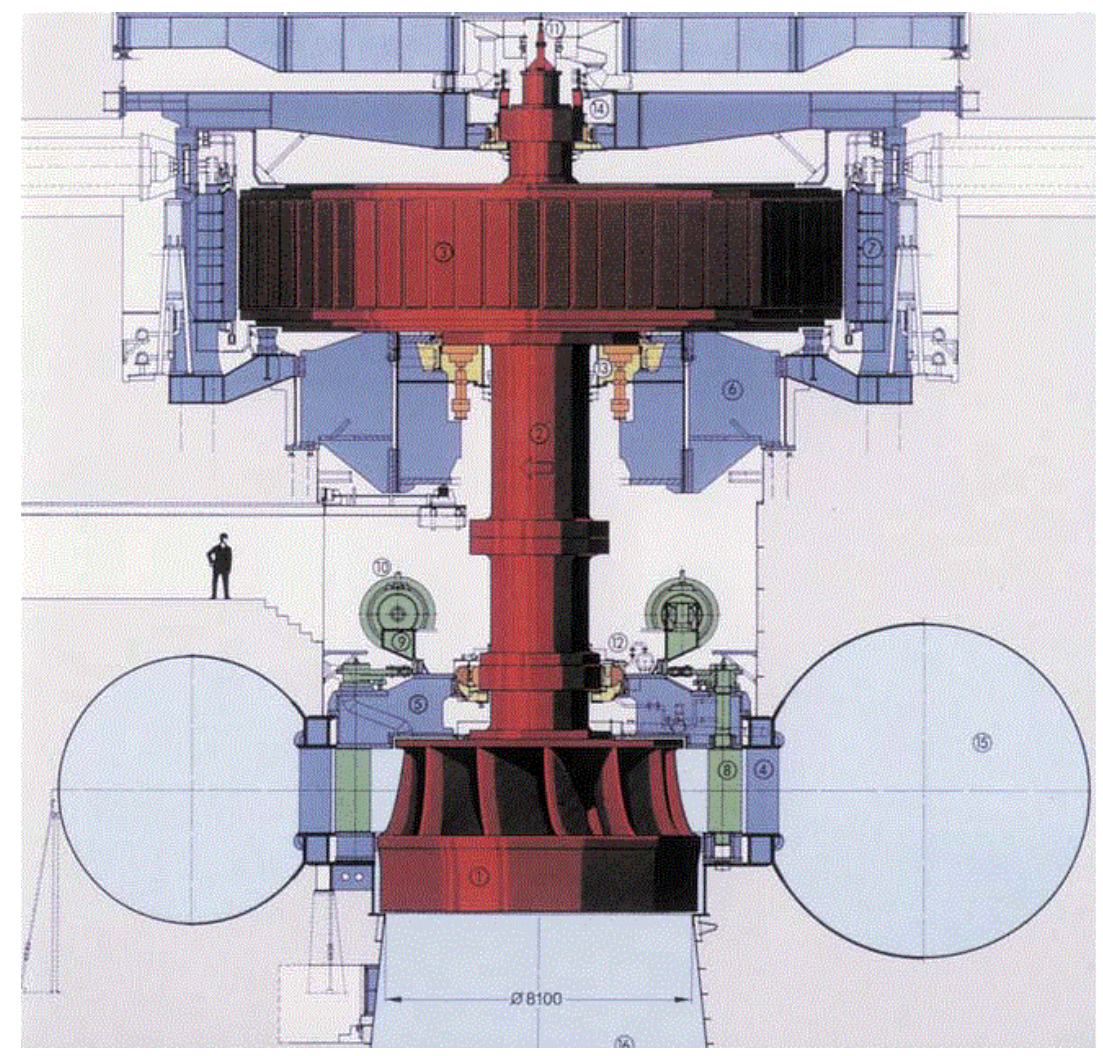

Figura 2.6 Exemplo de Turbina Francis. Figura extraída de VOITH (2004).

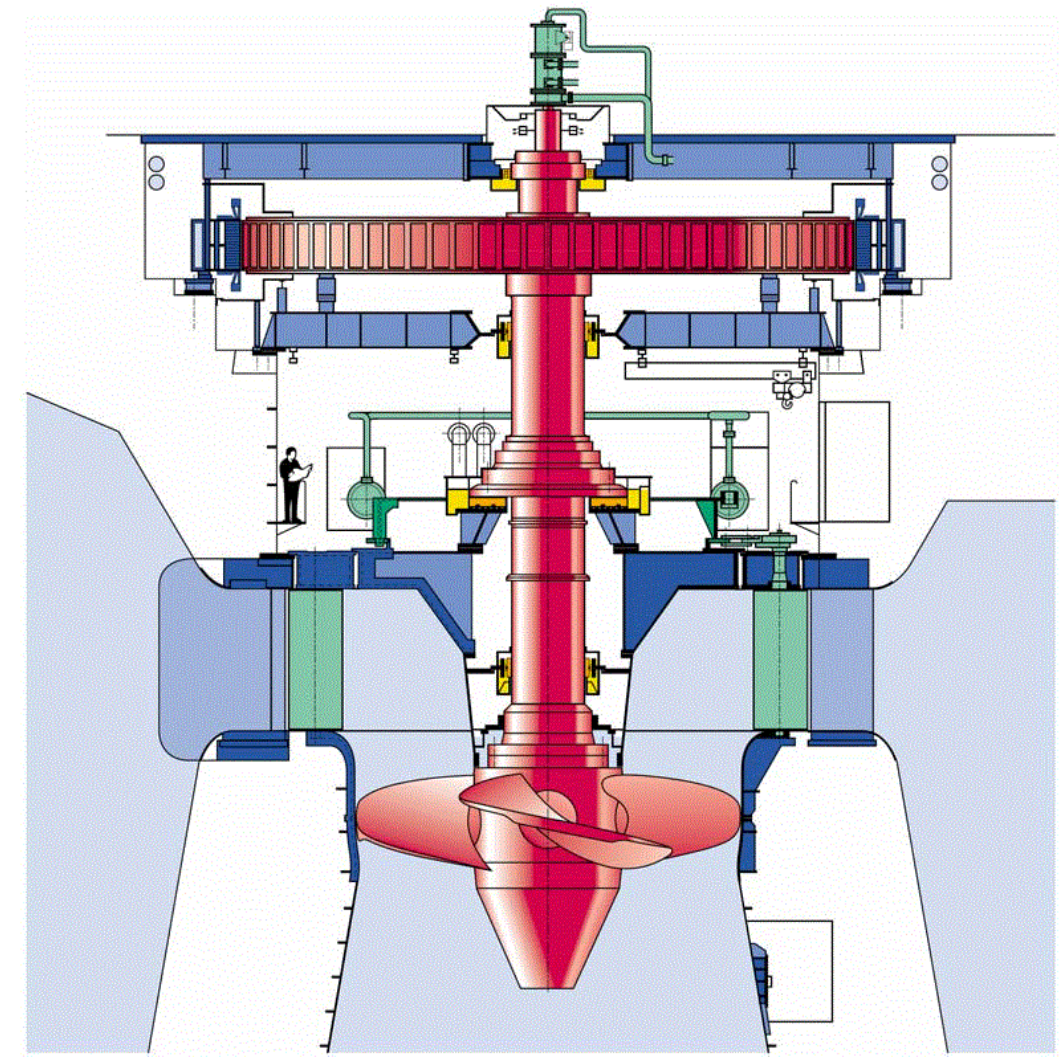

Figura 2.7 Exemplo de Turbina Kaplan. Figura extraída de VOITH (2004). 
A figura 2.8 mostra um exemplo de uma turbina tipo Straflo que segundo (SOUZA, 1999) tem coroa de pólos alojada nas extremidades das pás do rotor, resultando sérios problemas de vedação já que o mancal de escora encontra-se dentro do bulbo e qualquer deslocamento horizontal pode provocar vazamentos indesejáveis. Notar que este tipo de turbina tem semelhanças com a turbina em estudo neste trabalho, como por exemplo o fato de o gerador e o rotor da turbina se situarem no mesmo plano.

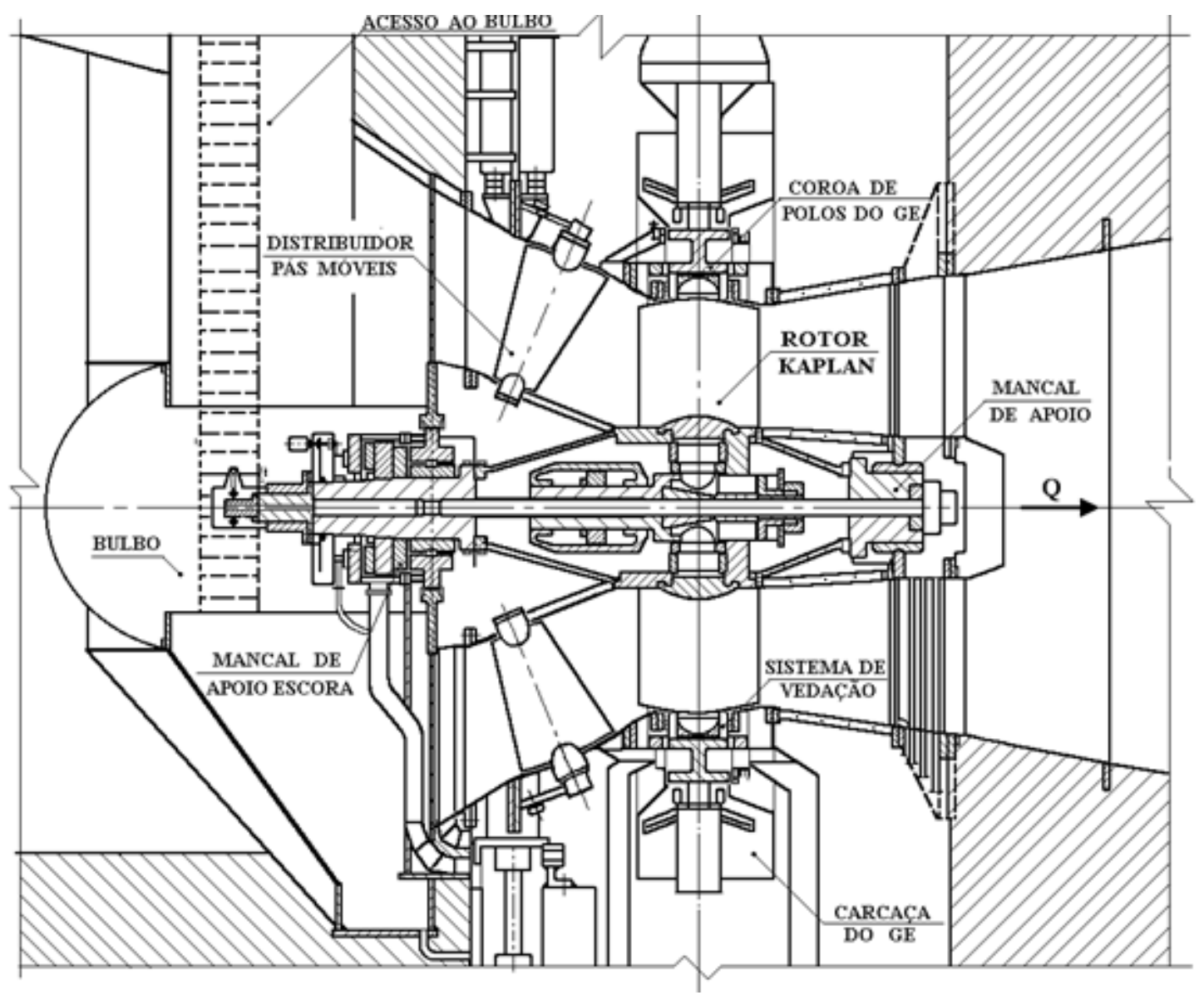

Figura 2.8 Exemplo de Turbina tipo Straflo. Figura extraída de SOUZA (1999).

A figura abaixo mostra a turbina tipo THA da empresa Hydrel, alvo deste estudo, como potência nominal de $20 \mathrm{~kW}$ e pás do distribuidor ajustáveis. Notar que os elementos girantes em vermelho fazem parte do rotor, onde está inserido o eixo, pás do rotor e imãs permanentes. 


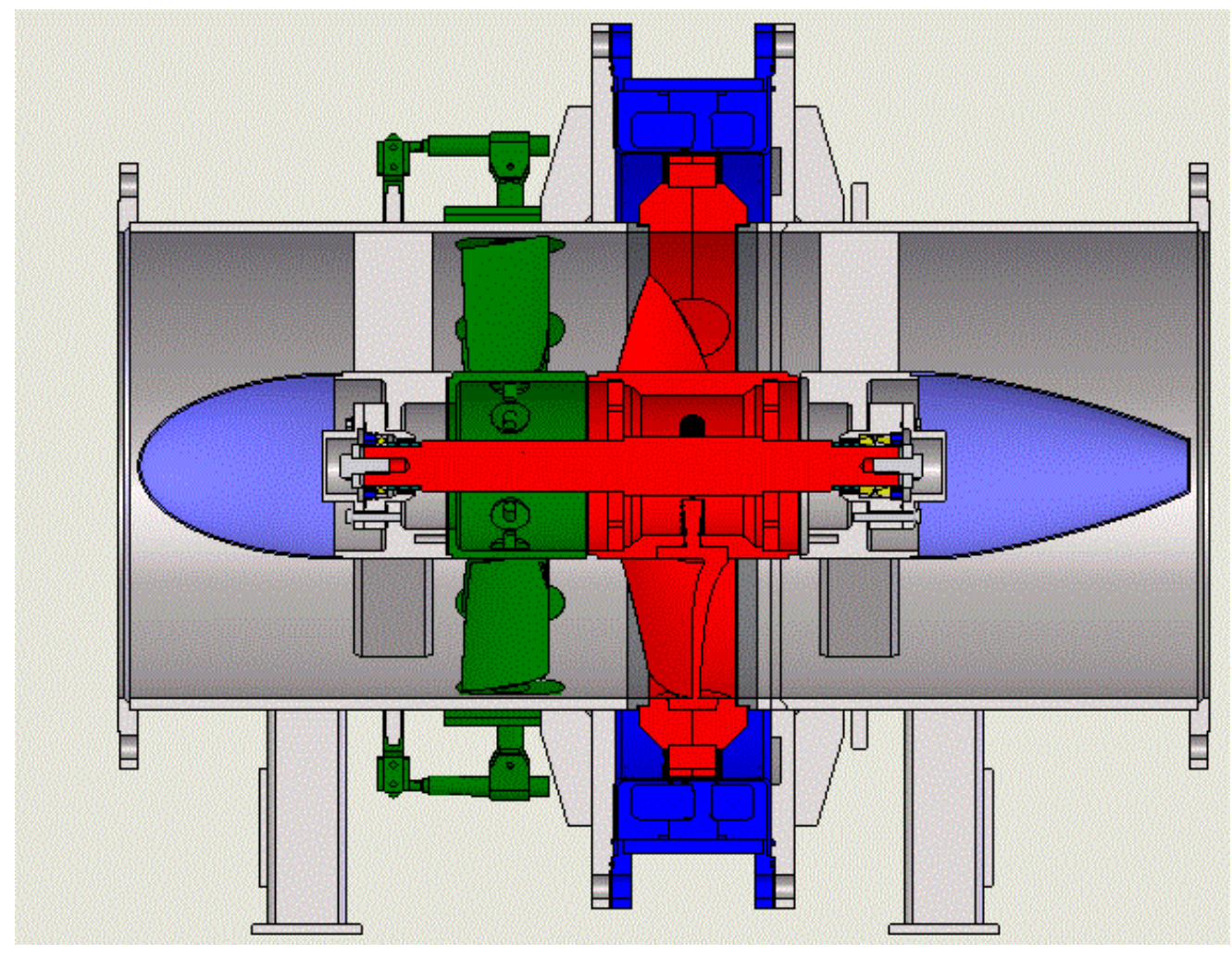

Figura 2.9 Turbina Axial THB de 20 kW [Cortesia: Hydrel].

\subsection{PARTES DE TURBINAS HIDRÁULICAS}

Apesar dos diferentes tipos de turbinas apresentados anteriormente, todos eles contam com os mesmos componentes e com a mesma disposição geral do conjunto.

Assim, os principais elementos são discutidos a seguir, para que se possa identifica-los e, logo, quais deles devem ser estudados no que se propõe este estudo.

Nos cortes de máquina exibidos no item 2.1, os elementos rotativos que formam a linha de eixo estão indicados em vermelho quando possível. São eles o rotor da turbina, eixo e rotor do gerador, composto por uma estrutura metálica central, sobre a qual é montada, por interferência, a coroa magnética, com polos em balanço em seu diâmetro externo. Em laranja e amarelo estão mostrados os mancais e seus sistemas auxiliares de bombeamento de óleo. Os elementos em verde correspondem às peças móveis, empregadas no sistema de regulação da máquina, e aos seus sistemas de comando. 
Para máquinas Francis, Kaplan e suas variantes tratam-se de palhetas diretrizes, bielismo, aro de regulação e servo-motores, já em turbinas Pelton são os injetores e defletores. O azul escuro aponta os elementos fixos, que consistem do estator do gerador, suportes dos mancais, tampa da turbina, travessas e caixa espiral. Finalmente, em azul claro, veem-se os volumes ocupados pelo escoamento e, em cinza, a estrutura civil.

Em todos estes cortes, percebe-se que, independentemente do tipo de máquina, todos os componentes possuem o mesmo arranjo geral e que elas contam, na sua maioria, com os mesmos elementos. Mais precisamente, todas apresentam a mesma disposição da linha de eixo, composta pelo eixo, rotor do gerador e rotor da turbina, assim como os mesmos componentes que interagem com ela, que são o estator do gerador, os mancais e os seus suportes.

A figura 2.9 mostra uma diferença que é particular às turbinas THB da Hydrel, que é à disposição das pás da turbina e gerador no mesmo plano. Isso de um lado torna a máquina mais compacta, porém insere uma massa adicional no cálculo da linha de eixo.

Para facilitar a visualização das partes que foram descritas, observa-se na figura 2.10 um corte de uma turbina Francis, onde os componentes estão indicados.

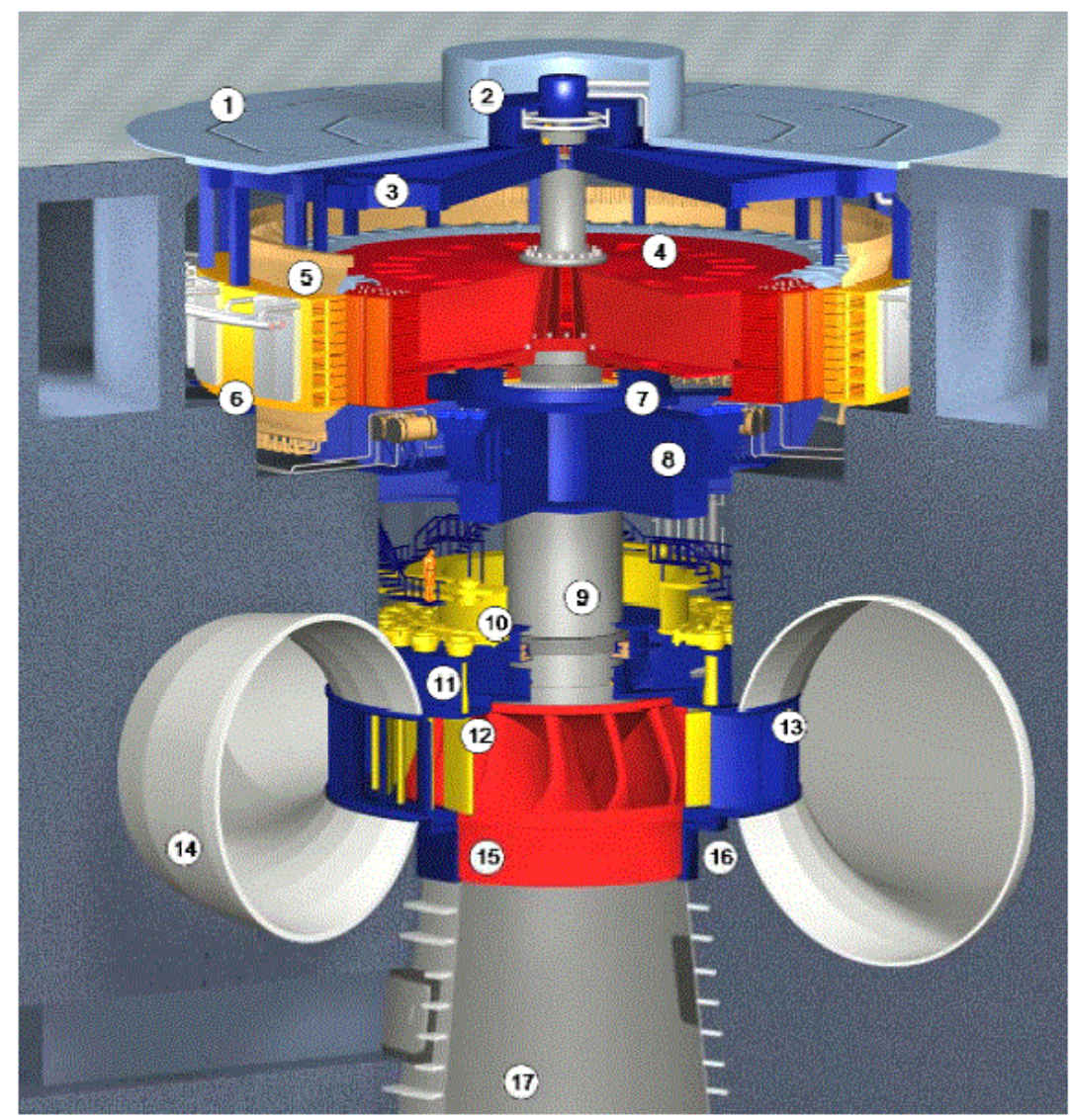
1) Tampa
2) Anel coletor
3) Cruzeta superior
4) Rotor do gerador
5) Estator
6) Refrigeraçăo
7) Freio
8) Cruzeta inferior
9) Eixo
10) Aro de regulaçāo
11) Tampa da turtina
12) Palheta diretriz
13) Travessa
14) Caixa espiral
15) Rotor da turbina
16) Aro de saida
17) Tubo de sucçào

Figura 2.10 Principais Elementos de uma Turbina. Figura extraída de VOITH (2004). 


\subsection{CONCEITOS LIGADOS A TURBINAS HIDRÁULICAS AXIAIS}

Neste capitulo estão apresentados os conceitos e definições necessárias para o desenvolvimento do trabalho.

\subsubsection{Esquema de Turbina Axial em Análise}

Para se estudar o escoamento através das pás do rotor e distribuidor é conveniente representar as pás por meio de desenvolvimento de seções cilíndricas concêntricas com o eixo do rotor. Isto se constitui o que se chama de grade (ou cascata) de pás. A figura 2.11 mostra um esquema básico da passagem do fluxo de água em na turbina hidráulica axial em estudo neste trabalho.

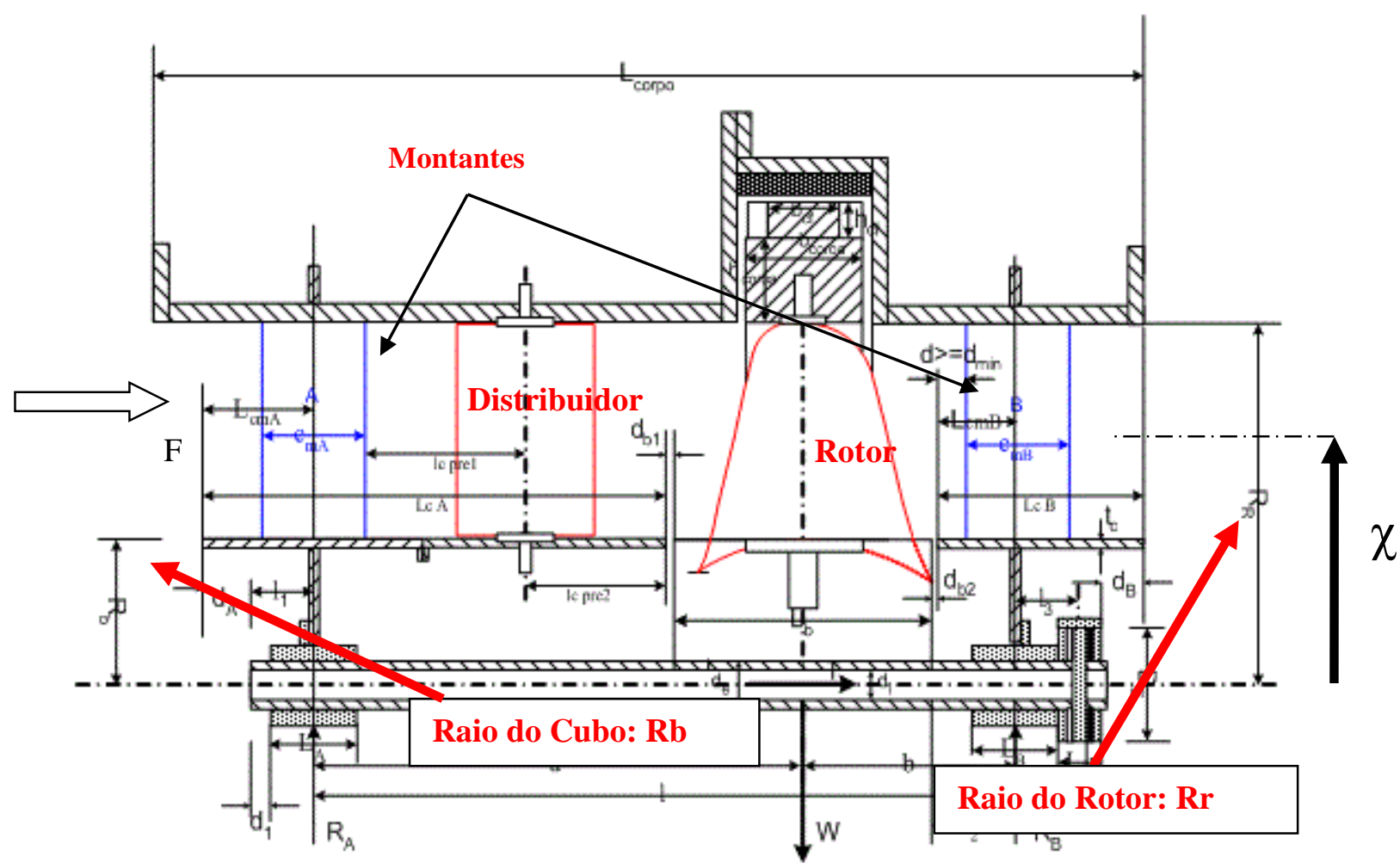

Figura 2.11 Esquema da turbina axial em analise. [Cortesia: Hydrel]

Os montantes mostrados na figura 2.11 não tem função hidráulica, servem somente como parte estrutural da máquina. A sua espessura é calculada e otimizada para que tenha uma perda de carga mínima no escoamento, na maioria dos casos são utilizadas quatro unidades.

Segundo FOX R.W (2006), o método de análise usado para turbo máquinas é escolhido de acordo com a informação desejada. Quando se quer informação geral sobre vazão, variação de pressão, torque e potência, deve ser usada uma análise de volume de controle finito. 
Caso se queiram informações detalhadas sobre ângulos de pás ou perfis de velocidade, que são os alvos deste estudo, então elementos de pás individuais devem ser analisados, usando um volume de controle infinitesimal ou outro procedimento detalhado.

\subsection{DEFINIÇÃO DAS VARIÁVEIS IMPORTANTES DE PROJETO}

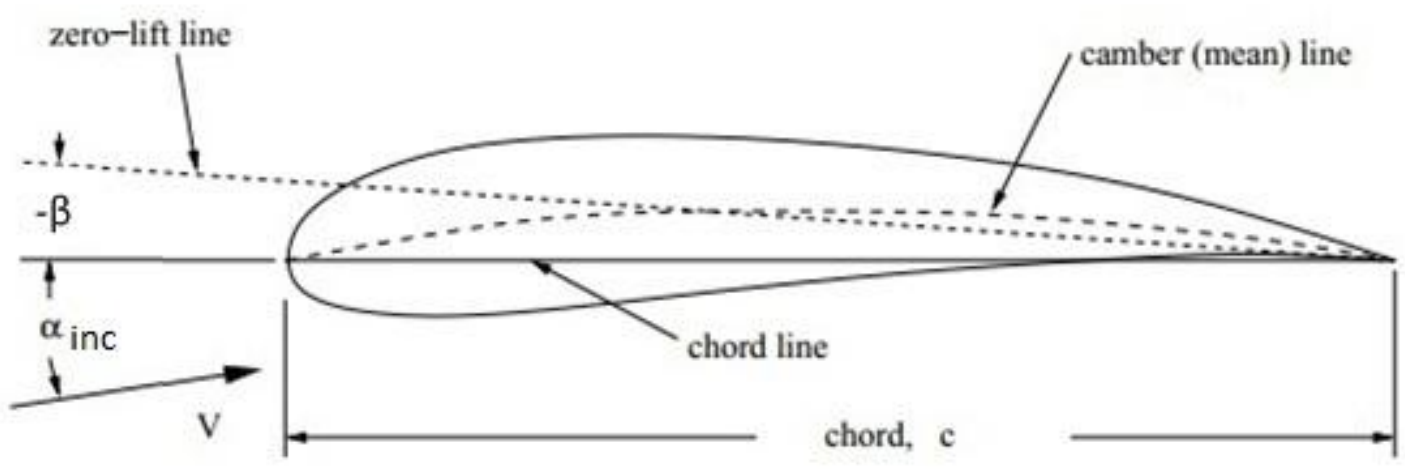

Figura 2.12 Geometria de uma seção de um aerofólio típico. Figura extraída de CARPENTER (2003).

A figura acima mostra uma típica seção de um aerofólio com suas características básicas. A linha reta que liga o bordo de ataque ao bordo de fuga define a corda do perfil $c$. A linha tracejada que divide o perfil em dois é conhecida com linha média ou como o arqueamento do perfil. Para um perfil simétrico, a linha média e a linha da corda são coincidentes. Para velocidades baixas (número de Mack $<<1)$ e número de Reynolds alto $(\operatorname{Re}>>1)$, a teoria do aerofólio fino (thinaerofoil-theory) consegue descrever as propriedades de sustentação do aerofólio completamente para ângulos não tão próximos do estol. A teoria do aerofólio fino prediz uma relação linear entre o coeficiente de sustentação de uma seção do aerofólio e o ângulo de incidência ou ataque $\alpha_{i n c}$ na forma de:

$$
C_{l}=a_{0}\left(\alpha_{i n c}-\beta\right)
$$

A relação acima pode ser visualizada na figura 2.13. O ângulo $\beta$ é conhecido como o ângulo de sustentação nula, quando $\beta=\alpha_{i n c}$. Para perfis simétricos temos $\beta=0$. 


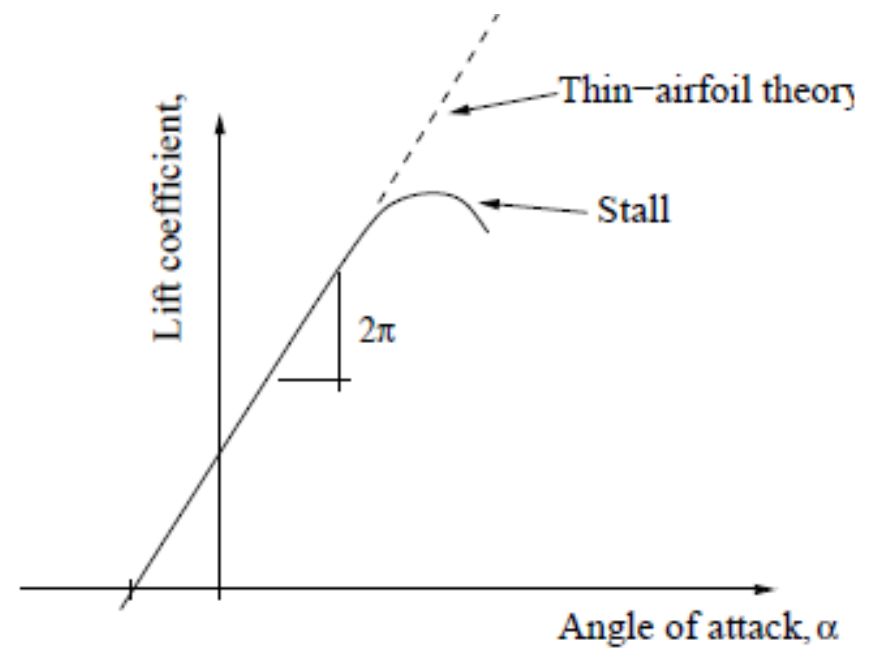

Figura 2.13 Coeficiente de Sustentação em função do ângulo de ataque. Figura extraída de CARPENTER (2003).

A teoria também prediz o valor da inclinação da curva de sustentação para um aerofólio único em meio fluido infinito e em translação a velocidade constante:

$$
a_{0}=\frac{\partial C_{L}}{\partial \alpha}=2 \pi
$$

O ângulo de sustentação nula é função apenas da forma da curva média. Quanto mais arqueado o perfil mais negativo será o ângulo de sustentação nula $\beta$. Para linhas médias de uma mesma família, como a NACA, por exemplo, o ângulo de sustentação nula é praticamente proporcional à magnitude da linha média, ou seja, do máximo desvio da linha média para a corda do perfil.

Segundo CARPENTER (2003) o valor de $C_{\text {Lmax }}$, que está atrelado ao estol do perfil (ver figura 2.13) é uma característica muito importante do aerofólio, pois determina, por exemplo, a mínima velocidade que uma aeronave pode voar. Vale lembrar que uma seção da asa, ou no caso do presente trabalho, uma seção da pá do rotor ou distribuidor, é conhecido como aerofólio. No caso do presente trabalho as pás do distribuidor e do rotor são divididas em seções, ou hidrofólios, onde são calculadas as propriedades pertinentes. Posteriormente é feita a integração para se obter a propriedade pertinente em toda a pá. A potência da turbina hidráulica é obtida desta maneira, como veremos mais adiante. Nos próximos itens vamos introduzir as propriedades pertinentes ao cálculo do escoamento através da turbina. 


\subsubsection{Coeficientes de Força}

Segundo CARPENTER (2003) o coeficiente de força vem da quantidade adimensional $F /\left(\rho V^{2} S\right)$, onde $F$ é uma força aero ou hidrodinâmica. Porém no lugar de $\rho V^{2}$ é de costume

usarmos $\frac{1}{2} \rho V^{2}$, que é a pressão dinâmica do escoamento livre. A área física do corpo, como a área de plataforma da asa, ou a máxima seção transversal da fuselagem, ou no caso da pá do rotor é usualmente chamada por $S$. Logo o coeficiente de força é usualmente definido por:

$$
C_{F_{t}}=\frac{F}{\frac{1}{2} \rho V^{2} S}
$$

Os dois coeficientes de força mais importantes são os de sustentação e de arrasto, definidos por:

$$
\begin{aligned}
& C_{L}=\frac{L}{\frac{1}{2} \rho V^{2} S} \\
& C_{D}=\frac{D}{\frac{1}{2} \rho V^{2} S}
\end{aligned}
$$

A área usada para a definição do coeficiente de sustentação e do arrasto do corpo é precisa ser definida para cada caso. Segundo KRUPPA (1969) o coeficiente de arrasto para seções totalmente molhadas, como número de Reynolds supercrítico e com valores moderados da relação espessura-corda está na ordem de:

$$
C_{D}=0,008
$$

Isso ocorre para Reynolds supercríticos $R_{e}=\frac{v c}{v}>5.10^{5}$ e valores moderados da relação espessura-corda $t / c \leq 0,15$. Na seção de resultados veremos que o coeficiente de arrasto tem boa aderência a esse valor. 


\subsubsection{Coeficiente de Pressão}

Segundo CARPENTER (2003) o desempenho hidro ou aerodinâmico de uma seção de um aerofólio pode ser estudado mais facilmente pela referência de distribuição de pressão sobre o mesmo. Esta distribuição é usualmente expressa em termos do coeficiente de pressão:

$$
C_{p}=\frac{\left(p-p_{\infty}\right)}{\frac{1}{2} \rho W_{\infty}^{2}}
$$

É conveniente lidar com as diferenças de pressão adimensional em termos de $p_{\infty}$, que é a pressão a montante e distante do aerofólio, sendo usado assim como uma referência.

A pressão sobre a superfície de um aerofólio em movimento é não uniforme. A figura 2.14 mostra algumas típicas distribuições de pressão para uma dada seção qualquer em vários ângulos de incidência.

Olhando na figura 2.14, para o ângulo incidência $(\alpha=0)$, podemos ver que há pequenas regiões no nariz e na cauda onde $C_{p}$ é positivo, porém na maioria da seção $C_{p}$ é negativo. No bordo de fuga o coeficiente de pressão chega próximo a +1 , mas na verdade não alcança este valor. A diferença de pressão entre a superfície superior do perfil (lado de sucção) e a superfície inferior (lado de pressão) faz com que apareça uma resultante de sustentação como representado na figura 2.15, onde a pressão em cada ponto do perfil está representada pelo coeficiente de pressão.

Conforme a incidência aumenta de zero para os pontos na figura podemos notar que a redução de pressão na superfície superior aumenta em intensidade e extensão, e para incidências maiores, esta invade uma pequena parte da superfície inferior frontal. Podemos identificar também que o ponto de estagnação move-se progressivamente para trás na superfície inferior. A redução de pressão na superfície inferior perde simultaneamente intensidade e extensão.

Para o ângulo de incidência de $15^{\circ}$ podemos notar que o valor de $C_{p}$ alcança valores muito negativos, em alguns casos podendo chegar a -6 ou -7. Isso se deve a velocidade do escoamento que alcança valores três vezes a velocidade da corrente sem perturbação. Para ângulos por volta de $18^{\circ}$ a $20^{\circ}$ a redução de pressão na parte superior sofre um colapso e a seção perde sustentação provocando o estol. 

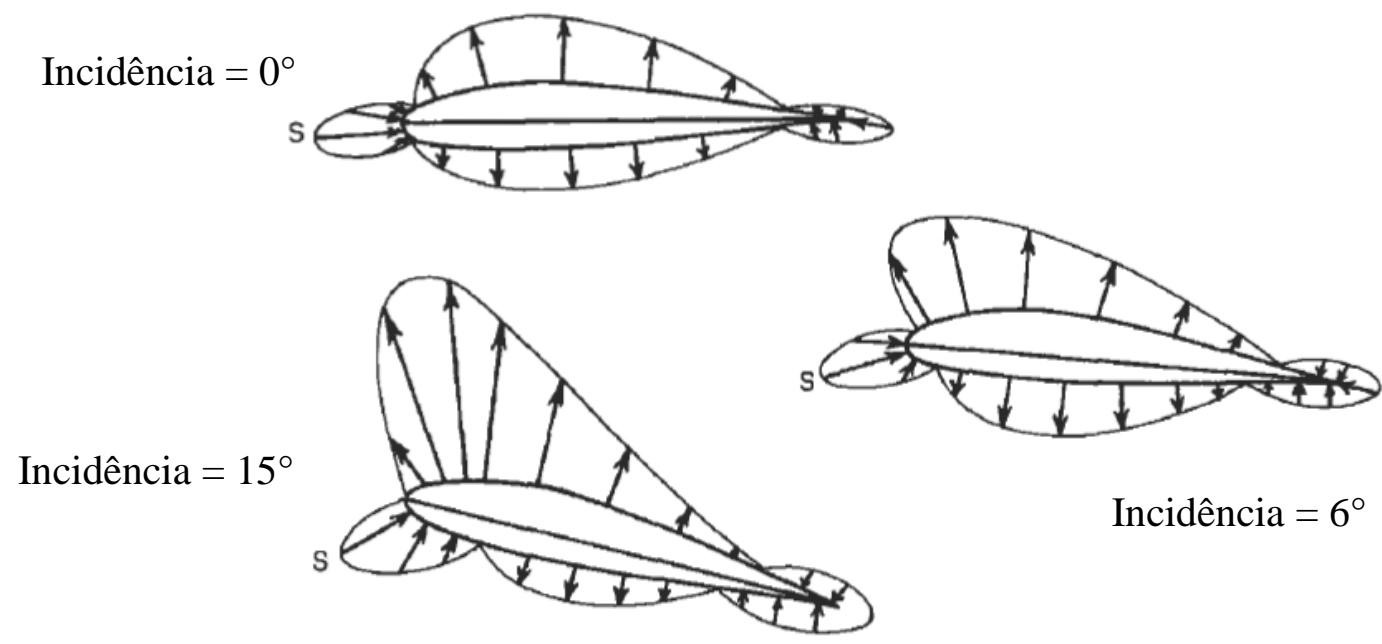

Figura 2.14 Distribuição típica de pressão em uma seção de um Aerofólio. Figura extraída de CARPENTER (2003).

Se usamos a equação de Bernoulli para escoamento permanente e incompressível, podemos reescrever a equação 2.8 como:

$$
1-C_{p}=\left(\frac{v}{v_{\infty}}\right)^{2}
$$

A figura 2.15 mostra dois tipos de visualização da distribuição do coeficiente de pressão ao longo da corda do perfil. Como a velocidade na parte superior do perfil é maior que na parte inferior quando a sustentação é positiva, o coeficiente de pressão $C_{p}$ tem valores menores na superfície superior e consequentemente a relação $\left(\frac{v}{v_{\infty}}\right)^{2}$ valores maiores.

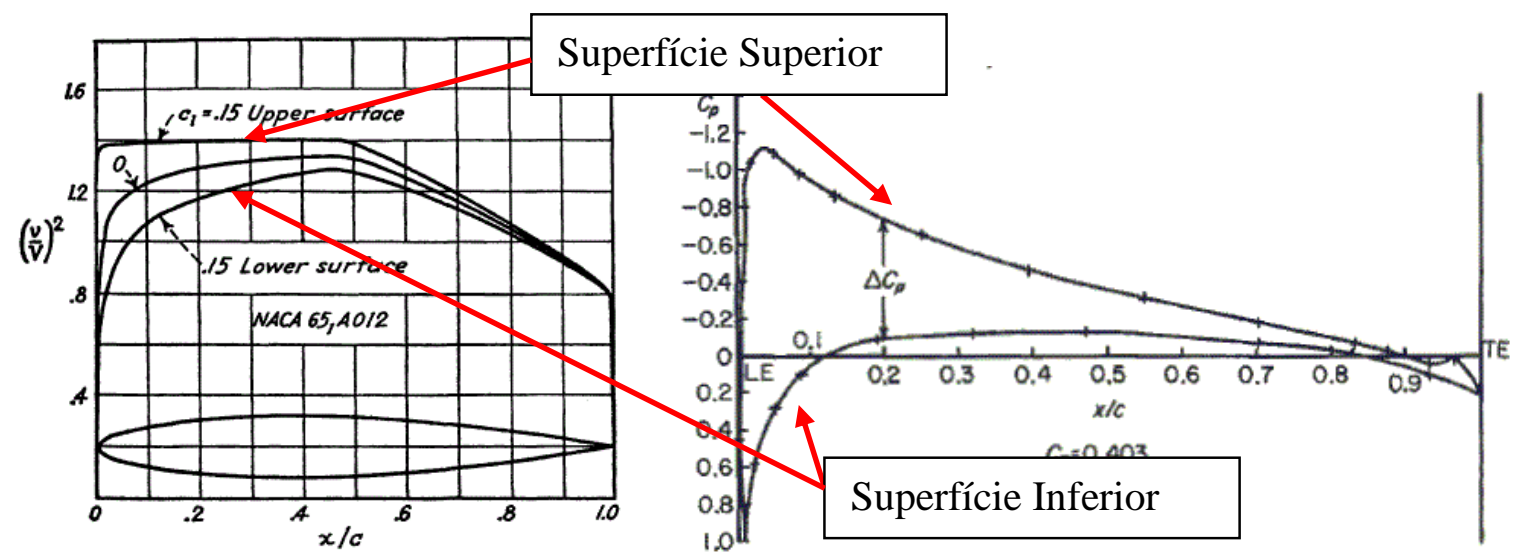

Figura 2.15 Coeficiente de Pressão sobre um aerofólio. Direita: em função da velocidade (figura extraída e adaptada de CARPENTER, 2003); Esquerda: em função de $C_{p}$ (Figura extraída e adaptada de ABBOTT, 1958). 
Quando o coeficiente de $C_{p}$ é igual à zero temos que a pressão do escoamento é igual à pressão do escoamento sem perturbação e quando o $C_{p}$ tem valor unitário positivo estamos no ponto de estagnação do perfil.

\subsection{DETERMINAÇÃO DOS PERFIS DA HÉLICE}

A determinação dos perfis dos aerofólios passa pela escolha de que tipo de aerofólio é mais adequado para o projeto em questão. Para isso deve se levar em questão fatores como a obtenção da máxima sustentação, boa distribuição de pressão e mínimo arrasto entre outros.

\subsubsection{Perfil NACA}

O que é pratica comum é escolher o perfil NACA (National Advisory Committee for Aeronautics) mais indicado para o projeto em que se está trabalhando.

Falando um pouco sobre a NACA, esta foi uma instituição federal do governo dos Estados Unidos fundada em 03 de março de 1915, para se encarregar, promover e institucionalizar a pesquisa aeronáutica. Em 1958 esta agencia foi dissolvida e seus recursos e pessoal transferidos para a recém-criada NASA (National Aeronautics and Space Administration).

Os perfis NACA são divididos em séries e para não se aprofundar nas características de cada série, que não é o objetivo deste trabalho, a tabela a seguir reúne as principais vantagens e desvantagens da cada uma das séries mais utilizadas.

\begin{tabular}{|c|c|c|c|}
\hline Familia & Vantagens & Desvantagens & Aplicações \\
\hline \multirow{3}{*}{ 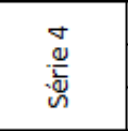 } & Boas Caracteristicas de Estolagem & Baixo Coeficiente de Sustentação & Aviação em Geral \\
\hline & Pequeno Efeito de Rugosidade & Alto Arrasto Relativo & Pás de Helicópteros \\
\hline & & Alto Coeficiente de Torque & Misseis e Foguetes \\
\hline \multirow{3}{*}{ 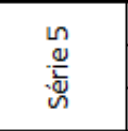 } & Coeficiente Máximo de Sustentação Alto & Comportamento de Estolagem pobre & Aviação em Geral \\
\hline & Baixo Coeficiente de Torque & Alto Arrasto Relativo & Jatos Comerciais \\
\hline & Baixo Efeito de Rugosidade & & \\
\hline \multirow{2}{*}{ 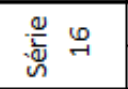 } & Evita picos de baixa pressão & Baixa Sustentação Relativa & Pás de Aviôes \\
\hline & Baixo Arrasto em Altas Velocidades & & Pás de Propeler \\
\hline \multirow{3}{*}{$\begin{array}{l}\mathscr{U} \\
\stackrel{\nu}{\nu} \\
\sim\end{array}$} & Máximo Coeficiente de Sustentação Alto & Alto Arrasto fora das Condições Òtimas & Jatos Supersonicos \\
\hline & Baixo Arrasto & Alto Coeficiente de Torque & Jatos Comerciais \\
\hline & Otimizado para Altas Velocidades & Muito Suceptivel a Rugosidade & Pás de Propeler \\
\hline \multirow{2}{*}{ 崩 $N$} & Baixo Arrasto & Máximo Coeficiente de Sustenção Reduzido & Raramente Usado \\
\hline & Baixo Coeficiente de Torque & Muito Suceptivel a Rugosidade & \\
\hline
\end{tabular}

Tabela 2.1 Características das Séries NACA. Tabela extraída e traduzida de ABBOTT, (1958) 
Geralmente em pás de hélices, que é o caso da máquina em estudo, em geral as séries de digito 16 e 6 são comumente utilizadas. As razões estão na tabela 2.1 e segundo GHOSE (2004) um tipo de aerofólio geralmente utilizado em hélices são as secções NACA com linha média $a=$ 0,8 e $a=1,0$ com distribuições de espessura da NACA 16 e NACA 66. A linha média da NACA $a=0,8$ e $a=1,0$ indica a fração de corda sobre qual a pressão de sucção na parte traseira da seção é constante no ângulo de ataque ideal. Ainda segundo GHOSE (2004) a linha média $a=0,8$ apresenta excelentes resultados na pratica e é amplamente utilizada juntamente com a distribuição de espessura da NACA 66 no projeto de hélices.

Não podemos avançar sem citar que o valor de $a$ representa a fração da corda, partindo se do bordo de ataque, sobre qual o carregamento é uniforme no ângulo de ataque ideal.

Segundo ABBOTT (1958) testes em túnel de vento e em voos da seção 6 da NACA foram realizados e mostraram que camadas laminares de grande extensão puderam ser mantidas para amplos valores do número de Reynolds se a superfície da asa fosse suficientemente lisa e suave. Estes testes também forneceram informações qualitativas sobre a magnitude do gradiente de pressão favorável, raio do bordo de fuga, e outras variáveis do perfil.

Segundo ABBOTT (1958), embora seções desenhadas para que em uma grande extensão do perfil se mantenha o escoamento laminar ofereçam coeficientes de arrasto excessivamente baixos próximos ao coeficiente de sustentação de projeto quando a superfície é lisa, o arrasto em tais perfis pode se tornar excessivamente grande quando a superfície é rugosa, particularmente para coeficientes de sustentação mais altos do que o projetado.

De acordo com os argumentos acima e da experiência do uso destes perfis na construção de propulsores a geometria escolhida para a determinação dos perfis das pás do rotor e distribuidor deste projeto foi à série 66 da NACA com linha média modificada $(a=0.8)$.

FERRO L.M.C (2011) realizou um estudo com seções de pás usando esse mesmo perfil para uma turbina de 0,5 metros de diâmetro com quatro pás comparando um método analítico com simulações numéricas (Fluent) e testes analíticos com boa concordância entre as medições e o projeto.

A figura 2.16 mostra a diferença no coeficiente de carregamento $P_{R}$ para dois tipos de linhas médias de um perfil NACA. Com isso é possível visualizar a fração de corda sobre qual a pressão de sucção na parte traseira da seção é constante no ângulo de ataque ideal para $a=0$ e $a=0,8$.

$$
\frac{\Delta v}{V}=\frac{1}{4} \frac{P_{R}}{v / V}
$$



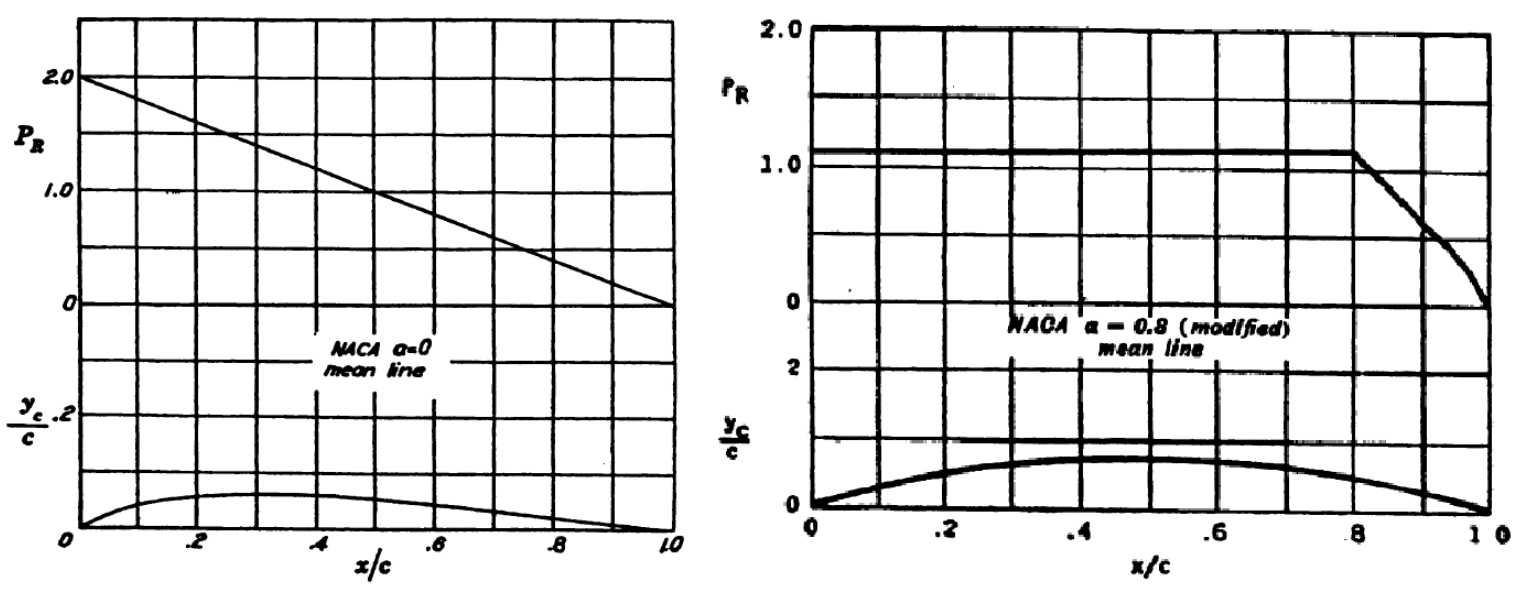

Figura 2.16 Coeficiente de Carregamento para duas linhas Médias. Direita: a=0.8; Esquerda: a=0. Figura extraída de ABBOTT (1958).

A figura 2.17 mostra a geometria da série NACA 66 mod. $a=0,8$ que pode ser encontrada em ABBOTT (1958). Essa referência é a principal fonte de perfis tipo NACA.

BROCKETT (1966) também mostra os valores referente a figura 2.17 especificando $\left(d y_{d} d x\right) / f_{0}$ como a inclinação do arqueamento do perfil (camber slope).

A geometria está em função das coordenadas da corda $c$, da espessura máxima to e da curvatura máxima da linha de arqueamento $f_{0}$.

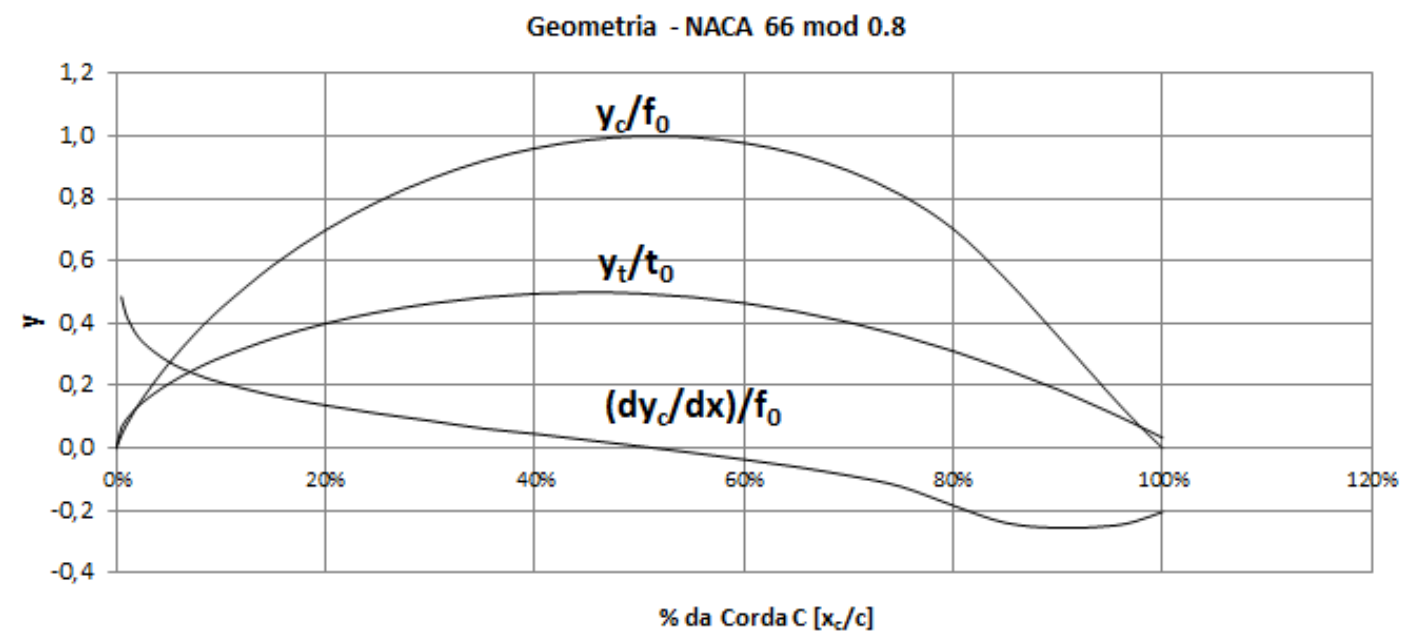

Figura 2.17 Geometria NACA $66 \bmod 0.8$ [Cortesia: Hydrel]

A figura 2.18 mostra a nomenclatura utilizada na determinação dos perfis da hélice. O que se chama de dorso também é conhecido com o lado de sucção do perfil e a face é também conhecida com o lado de pressão do perfil. 


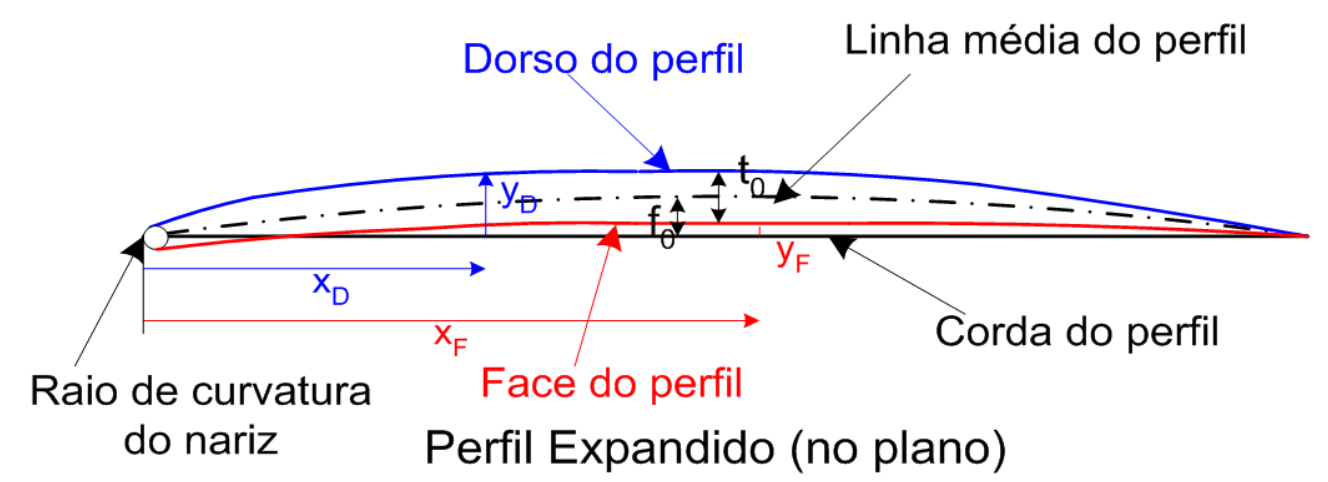

Figura 2.18 Nomenclatura do Perfil Expandido no plano [Cortesia: Hydrel]

A determinação das coordenadas cartesianas dos perfis para o projeto que se deseja passa pela transformação do perfil NACA que foi escolhido para as dimensões reais. Para isso devemse conhecer os parâmetros necessários para determinar os perfis expandidos da hélice e finalmente conhecer os pontos XYZ dos perfis.

A figura 2.19 mostra um perfil obtido dos dados do perfil NACA da figura 2.17 para uma geometria especifica. O perfil da figura 2.19 tem corda $c$ igual a 133,9 mm e espessura de $t_{0}$ de $6,3 \mathrm{~mm}$.

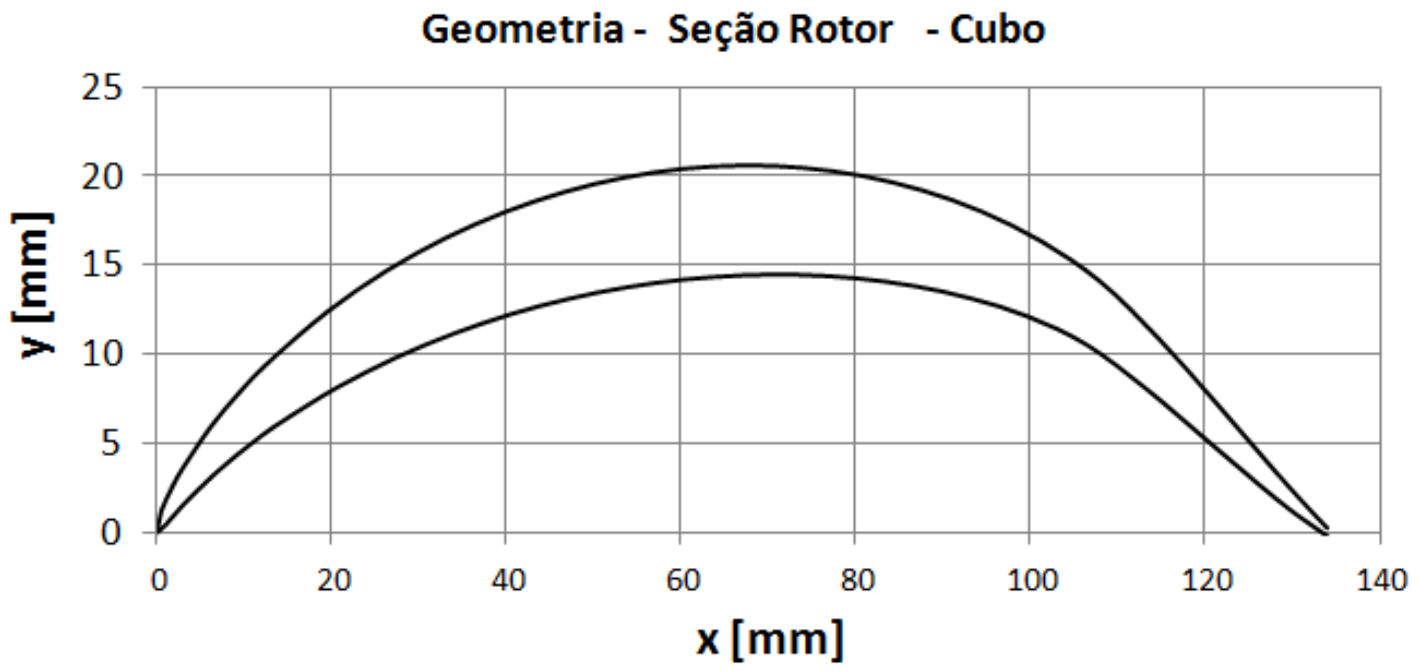

Figura 2.19 Seção Obtida dos Dados do Perfil NACA 66 [Cortesia: Hydrel] 


\subsubsection{Obtenção dos Perfis da Hélice}

O procedimento descrito neste item visa a obtenção das superfícies tanto do distribuidor quanto do rotor.

A metodologia aplicada aqui é do tipo vórtice livre "free vortex" e segundo SABERSKY e ACOSTA (1964) a velocidade tangencial após a passagem pelo distribuidor é do tipo $V_{t}=k / r$, onde $r$ é o raio do rotor ou distribuidor, $k$ é o parâmetro da relação espaçamento-corda e $V_{t}$ é a velocidade tangencial. Ainda segundo SABERSKY e ACOSTA (1964) para esse tipo de projeto demostra-se que as velocidades axiais após a passagem do escoamento pelo distribuidor são radialmente constantes, portanto as linhas de corrente situam-se em cilindros concêntricos. Como contrapartida o distribuidor tem torção radial assim como a superfície do rotor.

Para definirmos os perfis da hélice devemos estabelecer quais os objetivos no projeto da geometria a ser definida, que são basicamente:

a) Determinar o ângulo de sustentação zero dos perfis de uma cascata de fólios

b) Determinar a curvatura e o ângulo de ataque ideal do perfil da cascata

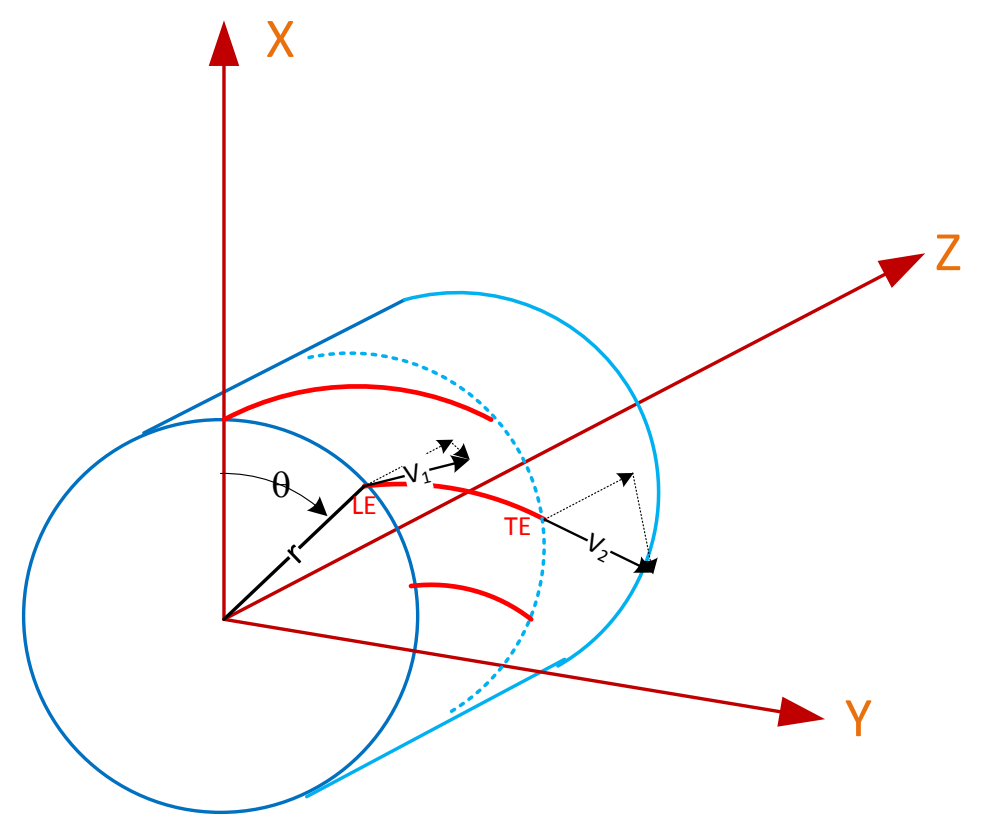

Figura 2.20. Traço das superfícies de referencia dos perfis [Cortesia: Hydrel]

De acordo com GOSTELOW (1984), devido a rotação e a formação da camada limite, o escoamento em uma turbo máquina é tridimensional. Assumir que o escoamento é bidimensional torna o problema mais fácil, para fazer isso devemos negligenciar a altura da pá e delinear um plano $Z Y^{*}$ em um dado raio $r$ do cilindro mostrado na figura 2.20. Em turbinas axiais se assume que o escoamento é bidimensional. 
O eixo $Z$ é orientado na direção axial ao escoamento, o eixo $Y^{*}$ é orientado na direção tangente ao escoamento e dá à direção de rotação do rotor que neste caso está no sentido negativo de $Y^{*}$. A figura 2.21 mostra a resultante planificação do cilindro de raio $r$ mostrado acima.

As seções da pá são definidas e posicionadas conforme a condição de entrada livre de choque "shock free entry" no bordo de ataque e com velocidades tangenciais na saída das seções do rotor iguais a zero. O termo "entrada livre de choque" em máquinas hidráulicas significa que a velocidade de entrada no bordo de ataque é tangente ao perfil.

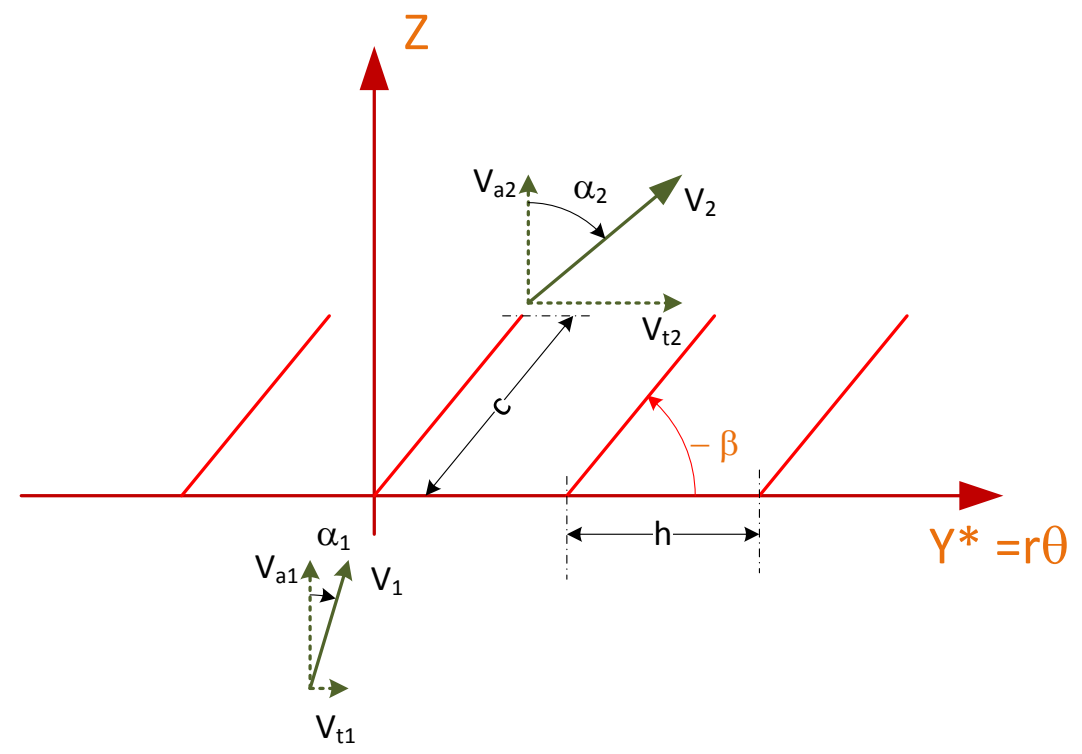

Figura 2.21. Traço das superfícies de referencias no plano $\mathrm{Z} ; \mathrm{Y}^{*}=\mathrm{r} \theta$ resultante da planificação do cilindro de raio r [Cortesia: Hydrel]

O ângulo $\beta$, referente a inclinação relativa ao eixo $Y^{*}=r \theta$, é o ângulo de sustentação nula quando se assume que a seção é uma placa fina e plana.

Segundo TWHAITES (1987) a velocidade e pressão tem valores diferentes antes e depois da cascata de perfis, o que é o esperado e veremos essa diferença na seção de resultados.

Ainda segundo TWHAITES (1987) a periodicidade do escoamento em intervalos $h$ medidos paralelamente ao eixo $\mathrm{Y}^{*}$ implica que é suficiente considerar um único intervalo com esse espaçamento para estabelecer as principais características do escoamento. Logo o coeficiente de sustentação é obtido para um único intervalo $h$.

De acordo com GOSTELOW (1984) o fluxo de massa $\rho_{1} V_{a 1} h$ antes a cascata de perfis e paralelo ao eixo z é igual ao fluxo de massa $\rho_{2} V_{a 2} h$ após a cascata onde o fluxo uniforme esta restabelecido. Para o escoamento incompressível, $\rho_{1}=\rho_{2}=\rho$, logo podemos escrever que $V_{a 1}=$ $V_{a 2}=V_{a}$ e os sufixos numéricos em $\rho$ e $V$ podem ser omitidos. 


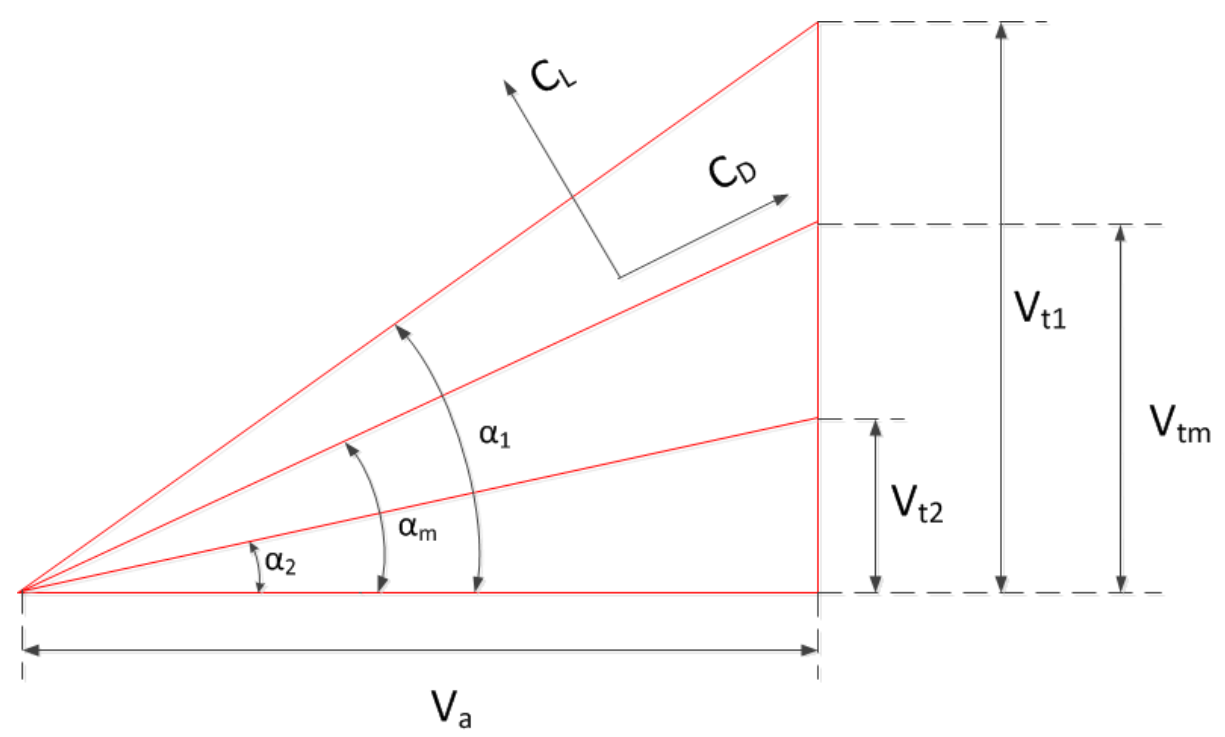

Figura 2.22 Esquema de notação para definir o coeficiente de arrasto e sustentação sobre uma cascata bidimensional [Cortesia: Hydrel]

A figura 2.22 é uma simplificação da figura 2.21 e serve como ilustração para definirmos os coeficientes de arrasto e sustentação da cascata, bem como outras grandezas pertinentes.

A circulação $\Gamma$ em torno de cada perfil pode ser calculada considerando um contorno consistente de duas linhas de correntes, separadas por uma distancia $h$ e ligadas por linhas paralelas ao eixo $Y^{*}$ em grandes distancias antes e depois do aerofólio. A soma das contribuições de duas linhas de corrente idênticas é zero, e então:

$$
\Gamma=\left(V_{t 1}-V_{t 2}\right) h=V_{a} h\left(\tan \alpha_{1}-\tan \alpha_{2}\right)
$$

O aumento da pressão estática através da cascata é expresso em termos de $V_{t 1}, V_{t 2}$ e $\bar{p}$ como:

$$
p_{2}-p_{1}=\frac{1}{2} \rho\left(V_{t 1}^{2}-V_{t 2}^{2}\right)-\bar{p}
$$

Onde $\bar{p}$ é a perda de pressão total que aparece devido à viscosidade.

O coeficiente de sustentação de um perfil pertencente à cascata de perfis é dado pela relação abaixo onde $k$ é o parametro da relação corda-espessura TWHAITES (1987):

$$
C_{L o}=A b s\left[\left(\frac{4}{S_{c} k}\right) \frac{\sin \left(\alpha_{m}+\beta\right)}{\cos \beta}\right]-C_{d} \tan \alpha_{m}
$$


Onde $S_{c}$ é a razão de solidez da cascata (solidity ratio):

$$
S_{c}=\frac{c}{h}
$$

onde:

$c$ : corda do perfil;

$h$ : espaçamento entre cordas.

Transformando a razão de solidez da cascata para o rotor ou distribuidor em analise:

$$
S_{c}=\left(\frac{z}{2 \pi \chi \cdot R_{R}}\right) c
$$

onde:

$c$ : corda do perfil;

$Z$ : Número de Pás do Rotor

$\chi$ : Raio Adimensional (percentual do raio do Rotor: $r / R_{R}$ )

$R_{R}:$ Raio do Rotor

O ângulo $\alpha_{m}$ é o ângulo médio do escoamento em sua passagem pela cascata de perfis:

$$
\alpha_{m}=\tan ^{-1}\left[\frac{\frac{V_{t 1}+V_{t 2}}{2}}{\frac{V_{a 1}+V_{a 2}}{2}}\right]
$$

Onde, $\mathrm{V}_{\mathrm{a}}$ é a velocidade do escoamento na direção $\mathrm{Z}$ (axial) e $\mathrm{V}_{\mathrm{t}}$ a componente tangencial do escoamento.

O coeficiente de arrasto do perfil é função da razão espessura corda do mesmo (espessura máxima). Os coeficientes correspondem ao ajuste do coeficiente de arrasto dos perfis NACA 66 validos para coeficientes de sustentação de 0 a 0,4

$$
C_{d}=\sum_{0}^{4} a_{n}\left(\frac{t_{0}}{c}\right)^{n}
$$


Podemos reescrever a equação 2.17 com os coeficientes retirados de ABBOTT (1958):

$$
C_{d}=-2,4736.10^{-1}\left(\frac{t_{0}}{c}\right)^{4}+3,0026\left(\frac{t_{0}}{c}\right)^{3}-4,1263 \cdot 10^{-1}\left(\frac{t_{0}}{c}\right)^{2}+7,6231 \cdot 10^{-3}\left(\frac{t_{0}}{c}\right)+8,5906 \cdot 10^{-3}
$$

O parâmetro k é dado por TWHAITES (1987):

$$
\frac{k+1}{k-1}=u=\frac{\tan \alpha_{1}+\tan \beta}{\tan \alpha_{2}+\tan \beta}
$$

Rearranjando para k:

$$
k=\frac{2 \tan \beta+\tan \alpha_{1}+\tan \alpha_{2}}{\tan \alpha_{1}-\tan \alpha_{2}}
$$

O parâmetro $m$ estabelece a relação entre o coeficiente de sustentação de um perfil situado em uma cascata de razão de solidez $S$ e o mesmo perfil isolado:

$$
m=\frac{C_{L o}}{C_{\text {Lisolado }}}=\left(\frac{2}{\pi}\right)\left(\frac{1}{S_{c} k}\right)\left(\frac{1}{\cos \beta}\right)-\left(\frac{C_{d}}{2 \pi}\right) \frac{\tan \alpha_{m}}{\operatorname{abs}\left(\sin \left(\alpha_{m}+\beta\right)\right)}
$$

Podemos ver na figura 2.23 a influência do ângulo $\beta$ e da relação espaçamento-corda no parâmetro $m$ descrito acima. Nota-se que o aumento do espaçamento entre os perfis em cascata $h$ faz a relação $m$ tender a unidade, e assim o coeficiente de sustentação do perfil em cascata tende a ser o coeficiente do perfil isolado.

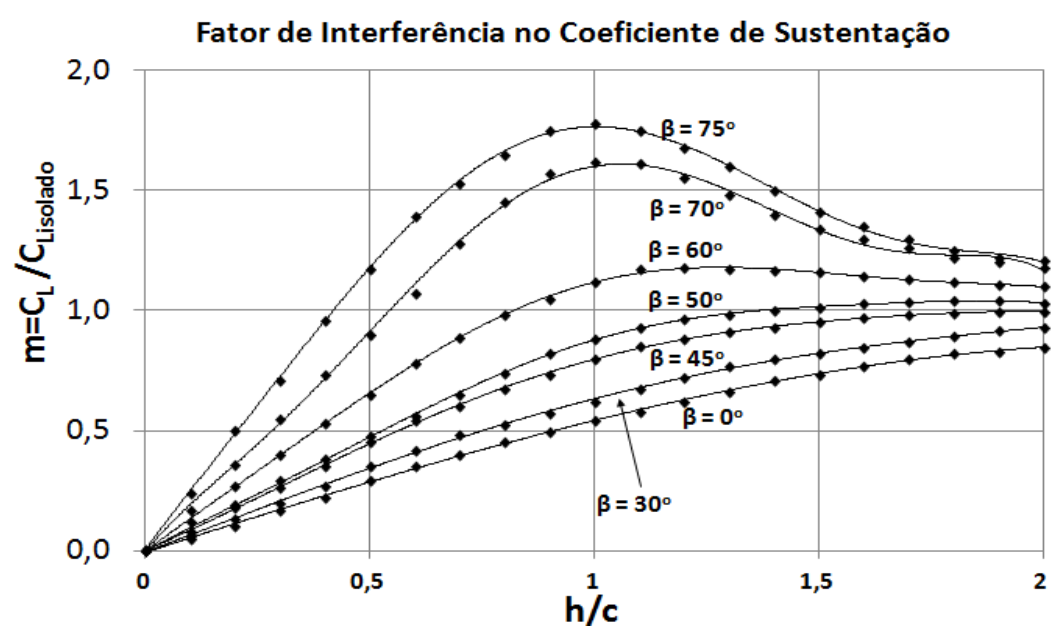

Figura 2.23. Efeito do ângulo de sustentação zero e da relação espaçamento corda no Coeficiente de Sustentação. Figura extraída de TWHAITES (1987). 
A equação 2.21 é resolvida numericamente para a determinação de $\beta$ a partir do conhecimento de $\alpha_{1}$ e $\alpha_{2}$ e $S_{c}$ levando-se em conta as equações 2.19 e 2.22 .

$$
F_{i t} \equiv 0=\pi S_{c}-\ln (u) \cos \beta-2 \theta_{c} \operatorname{sen} \beta
$$

onde:

$$
\theta_{c}=\tan ^{-1}\left(\frac{\tan \beta}{k}\right)
$$

A primeira estimativa de $\beta$, será $\beta_{\text {estl }}=f . \alpha_{2} \operatorname{com} \mathrm{f}>1,0$.

O ângulo $\beta$ determinado a partir de 2.21 é o ângulo $\beta_{z l}$ a partir do qual o perfil é posicionado para desenvolver a sustentação requerida. A cada raio, o perfil deverá ser posicionado com relação ao escoamento médio, definido pelo ângulo $\alpha_{m}$.

Para tal, a inclinação da corda do perfil $\beta_{c o}$ relativa ao eixo $Y^{*}=r \theta$ deverá ser:

$$
\beta_{c o}=\beta_{z l}-\alpha_{z l}
$$

A relação 2.23 nada mais é que a correção do ângulo de posicionamento da corda do perfil levando em consideração a correção da espessura do perfil, já que $\beta_{z l}$ é o ângulo de posicionamento se os perfis fosse placas planas e o ângulo de incidência $\alpha_{z l}$ é o ângulo de posicionamento da cascata de hidrofólios, dado por:

$$
\alpha_{z l}=m_{3} C_{\text {Lisolado }}=m_{3} \frac{C_{L o}}{m}
$$

Onde $m_{3}$ é uma constante dada por TWHAITES (1987) para perfis NACA 66. Para linhas medias de seções NACA $66 \operatorname{com} a=0,8 ; m_{3}=0,132$. O ângulo de incidência do perfil relativamente ao escoamento médio $\alpha_{m}$ deverá ser:

$$
\alpha_{i n c}=a b s\left(\beta_{c o}\right)-\alpha_{m}
$$


Este ângulo de incidência deverá coincidir com o ângulo de ataque ideal do perfil com a linha media especificada:

$$
\alpha_{\text {inc }}=\alpha_{\text {id }}=m_{2} C_{\text {Lisolado }}=m_{2} \frac{C_{L o}}{m}
$$

Para a linha media NACA 0,$8 ; \mathrm{m}_{2}=0,027$.

Para desenvolver a sustentação requerida, o perfil além de posicionado em seu ângulo de ataque ideal $\left(\alpha_{\mathrm{inc}}=\alpha_{\mathrm{id}}\right)$ relativo ao escoamento, deverá ter a flecha correta (camber) de sua linha de media. O valor máximo da flecha $\left(f_{o}\right)$ da linha media deverá ser:

$$
\frac{f_{o}}{c}=m_{5} C_{\text {Lisolado }}=m_{5} \frac{C_{L o}}{m}
$$

Onde $c$ é a corda do perfil. Segundo KRUPPA (1969), para a linha media NACA 0,8 $m_{5}=$ 0,0679 , que representa uma relação entre o máximo arqueamento do perfil $f_{0}$ com o coeficiente de sustentação.

A determinação do coeficiente de sustentação através da iteração acima é fundamental para o cálculo da potência da unidade geradora.

\subsubsection{Cavitação em Hélices}

O desempenho de hélices vai ser largamente dependente do tipo de seção a ser utilizada. Apesar de o escoamento através de hélices ser predominantemente tridimensional, dados bidimensionais de fólios são uteis na derivação do critério sobre o qual a seleção do tipo de perfil será baseada.

Para se decidir se um perfil de hélice em particular pode ou não ser usado como base para o projeto de uma turbina é indispensável saber sua distribuição de pressão sobre uma faixa suficientemente grande de ângulos de ataque. E é sobre o valor da mínima pressão sobre a superfície do fólio que o projetista tem que olhar com cuidado, pois se a pressão no escoamento cair abaixo de uma pressão crítica, cavitação pode ocorrer. 
Segundo KRUPPA (1969) o critério de cavitação necessário à determinação da espessura mínima da seção se dá pela determinação da máxima relação permissível entre espessura e corda:

$$
\left(\frac{t_{o}}{c}\right)_{c a v}=\frac{\left[\left(\sqrt{\frac{1+\sigma}{1+S_{c a v}}}-1\right)-C_{2} \cdot C_{L}\right]}{C_{1}}
$$

Na equação 2.28 podemos identificar os seguintes termos:

$C_{L}$ - Coeficiente de Sustentação da Seção

$\sigma$ - Número de Cavitação

$C_{1}$ - Constante do tipo de distribuição de espessura

$C_{2}$ - Constante de Arqueamento do Perfil

$S_{c a v}$ - Margem de Segurança para o início de Cavitação

Na pratica a seção que está sendo analisada deve passar pelo critério de cavitação que estabelece uma relação de espessura-corda máxima, e esta mesma seção deve ter uma espessura tal que o esforço mecânico não ultrapasse os limites de escoamento do material utilizado. O que se observa é que a espessura máxima obtida pelo critério de cavitação é quase sempre maior do que a espessura mínima obtida pelo critério de esforços, logo a razão de espessura-corda quase sempre é definida pelos esforços mecânicos gerados pelo escoamento.

De acordo com KRUPPA (1969) a constante $C_{1}$ mede a qualidade da seção do perfil com relação ao efeito de deslocamento. Para alguns perfis usados em hélices a tabela 2.2 mostra valores de $C_{1}$.

Tabela 2.2 Valores da constante $C_{1}$ para alguns tipos de perfis (KRUPPA, 1969).

\begin{tabular}{c|c|c|c|c}
\hline Tipo de Seção do Perfil & $\begin{array}{c}\text { Puramente } \\
\text { Elíptico }\end{array}$ & $\begin{array}{c}\text { Elíptico } \\
\text { Parabólico }\end{array}$ & NACA 16 & NACA 66 \\
\hline $\boldsymbol{C}_{\mathbf{1}}$ & 1.00 & 1.06 & 1.14 & 1.28 \\
\hline
\end{tabular}

As seções elípticas e elípticas parabólicas estão na tabela 2.2 para efeito de comparação. Essas seções são muito largas na parte traseira do perfil para ser consideradas em termos de sustentação e arrasto. 
No projeto de hélices deve se distinguir entre dois tipos de números de cavitação, o número de cavitação da hélice $\sigma_{0}$ (usado principalmente em hélices de navios) e o numero de cavitação local ou da seção $\sigma_{x}$.

$$
\sigma_{0}=\frac{2 .\left(p_{0}+\rho g h_{a}-p_{v}\right)}{\rho V^{2}}
$$

O número de cavitação $\sigma_{0}$ depende do afogamento $h_{\mathrm{a}}$ da hélice conforme mostrado na figura 2.24 .

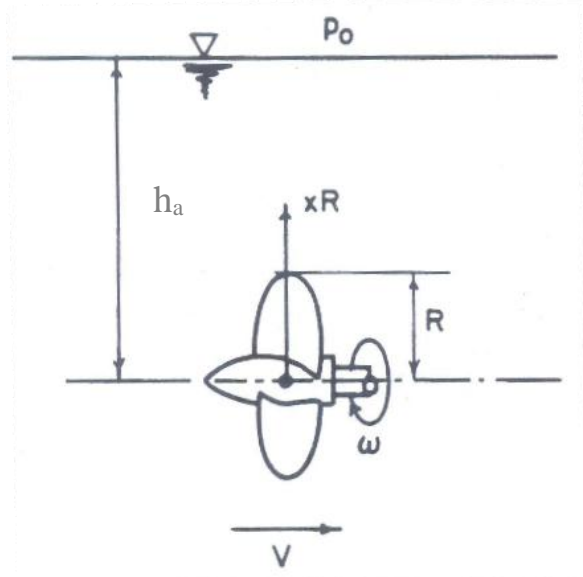

Figura 2.24 Rotor Afogado - Número de Cavitação. Figura extraída de KRUPPA (1969).

O termo $p_{v}$ é a pressão de vapor do escoamento na temperatura de operação.

O número local de cavitação $\sigma_{x}$ é baseado na pressão de estagnação referente a velocidade relativa à seção do perfil. A pressão $p_{0 e p x}$ é estimada no escoamento a montante do perfil estudado.

$$
\sigma_{x}=\frac{2 \cdot\left(p_{0 e p x}-p_{v}\right)}{\rho\left(k_{w_{m}} \cdot V_{t}\right)^{2}}
$$

A velocidade $V_{t}$ é a velocidade tangencial ao perfil em analise e o termo $k_{w m}$ é um termo de correção de espessura da seção do perfil em estudo e depende da Solidez $S_{c}$ da cascata de perfis e da relação $\frac{t_{o}}{c}$. Esse termo apresenta na prática valores próximos à unidade e é utilizado para corrigir a velocidade tangencial ao perfil, já que este tem uma espessura não nula. 


$$
k_{w_{m}}=\frac{1}{\left(1-S_{c} \cdot \frac{t_{o}}{c}\right)}
$$

Segundo KRUPPA (1969) um fator de segurança $S_{\text {cav }}$ deve ser inserido na equação 2.31 contra o aparecimento de cavitação sobre condições de escoamento com entrada tangente ao perfil na entrada do mesmo. Na prática esse fator faz com que a espessura da seção seja um pouco menor com consequente aumento no coeficiente de pressão local evitando assim o aparecimento de cavitação.

$$
S_{c a v}=\frac{\sigma_{x}}{\frac{\Delta_{m a x}}{\frac{\rho}{2} v_{\infty}^{2}}}-1 \approx 0,18
$$

Em perfis de seções arqueadas, no ângulo de ataque de projeto, a sustentação é predominantemente produzida pela linha média e não pelo ângulo de ataque. A razão disso é que o coeficiente de sustentação de perfis com distribuição de espessura super-imposta é sempre maior do que aqueles sem essa imposição $\left(C_{L_{i}}\right)$, ou perfis finos. A qualidade das linhas médias pode ser então comparada para um dado coeficiente de sustentação $C_{L_{i}}$ e pode ser mostrado que:

$$
\frac{\Delta v_{\max }}{V_{\infty}}=C_{2} \cdot C_{L_{i}}
$$

Onde $C_{2}$ que faz parte da equação 2.28 é definido por:

$$
C_{2}=\frac{1}{[2 \cdot(1+a)]}=0,278
$$

Para as linhas médias mais comuns em projetos de hélices, valores de $C_{2}$ são dados na tabela 2.3:

Tabela 2.3 Constante $C_{2}$ para perfis arqueados (KRUPPA, 1969)

\begin{tabular}{c|c|c}
\hline NACA - a - Linha Média & 1.0 & 0.8 \\
\hline$C_{2}$ & 0.25 & 0.278 \\
\hline
\end{tabular}


Com o cálculo dos parâmetros necessários para o teste de cavitação para cada seção o teste pode ser feito. Na prática o que se faz é dividir a geometria em seções a partir do diâmetro do cubo e comparar o critério de cavitação com a relação $t_{0} / c$ dada pelo cálculo estrutural.

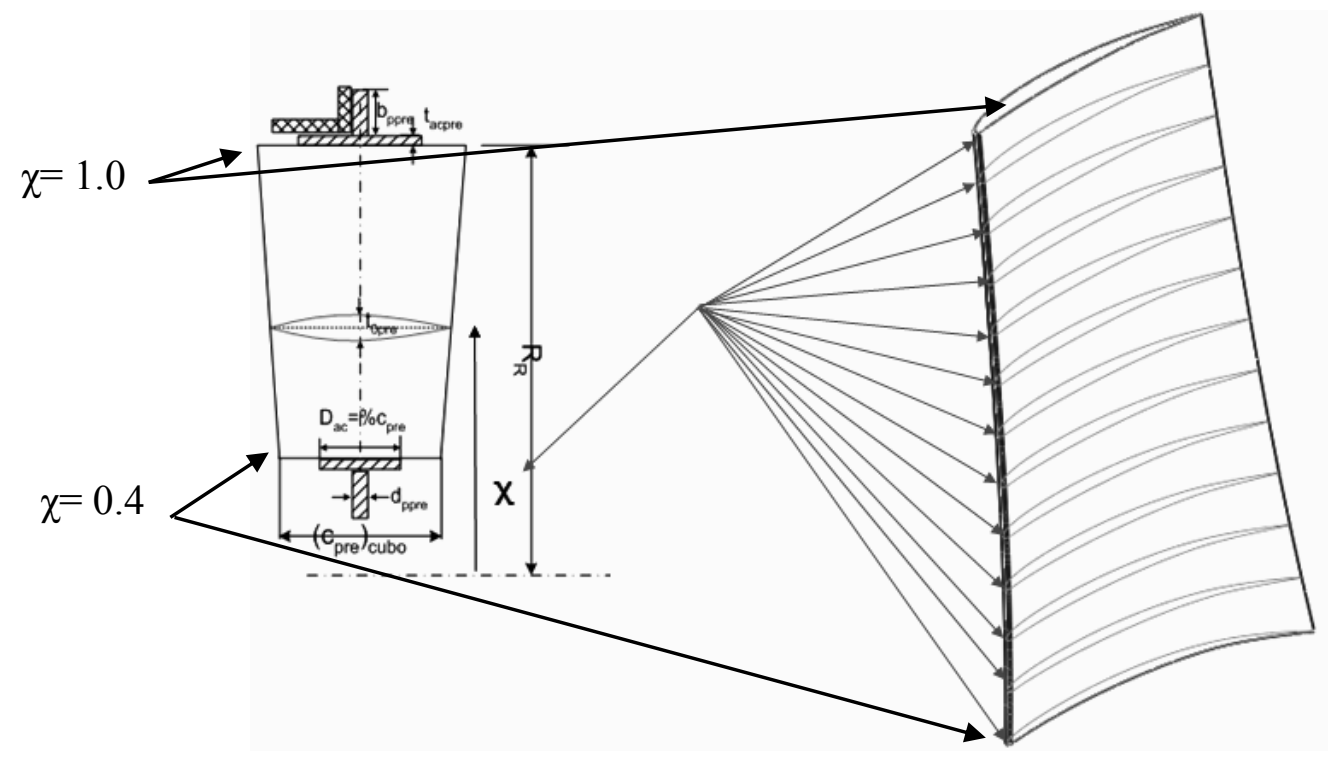

Figura 2.25 Seções para cálculo do critério de Cavitação em uma seção qualquer [Cortesia: Hydrel] 


\subsection{MÉTODO DOS PAINÉIS}

\subsubsection{Introdução}

Como exposto na introdução a ideia é comparar a metodologia analítica para determinação das seções das pás do rotor e distribuidor com um método numérico que neste caso é o método dos painéis.

O escoamento potencial sobre um aerofólio tem um papel histórico importante na aerodinâmica e hidrodinâmica. A equação que governa o escoamento potencial é a equação de Laplace, uma equação diferencial parcial linear amplamente estudada.

Uma das identidades do teorema de Green pode ser usada para escrever a solução para a equação de Laplace como um limite integral. Modelos numéricos baseados nesta aproximação são conhecidos como Método dos Painéis na comunidade aerodinâmica. O método dos painéis modela o escoamento potencial sobre um corpo distribuindo fontes sobre a superfície do mesmo. Desta maneira o escoamento potencial sobre um corpo de qualquer forma pode ser calculado com um alto grau de precisão. O método escolhido para utilização foi o método de vorticidade superficial proposto por MARTENSEN (1959), que não somente se aproveitou de técnicas computacionais poderosas como estendeu sua teoria de integral limite para lidar com cascatas de turbo máquinas. Fato esse que justifica a escolha desse método já que uma turbina axial nada mais é que uma cascata de perfis com espaçamento $h$.

\subsubsection{Modelo de Vorticidade Superficial para Escoamentos planos bidimensionais}

Aqui o objetivo é apresentar alguns detalhes sobre o método da vorticidade superficial e como essa distribuição de vorticidade é estabelecida para um corpo qualquer. O entendimento dessa formulação é importante para que se possam estabelecer relações com o cálculo analítico.

Considere o escoamento sobre um corpo bidimensional no plano $(x, y)$, imerso em uma corrente uniforme $W_{\infty}$ inclinada com ângulo $\alpha_{\infty}$ em relação ao eixo $x$, ver figura 2.26.

Segundo LEWIS (1991) podemos representar o escoamento por um lençol de vorticidade $\gamma(s)$ encobrindo todo o corpo, porém inicialmente com intensidade desconhecida.

A distância $s$ é medida no sentido horário sobre o perímetro do corpo começando de uma referência zero, que pode ser o bordo de ataque do perfil.

Segundo LEWIS (1991) a velocidade $d q_{m n}$ induzida em $s_{m}$ devido ao pequeno elemento de vorticidade $\gamma(s) d s_{n}$ localizado em qualquer outra parte do corpo $s_{n}$, seguidos pela Lei de BiotSavart que neste caso reduz a velocidade induzida por um anel retangular, escrito por: 


$$
d q_{m n}=\frac{\gamma\left(s_{n}\right) d s_{n}}{2 \pi r_{m n}}
$$

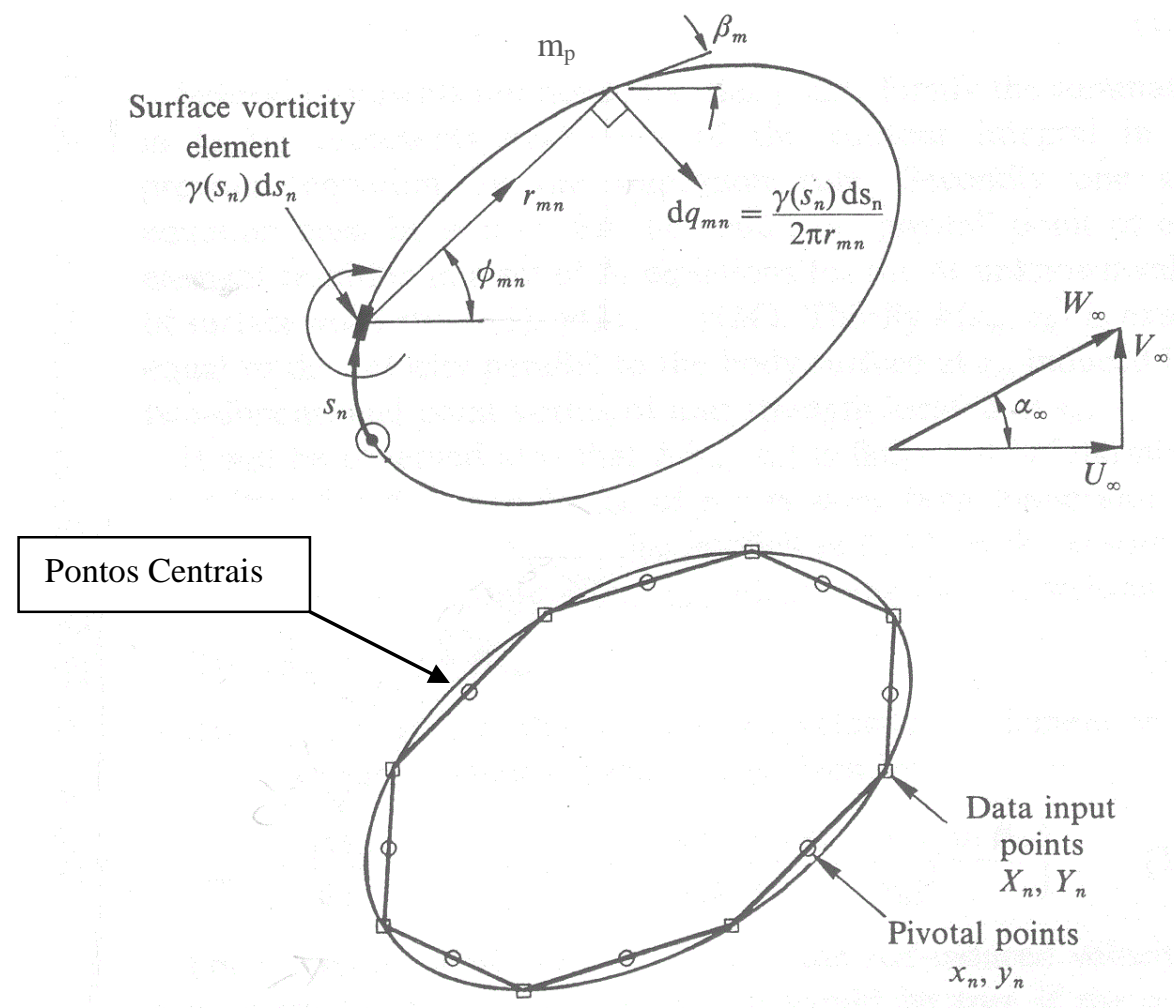

Figura 2.26 Modelo de Vorticidade para um corpo bidimensional; Em cima: Velocidade induzida pelo elemento superficial em $s_{n}$; Em baixo: Representação da superfície do corpo por elementos de linha retilíneos. Figura extraída de LEWIS (1991).

Precisamos resolver $d q_{m n}$ paralelo à superfície do corpo em $m_{p}$ onde a inclinação do perfil é definida por $\beta_{m}$. Por conveniência computacional as componentes $(x, y)$ de $d q_{m n}$ podem primeiramente ser expressas em termos da localização nas coordenadas através de:

$$
\left.\begin{array}{l}
d U_{m n}=\frac{\gamma\left(s_{n}\right) d s_{n}}{2 \pi r_{m n}} \operatorname{sen} \phi_{m n}=\left(\frac{y_{m}-y_{n}}{2 \pi r_{m n}{ }^{2}}\right) \gamma\left(s_{n}\right) d s_{n} \\
d V_{m n}=-\frac{\gamma\left(s_{n}\right) d s_{n}}{2 \pi r_{m n}} \cos \phi_{m n}=-\left(\frac{x_{m}-x_{n}}{2 \pi r_{m n}{ }^{2}}\right) \gamma\left(s_{n}\right) d s_{n}
\end{array}\right\}
$$

Resolvendo $d q_{m n}$ paralelo a $s_{m}$ então obtemos:

$$
d v_{s m n}=\frac{1}{2 \pi}\left\{\frac{\left(y_{m}-y_{n}\right) \cos \beta_{m}-\left(x_{m}-x_{n}\right) \operatorname{sen} \beta_{m}}{\left(x_{m}-x_{n}\right)^{2}+\left(y_{m}-y_{n}\right)^{2}}\right\} \gamma\left(s_{n}\right) d s_{n}
$$


A condição de Dirichlet estabelece que a vorticidade seja zero sobre e paralela à superfície do corpo em $m_{p}$. Usando essa condição em $s_{m}$, temos para um escoamento plano bidimensional, segundo LEWIS (1991):

$$
-\frac{1}{2} \gamma\left(s_{m}\right)+\oint k\left(s_{m}, s_{n}\right) \gamma\left(s_{n}\right) d s_{n}+W_{\infty}\left(\cos \alpha_{\infty} \cos \beta_{m}+\operatorname{sen} \alpha_{\infty} \operatorname{sen} \beta_{m}\right)=0
$$

O último termo da equação 2.37 é o componente de $W_{\infty}$ resolvido paralelamente a superfície em $m$ e o coeficiente de acoplamento $k\left(s_{m}, s_{n}\right)$ é dado por:

$$
k\left(s_{m}, s_{n}\right)=\frac{1}{2 \pi}\left\{\frac{\left(y_{m}-y_{n}\right) \cos \beta_{m}-\left(x_{m}-x_{n}\right) \operatorname{sen} \beta_{m}}{\left(x_{m}-x_{n}\right)^{2}+\left(y_{m}-y_{n}\right)^{2}}\right\}
$$

A equação 2.37 é a equação integral limite de Martensen para o escoamento bidimensional e a equação integral de Fredholm de segunda ordem. Essa deve ser satisfeita em todos os pontos sobre a superfície do corpo em estudo.

Uma pratica aproximação essa aproximação seria selecionar um número finito $M$ de "pivotal points", que podem ser chamados de pontos centrais e que sejam representativos da superfície, ver figura 2.26. Isso pode ser alcançado se a superfície for quebrada em um número $M$ finito de elementos de comprimento $\Delta s_{n}$, de modo que possamos escrever:

$$
\sum_{n=1}^{M} K\left(s_{m}, s_{n}\right) \gamma\left(s_{n}\right)=-U_{\infty} \cos \beta_{m}-V_{\infty} \operatorname{sen} \beta_{m}
$$

$U_{\infty}$ e $V_{\infty}$ são componentes de $W_{\infty}$ paralelo aos eixos $x$ e $y, K\left(s_{m}, s_{n}\right)$ são os coeficientes de acoplamento que ligam os coeficientes $m$ e $n$ dados, segundo LEWIS (1991), por:

$$
\begin{aligned}
& K\left(s_{m}, s_{n}\right)=\frac{\Delta s_{n}}{2 \pi}\left\{\frac{\left(y_{m}-y_{n}\right) \cos \beta_{m}-\left(x_{m}-x_{n}\right) \operatorname{sen} \beta_{m}}{\left(x_{m}-x_{n}\right)^{2}+\left(y_{m}-y_{n}\right)^{2}}\right\} \\
& =k\left(s_{m}, s_{n}\right) \Delta s_{n}
\end{aligned}
$$


O termo $K\left(s_{m}, s_{n}\right)$ é finito porém indeterminado para o caso em que $m=n$ uma vez que o numerador e o denominador são zero. Também implícito na equação 2.39 está a absorção do termo $-\frac{1}{2} \gamma\left(s_{m}\right)$ no termo $K\left(s_{m}, s_{m}\right)$ que pode então ser escrito:

$$
K\left(s_{m}, s_{m}\right)=-\frac{1}{2}+K_{m m^{\prime}}
$$

Onde $K_{m m^{\prime}} \cdot \gamma\left(s_{m}\right)$ é a velocidade auto induzida do elemento $m$ e o coeficiente de acoplamento de auto indução é dado por:

$$
K_{m m^{\prime}}=\frac{\Delta s_{m}}{2 \pi}\left\{\frac{\left(y_{m}-y_{n}\right) \cos \beta_{m}-\left(x_{m}-x_{n}\right) \operatorname{sen} \beta_{m}}{\left(x_{m}-x_{n}\right)^{2}+\left(y_{m}-y_{n}\right)^{2}}\right\}
$$

O valor do termo $K_{m m^{\prime}}$ é zero quando o corpo é dividido em elementos retos, se fossem usados elementos curvos então esse valor seria diferente de zero. Existe uma correção apropriada para a correção devido a esse efeito de curvatura da superfície:

$$
K_{m m^{\prime}}=-\frac{\Delta \beta_{m}}{4 \pi}
$$

A equação 2.39 então fica com na forma matricial proposta por LEWIS (1991) (elementos retos):

$$
\left(\begin{array}{ccccc}
-0.5 & K_{12} & K_{13} & \ldots & K_{1 M} \\
K_{21} & -0.5 & K_{23} & \ldots & K_{2 M} \\
K_{31} & K_{32} & -0.5 & \ldots & K_{3 M} \\
\cdot & \cdot & \cdot & \ldots & \cdot \\
\cdot & \cdot & \cdot & \ldots & . \\
K_{M 1} & K_{M 2} & K_{M 3} & \ldots & -0.5
\end{array}\right)\left(\begin{array}{c}
\gamma\left(s_{1}\right) \\
\gamma\left(s_{2}\right) \\
\gamma\left(s_{3}\right) \\
\cdot \\
\cdot \\
\gamma\left(s_{M}\right)
\end{array}\right)=\left(\begin{array}{c}
\mathrm{rhs}_{1} \\
\mathrm{rhs}_{2} \\
\mathrm{rhs}_{3} \\
\cdot \\
\cdot \\
\mathrm{rhs}_{M}
\end{array} \mid\right.
$$

Com a notação simplificada $K_{\mathrm{mn}} \equiv K\left(s_{m}, s_{n}\right)$ e com o lado direito igual a: $r h s_{m}=-U_{\infty} \cos \beta_{m}-V_{\infty} \operatorname{sen} \beta_{m}$

O significado físico da relação acima se pela condição de tangência do escoamento na entrada. 


\subsubsection{Esquema computacional para análise da Vorticidade Superficial}

Agora podemos preparar o esquema computacional para calcular o escoamento através de um corpo qualquer, que também pode e será utilizado para o cálculo do perfil isolado e em cascata como veremos adiante. Os esquema se divide em 06 etapas definidas a seguir.

\section{a) Entrada de Dados}

Especificar $M+1$ coordenadas de dados de entrada $\left(X_{n}, Y_{n}\right)$ como ilustrado na figura 2.26 movendo se no sentido horário do perfil partindo do bordo de ataque.

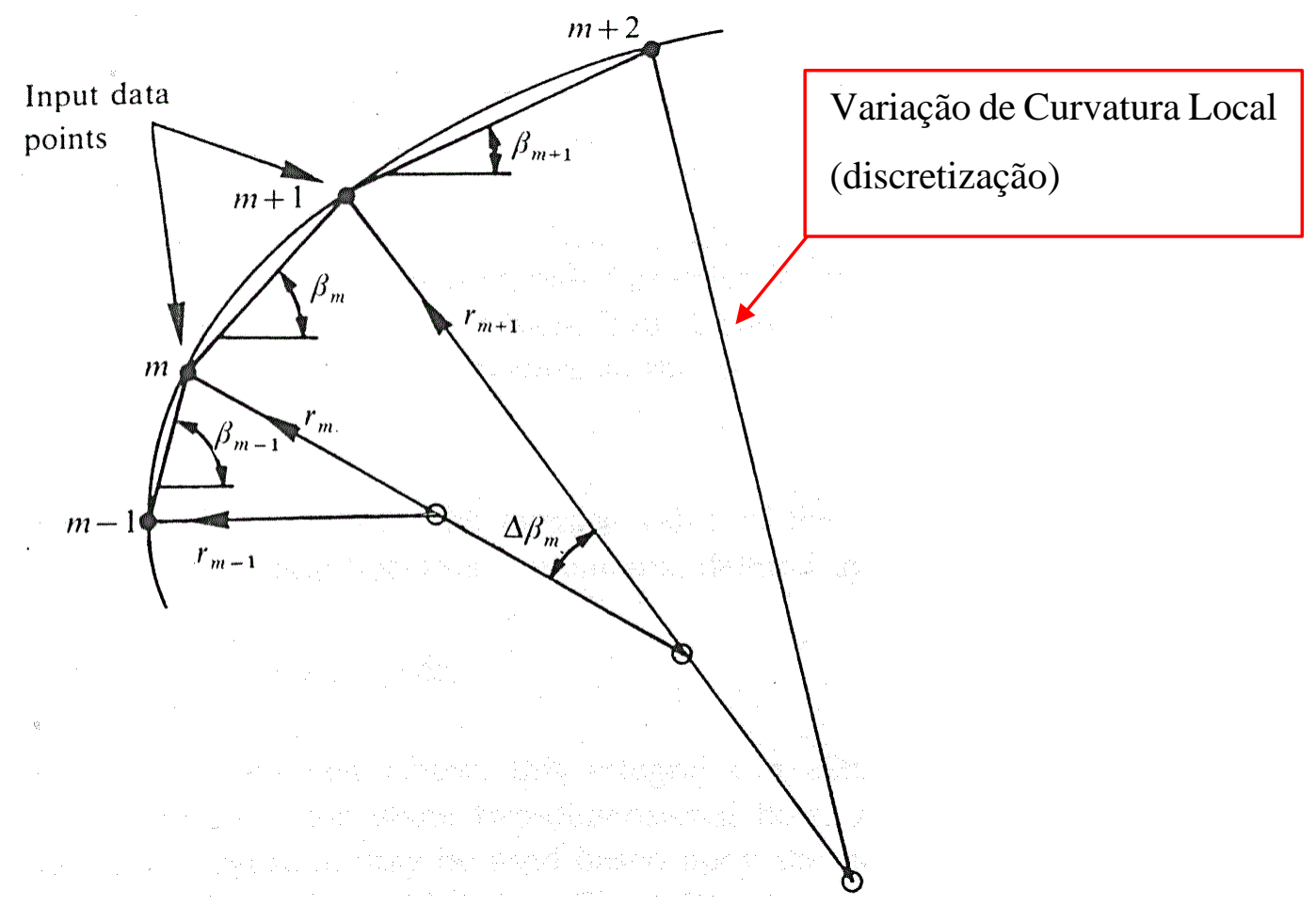

Figura 2.27 Arco circular relacionado ao uso do elementos de linha reta. Figura extraída de LEWIS (1991).

O ponto $M+1$ coincide com o ponto 1, assegurando assim o fechamento do perfil.

\section{b) Preparação dos Dados}

Os elementos de linhas retas são obtidos pela junção de pontos sucessivos. Os comprimentos dos elementos dados por:

$$
\Delta s_{n}=\sqrt{\left(X_{n+1}-X_{n}\right)^{2}+\left(Y_{n+1}-Y_{n}\right)^{2}}
$$

e os ângulos do perfil seguem de equações na forma de diferença finita: 
$\left.\begin{array}{l}\cos \beta_{n}=\left(X_{n+1}-X_{n}\right) / \Delta s_{n} \\ \operatorname{sen} \beta_{n}=\left(Y_{n+1}-Y_{n}\right) / \Delta s_{n}\end{array}\right\}$

Esses valores podem ser usados para avaliar a inclinação do perfil $\beta_{n}$ cuidando para selecionar o quadrante correto.

Os pontos centrais $\left(x_{n}, y_{n}\right)$ são então localizados no centro de cada elemento através de:

$$
\left.\begin{array}{l}
x_{n}=\frac{1}{2}\left(X_{n+1}+X_{n}\right) \\
y_{n}=\frac{1}{2}\left(Y_{n+1}+Y_{n}\right)
\end{array}\right\}
$$

\section{c) Coeficientes de Acoplamento}

Os valores $K\left(s_{m}, s_{n}\right)$ são agora calculados através da equação (2.41) para $m \neq n$, onde o termo $K_{m m}$ ' pode ser simplificado resultando na equação (2.48).

O termo $\Delta \beta_{m}=\left(\beta_{m+1}-\beta_{m-1}\right)$ pode ser estimado como metade da mudança de inclinação entre dois elementos adjacentes.

Logo:

$K\left(s_{m}, s_{m}\right)=-\frac{1}{2}+\frac{1}{8 \pi}\left(\beta_{m+1}-\beta_{m-1}\right)$

\section{d) Inversão da Matriz}

A matriz de coeficientes de acoplamento tem valores finitos em toda a parte com uma diagonal dominante, não oferecendo dificuldades para a solução da matriz inversa. Cabe neste caso montar um esquema que não sobrecarregue a memória do computador.

\section{e) Lado direito da matriz}

Os valores do lado direito seguem direto da equação 2.39 .

\section{f) Solução}

A solução é obtida com a multiplicação da matriz invertida pelo vetor $r h s$ do lado direito da matriz. 


\subsubsection{Método da Vorticidade Superficial para Perfis Isolados (Aerofólios)}

O esquema da figura 2.28 mostra o diagrama de fluxo que permite a especificação do perfil no quadro 1 e uma técnica econômica para repetir o cálculo variando $W_{\infty}$ e $\alpha_{\infty}$, quadros 7 e 8 da figura 2.28. O esquema contempla os passos mostrados no item 2.6.3.

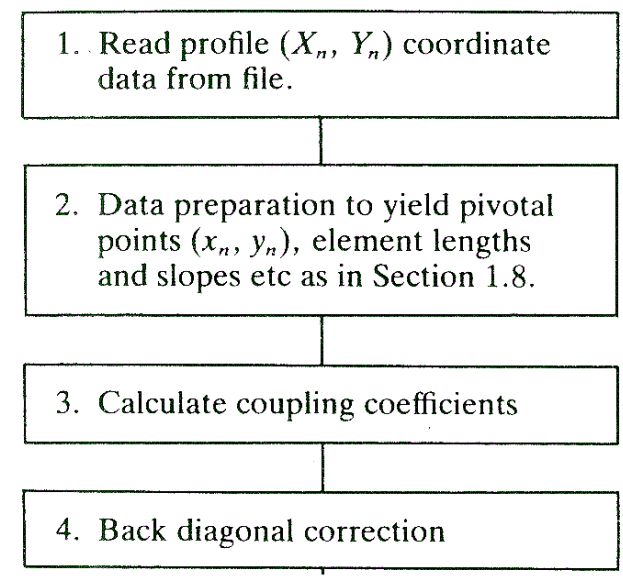

Figura 2.28 Perfil Isolado - Esquema de Implementação. Figura extraída de LEWIS (1991).

Para o caso em que temos solução unitária, ou seja, $U_{\infty}=1$ e $V_{\infty}=1$, podemos definir vorticidades também unitárias $\gamma_{u}\left(s_{n}\right)$ e $\gamma_{v}\left(s_{n}\right)$ definidas por:

$$
\gamma\left(s_{n}\right)=U_{\infty} \gamma_{u}\left(s_{n}\right)+V_{\infty} \gamma_{v}\left(s_{n}\right)=W_{\infty}\left(\cos \alpha_{\infty} \gamma_{u}\left(s_{n}\right)+\operatorname{sen} \alpha_{\infty} \gamma_{v}\left(s_{n}\right)\right)
$$

Podemos separar a equação 2.49 em duas equações para os componentes individuais para o lado direito:

$$
\begin{aligned}
& \sum_{n=1}^{M} K\left(s_{m}, s_{n}\right) \gamma_{u}\left(s_{n}\right)=-\cos \beta_{m} \\
& \sum_{n=1}^{M} K\left(s_{m}, s_{n}\right) \gamma_{v}\left(s_{n}\right)=-\operatorname{sen} \beta_{m}
\end{aligned}
$$

O termo $\beta_{m}$ é a inclinação do perfil no elemento $m$. Soluções unitárias são independentes da velocidade da corrente principal $W_{\infty}$ e do ângulo de ataque $\alpha_{\infty}$. Seguindo a equação 2.50, o termo $\gamma\left(s_{n}\right)$ pode ser resolvido para qualquer escolha de $W_{\infty}$ e $\alpha_{\infty}$ pela combinação das soluções unitárias através das equações 2.49 e este procedimento está escrito no diagrama de fluxo da figura 2.28 . 
A velocidade superficial é dada de acordo com LEWIS (1991) por $v_{s}=\gamma\left(s_{n}\right)$. Conhecida a velocidade superficial, o coeficiente de pressão é dado por:

$$
C_{p}=\frac{\left(p-p_{\infty}\right)}{\frac{1}{2} \rho W_{\infty}^{2}}=1-\left\{\frac{\gamma\left(s_{n}\right)}{W_{\infty}}\right\}^{2}
$$

O coeficiente de sustentação dado por 2.5 agora se torna:

$$
C_{L}=\frac{2 \Gamma}{W_{\infty} l}=\frac{2}{l}\left\{\cos \alpha_{\infty} \sum_{n=1}^{M} \gamma_{u}\left(s_{n}\right) \Delta s_{n}+\operatorname{sen} \alpha_{\infty} \sum_{n=1}^{M} \gamma_{v}\left(s_{n}\right) \Delta s_{n}\right\}
$$

onde $l$ é calculado como sendo a corda do perfil do aerofólio.

O quadro número 5 da figura 2.28 mostra que deve ocorrer a implementação da condição de Kutta, o que devemos comentar. A condição de Kutta resolve um problema que surge do fato de desprezarmos a viscosidade do escoamento, pois com isso o escoamento potencial tende a contornar o bordo de fuga do aerofólio. A condição de Kutta resolve esse problema impondo que, no bordo de fuga, as velocidades da face e do dorso sejam iguais. Em escoamentos reais, onde há o efeito da viscosidade (LEWIS, 1991), podemos afirmar que a pressão estática vai se igualando conforme se move em direção ao bordo de saída ao longo da superfície inferior e superior. O método empregado por WILKINSON (1967) sugere que a pressão estática e consequentemente a vorticidade superficial nos dois elementos do bordo de fuga na superfície superior e inferior devam ter o mesmo valor. Isso pode ser realizado se impormos a restrição:

$$
\gamma\left(s_{t e}\right)=-\gamma\left(s_{t e+1}\right)
$$

A vantagem nisso é que se elimina uma variável do sistema de equações a ser resolvido com a possibilidade de eliminar uma equação do sistema. 


\subsubsection{Método dos Painéis para perfis em cascata}

Com modificações apropriadas às análises feitas para um perfil isolado podem ser estendidas para uma cascata de perfis com espaçamento $h$ paralelo ao eixo $y$ como mostra a figura 2.29.

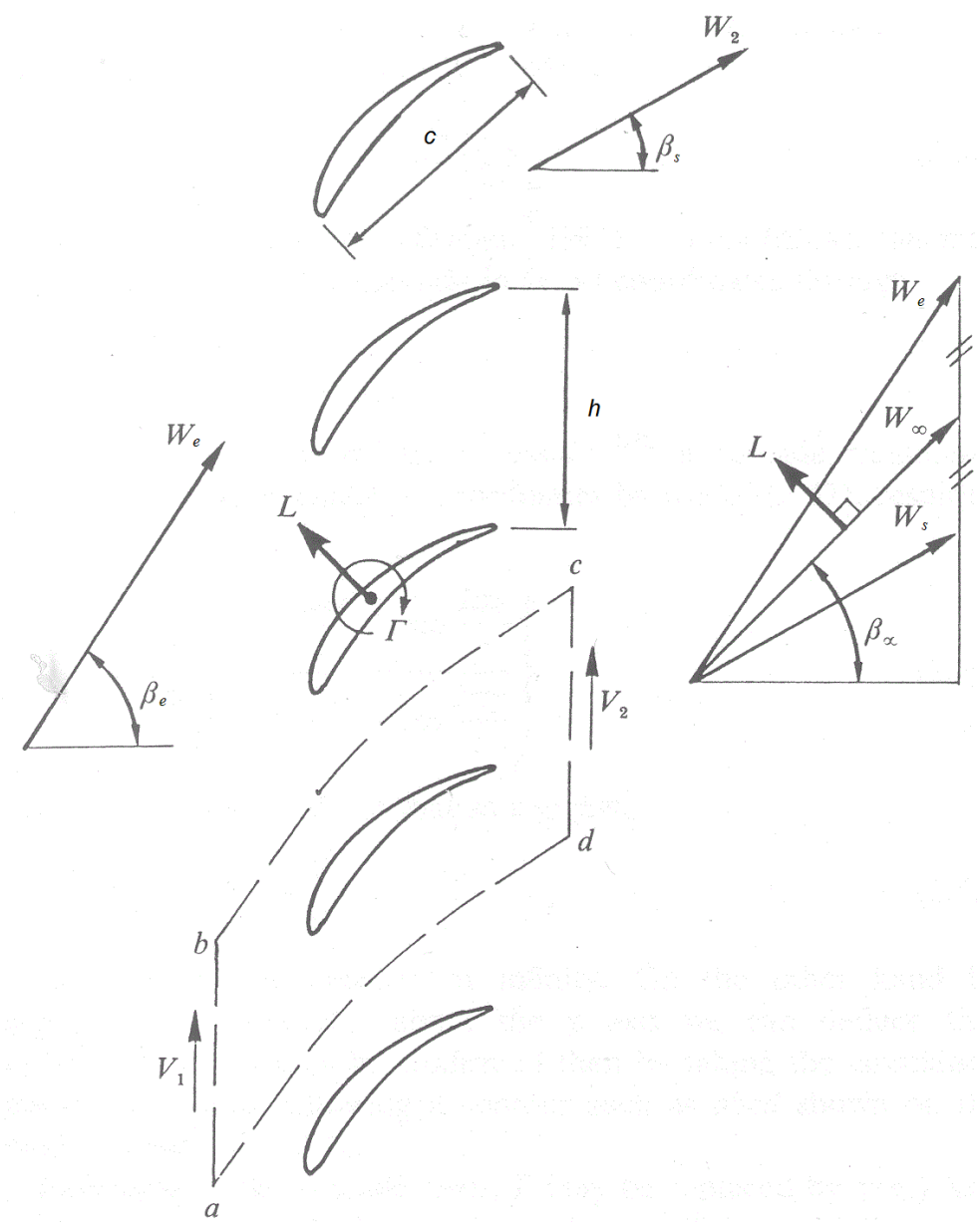

Figura 2.29 Geometria em cascata e seus triângulos de velocidade. Figura extraída de LEWIS (1991).

Em síntese o que se torna necessário é derivar o coeficiente de acoplamento $K\left(s_{m}, s_{n}\right)$ modificado do perfil isolado para a cascata de perfis.

Para isso, segundo LEWIS (1991), pode-se considerar uma velocidade induzida por um infinito arranjo de pontos de vórtices, de intensidade $\Gamma$ e passo $h$ como mostra a figura 2.30 (esquerda) localizados ao longo do eixo $y$ entre $y= \pm \infty$. O campo de escoamento induzido por esse arranjo no plano $z$ pode ser transformado em um escoamento equivalente no plano $Z$ devido à intensidade de vórtice $\Gamma$ localizado em $(1,0)$ e um segundo vórtice na origem de intensidade $-\Gamma / 2$, pela transformação conforme:

$$
Z=\ln Z
$$


Os pontos $P,\left(Z=\mu e^{-i \theta}\right)$, no plano $Z$ e seu equivalente ponto $p,(z=x+i y)$, no plano $z$ são relacionados através da relação abaixo (Schwartz-Christofell's transformation):

$$
x+i y=\ln \mu+i \phi
$$

para então:

$$
\left.\begin{array}{l}
x=\ln \mu \\
y=\phi
\end{array}\right\}
$$

Então o círculo $P^{\prime} P^{\prime}$ de raio $\mu$ é a transformação da linha $p$ 'p' paralela ao eixo $y$, que ao longo do qual seu fluxo é periódico. Da equação (2.55b) nós então temos a relação:

$$
h=2 \pi
$$

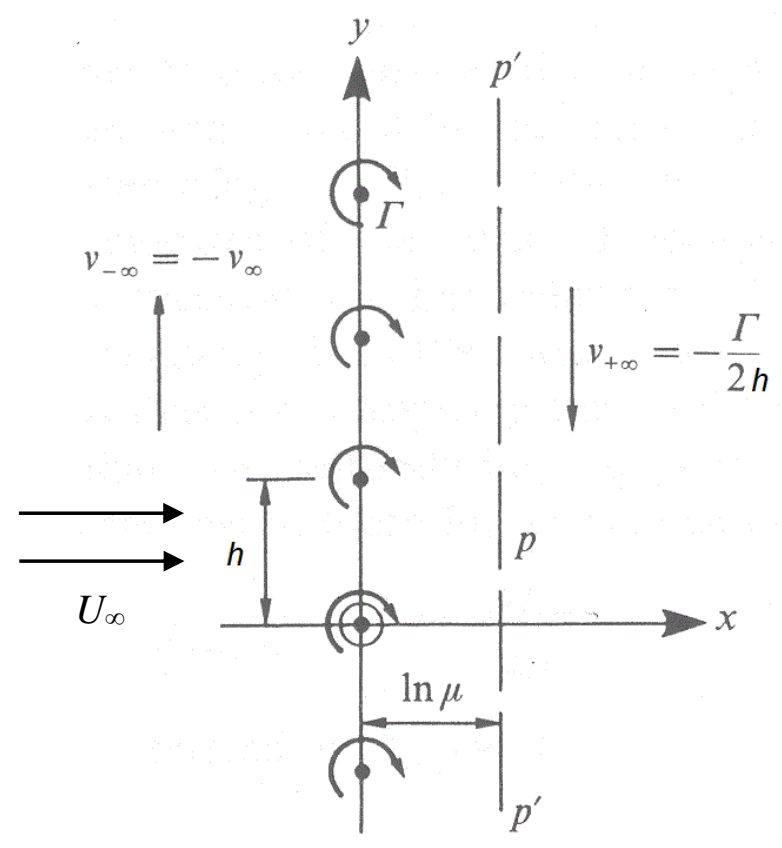

plano z

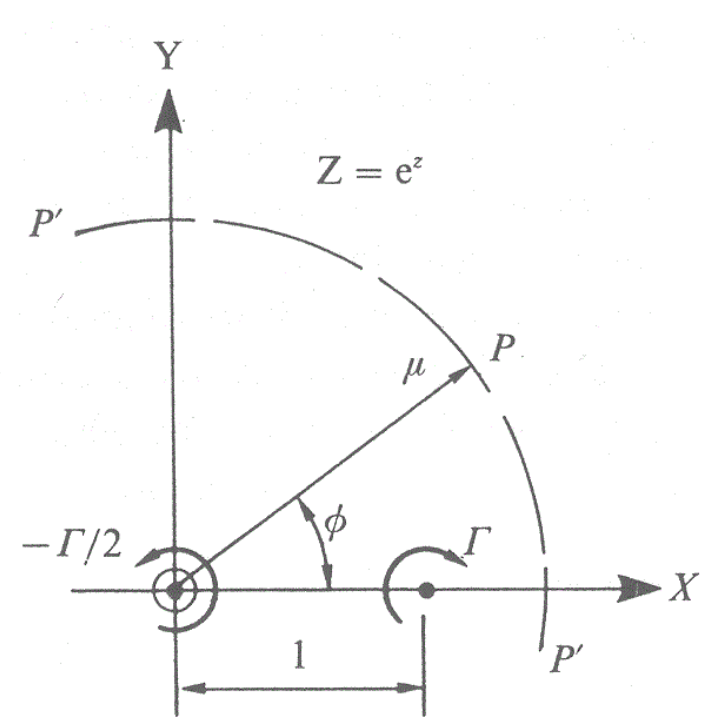

plano Z

Figura 2.30 Transformação do arranjo de vórtices no plano z para o par de vórtices no plano Z. Figura extraída de LEWIS (1991).

A singularidade da transformação em $\mu=0$ no plano $Z$ se transforma em $x=-\infty$, onde o vórtice $-\Gamma / 2$ é transformado em uma corrente uniforme vertical $v_{-\infty}$ no plano $z$.

A intenção aqui não é transcrever todas as passagens para demonstrar como se obtém o coeficiente de acoplamento modificado para a cascata de perfis e sim explanar brevemente sobre como a transformação conforme é utilizada neste caso. Para a visualização de todas as passagens pode-se consultar LEWIS (1991). 
Logo podemos escrever o coeficiente de acoplamento modificado conforme:

$$
\begin{aligned}
& K\left(s_{m}, s_{n}\right)=u_{m n} \cos \beta_{m}+v_{m n} \operatorname{sen} \beta_{m} \\
& \quad=\frac{\Delta s_{n}}{2 h}\left\{\frac{\operatorname{sen} \frac{2 \pi}{h}\left(y_{m}-y_{n}\right) \cos \beta_{m}-\operatorname{senh} \frac{2 \pi}{h}\left(x_{m}-x_{n}\right) \operatorname{sen} \beta_{m}}{\cosh \frac{2 \pi}{h}\left(x_{m}-x_{n}\right)-\cos \frac{2 \pi}{h}\left(y_{m}-y_{n}\right)}\right\} \text { para } m \neq n
\end{aligned}
$$

As mesmas equações lineares como as usadas para o caso do aerofólio isolado podem ser usadas para determinar o modelo de vorticidade superficial para a cascata de perfis com o coeficiente de acoplamento sendo a única diferença essencial.

Como no caso do perfil isolado os coeficientes de acoplamento de autoindução, isto é, quando $m=n$ são idênticos aos usados no caso do aerofólio isolado. Isso se deve ao fato de que a velocidade liquida no arranjo de vórtices da cascata é zero.

$$
K\left(s_{m}, s_{m}\right)=-\frac{1}{2}-\frac{\Delta \beta_{m}}{4 \pi}
$$

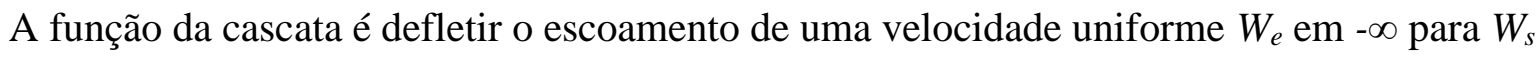
em $+\infty$, ver figura 2.30. Alternativamente, para o propósito da análise de dinâmica dos fluidos, podemos considerar o escoamento completo como uma superposição de um arranjo de vórtices e uma corrente uniforme e singular $W_{\infty}$, que é o vetor médio entre $W_{e}$ e $W_{s}$, que nada mais é do que a média das velocidades de entrada e saída do perfil em estudo.

O coeficiente de sustentação, baseado no vetor médio $W_{\infty}$, escrito previamente para o perfil isolado fica escrito em função da relação passo/corda $t / \ell$ e dos ângulos de escoamento $\beta_{e}, \beta_{s} \mathrm{e}$ $\beta_{\infty}$, ver figura 2.29 .

$$
C_{L_{0}}=\frac{L}{\frac{1}{2} \rho W_{\infty}^{2} c}=2\left(\frac{h}{\ell}\right)\left(\tan \beta_{e}-\tan \beta_{s}\right) \cos \beta_{\infty}
$$

O problema como está proposto neste caso é o prognóstico das condições de saída $\left(\beta_{s}, W_{s}\right)$, para uma faixa de escoamentos de entrada prescrita $\left(\beta_{e}, W_{e}\right)$ para uma cascata de uma dada geometria, com as quantidades dos vetores médios sendo o menor valor. 
O ângulo de saída $\beta_{s}$ pode ser expresso em função das circulações unitárias $\Gamma_{u}$ e $\Gamma_{v}$ e $\beta_{e}$ através de:

$$
\beta_{s}=\arctan \left\{\left(\frac{1-\Gamma_{v} / 2 h}{1+\Gamma_{v} / 2 h}\right) \tan \beta_{e}-\left(\frac{2}{1+\Gamma_{v} / 2 h}\right) \frac{\Gamma_{u}}{2 h}\right\}
$$

As circulações unitárias $\Gamma_{u}$ e $\Gamma_{v}$ podem ser derivadas das velocidades unitárias $U_{\infty}=1 \mathrm{e}$ $V_{\infty}=1$ respectivamente.

O coeficiente de pressão neste caso difere do caso do aerofólio isolado e pode ser obtido por:

$$
C_{p 1}=\frac{p-p_{1}}{\frac{1}{2} \rho W_{1}^{2}}=C_{p \infty}\left(\frac{\cos \beta_{e}}{\cos \beta_{\infty}}\right)^{2}
$$

A figura 2.31 mostra o diagrama de fluxo para implementação do programa para cálculo do escoamento através de uma cascata de perfis.
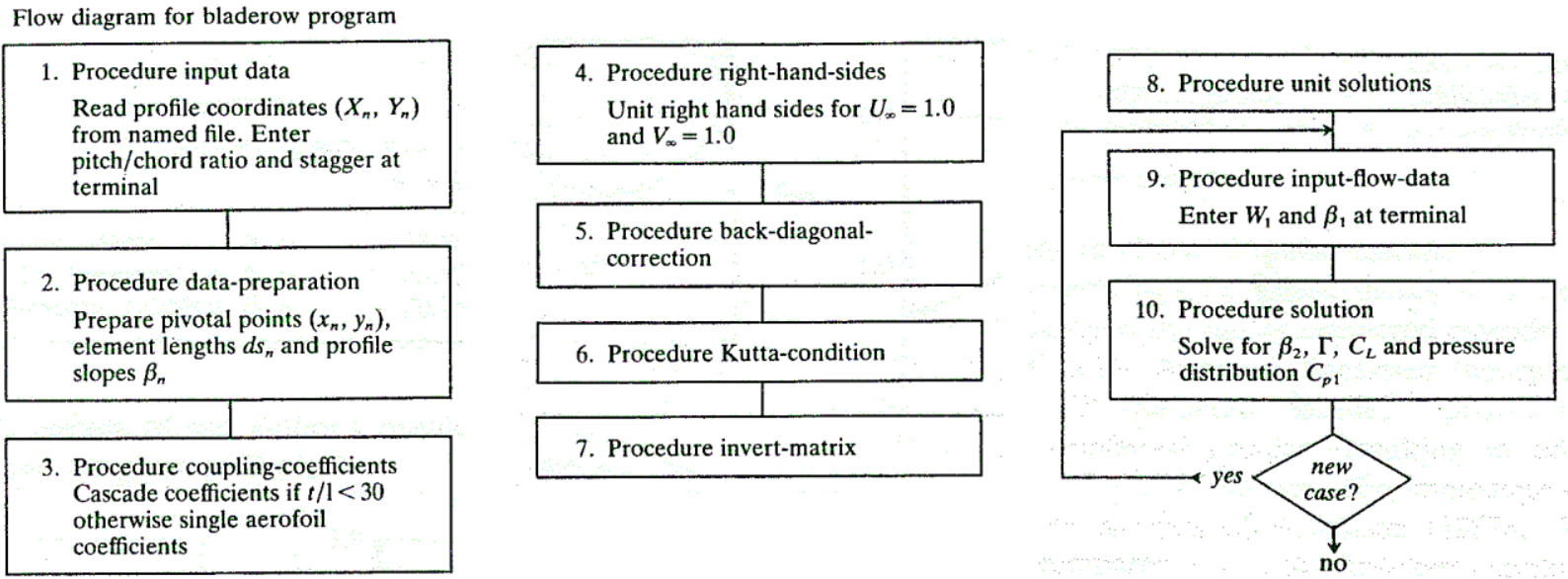

Figura 2.31 Diagrama de fluxo para o programa "Blade row". Figura extraída de LEWIS (1991). 


\section{DESENVOLVIMENTO}

\subsection{OBTENÇÃO DOS PERFIS DO ROTOR E DISTRIBUIDOR}

Com os dados da barragem é possível determinar os dados da máquina, porém neste caso a turbina ensaiada já existia e se aproveitou a instalação para adequar a máquina. Como se trata de um tanque em que a queda é ajustável não existe impedimento da operação da unidade nas condições de projeto.

A tabela 3.1 mostra valores nominais da máquina que servem de dados de entrada para o cálculo e confecção das pás do rotor e distribuidor.

Tabela 3.1 Dados - Maquina $20 \mathrm{~kW}$.

\begin{tabular}{|l|l|}
\hline Potência Nominal da Turbina & $20 \mathrm{~kW}$ \\
\hline Eficiência Hidráulica do Rotor & 0,90 (Estimado) \\
\hline Eficiência Global da Turbina & 0,60 (Estimado) \\
\hline Diâmetro do Rotor & $600 \mathrm{~mm}$ \\
\hline Diâmetro do Cubo & $240 \mathrm{~mm}$ \\
\hline Queda Líquida & $2,57 \mathrm{~m}$ \\
\hline Vazão Nominal & $1,15 \mathrm{~m}^{3} / \mathrm{s}$ \\
\hline Sentido de Rotação (sentido Fluxo) & Horário \\
\hline Rotação de Disparo do Rotor & $1250 \mathrm{rpm}$ \\
\hline Rotação Nominal & $450 \mathrm{rpm}$ \\
\hline Empuxo Axial na Turbina & $45000 \mathrm{~N}$ \\
\hline Torque no Rotor da Turbina & $4600 \mathrm{~N} . \mathrm{m}$ \\
\hline GD2 do Rotor & $220 \mathrm{~N} . \mathrm{m}^{2}$ \\
\hline Rotação Específica & 63 \\
\hline Número de pares de Polos do Gerador & 8 \\
\hline
\end{tabular}

A figura 3.1 mostra a disposição do arranjo distribuidor-rotor com a velocidade axial de entrada $V_{a}$ com o ângulo de inclinação da corda dos perfis $\beta_{c o}$, ângulo do passo $\Phi$. Conforme os perfis são posicionados ao longo do raio adimensional $\chi$, isto é, do raio do cubo $R_{B}$ ao raio do rotor $R_{R}$, esses ângulos variam e conferem a torção necessária ao perfil das pás.

Notando a direção de rotação do rotor com velocidade $r \Omega$, como $r$ varia em direção ao diâmetro do rotor $D_{R}$ as velocidades do escoamento relativas a pá do rotor também variam e por esse motivo a geometria do rotor deve ser torcida e como consequência a geometria do distribuidor também sofre torção. A torção do distribuidor não é comum em turbinas hidráulicas, onde se assume uma perda hidráulica de eficiência em troca de uma pá de mais fácil execução. 


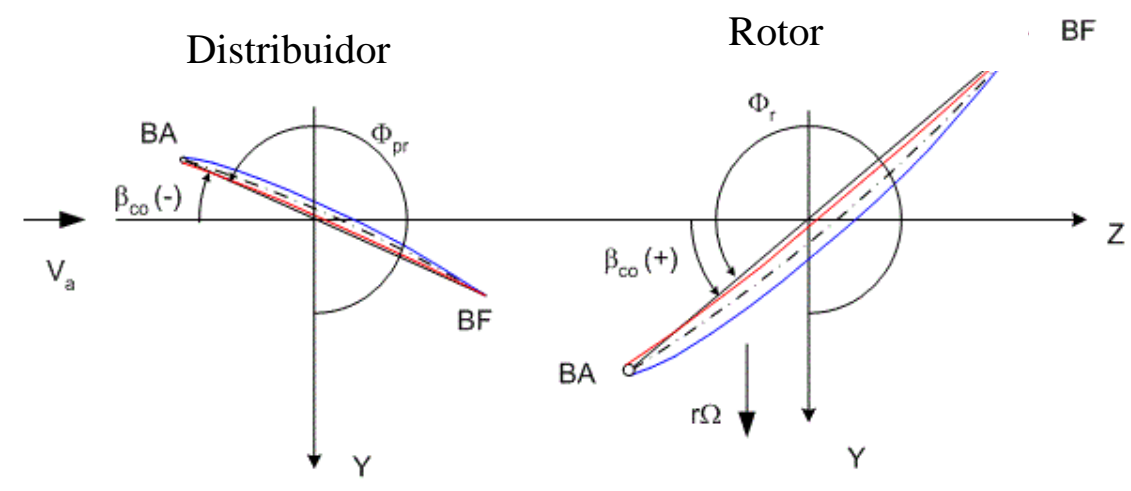

Figura 3.1 Ângulos do passo e ângulos de inclinação das cordas - Distribuidor e Rotor.

\subsubsection{Velocidades e Ângulos de Projeto}

Já com os dados de potência, número de polos e diâmetro do rotor e cubo definidos podemos partir para o cálculo da geometria das pás. Abaixo segue uma representação da pá do distribuidor com as grandezas pertinentes ao projeto referente ao distribuidor.

Como dado de entrada para cálculo do das pás temos que obter a velocidade média do escoamento a montante da pá do distribuidor $V_{a}$, com base nos dados da tabela 3.1. A figura 3.2 mostra representativamente a velocidade de entrada da máquina $V_{0}$, diâmetro do rotor $D_{R}=$ $600 \mathrm{~mm}$ e o diâmetro do cubo $D_{B}=240 \mathrm{~mm}$.

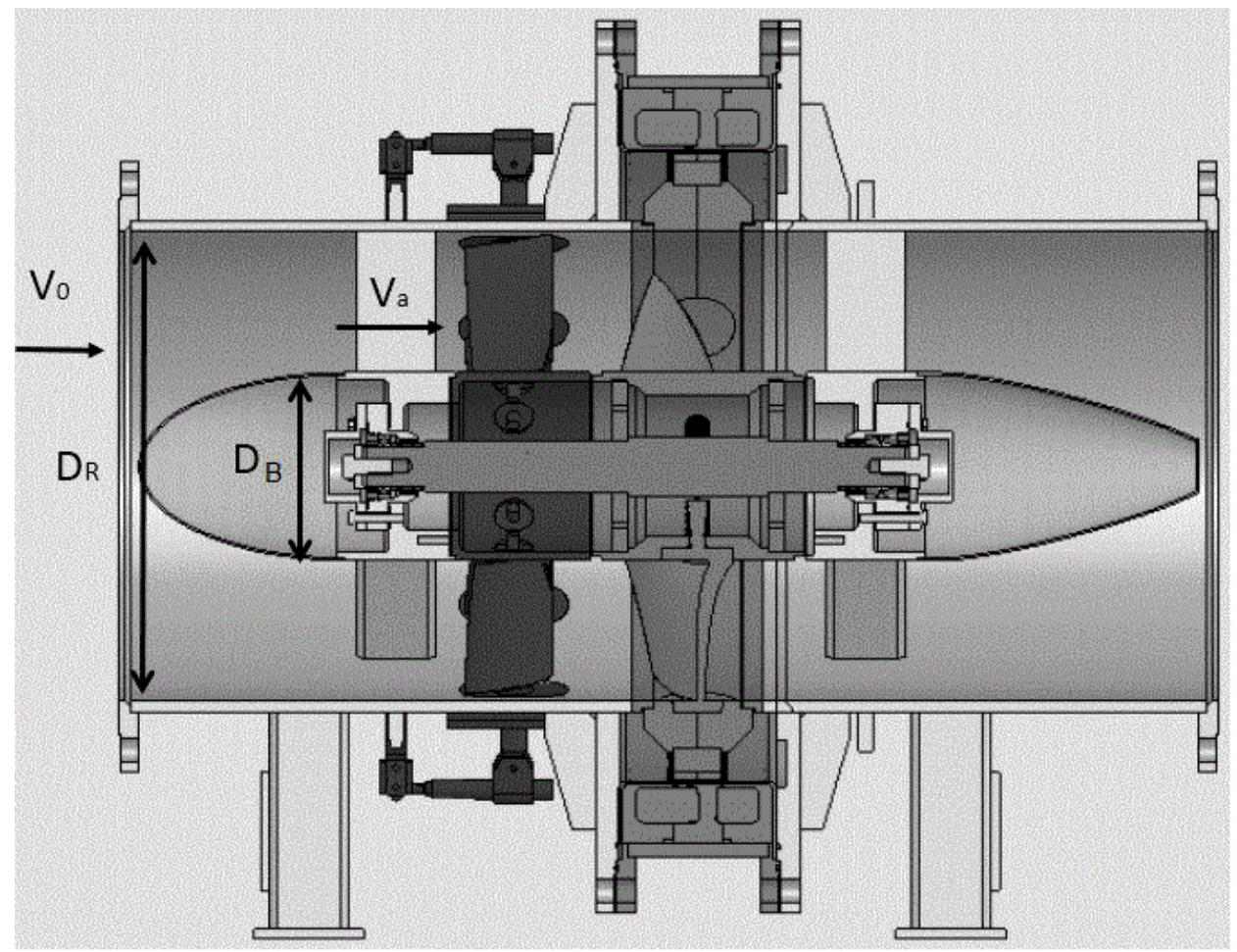

Figura 3.2 Velocidades de Entrada [Cortesia: Hydrel]. 


$$
\begin{aligned}
& V_{o}=\frac{Q}{A_{0}}=\frac{Q}{\frac{\pi D_{R}^{2}}{4}}=\frac{1,15 \mathrm{~m} / \mathrm{s}^{3}}{\frac{\pi(0,6)^{2}}{4}}=4,07 \mathrm{~m} / \mathrm{s} \\
& V_{a}=\frac{Q}{A_{a}}=\frac{Q}{\frac{\pi D_{R}^{2}\left(1-\chi_{b}^{2}\right)}{4}}=\frac{1,15}{\frac{\pi(0,6)^{2}\left(1-0,4^{2}\right)}{4}}=4,84 \mathrm{~m} / \mathrm{s}
\end{aligned}
$$

A velocidade axial média do escoamento logo a montante das pás do distribuidor $V_{a}$ é o dado de entrada para o cálculo das pás e seu valor pode diferir do escoamento real por perdas na linha de adução da máquina. O ensaio de campo é uma maneira de verificar esse valor como esta verificado no capitulo 4.

O cálculo do posicionamento dos perfis e das velocidades é realizado em seções planificadas a partir do raio do cubo, onde $\chi=0,4$ - ver figura 2.25, até o raio do rotor, onde $\chi=1.0$. Para melhor visualização e entendimento vamos exemplificar o procedimento em uma seção planificada e logo em seguida apresentar os valores paras as demais seções. Procedimento esse realizado para o rotor e o distribuidor. Vamos usar $\chi=0,4$ para o exemplo.

A figura 3.3 mostra a grade do distribuidor e rotor com suas velocidades pertinentes para uma seção planificada. Como no trabalho de ALBUQUERQUE (2006), que usou equações de equilíbrio radial para otimização de pás de turbinas axiais, este trabalho também não calcula o campo de escoamento ao redor dos perfis das pás, posto que a principal preocupação é com relação às deflexões resultantes do escoamento nas grades.

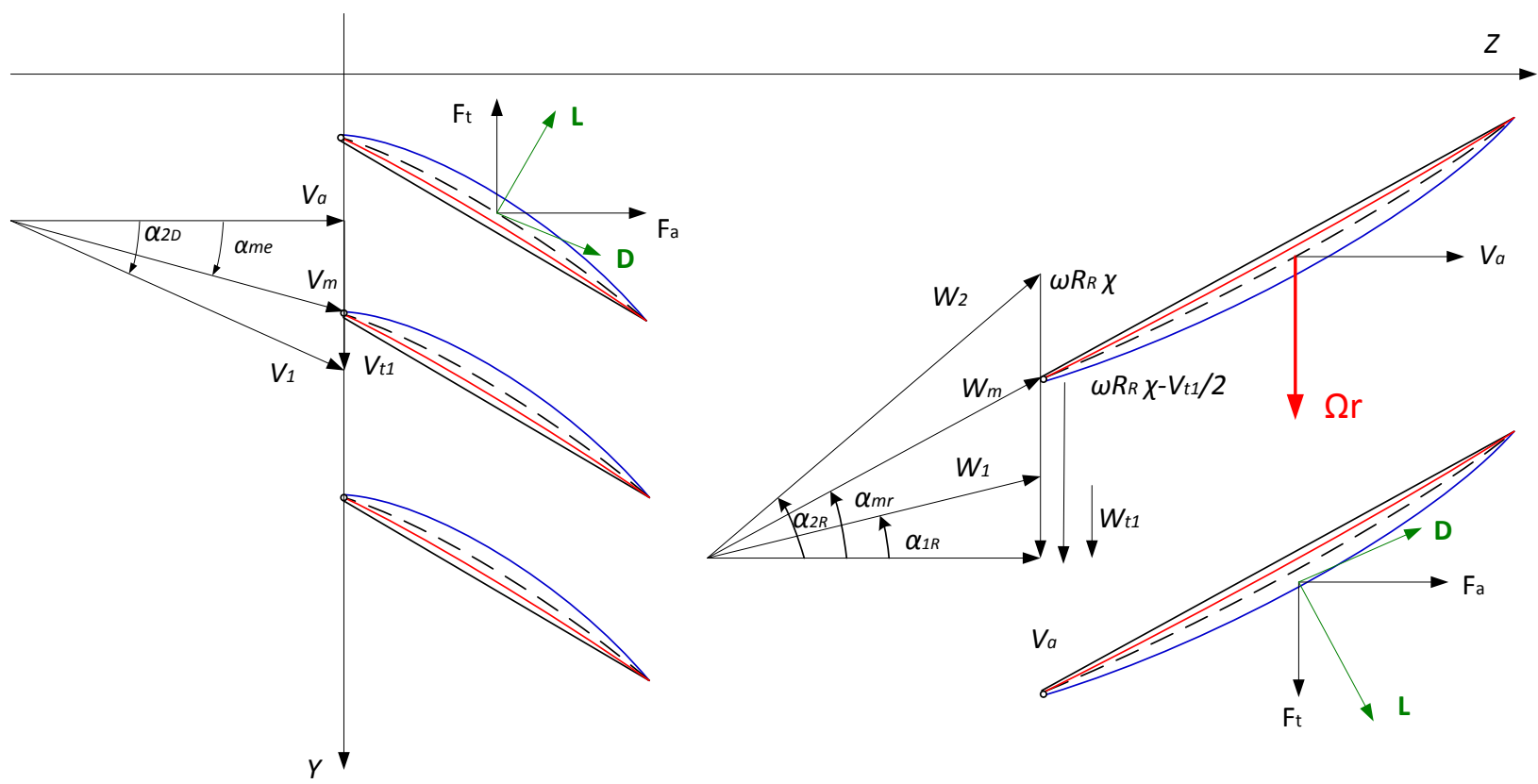

Figura 3.3 Velocidades - Grades do Distribuidor e Rotor 
A velocidade tangencial aos perfis em cascata do distribuidor $V_{t 1}$ depende da queda líquida na entrada do distribuidor $\Delta H_{\mathrm{R}}$, da velocidade angular $\omega$ e da posição radial do perfil $R_{R} \cdot \chi$.

$$
V_{t 1}=\frac{g \cdot \Delta H_{\mathrm{R}}}{\omega \cdot R_{R} \cdot \chi}=\frac{(9,81) \cdot(1,99)}{\left(\frac{2 \pi 450}{60}\right) \cdot(0,3) \cdot(0,4)}=3,45 \mathrm{~m} / \mathrm{s}
$$

A velocidade de incidência $V_{1}$ é obtida geometricamente através da relação:

$$
V_{1}=\sqrt{V_{t 1}^{2}+V_{a}^{2}}=5,95 \mathrm{~m} / \mathrm{s}
$$

A velocidade média $V_{m}$ também é obtida geometricamente e é utilizada para o cálculo de cavitação já que é a velocidade que tangencia o perfil paralelamente a linha média.

$$
V_{m}=\sqrt{V_{a}^{2}+\left(\frac{V_{t 1}}{2}\right)^{2}}=5,14 \mathrm{~m} / \mathrm{s}
$$

Com isso podemos calcular os ângulos $\alpha_{1}$ e $\alpha_{m e}$ geometricamente de acordo com a figura 3.3 .

$$
\begin{aligned}
& \alpha_{2 D}=\operatorname{arctg}\left(\frac{V_{t 1}}{V_{a}}\right)=\operatorname{arctg}\left(\frac{3,45}{4,84}\right)=35,47^{\circ} \\
& \alpha_{m e}=\operatorname{arctg}\left(\frac{0,5 \cdot V_{t 1}}{V_{a}}\right)=\operatorname{arctg}\left(\frac{0,5 \cdot 3,95}{4,84}\right)=20,37^{\circ}
\end{aligned}
$$

Com as velocidades do distribuidor calculadas podemos calcular as velocidades referentes a seção do rotor. A velocidade $V_{t 1}$ é uma velocidade induzida pelo distribuidor logo permanece com mesmo módulo e direção.

$$
V_{t 1}=3,45 m / s
$$

A velocidade $W_{t 1}$ tangencial relativa ao rotor é obtida subtraindo a velocidade induzida no distribuidor da parcela da rotação do rotor.

$$
W_{t 1}=\omega \cdot R_{R} \cdot \chi-V_{t 1}=5,65-3,45=2,20 \mathrm{~m} / \mathrm{s}
$$


A velocidade paralela ao rotor $W_{m}$ é obtida geometricamente e é utilizada para o cálculo do número de cavitação do rotor. Notar que o valor é sempre superior as velocidades tangenciais como esperado. Velocidades tangenciais ou radiais com valores elevados indicam perdas no escoamento e devem ser evitadas.

$$
W_{m}=\sqrt{V_{a}^{2}+\left(\omega \cdot R_{R} \cdot \chi-\frac{V_{t 1}}{2}\right)^{2}}=6,23 \mathrm{~m} / \mathrm{s}
$$

Com isso podemos obter os ângulos pertinentes ao escoamento do rotor de acordo com a figura 3.3.

$$
\begin{aligned}
& \alpha_{1 R}=\operatorname{arctg}\left(\frac{W_{t 1}}{V_{a}}\right)=24,46^{\circ}--\alpha_{2 R}=\operatorname{arctg}\left(\frac{\omega \cdot R_{R} \cdot \chi}{V_{a}}\right)=49,42^{\circ} \\
& \alpha_{m r}=\operatorname{arctg}\left(\frac{\omega \cdot R_{R} \cdot \chi-\frac{V_{t 1}}{2}}{V_{a}}\right)=39,05^{\circ}
\end{aligned}
$$

A tabela 3.2 mostra os valores das velocidades e ângulos calculados para os demais raios adimensionais $\chi$.

Tabela 3.2 Velocidades no Distribuidor e Rotor

\begin{tabular}{ccccccccccc}
\hline $\begin{array}{c}\chi \\
{[\mathbf{u n}]}\end{array}$ & $\begin{array}{c}\boldsymbol{V}_{\boldsymbol{t} \boldsymbol{I}} \\
{[\mathbf{m} / \mathbf{s}]}\end{array}$ & $\begin{array}{c}\boldsymbol{V}_{\boldsymbol{I}} \\
{[\mathbf{m} / \mathbf{s}]}\end{array}$ & $\begin{array}{c}\boldsymbol{V}_{\boldsymbol{m}} \\
{[\mathbf{m} / \mathbf{s}]}\end{array}$ & $\begin{array}{c}\boldsymbol{a}_{\boldsymbol{2} \boldsymbol{D}} \\
{\left[{ }^{\circ}\right]}\end{array}$ & $\begin{array}{c}\boldsymbol{a}_{\boldsymbol{m} \boldsymbol{e}} \\
{\left[{ }^{\circ}\right]}\end{array}$ & $\begin{array}{c}\boldsymbol{W}_{\boldsymbol{t} \boldsymbol{I}} \\
{[\mathbf{m} / \mathbf{s}]}\end{array}$ & $\begin{array}{c}\boldsymbol{W}_{\boldsymbol{m}} \\
{[\mathbf{m} / \mathbf{s}]}\end{array}$ & $\begin{array}{c}\boldsymbol{\alpha}_{\boldsymbol{I R}} \\
{\left[{ }^{\circ}\right]}\end{array}$ & $\begin{array}{c}\boldsymbol{\alpha}_{\boldsymbol{2} \boldsymbol{R}} \\
{\left[{ }^{\circ}\right]}\end{array}$ & $\begin{array}{c}\boldsymbol{\alpha}_{\boldsymbol{m} \boldsymbol{r}} \\
{\left[{ }^{\circ}\right]}\end{array}$ \\
\hline 0,40 & 3,45 & 5,95 & 5,14 & 35,47 & 19,61 & 2,20 & 6,23 & 24,46 & 49,42 & 39,05 \\
0,45 & 3,07 & 5,73 & 5,08 & 32,35 & 17,57 & 3,29 & 6,84 & 34,21 & 52,71 & 44,90 \\
0,50 & 2,76 & 5,57 & 5,03 & 29,68 & 15,91 & 4,31 & 7,47 & 41,64 & 55,58 & 49,58 \\
0,55 & 2,51 & 5,45 & 5,00 & 27,39 & 14,53 & 5,26 & 8,12 & 47,39 & 58,08 & 53,39 \\
0,60 & 2,30 & 5,36 & 4,98 & 25,41 & 13,36 & 6,18 & 8,78 & 51,92 & 60,27 & 56,55 \\
0,65 & 2,12 & 5,29 & 4,96 & 23,68 & 12,37 & 7,06 & 9,46 & 55,57 & 62,21 & 59,20 \\
0,70 & 1,97 & 5,23 & 4,94 & 22,15 & 11,51 & 7,92 & 10,14 & 58,56 & 63,92 & 61,47 \\
0,75 & 1,84 & 5,18 & 4,93 & 20,81 & 10,76 & 8,76 & 10,82 & 61,07 & 65,45 & 63,42 \\
0,80 & 1,72 & 5,14 & 4,92 & 19,61 & 10,10 & 9,58 & 11,51 & 63,19 & 66,82 & 65,13 \\
0,85 & 1,62 & 5,11 & 4,91 & 18,54 & 9,52 & 10,39 & 12,20 & 65,01 & 68,05 & 66,62 \\
0,90 & 1,53 & 5,08 & 4,90 & 17,57 & 9,00 & 11,18 & 12,89 & 66,59 & 69,16 & 67,95 \\
0,95 & 1,45 & 5,06 & 4,90 & 16,70 & 8,53 & 11,97 & 13,59 & 67,98 & 70,17 & 69,13 \\
1,00 & 1,38 & 5,03 & 4,89 & 15,91 & 8,11 & 12,75 & 14,29 & 69,21 & 71,09 & 70,19 \\
\hline
\end{tabular}




\subsubsection{Limite de Cavitação}

O item 2.5.3 mostrou procedimento para o cálculo do limite de cavitação nas pás em que se compara o limite estrutural das pás com as condições de velocidade na superfície das mesmas. Neste item vamos mostrar o procedimento de cálculo do limite de cavitação para as geometrias do distribuidor e rotor.

Como realizado no item 3.1.1 vamos mostrar o procedimento de cálculo para uma seção planificada do rotor onde $\chi=0,4$ e logo após mostrar os resultados para as demais seções do rotor e distribuidor, já que o procedimento é o mesmo.

$\mathrm{Na}$ condição de projeto a relação espessura-corda do perfil deve respeitar a espessura máxima relacionada com a condição de cavitação do perfil para que o mesmo não sofra cavitação.

Assim podemos escrever:

$$
\frac{t_{o}}{c}<\left(\frac{t_{o}}{c}\right)_{c a v}
$$

A relação espessura corda para a pá do rotor:

$$
\frac{t_{o}}{c}=\frac{0,021 m}{0,45 m}=0,047
$$

Os valores das constantes $S_{c a v}, C_{1}, C_{2}$ e $a$ foram definidos na seção 2.5.3. O número de cavitação $\sigma_{x}$ também presente na equação 2.28 é calculado abaixo:

$$
\sigma_{x}=\frac{2 \cdot\left(p_{0 e p x}-p_{v}\right)}{\rho\left(k_{w_{m}} \cdot W_{m}\right)^{2}}=\frac{2 \cdot\left(8,18 \cdot 10^{4} P a-2,34 \cdot 10^{3} P a\right)}{1000 \mathrm{~kg} / \mathrm{m}^{3}(1,026 \cdot 6,26 \mathrm{~m} / \mathrm{s})^{2}}=3,88
$$

Que por sua vez depende do termo de correção de espessura $k_{w_{m}}$ e da solidez $S_{c}$ do rotor calculados abaixo:

$$
\begin{aligned}
& k_{w_{m}}=\frac{1}{\left(1-S_{C} \cdot \frac{t_{o}}{c}\right)}=\frac{1}{(1-0,53 \cdot 0,047)}=1,026 \\
& S_{c}=\frac{Z}{2 \cdot \pi} \cdot \frac{\left(\frac{c}{R_{R}}\right)}{\chi}=\frac{3}{2 \cdot \pi} \cdot \frac{(0,45)}{0,4}=0,53
\end{aligned}
$$


Usando a equação 2.28 podemos calcular a condição de cavitação para a seção estudada.

$$
\left(\frac{t_{o}}{c}\right)_{c a v}=\frac{\left[\left(\sqrt{\frac{1+\sigma_{x}}{1+S_{c a v}}}-1\right)-C_{2} \cdot C_{L}\right]}{C_{1}}=\frac{\left[\left(\sqrt{\frac{1+3,88}{1+0,18}}-1\right)-0,278.2,08\right]}{1,28}=0,39
$$

O termo Z é o número de pás do rotor. E assim podemos comparar a equação 3.1 e checar se a condição de cavitação é atendida.

$$
\frac{t_{o}}{c}<\left(\frac{t_{o}}{c}\right)_{c a v} \leftrightarrow 0,05<0,39 \rightarrow o k
$$

Podemos notar que a condição de cavitação é bem superior a relação espessura-corda, em tese então, poderíamos aumentar a espessura do perfil até o limite onde $t_{o R} / c_{R}=0,39$, porém isso não é possível pois o aumento da espessura do perfil do rotor também tem efeitos no índice de cavitação e assim o intervalo que a relação $t_{o} / c$ pode assumir é:

$$
0,02 \leq t_{o} / c \leq 0,2
$$

\begin{tabular}{|c|c|c|c|c|c|c|}
\hline $\begin{array}{c}\chi \\
\text { [un] }\end{array}$ & $\begin{array}{c}\left(t_{0} / c\right)_{\text {struct }} \\
\mathrm{m} / \mathrm{s}\end{array}$ & $\begin{array}{c}S_{x} \\
\text { [un] }\end{array}$ & $\begin{array}{l}k W m \\
\text { [un] }\end{array}$ & $\begin{array}{c}\sigma_{x} \\
{[u n]}\end{array}$ & $\begin{array}{c}\left(t_{0} / c\right)_{c a v} \\
{[\mathrm{un}]}\end{array}$ & $\begin{array}{l}\text { Critério de } \\
\text { Cavitação }\end{array}$ \\
\hline 0,40 & 0,047 & 0,53 & 1,02 & 3,88 & 0,386 & Ok \\
\hline 0,45 & 0,043 & 0,49 & 1,02 & 3,29 & 0,347 & Ok \\
\hline 0,50 & 0,040 & 0,46 & 1,01 & 2,80 & 0,309 & Ok \\
\hline 0,55 & 0,036 & 0,43 & 1,01 & 2,39 & 0,273 & Ok \\
\hline 0,60 & 0,033 & 0,41 & 1,01 & 2,06 & 0,241 & Ok \\
\hline 0,65 & 0,031 & 0,39 & 1,01 & 1,79 & 0,211 & Ok \\
\hline 0,70 & 0,028 & 0,37 & 1,01 & 1,56 & 0,185 & Ok \\
\hline 0,75 & 0,026 & 0,35 & 1,00 & 1,38 & 0,161 & Ok \\
\hline 0,80 & 0,025 & 0,33 & 1,00 & 1,22 & 0,139 & Ok \\
\hline 0,85 & 0,023 & 0,31 & 1,00 & 1,09 & 0,118 & Ok \\
\hline 0,90 & 0,021 & 0,29 & 1,00 & 0,97 & 0,100 & Ok \\
\hline 0,95 & 0,020 & 0,27 & 1,00 & 0,88 & 0,082 & Ok \\
\hline 1,00 & 0,019 & 0,25 & 1,00 & 0,79 & 0,067 & Ok \\
\hline
\end{tabular}

A tabela 3.3 mostra os valores para as demais seções do rotor.

Tabela 3.3 Pá do Rotor - Critério de Cavitação. 
A tabela 3.4 mostra os valores do critério de cavitação para todas as seções da pá.

Tabela 3.4 Pá do Distribuidor - Critério de Cavitação.

\begin{tabular}{|c|c|c|c|c|c|c|}
\hline $\begin{array}{c}\chi \\
\text { [un] }\end{array}$ & $\begin{array}{c}\left(t_{0} / c\right)_{\text {struct }} \\
{[\mathrm{un}]}\end{array}$ & $\begin{array}{c}S e \\
{[u n]}\end{array}$ & $\begin{array}{l}k_{W m} \\
{[\mathbf{u n}]}\end{array}$ & $\begin{array}{c}\sigma_{x} \\
{[u n]}\end{array}$ & $\begin{array}{c}\left(t_{0} / c\right)_{c a v} \\
{[\mathrm{un}]}\end{array}$ & $\begin{array}{l}\text { Critério de } \\
\text { Cavitação }\end{array}$ \\
\hline 0,40 & 0,071 & 1,86 & 1,15 & 4,84 & 0,827 & Ok \\
\hline 0,45 & 0,071 & 1,65 & 1,13 & 5,12 & 0,865 & Ok \\
\hline 0,50 & 0,071 & 1,49 & 1,12 & 5,34 & 0,892 & Ok \\
\hline 0,55 & 0,071 & 1,35 & 1,11 & 5,52 & 0,919 & Ok \\
\hline 0,60 & 0,071 & 1,24 & 1,10 & 5,67 & 0,938 & Ok \\
\hline 0,65 & 0,071 & 1,14 & 1,09 & 5,79 & 0,954 & Ok \\
\hline 0,70 & 0,071 & 1,06 & 1,08 & 5,89 & 0,967 & Ok \\
\hline 0,75 & 0,071 & 0,99 & 1,08 & 5,97 & 0,978 & Ok \\
\hline 0,80 & 0,071 & 0,93 & 1,07 & 6,04 & 0,988 & Ok \\
\hline 0,85 & 0,071 & 0,87 & 1,07 & 6,10 & 0,996 & Ok \\
\hline 0,90 & 0,071 & 0,83 & 1,06 & 6,16 & 1,002 & Ok \\
\hline 0,95 & 0,071 & 0,78 & 1,06 & 6,20 & 1,008 & Ok \\
\hline 1,00 & 0,071 & 0,74 & 1,06 & 6,24 & 1,013 & Ok \\
\hline
\end{tabular}

\subsubsection{Ajuste de Cascata}

A solução da equação 2.21 tem o objetivo de fornecer para cada raio adimensional $\chi 0$ posicionamento correto, fornecendo o ângulo $\beta$ do perfil em relação ao escoamento. A solução numérica tem o seguinte esquema:

Com nos itens anteriores vamos usar o raio adimensional $\chi=0,4$ do perfil do rotor como exemplo e logo após apresentar os resultados para os demais perfis.

A iteração acontece até $F$ igual a zero. Para isso se começa, conforme já escrito na seção 2.5.3, com $\beta_{\text {estl }}=f . \alpha_{2 R}=1 .(-49,417)$ como podemos ver na linha 1 da tabela 3.5. Para a determinação de $k$ usa se o valor de $\alpha_{1 R}$ e $\alpha_{2 R} \operatorname{com}$ o valor de $\beta$ da última iteração. $\mathrm{O}$ valor de $\theta_{c}$ é dado pela equação 2.22. Na penúltima linha da tabela 3.5 o valor de $F$ converge e o valor de $\beta$ é calculado pela interpolação da penúltima com a antepenúltima linha $\left(\beta=-56,91^{\circ}\right)$.

O mesmo procedimento é usado para o cálculo do distribuidor, geralmente a iteração é simples para a determinação de $\beta$. 
O primeiro valor em negrito da coluna de $f m$ da tabela $3.5(0,022)$ é o passo do incremento de $f m$. A iteração para se determinar $\beta$ depende acontece quando $F=0$.

Tabela 3.5 Esquema de Determinação do ângulo de Sustentação Nula (Exemplo: Perfil do Rotor $-\chi=0,4)$

\begin{tabular}{cccccc}
\hline $\begin{array}{c}\mathrm{fm} \\
\mathbf{2 , 2 0 E}-02\end{array}$ & $\begin{array}{c}\beta \\
{\left[^{\circ}\right]}\end{array}$ & $k$ & $u$ & $\begin{array}{c}\theta_{c} \\
{[\mathrm{rad}]}\end{array}$ & $F$ \\
\cline { 2 - 6 } $1,00 \mathrm{E}+00$ & $-49,417$ & 1,000 & 17485,258 & $-0,862$ & $-5,992$ \\
1,0220 & $-50,505$ & 1,129 & 16,527 & $-0,821$ & $-1,378$ \\
1,0440 & $-51,592$ & 1,264 & 8,588 & $-0,784$ & $-0,892$ \\
1,0660 & $-52,679$ & 1,405 & 5,939 & $-0,751$ & $-0,601$ \\
1,0880 & $-53,766$ & 1,554 & 4,613 & $-0,721$ & $-0,393$ \\
1,1100 & $-54,853$ & 1,710 & 3,817 & $-0,693$ & $-0,231$ \\
1,1320 & $-55,940$ & 1,875 & 3,285 & $-0,668$ & $-0,099$ \\
1,1540 & $-57,028$ & 2,050 & 2,905 & $-0,645$ & 0,012 \\
1,1760 & $-58,115$ & 2,235 & 2,619 & $-0,623$ & 0,106 \\
\hline
\end{tabular}

A tabela 3.6 e 3.7 a seguir mostra os valores de $\beta_{z l}$ para os demais perfis do rotor e distribuidor seguindo o mesmo procedimento exemplificado até aqui.

Tabela 3.6 Resultados dos ângulos de posicionamento dos perfis do rotor

\begin{tabular}{|c|c|c|c|c|c|c|c|c|}
\hline$x$ & $\begin{array}{c}\alpha_{1 R} \\
\text { graus }\end{array}$ & $\begin{array}{c}\alpha_{2 R} \\
\text { graus }\end{array}$ & $\begin{array}{c}\beta z l \\
\text { graus }\end{array}$ & $\begin{array}{c}\alpha_{m R} \\
\text { graus }\end{array}$ & $\begin{array}{c}\alpha_{z l} \\
\text { graus }\end{array}$ & $\begin{array}{c}\beta_{c o} \\
\text { graus }\end{array}$ & $\begin{array}{c}\alpha_{\text {inc }} \\
\text { graus }\end{array}$ & $\begin{array}{c}\alpha_{i d} \\
\text { graus }\end{array}$ \\
\hline 0,40 & 24,46 & 49,42 & $-56,91$ & 39,05 & $-15,31$ & $-41,68$ & 2,63 & 2,61 \\
\hline 0,45 & 34,21 & 52,71 & $-60,20$ & 44,90 & $-13,17$ & $-47,12$ & 2,22 & 2,25 \\
\hline 0,50 & 41,64 & 55,58 & $-62,90$ & 49,58 & $-11,49$ & $-51,50$ & 1,92 & 1,96 \\
\hline 0,55 & 47,39 & 58,08 & $-65,12$ & 53,39 & $-10,14$ & $-55,08$ & 1,69 & 1,73 \\
\hline 0,60 & 51,92 & 60,27 & $-67,07$ & 56,55 & $-9,11$ & $-58,06$ & 1,51 & 1,55 \\
\hline 0,65 & 55,57 & 62,21 & $-68,73$ & 59,20 & $-8,26$ & $-60,58$ & 1,38 & 1,41 \\
\hline 0,70 & 58,56 & 63,92 & $-70,22$ & 61,47 & $-7,59$ & $-62,74$ & 1,27 & 1,30 \\
\hline 0,75 & 61,07 & 65,45 & $-71,60$ & 63,42 & $-7,09$ & $-64,62$ & 1,20 & 1,21 \\
\hline 0,80 & 63,19 & 66,82 & $-72,83$ & 65,13 & $-6,69$ & $-66,26$ & 1,13 & 1,14 \\
\hline 0,85 & 65,01 & 68,05 & $-73,95$ & 66,62 & $-6,36$ & $-67,71$ & 1,09 & 1,09 \\
\hline 0,90 & 66,59 & 69,16 & $-74,97$ & 67,95 & $-6,10$ & $-68,99$ & 1,05 & 1,04 \\
\hline 0,95 & 67,98 & 70,17 & $-75,90$ & 69,13 & $-5,88$ & $-70,14$ & 1,01 & 1,00 \\
\hline 1,00 & 69,21 & 71,09 & $-76,76$ & 70,19 & $-5,71$ & $-71,18$ & 0,99 & 0,97 \\
\hline
\end{tabular}

A figura 3.4 mostra graficamente os ângulos obtidos acima de forma a facilitar o entendimento dos resultados. A comparação a ser feita de acordo com o item 2.5.2 fica entre o ângulo de incidência e o ângulo de ataque ideal do perfil com a linha media, que deverão coincidir, ou seja $\alpha_{i n c}=\alpha_{i d}$, e podemos verificar que os valores são bem próximos para o rotor e o distribuidor. 


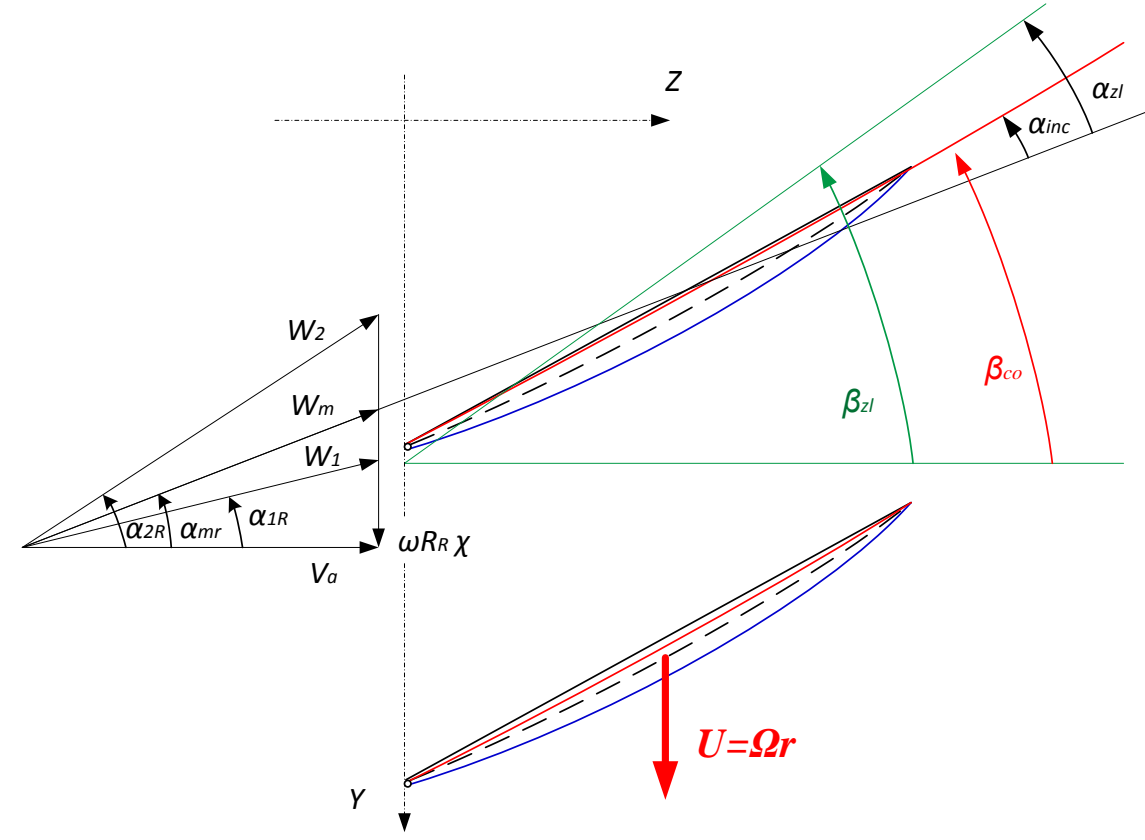

Figura 3.4 Ângulos pertinentes para o posicionamento dos perfis ao longo do raio $\chi$ (Perfil do Rotor).

Conforme $\chi$ tende a unidade o ângulo da corda $\beta_{c o}$ fica mais negativo, ou seja, a pá sofre torção no sentido anti-horário para se alinhar ao escoamento.

Abaixo a tabela 3.7 mostra os ângulos referentes ao distribuidor e neste caso como o ângulo $\beta_{c o}$ fica mais negativo conforme $\chi \rightarrow 1$ e a pá também sofre torção no sentido anti-horário concordando com torção das pás do rotor.

Tabela 3.7 Resultados dos ângulos de posicionamento dos perfis do Distribuidor.

\begin{tabular}{ccccccc}
\hline $\boldsymbol{x}$ & $\begin{array}{c}\boldsymbol{\alpha}_{2 \boldsymbol{D}} \\
\text { graus }\end{array}$ & $\begin{array}{c}\boldsymbol{\beta}_{\mathbf{z l}} \\
\text { graus }\end{array}$ & $\begin{array}{c}\boldsymbol{\alpha}_{\mathbf{z} \mathbf{}} \\
\text { graus }\end{array}$ & $\begin{array}{c}\beta_{c o} \\
\text { graus }\end{array}$ & $\begin{array}{c}\alpha_{\text {inc }} \\
\text { graus }\end{array}$ & $\begin{array}{c}\alpha_{\text {id }} \\
\text { graus }\end{array}$ \\
\hline 0,40 & 35,47 & $-35,58$ & $-13,73$ & $-21,85$ & 2,24 & 2,34 \\
0,45 & 32,35 & $-32,45$ & $-12,81$ & $-19,64$ & 2,07 & 2,19 \\
0,50 & 29,68 & $-30,16$ & $-12,28$ & $-17,88$ & 1,97 & 2,10 \\
0,55 & 27,39 & $-27,75$ & $-11,41$ & $-16,34$ & 1,81 & 1,95 \\
0,60 & 25,41 & $-25,87$ & $-10,80$ & $-15,06$ & 1,70 & 1,84 \\
0,65 & 23,68 & $-24,30$ & $-10,32$ & $-13,98$ & 1,62 & 1,76 \\
0,70 & 22,15 & $-22,92$ & $-9,87$ & $-13,05$ & 1,54 & 1,68 \\
0,75 & 20,81 & $-21,86$ & $-9,61$ & $-12,25$ & 1,49 & 1,64 \\
0,80 & 19,61 & $-20,71$ & $-9,18$ & $-11,52$ & 1,42 & 1,57 \\
0,85 & 18,54 & $-19,78$ & $-8,89$ & $-10,89$ & 1,37 & 1,52 \\
0,90 & 17,57 & $-17,83$ & $-7,66$ & $-10,17$ & 1,17 & 1,31 \\
0,95 & 16,70 & $-18,25$ & $-8,43$ & $-9,83$ & 1,30 & 1,44 \\
1,00 & 15,91 & $-17,62$ & $-8,24$ & $-9,38$ & 1,27 & 1,41 \\
\hline \hline
\end{tabular}




\subsubsection{Coeficiente de Sustentação e Potência da Unidade Geradora}

O coeficiente de sustentação $C_{L}$ é a variável mais importante na determinação da potência hidráulica do rotor $P_{h}$. Como o coeficiente de sustentação depende da determinação do ângulo de sustentação zero $\beta_{z l}$, sua determinação é dependente do processo iterativo descrito anteriormente.

O objetivo aqui é mostrar o cálculo da sustentação para um dado perfil, como feito anteriormente no caso das velocidades e ângulos do escoamento e depois mostrar os resultados para todos os perfis para o rotor e distribuidor e em seguida mostrar o cálculo da potência hidráulica utilizando o $C_{L}$ do Rotor.

A equação 2.13 calcula o coeficiente de sustentação dos perfis que depende da equação 2.19 para o cálculo do parâmetro $k$ que determina razão espaçamento-corda $h / c$ da cascata de perfis.

$$
\begin{aligned}
& C_{L_{\text {Rotor }}}=\left|\frac{4}{S_{e} \cdot k} \cdot \frac{\operatorname{sen}\left(\alpha_{m}+\beta_{z l}\right)}{\cos \left(\beta_{z l}\right)}\right|=\left|\frac{4 \cdot \operatorname{sen}\left(39,04^{\circ}-56,91^{\circ}\right)}{(0,53 \cdot 2,03) \cdot \cos \left(-56,91^{\circ}\right)}\right|=2,08 \\
& k_{\text {Rotor }}=\frac{2 \tan \beta_{z l}+\tan \alpha_{1 R}+\tan \alpha_{2 R}}{\tan \alpha_{1 R}-\tan \alpha_{2 R}}=\frac{2 \tan \left(56,91^{\circ}\right)+\tan \left(24,46^{\circ}\right)+\tan \left(49,42^{\circ}\right)}{\tan \left(24,46^{\circ}\right)-\tan \left(49,42^{\circ}\right)}=2,03 \\
& C_{L_{\text {Distr. }}}=\left|\frac{4}{S_{c} \cdot k} \cdot \frac{\operatorname{sen}\left(\alpha_{m}+\beta\right)}{\cos (\beta)}\right|=\left|\frac{4 \cdot \operatorname{sen}\left(19,61^{\circ}-35,58^{\circ}\right)}{(1,86 \cdot 1,008) \cdot \cos \left(35,58^{\circ}\right)}\right|=0,723 \\
& k_{\text {Distr. }}=\frac{2 \tan \beta_{z l}+\tan \alpha_{1 D}+\tan \alpha_{2 D}}{\tan \alpha_{1 D}-\tan \alpha_{2 D}}=\frac{2 \tan \left(-35,58^{\circ}\right)+\tan \left(0^{\circ}\right)+\tan \left(35,47^{\circ}\right)}{\tan \left(0^{\circ}\right)-\tan \left(35,47^{\circ}\right)}=1,008
\end{aligned}
$$

A tabela 3.8 mostra os demais valores dos coeficientes de sustentação do rotor e distribuidor para todos os raios adimensionais $\chi$.

O coeficiente de sustentação do distribuidor é praticamente constante ao longo do raio devido a sua corda $c$ que é constante ao longo da altura da pá. O parâmetro mais importante na tabela 3.8 é o coeficiente de sustentação das pás do rotor que é o que confere à máquina a potência hidráulica de acordo com as condições de carga. Notar que o coeficiente de sustentação dos perfis do rotor reduz com o aumento de $\chi$, o que já era esperado se analisarmos a equação 2.5 que tem a velocidade no denominador da expressão clássica do coeficiente de sustentação, pois a velocidade do escoamento paralelo as pás é maior quanto maior o raio $(v=\omega r)$. 
Tabela 3.8 Coeficiente de Sustentação - Rotor e Distribuidor

\begin{tabular}{ccccc}
\hline $\boldsymbol{x}$ & $\boldsymbol{C}_{\mathbf{L} \text { (Rotor) }}$ & $\boldsymbol{k}_{\text {Rotor }}$ & $\boldsymbol{C}_{\mathbf{L} \text { (Distrib.) }}$ & $\boldsymbol{k}_{\text {Distrib. }}$ \\
\hline 0,40 & 2,08 & 2,03 & 0,72 & 1,01 \\
0,45 & 1,82 & 2,37 & 0,73 & 1,01 \\
0,50 & 1,59 & 2,74 & 0,75 & 1,02 \\
0,55 & 1,41 & 3,13 & 0,74 & 1,03 \\
0,60 & 1,26 & 3,58 & 0,75 & 1,04 \\
0,65 & 1,14 & 4,07 & 0,75 & 1,06 \\
0,70 & 1,04 & 4,63 & 0,75 & 1,08 \\
0,75 & 0,96 & 5,31 & 0,75 & 1,11 \\
0,80 & 0,90 & 6,09 & 0,76 & 1,12 \\
0,85 & 0,85 & 6,96 & 0,76 & 1,15 \\
0,90 & 0,81 & 7,96 & 0,76 & 1,03 \\
0,95 & 0,78 & 9,07 & 0,76 & 1,20 \\
1,00 & 0,75 & 10,35 & 0,76 & 1,23 \\
\hline \hline
\end{tabular}

Basicamente a integração numérica do coeficiente de força tangencial que depende do coeficiente de sustentação envolvendo todos os perfis conferem a potência da máquina. Porém é importante o cálculo passo a passo dos parâmetros importantes para que se possa entender o procedimento adotado.

Segundo KRUPPA (1969) o coeficiente de força tangencial pode ser obtido por:

$$
\frac{\mathrm{dC}_{\mathrm{Ft}}}{\mathrm{dx}}=\left(\frac{W_{m}}{V_{a}}\right) \cdot \frac{c}{R_{R}} \cdot C_{L} \cdot\left[\cos \left(\alpha_{m r}\right)-\varepsilon \cdot \operatorname{sen}\left(\alpha_{m r}\right)\right]
$$

O parâmetro $\varepsilon$ é uma relação de arrasto do perfil. Substituindo os valores para o raio adimensional $\chi=0,4$ obtemos:

$$
\frac{\mathrm{dC}_{\mathrm{Ft}}}{\mathrm{dx}}=(1,29)^{2} \cdot 0,45 \cdot 2,08 \cdot\left[\cos \left(39,04^{\circ}\right)-8,04 \cdot 10^{-3} \cdot \operatorname{sen}\left(39,04^{\circ}\right)\right]=-1,186
$$

Se multiplicarmos o coeficiente acima pelo raio adimensional obtemos o coeficiente de força radial.

$$
\frac{\mathrm{dC}_{\mathrm{Fr}}}{\mathrm{dx}}=\frac{\mathrm{dC}_{\mathrm{Ft}}}{\mathrm{dx}} \cdot \chi=-1,186 \cdot(0,4)=-0,474
$$


Este item fornece todos os valores para o cálculo da equação 3.2. O coeficiente de força tangencial agora deve ser integrado para os demais perfis, o método de integral utilizado é o método numérico de Simpson. Logo cada perfil tem seu coeficiente de força radial multiplicado pelos coeficientes da integral de Simpson.

Tabela 3.9 Coeficiente de Torque Radial - Rotor.

\begin{tabular}{ccccc}
\hline $\boldsymbol{\chi}$ & $\begin{array}{c}\boldsymbol{d C}_{\boldsymbol{F}} / \boldsymbol{d} \boldsymbol{x} \\
\text { tangencial }\end{array}$ & $\begin{array}{c}\boldsymbol{d} \boldsymbol{C}_{\boldsymbol{T}} / \boldsymbol{d} \boldsymbol{x} \\
\text { torque }\end{array}$ & $\begin{array}{c}\text { Multiplicador } \\
\text { Simpson }\end{array}$ & $\begin{array}{c}\boldsymbol{C}_{\boldsymbol{T r}} \\
\text { torque }\end{array}$ \\
\hline 0,40 & $-1,19$ & $-0,47$ & 1,00 & $-0,47$ \\
0,45 & $-1,18$ & $-0,53$ & 4,00 & $-2,13$ \\
0,50 & $-1,18$ & $-0,59$ & 2,00 & $-1,18$ \\
0,55 & $-1,17$ & $-0,65$ & 4,00 & $-2,58$ \\
0,60 & $-1,17$ & $-0,70$ & 2,00 & $-1,40$ \\
0,65 & $-1,16$ & $-0,76$ & 4,00 & $-3,02$ \\
0,70 & $-1,16$ & $-0,81$ & 2,00 & $-1,62$ \\
0,75 & $-1,15$ & $-0,86$ & 4,00 & $-3,44$ \\
0,80 & $-1,14$ & $-0,91$ & 2,00 & $-1,82$ \\
0,85 & $-1,13$ & $-0,96$ & 4,00 & $-3,85$ \\
0,90 & $-1,13$ & $-1,01$ & 2,00 & $-2,03$ \\
0,95 & $-1,12$ & $-1,07$ & 4,00 & $-4,26$ \\
1,00 & $-1,12$ & $-1,12$ & 1,00 & $-1,12$ \\
\hline \hline \multicolumn{5}{c}{}
\end{tabular}

A soma, que é uma integração numérica dos coeficientes de torque radial fornece o coeficiente de torque de uma das pás do rotor.

$$
\mathrm{C}_{\mathrm{T}}=\frac{\mathrm{D}_{\mathrm{X}}}{\mathrm{Z}} \cdot \sum C_{T r}=\frac{0,05}{3}(-28,93)=-0,482
$$

Com o coeficiente de torque é possível calcular qual o torque hidráulico produzido por cada pá através de:

$$
\begin{aligned}
& \frac{\mathrm{T}}{\mathrm{Z}}=\mathrm{C}_{\mathrm{T}} \cdot(0,5) \cdot \rho \cdot\left(V_{a} \cdot R_{R}\right)^{2} \cdot R_{R} \\
& \frac{\mathrm{T}}{\mathrm{Z}}=-0,48 \cdot(0,5) \cdot 1000 \cdot[4,84 \cdot(0,3)]^{2} \cdot 0,3=-1,53 \cdot 10^{2} \mathrm{Nm}
\end{aligned}
$$


Somando para obter o torque total hidráulico no rotor:

$$
M_{t}=\left(\frac{\mathrm{T}}{\mathrm{Z}}\right) \cdot Z=\left(-1,53 \cdot 10^{2}\right) \cdot 3=-4,58 \cdot 10^{2} \mathrm{Nm}
$$

Para finalmente obtermos a potência hidráulica no rotor através da rotação nominal da máquina:

$$
P_{h}=\left|M_{t}\right| \cdot w=\left|-4,58 \cdot 10^{2}\right| \cdot 47,1=21500 \mathrm{~W}
$$

O torque $M_{t}$ fornecido pelo rotor é igual ao torque fornecido ao escoamento pelo distribuidor (menos as perdas). O distribuidor tem papel fundamental, é no distribuidor que a energia potencial do escoamento de entrada é transformada em energia de rotação. Este por sua vez, quando alcança o rotor é transformado em torque no eixo e consequentemente em energia mecânica. A condição de eficiência máxima (condição de projeto) é aquela em que o escoamento deixa o rotor sem rotação, isto é, com velocidades tangenciais nulas.

\subsection{ENSAIO DE CAMPO - MÁQUINA DE $20 \mathrm{KW}$}

A máquina em estudo tem as seguintes características nominais que serão comprovadas no ensaio de campo:

- Potência Nominal

- Eficiência Hidráulica do Rotor

- Eficiência Global Nominal

- Queda Líquida

- Vazão Nominal

- Rotação Nominal

- Abertura do Distribuidor
: $20 \mathrm{~kW}$

: $90 \%$

: $60 \%$

: $2,57 \mathrm{~m}$

: $1,15 \mathrm{~m}^{3} / \mathrm{s}$

: $450 \mathrm{rpm}$

: $75 \%$ 
Os ensaios serão realizados visando verificar basicamente as seguintes características:

- Determinar a característica da curva de rendimento da turbina para uma queda liquida

- Determinar o ponto ótimo de abertura do distribuidor

- Validar o procedimento de cálculo utilizado na confecção das unidades geradoras

Os procedimentos de ensaios aqui definidos obedecerão às prescrições da Norma IEC 60041, "Field Acceptance Tests to Determine the Hydraulic Performance of Hydraulic Turbines, Storage Pumps, and Pump-Turbines", $3^{\text {a }}$ edição, publicação de 1991.

A primeira impressão a eficiência global da turbina da máquina em estudo pode parecer baixa, porém segundo HYDRAULIC ENERGY PROGRAM (2004) geralmente, eficiências globais são menores para micro aproveitamentos. Máquinas acima de $10 \mathrm{~kW}$ apresentam eficiências entre 60 a $70 \%$ devido a perdas viscosas no conduto forçado e tubo de sucção que são maiores se comparadas a máquinas com grandes quedas.

Um resumo da metodologia aplicada para a análise de desempenho de turbinas hidráulicas foi realizado por JUSTINO (2006) e foi utilizado como guia para determinação do tipo de ensaio realizado nas instalações da Fazenda Ipanema.

A figura 3.5 mostra a curvatura da curva de rendimento esperada para turbinas axiais sem a regulação das pás do rotor.

A obtenção desta curva é realizada através da medição de potências, vazões e quedas ao longo da faixa de operação da máquina. Utilizando-se esses dados calcula-se o rendimento relativo para cada um dos pontos, através da equação 3.6 dada por IEC 60041 (1991).

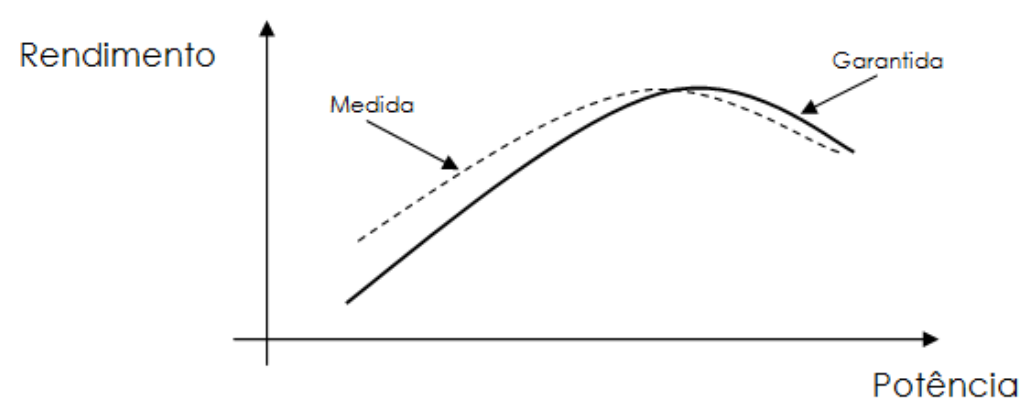

Figura 3.5 Curva de Rendimento Esperada. 
A eficiência global na condição de projeto de uma turbina é definido por:

$$
\eta_{G}=\frac{P_{t}}{\rho_{w} \cdot g \cdot Q \cdot H_{l}}
$$

- $\quad P_{t}=$ Potência mecânica no eixo da turbina [W]

- $\quad \rho=998,00 \mathrm{~kg} / \mathrm{m}^{3}$ (densidade da água) *

- $\quad g=9,7580 \mathrm{~m} / \mathrm{s}^{2}$ (aceleração da gravidade local) $* *$

- $\mathrm{Q}=$ vazão turbinada $\left[\mathrm{m}^{3} / \mathrm{s}\right]$

- $\quad H_{l}=$ queda líquida $[\mathrm{m}]$

- $\quad \eta_{G}=$ Eficiência Global da Turbina

* Valor ajustado para água a $20^{\circ} \mathrm{C}$.

* Valores definidos de acordo com (NBR11374, 1990).

Nos itens a seguir mostraremos como as grandezas acima foram obtidas para que possa ser possível o cálculo do rendimento da máquina.

\subsubsection{Queda Líquida}

A queda líquida se caracteriza pela queda útil que a turbina enxerga para a produção de energia elétrica. Logo a queda liquida é igual à queda bruta (diferença de altura entre jusante e montante) menos as perdas no conduto de adução e tubo de sucção da unidade.

A queda líquida $\left(H_{l}\right)$ para turbinas hidráulicas é calculada utilizando a equação 3.7, segundo IEC 60041 (1991), item 2.

$$
H_{l}=\frac{p_{1}-p_{2}}{\rho . g}+\frac{v_{1}^{2}-v_{2}^{2}}{2 . g}+Z_{e l}
$$

- $\quad p_{1}$ - Pressão na entrada da máquina (medida em Pa)

- $\quad p_{2}$ - Pressão na saída do tubo de sucção (medida em Pa)

- $\quad v_{1}$ - Velocidade média na entrada da turbina (calculada)

- $\quad v_{2}$ - Velocidade média na saída do tubo de sucção (calculada)

- $\quad Z_{\mathrm{el}}$ - Distância vertical em metros entre os pontos das tomadas de pressão 1 e 2. 
As velocidades $v_{1}$ e $v_{2}$ não são conhecidas na prática e, portanto, devem ser calculadas em função da vazão turbinada e das seções onde são medidas $p_{a b s 1}$ e $p_{a b s 2}$.

- $A_{l}=0,2827 m^{2}$ - pressão absoluta na entrada da caixa espiral (medida)

- $A_{2}=1,131 \mathrm{~m}^{2}$ - pressão absoluta na saída do tubo de sucção (medida)

A equação 3.7 é exatamente igual à equação da figura 3.6 que está em IEC 60041 (1991). Uma constatação recorrente da equação 3.7 é que quanto menor $v_{2}$ maior a queda liquida e consequentemente a potência da máquina, logo o tubo de sucção ideal teria área de saída tendendo ao infinito, aproveitando assim toda a energia cinética que deixa a máquina.

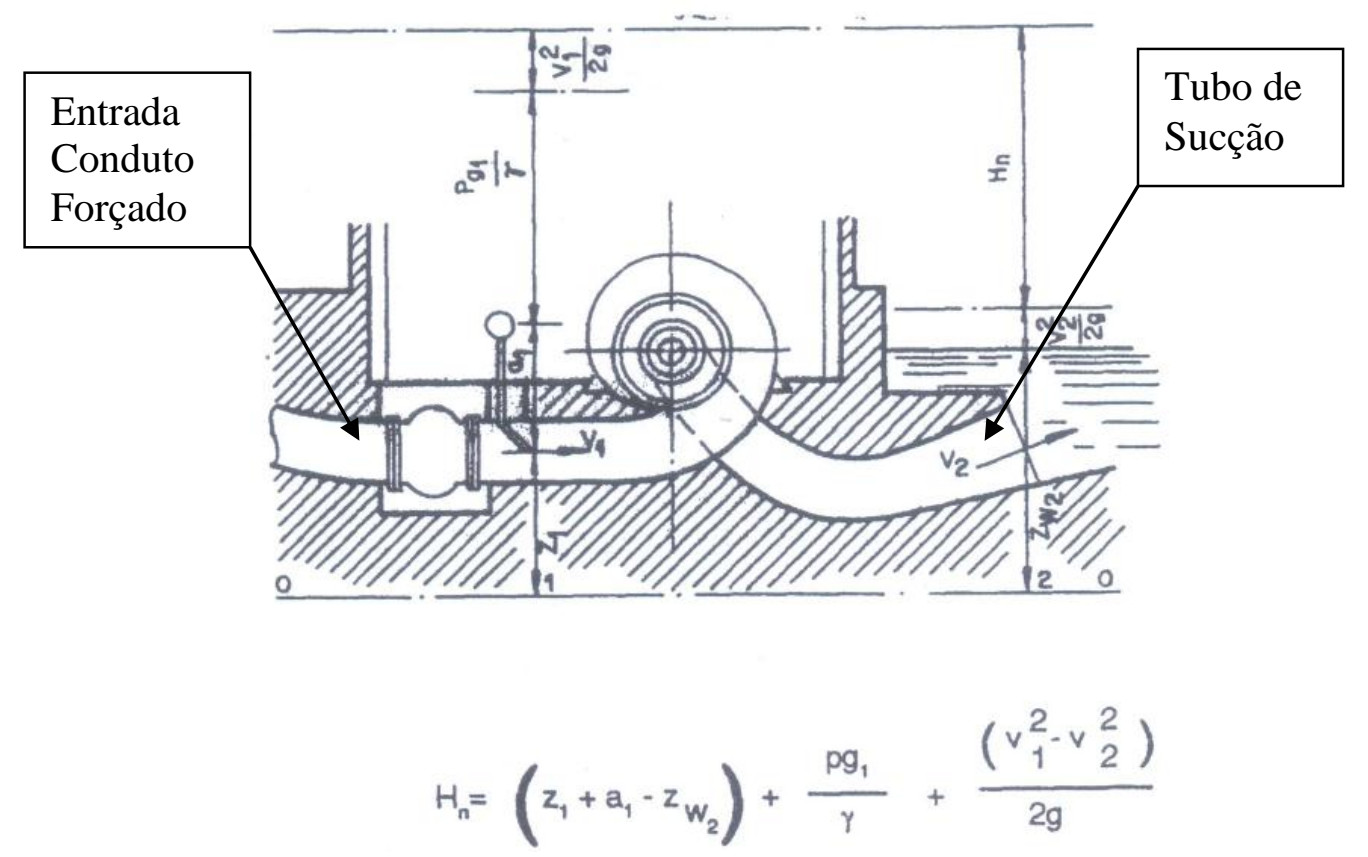

Figura 3.6 Turbina de Reação - Eixo Horizontal - figura extraída da IEC 60041.

\subsubsection{Medição de Vazão}

O método escolhido para a medição de vazão foi o vertedor calibrado, que é contemplado na norma IEC 60041 (1991). A razão para escolha deste tipo de método se deu por motivos econômicos e técnicos. Este método se baseia na determinação da vazão a partir da medição do nível d'água. $\mathrm{O}$ vertedor é geralmente instalado a jusante da turbina e deve-se tomar cuidado quanto às condições do escoamento, que deve ser regular, ou seja, isento de vórtices, de perturbações da superfície ou da presença de grande quantidade de ar carreado no canal de adução. 


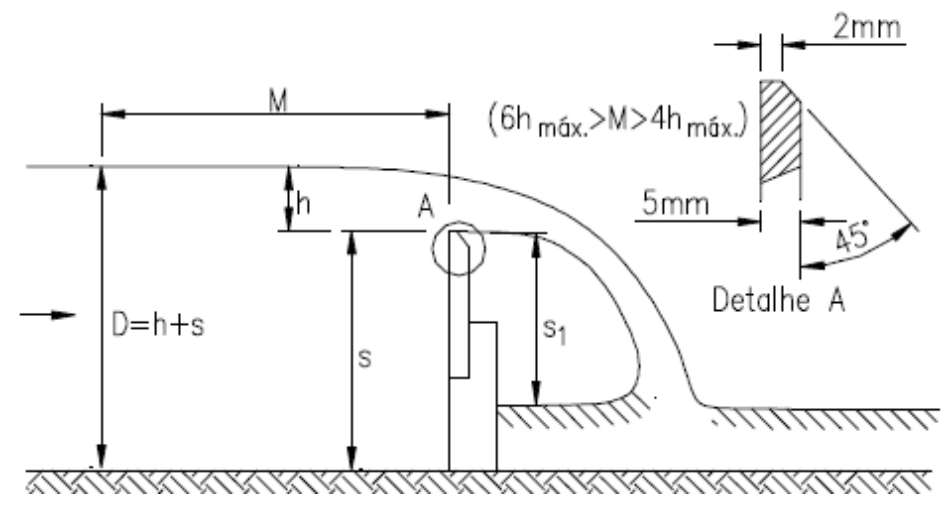

Figura 3.7 Dimensões do Vertedor segundo Norma NBR11374 (1990)

A altura de lamina (h) deve ser medida a montante do vertedor a uma distância de 4 a 6 vezes a altura da lamina máxima. O número de medidas que devem ser feitas transversalmente ao canal deve respeitar (NBR11374, 1990), e deve ser realizadas conforme a tabela 3.10.

Tabela 3.10 Medidas Transversais ao canal

\begin{tabular}{c|c}
\hline LARGURA DA CRISTA $(\mathrm{b})$ & NÚMERO DE PONTOS DE MEDIDA \\
\hline Para $\mathrm{b} \leq 2 \mathrm{~m}$ & 2 \\
\hline $2 \mathrm{~m}<\mathrm{b} \leq 6 \mathrm{~m}$ & 3 \\
\hline $\mathrm{b}>6 \mathrm{~m}$ & 4 pelo menos \\
\hline
\end{tabular}

A relação geral para o cálculo de vazão através de um vertedor de contração lateral é a de Poleni:

$$
Q=\frac{2}{3} \mu_{v} \cdot b \cdot h^{3 / 2} \cdot \sqrt{2 \cdot g}
$$

$$
\begin{array}{ll}
\mu_{v} & \text { - coeficiente de cascata (depende do tipo de crista utilizada) } \\
b & \text { - largura da crista } \\
h_{c} & \text { - altura da crista } \\
g & \text { - aceleração da gravidade }
\end{array}
$$

O tipo de crista utilizada é a chanfrada como no detalhe A da figura 4.3. O coeficiente $\mu$ para esse tipo de crista é 0,64 . 


\subsubsection{Potência da Turbina}

A potência mecânica pode ser medida em ensaios de campo por duas maneiras, direta e indiretamente. Diretamente através de freios ou dinamômetros, método este que é usado em ensaio de modelo reduzido e indiretamente quando a turbina esta acoplada ao gerador elétrico. O método mais utilizado em ensaios de campo é o indireto, porém para isso devemos saber quantificar as perdas elétricas e mecânicas.

A potência da turbina para o ensaio foi determinada pela relação a seguir:

$$
\begin{array}{ll}
P_{t}=\frac{P_{g}}{\eta_{g e n o}}+P_{f} \\
P_{t} \quad \text { - Potência da Turbina [W] } \\
P_{g} \quad \text { - Potência do Gerador [W] } \\
\eta_{g e n o} \quad \text { - Rendimento do Gerador [un] } \\
P_{f} \quad \text { - Potência dissipada nos Mancais [W] }
\end{array}
$$

A potência da turbina segundo ELETROBRÁS (1999) não contempla as perdas nos mancais, logo se supõe que esta englobado na eficiência global da turbina segundo essa diretriz.

\subsubsection{Perdas Elétricas}

O rendimento do gerador contempla as perdas para toda a faixa de operação do gerador. Geralmente o que se utiliza é a curva teoria de eficiência versus carga fornecida pelo fabricante. Quando o ensaio de rendimento é realizado para verificação da curva teórica este pode ser realizado de duas maneiras: o método da desaceleração e o método calorimétrico, sendo o segundo mais comum. O método calorimétrico se baseia em medir o aquecimento do fluido de refrigeração.

Porém na máquina em estudo neste trabalho vamos utilizar a curva fornecida pelo cálculo elétrico, que foi tirada do estudo eletromagnético realizado através do software Ansys. 
A curva de rendimento teórico pode ser visualizada a seguir.

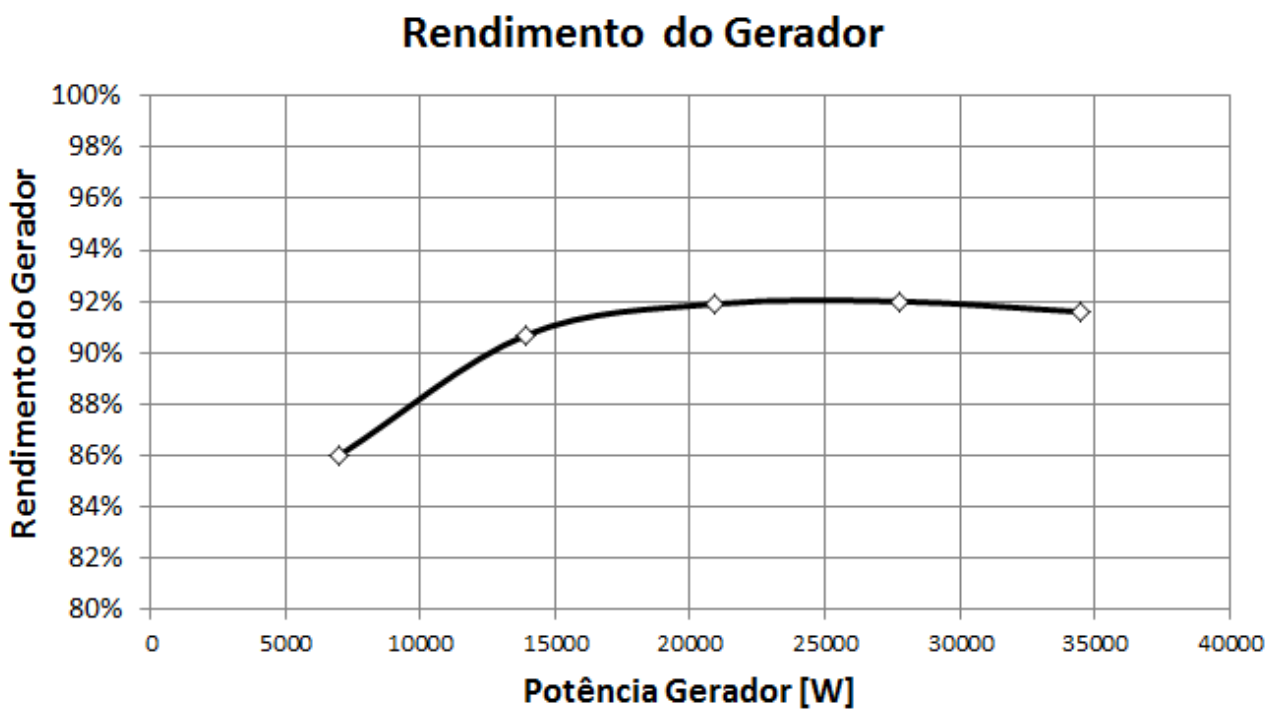

Figura 3.8 Rendimento Teórico do Gerador.

As faixas de potência ensaiadas foram interpoladas de acordo com a curva acima para obtenção da potência da turbina. Nota-se que potencias abaixo de $7 \mathrm{~kW}$ não foram geradas no cálculo elétrico, logo valores abaixo desse estão extrapolados parabolicamente.

\subsubsection{Perdas Mecânicas}

As perdas mecânicas em maquinas síncronas são constantes em toda a faixa de operação da unidade geradora. Essas perdas se referem a perdas nos mancais escoras e guias e devem ser medidas através da vazão e aquecimento do fluido de refrigeração.

Quando não é possível medir diretamente essas perdas, elas podem ser estimadas de comum acordo entre as partes contratantes, através de fórmulas empíricas ou por comparação.

A máquina em estudo utiliza mancais de rolamento tanto de escora quanto de guia e as perdas podem ser estimadas através de formulas empíricas obtidas do fabricante.

Como neste caso a máquina utiliza imãs permanentes no gerador e, portanto a rotação do eixo varia, as perdas são variáveis e devem estar relacionadas à rotação para cada ponto medido no ensaio. 
Na máquina em questão temos uma configuração com três rolamentos, dois rolamentos auto-compensador de rolos na saída da turbina que servem para absorver principalmente o empuxo axial da unidade $(4,2 \mathrm{kN}$ - Potência Nominal) e um rolamento de uma carreira de esferas que sustenta principalmente os esforços radiais no eixo na entrada da máquina.

O gráfico da figura 3.9 mostra as perdas isoladas destes rolamentos segundo dados da SKF (fabricante) bem como a perda total, que usamos no ensaio. As perdas foram calculadas com interpolação simples para cada ponto de medição no ensaio.

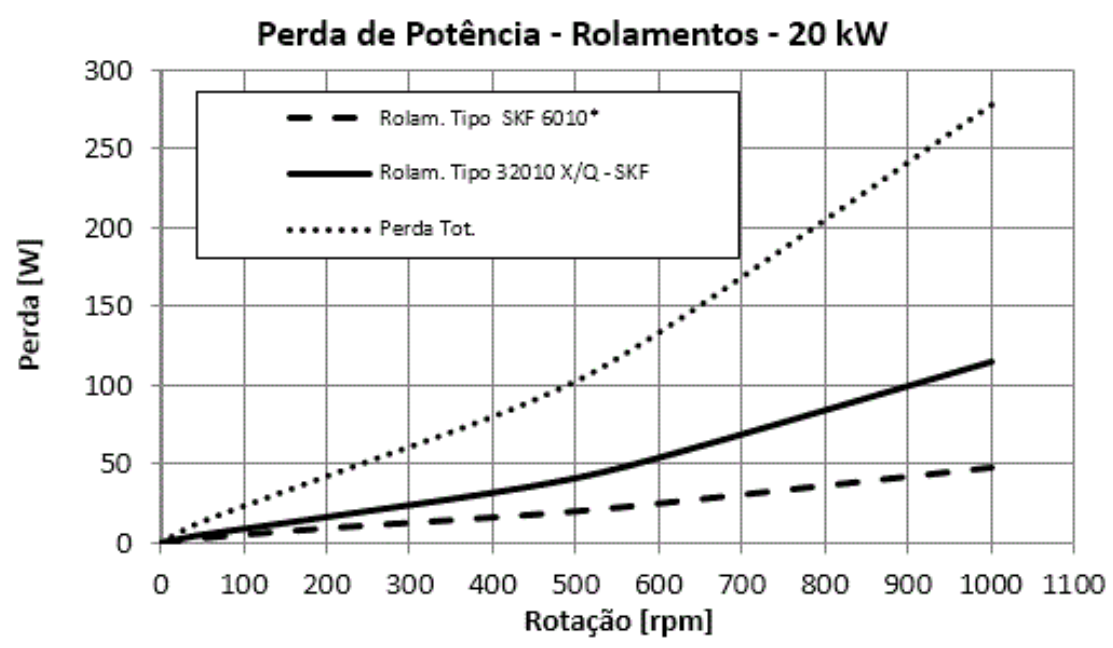

Figura 3.9 Perda de Potencia nos Mancais (Fonte: Manual SKF) 


\section{RESULTADOS E DISCUSSÕES}

Este item tem o objetivo de mostrar os resultados das três frentes do estudo que são:

- Determinação dos Perfis das Hélices - Método Analítico;

- Método dos Painéis;

- Ensaios de Campo.

Vamos comparar os resultados de forma que o método analítico possa ser validado pelo método dos painéis e pelos ensaios de campo. Basicamente o que se quer é comprovar que os perfis gerados do rotor e distribuidor podem produzir a potência turbinada esperada no cálculo. Isso pode ser feito comparando os resultados dos Ensaios de Campo com os resultados esperados pelo método analítico.

O que se quer, em resumo, quando comparamos o Método Analítico de determinação das pás com o Método dos Painéis é comparar o coeficiente de sustentação obtido em ambos, já que esse é de fundamental importância para a determinação da potência entregue pela turbina. Dessa forma podemos comparar um método que foi desenvolvido nos anos 60 com o método dos painéis, que é um método computacional mais atual.

Agregando à análise também os resultados experimentais, teremos uma comparação entre os resultados das três frentes de estudo.

\subsection{DETERMINAÇÃO DOS PERFIS DA HÉLICE (MÉTODO ANALÍTICO)}

Os resultados referentes do método de cálculo analítico são as geometrias obtidas para o distribuidor e rotor mostrando também as pás fabricadas de acordo com o projeto e a geometria da máquina que é resultado deste procedimento de cálculo.

A figura 4.1 mostra a geometria do distribuidor desenhada de acordo com os resultados do método analítico.

No capítulo 3 vimos como são posicionados os perfis do rotor e distribuidor de acordo com o escoamento para fornecer a sustentação requerida. Depois de posicionado o perfil expandido deve ser obtido a partir da geometria NACA $66 \mathrm{a}=0,8$ de acordo com a corda $c$, espessura máxima $t_{0}$ e flecha da linha média $f_{0}$. Como dito anteriormente os perfis expandidos são planificações da pá no plano $Z$ (ver Figura 2.21) e para a confecção das pás é preciso transformar esses perfis expandidos em perfis tridimensionais. 


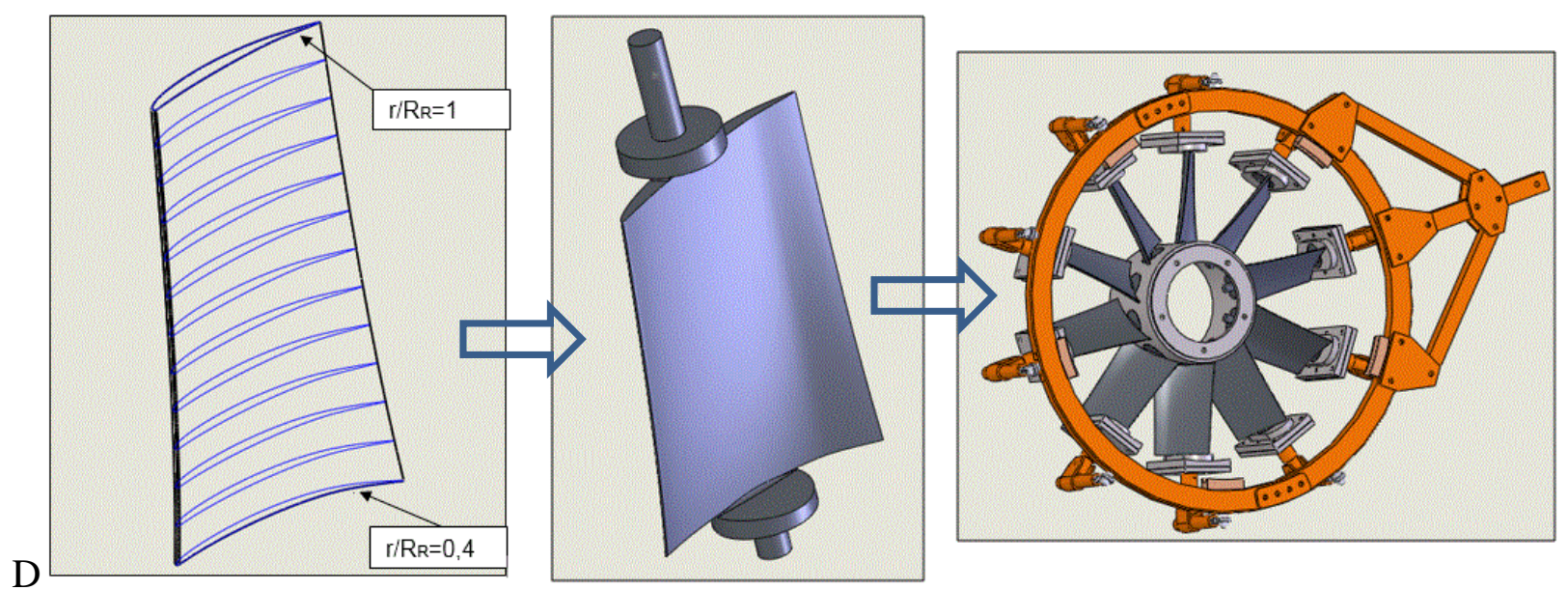

Figura 4.1 Pá do Distribuidor - Geometria e Adequação no Servo Mecanismo de Abertura [Cortesia: Hydrel]

A figura 4.2 mostra a transformação dos parâmetros adimensionais do perfil NACA 66 no perfil expandido do rotor em $\chi=0,4$. Como já temos os valores da corda $c$, da espessura máxima $t_{0}$ e a flecha máxima da linha média $f_{0}$ para o perfil, basta a multiplicação simples pelos dados adimensionais para se obter $x_{c}, y_{t}$ e $y_{c}$.
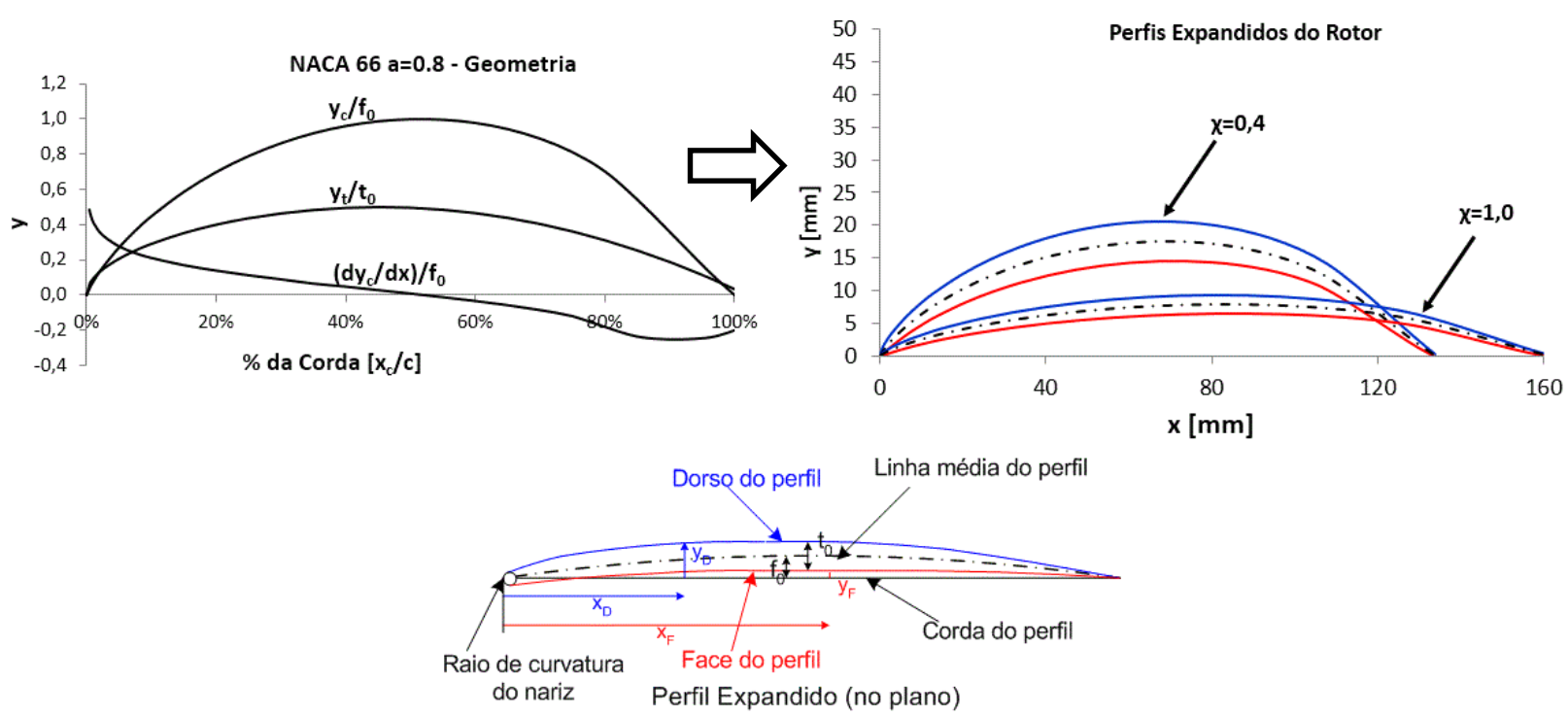

Figura 4.2 Obtenção do Perfil Expandido através da Geometria NACA 66.

A tabela 4.1 mostra os pontos relativos ao perfil NACA 66 modificado com linha média a $=0,8$. As coordenadas $x_{D}, y_{D}, x_{F}$ e $y_{F}$ representam o perfil expandido da figura 4.2 (lado direito) com suas coordenadas da Face e Dorso. Notar que a curva tracejada $y_{c}$ se trata da linha média do perfil. 
Tabela 4.1 Transformação do Perfil NACA 66 em um Perfil do Rotor $-\chi=0,4$ [Cortesia: Hydrel].

\begin{tabular}{|c|c|c|c|}
\hline \multicolumn{4}{|c|}{ NACA $66 \mathrm{a}=0,8$} \\
\hline$X_{c} / c$ & $y t / t_{0}$ & $y c / f o$ & $\left(d y_{c} / d x\right) / f_{0}$ \\
\hline 0,00 & 0,00 & 0,00 & \\
\hline 0,01 & 0,07 & 0,04 & 7,15 \\
\hline 0,01 & 0,08 & 0,06 & 6,62 \\
\hline 0,01 & 0,10 & 0,09 & 5,94 \\
\hline 0,03 & 0,15 & 0,16 & 5,02 \\
\hline 0,05 & 0,21 & 0,27 & 4,08 \\
\hline 0,08 & 0,25 & 0,37 & 3,52 \\
\hline 0,10 & 0,29 & 0,45 & 3,10 \\
\hline 0,15 & 0,35 & 0,59 & 2,49 \\
\hline 0,20 & 0,40 & 0,70 & 2,02 \\
\hline 0,25 & 0,44 & 0,79 & 1,64 \\
\hline 0,30 & 0,46 & 0,86 & 1,29 \\
\hline 0,35 & 0,48 & 0,92 & 0,93 \\
\hline 0,40 & 0,50 & 0,96 & 0,68 \\
\hline 0,45 & 0,50 & 0,99 & 0,39 \\
\hline 0,50 & 0,50 & 1,00 & 0,09 \\
\hline 0,55 & 0,48 & 1,00 & $-0,21$ \\
\hline 0,60 & 0,47 & 0,98 & $-0,53$ \\
\hline 0,65 & 0,44 & 0,94 & $-0,89$ \\
\hline 0,70 & 0,40 & 0,89 & $-1,30$ \\
\hline 0,75 & 0,36 & 0,81 & $-1,81$ \\
\hline 0,80 & 0,31 & 0,70 & $-2,71$ \\
\hline 0,85 & 0,25 & 0,54 & $-3,52$ \\
\hline 0,90 & 0,19 & 0,36 & $-3,77$ \\
\hline 0,95 & 0,11 & 0,17 & $-3,67$ \\
\hline 0,98 & 0,07 & 0,08 & $-3,44$ \\
\hline 1,00 & 0,03 & 0,00 & $-3,00$ \\
\hline
\end{tabular}

\begin{tabular}{|c|c|c|c|c|c|c|c|}
\hline$\chi$ & $\begin{array}{c}\boldsymbol{c} \\
\mathrm{mm}\end{array}$ & $\begin{array}{c}\boldsymbol{t}_{0} \\
\mathrm{~mm}\end{array}$ & $\begin{array}{c}\boldsymbol{f}_{0} \\
\mathrm{~mm}\end{array}$ & $f_{0} / c$ & & & \\
\hline 0,4 & 133,906 & 6,3 & 17,526 & 0,131 & & & \\
\hline $\begin{array}{c}\boldsymbol{X}_{\boldsymbol{c}} \\
\mathrm{mm}\end{array}$ & $\begin{array}{c}\boldsymbol{y t}_{\boldsymbol{t}} \\
\mathrm{mm}\end{array}$ & $\begin{array}{c}\boldsymbol{y}_{\boldsymbol{f}} \\
\mathrm{mm}\end{array}$ & $\theta_{c o}$ & $\begin{array}{l}\boldsymbol{X} \boldsymbol{D} \\
\mathrm{mm}\end{array}$ & $\begin{array}{c}\boldsymbol{Y} \boldsymbol{D} \\
\mathrm{mm}\end{array}$ & $\begin{array}{c}\boldsymbol{X}_{\boldsymbol{F}} \\
\mathrm{mm}\end{array}$ & $\begin{array}{c}\boldsymbol{y} \boldsymbol{F} \\
\mathrm{mm}\end{array}$ \\
\hline 0,00 & 0,00 & 0,00 & & 0,00 & 0,00 & 0,00 & 0,00 \\
\hline 0,67 & 0,42 & 0,74 & 0,71 & 0,40 & 1,06 & 0,94 & 0,42 \\
\hline 1,00 & 0,51 & 1,04 & 0,66 & 0,69 & 1,45 & 1,32 & 0,64 \\
\hline 1,67 & 0,66 & 1,59 & 0,58 & 1,31 & 2,14 & 2,04 & 1,04 \\
\hline 3,35 & 0,92 & 2,78 & 0,49 & 2,91 & 3,59 & 3,78 & 1,97 \\
\hline 6,70 & 1,30 & 4,75 & 0,43 & 6,15 & 5,94 & 7,24 & 3,57 \\
\hline 10,04 & 1,59 & 6,41 & 0,39 & 9,44 & 7,88 & 10,64 & 4,94 \\
\hline 13,39 & 1,83 & 7,86 & 0,31 & 12,82 & 9,60 & 13,96 & 6,11 \\
\hline 20,09 & 2,22 & 10,29 & 0,26 & 19,52 & 12,43 & 20,65 & 8,14 \\
\hline 26,78 & 2,52 & 12,26 & 0,21 & 26,25 & 14,72 & 27,31 & 9,79 \\
\hline 33,48 & 2,75 & 13,85 & 0,17 & 33,02 & 16,56 & 33,93 & 11,14 \\
\hline 40,17 & 2,92 & 15,13 & 0,12 & 39,82 & 18,03 & 40,53 & 12,23 \\
\hline 46,87 & 3,04 & 16,13 & 0,09 & 46,60 & 19,16 & 47,14 & 13,10 \\
\hline 53,56 & 3,12 & 16,85 & 0,05 & 53,41 & 19,97 & 53,72 & 13,74 \\
\hline 60,26 & 3,15 & 17,32 & 0,01 & 60,22 & 20,47 & 60,30 & 14,17 \\
\hline 66,95 & 3,13 & 17,53 & $-0,03$ & 67,04 & 20,65 & 66,87 & 14,40 \\
\hline 73,65 & 3,05 & 17,48 & $-0,07$ & 73,86 & 20,52 & 73,44 & 14,43 \\
\hline 80,34 & 2,93 & 17,15 & $-0,12$ & 80,68 & 20,06 & 80,01 & 14,24 \\
\hline 87,04 & 2,76 & 16,53 & $-0,17$ & 87,50 & 19,26 & 86,58 & 13,81 \\
\hline 93,73 & 2,54 & 15,58 & $-0,23$ & 94,32 & 18,06 & 93,15 & 13,11 \\
\hline 100,43 & 2,28 & 14,23 & $-0,34$ & 101,19 & 16,38 & 99,67 & 12,09 \\
\hline 107,13 & 1,96 & 12,32 & $-0,43$ & 107,95 & 14,09 & 106,30 & 10,54 \\
\hline 113,82 & 1,60 & 9,51 & $-0,46$ & 114,53 & 10,94 & 113,11 & 8,08 \\
\hline 120,52 & 1,18 & 6,28 & $-0,45$ & 121,03 & 7,35 & 120,00 & 5,22 \\
\hline 127,21 & 0,72 & 3,00 & $-0,42$ & 127,51 & 3,66 & 126,92 & 2,35 \\
\hline 130,56 & 0,47 & 1,44 & $-0,37$ & 130,73 & 1,88 & 130,39 & 1,00 \\
\hline 133,91 & 0,21 & 0,00 & 0,00 & 133,91 & 0,21 & 133,91 & $-0,21$ \\
\hline
\end{tabular}

Por geometria temos as expressões que transformam o perfil adimensional no real. Começando pelo ângulo da corda $\theta_{c o}$.

$$
\theta_{c o}=\operatorname{arctg}\left[\left(\frac{d y_{c}}{d x} / f_{0}\right) \cdot \frac{f_{0}}{c}\right]
$$

E assim podemos obter as coordenadas do perfil expandido, através das relações:

Dorso: $x_{D}=x_{C}-y_{t} \operatorname{sen} \theta_{C}$ e $y_{D}=y_{C}+y_{t} \cos \theta_{C}$

Face: $x_{F}=x_{C}+y_{t} \operatorname{sen} \theta_{C}$ e $y_{F}=y_{C}-y_{t} \cos \theta_{C}$ 
Com o perfil expandido definido podemos então determinar o perfil tridimensional. A figura 4.3 mostra a superfície final do rotor obtida através da transformação dos perfis expandidos.

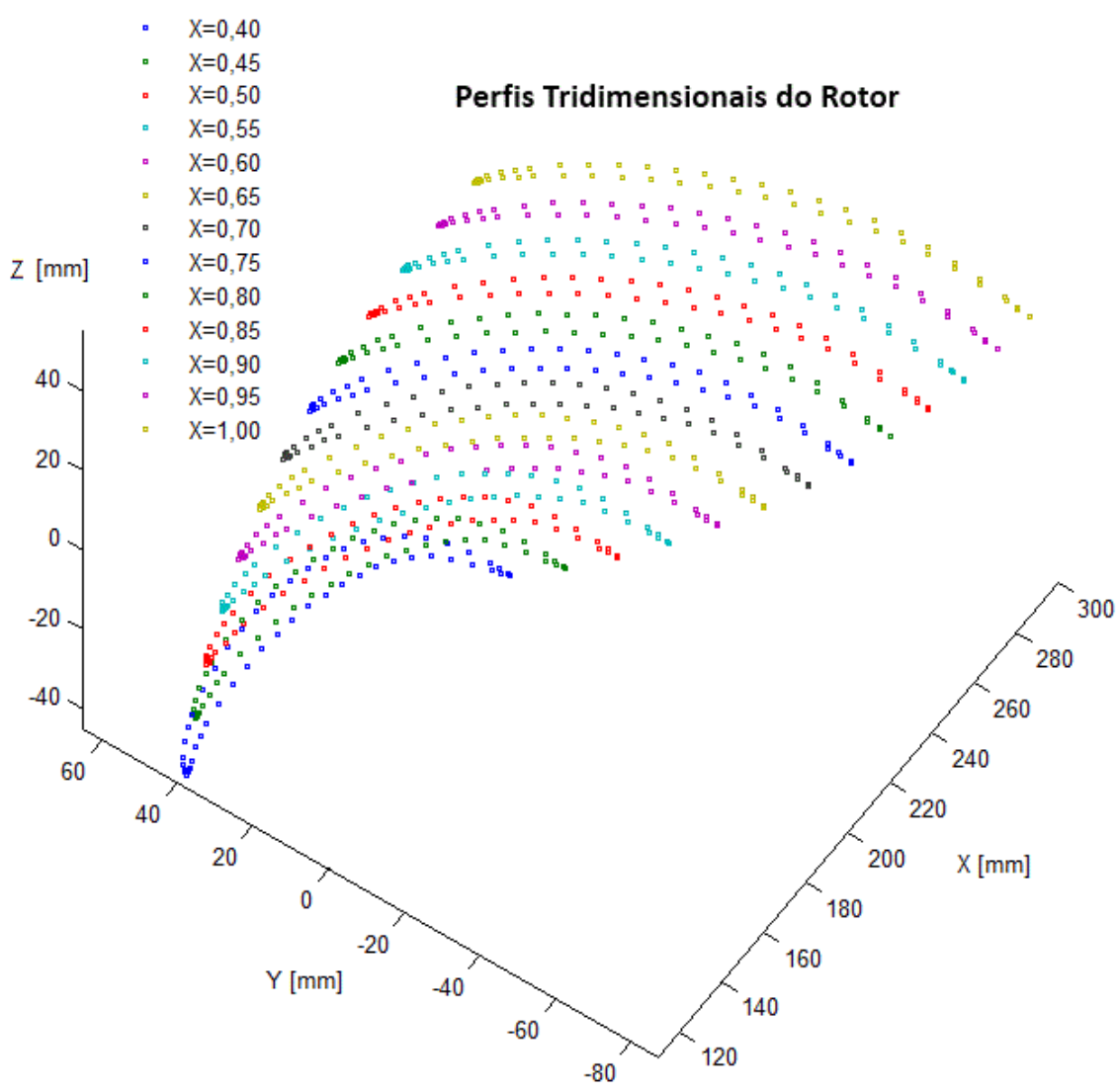

Figura 4.3 Perfil Tridimensional obtido do Perfil expandido.

Para se obter as coordenadas espaciais do dorso e da face, que estão expostos na tabela 4.2 dos perfis temos que conhecer a relação $r \theta_{D}$ e $r \theta_{F}$.

$$
\begin{aligned}
& r \theta_{D}=\left(c_{B A}-x_{D}\right) \operatorname{sen} \beta_{c o}+y_{D} \cos \beta_{c o} \\
& r \theta_{F}=\left(c_{B A}-x_{F}\right) \operatorname{sen} \beta_{c o}+y_{F} \cos \beta_{c o}
\end{aligned}
$$

Os ângulos polares da face e do dorso dependem do raio adimensional $\chi$ e do raio do rotor $R_{R}$

$$
\begin{aligned}
& \Theta_{D}=57,3 \frac{r \theta_{D}}{\chi \cdot R_{R}} \\
& \Theta_{F}=57,3 \frac{r \theta_{F}}{\chi \cdot R_{R}}
\end{aligned}
$$


A tabela 4.2 mostra as coordenadas tridimensionais do perfil para o raio adimensional $\chi=0,4$ $(r=120 \mathrm{~mm})$.

Tabela 4.2 Coordenadas Tridimensionais - Perfil Rotor $-\chi=0,4$.

\begin{tabular}{|c|c|c|c|c|c|c|c|c|c|c|}
\hline & \multirow{3}{*}{$\begin{array}{c}\text { polar } \\
\text { r } \theta \mathrm{D} \\
\mathrm{mm}\end{array}$} & \multirow{3}{*}{$\begin{array}{c}\text { polar } \\
\text { Dorso } \\
\text { @D } \\
\text { graus }\end{array}$} & \multicolumn{3}{|c|}{ Coordenadas dorso } & \multirow{3}{*}{$\begin{array}{c}\text { polar } \\
\text { r } \theta_{\mathrm{F}} \\
\mathrm{mm}\end{array}$} & \multirow{3}{*}{$\begin{array}{c}\text { polar } \\
\text { Face } \\
\text { OF } \\
\text { graus }\end{array}$} & \multicolumn{3}{|c|}{ Coordenadas face } \\
\hline & & & $X_{D}$ & $Y_{D}$ & $Z_{D}$ & & & $X_{F}$ & $Y_{F}$ & $\mathrm{Z}_{\mathrm{F}}$ \\
\hline & & & $\mathrm{mm}$ & $\mathrm{mm}$ & $\mathrm{mm}$ & & & $\mathrm{mm}$ & $\mathrm{mm}$ & $\mathrm{mm}$ \\
\hline$X$ & 40,07 & 19,13 & 113,37 & 39,33 & $-45,01$ & 40,07 & 19,13 & 113,37 & 39,33 & $-45,01$ \\
\hline 0,4 & 40,59 & 19,38 & 113,20 & 39,82 & $-44,01$ & 39,76 & 18,98 & 113,47 & 39,03 & $-44,02$ \\
\hline$\beta_{\mathrm{co}}$ & 40,69 & 19,43 & 113,17 & 39,91 & $-43,53$ & 39,67 & 18,94 & 113,50 & 38,95 & $-43,60$ \\
\hline$\left[{ }^{\circ}\right]$ & 40,79 & 19,48 & 113,13 & 40,01 & $-42,60$ & 39,49 & 18,86 & 113,56 & 38,78 & $-42,80$ \\
\hline 41,679 & 40,81 & 19,49 & 113,13 & 40,03 & $-40,44$ & 39,02 & 18,63 & 113,71 & 38,34 & $-40,88$ \\
\hline CBA & 40,41 & 19,30 & 113,26 & 39,65 & $-36,47$ & 37,92 & 18,11 & 114,06 & 37,29 & $-37,23$ \\
\hline$[\mathrm{mm}]$ & 39,67 & 18,94 & 113,50 & 38,96 & $-32,71$ & 36,68 & 17,51 & 114,44 & 36,11 & $-33,78$ \\
\hline 60,258 & 38,71 & 18,48 & 113,81 & 38,04 & $-29,05$ & 35,35 & 16,88 & 114,83 & 34,84 & $-30,52$ \\
\hline $\mathrm{R}_{\mathrm{R}}$ & 36,37 & 17,37 & 114,53 & 35,82 & $-22,16$ & 32,41 & 15,48 & 115,65 & 32,02 & $-24,17$ \\
\hline$[\mathrm{mm}]$ & 33,60 & 16,05 & 115,33 & 33,17 & $-15,61$ & 29,22 & 13,95 & 116,46 & 28,93 & $-18,10$ \\
\hline 300 & 30,48 & 14,56 & 116,15 & 30,16 & $-9,33$ & 25,83 & 12,33 & 117,23 & 25,63 & $-12,25$ \\
\hline \multirow{3}{*}{$\begin{array}{c}r \\
{[\mathrm{~mm}]} \\
120 \\
\end{array}$} & 27,06 & 12,92 & 116,96 & 26,83 & $-3,28$ & 22,26 & 10,63 & 117,94 & 22,13 & $-6,60$ \\
\hline & 23,39 & 11,17 & 117,73 & 23,25 & 2,54 & 18,51 & 8,84 & 118,58 & 18,43 & $-1,09$ \\
\hline & 19,47 & 9,30 & 118,42 & 19,38 & 8,16 & 14,61 & 6,97 & 119,11 & 14,57 & 4,25 \\
\hline & 15,31 & 7,31 & 119,02 & 15,27 & 13,58 & 10,56 & 5,04 & 119,54 & 10,54 & 9,45 \\
\hline & 10,92 & 5,21 & 119,50 & 10,90 & 18,80 & 6,36 & 3,04 & 119,83 & 6,36 & 14,51 \\
\hline & 6,28 & 3,00 & 119,84 & 6,28 & 23,80 & 2,01 & 0,96 & 119,98 & 2,01 & 19,44 \\
\hline & 1,41 & 0,67 & 119,99 & 1,41 & 28,59 & $-2,50$ & $-1,19$ & 119,97 & $-2,50$ & 24,22 \\
\hline & $-3,73$ & $-1,78$ & 119,94 & $-3,73$ & 33,15 & $-7,18$ & $-3,43$ & 119,78 & $-7,18$ & 28,84 \\
\hline & $-9,16$ & $-4,37$ & 119,65 & $-9,15$ & 37,45 & $-12,08$ & $-5,77$ & 119,39 & 12,06 & 33,28 \\
\hline & $-14,98$ & $-7,16$ & 119,07 & 14,95 & 41,46 & $-17,18$ & $-8,20$ & 118,77 & $-7,12$ & 37,47 \\
\hline & $-21,18$ & $-10,11$ & 118,14 & 21,07 & 44,99 & $-22,75$ & $-10,86$ & 117,85 & 22,61 & 41,40 \\
\hline & $-27,91$ & $-13,33$ & 116,77 & 27,66 & 47,81 & $-29,11$ & $-13,90$ & 116,49 & 28,83 & 44,85 \\
\hline & $-34,92$ & $-16,67$ & 114,96 & 34,43 & 50,28 & $-35,83$ & $-17,11$ & 114,69 & 35,30 & 48,10 \\
\hline & $-41,98$ & $-20,05$ & 112,73 & 41,13 & 52,66 & $-42,57$ & $-20,33$ & 112,53 & 41,68 & 51,35 \\
\hline & $-45,45$ & $-21,70$ & 111,49 & 44,37 & 53,89 & $-45,88$ & $-21,91$ & 111,34 & 44,77 & 53,05 \\
\hline & $-48,81$ & $-23,31$ & 110,21 & 47,48 & 55,15 & $-49,13$ & $-23,46$ & 110,08 & 47,77 & 54,87 \\
\hline
\end{tabular}

Com os ângulos polares podemos fazer a mudança de coordenada para obtermos as coordenadas cartesianas do perfil.

$$
\begin{aligned}
& x_{D}=r \cdot \cos \Theta_{D} \\
& x_{F}=r \cdot \cos \Theta_{F} \\
& y_{D}=r \cdot \operatorname{sen} \Theta_{D} \\
& y_{F}=r \cdot \operatorname{sen} \Theta_{F} \\
& z_{D}=\left(c_{B A}-x_{D}\right) \cos \beta_{c o}-y_{D} \operatorname{sen} \beta_{c o} \\
& z_{F}=\left(c_{B A}-x_{F}\right) \cos \beta_{c o}-y_{F} \operatorname{sen} \beta_{c o}
\end{aligned}
$$


A cota $c_{B A}$ é a distância da linha de referência que pode ser visualizada na figura 4.4

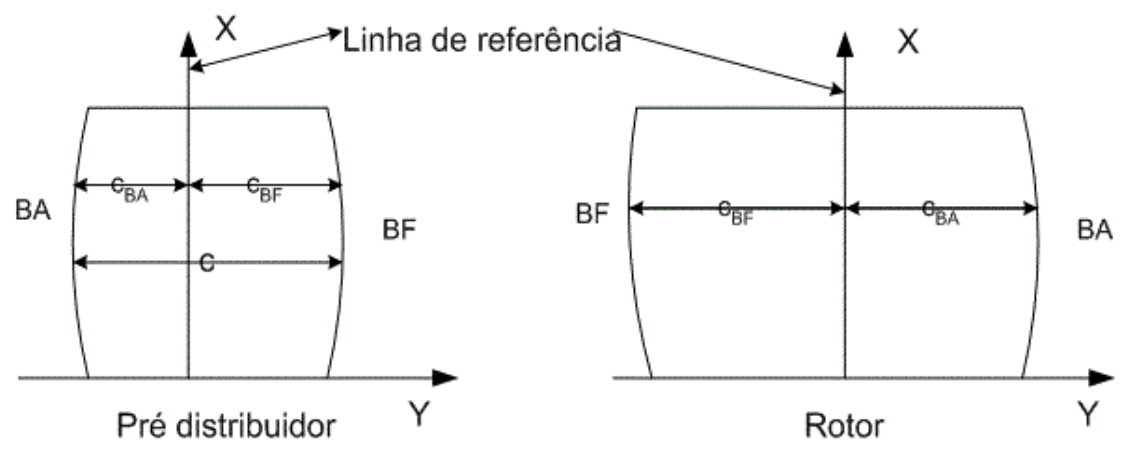

Figura 4.4 Contornos expandidos das Pás.

Como nos capítulos anteriores apresentamos o procedimento de cálculo para um perfil tridimensional, o mesmo processo é utilizado para obtenção dos demais perfis assim como os perfis do distribuidor. A tabela 4.3 e 4.4 mostram as características principais das pás do rotor e distribuidor respectivamente. Como tínhamos mencionado antes a corda do distribuidor não é variável, porém o perfil tem torção ao longo do raio. O raio da secção $r$ vai de 120 a 300 milímetros que são os raios do rotor e do cubo respectivamente.

Tabela 4.3 Principais dimensões das Pás do Rotor.

\begin{tabular}{|c|c|c|c|c|c|c|c|c|}
\hline $\begin{array}{c}\text { raio } \\
\text { adimensional } \\
\boldsymbol{x} \\
\boldsymbol{r} / \boldsymbol{R}_{\boldsymbol{R}}\end{array}$ & $\begin{array}{l}\text { raio da } \\
\text { seção } \\
r \\
\boldsymbol{m} \boldsymbol{m}\end{array}$ & 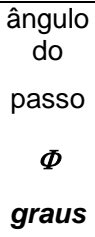 & $\begin{array}{c}\text { ângulo } \\
\text { da } \\
\text { corda } \\
\beta_{c o} \\
\text { graus }\end{array}$ & $\begin{array}{c}\text { corda } \\
\text { do perfil } \\
\text { c } \\
\mathbf{m m}\end{array}$ & $\begin{array}{c}\text { distância } \\
\text { BA } \\
\text { linha de ref } \\
c_{B A} \\
m m\end{array}$ & $\begin{array}{c}\text { distância } \\
\text { BF } \\
\text { linha de ref } \\
c_{B F} \\
m m\end{array}$ & $\begin{array}{c}\text { espessura } \\
\text { máxima } \\
\boldsymbol{t}_{0} \\
\mathbf{m m}\end{array}$ & $\begin{array}{c}\text { flecha } \\
\text { da } \\
\text { linha } \\
\text { média } \\
\boldsymbol{f}_{0} \\
\mathbf{m m}\end{array}$ \\
\hline 0,40 & 120,0 & 311,7 & 41,7 & 133,9 & 60,3 & $-73,6$ & 6,3 & 17,5 \\
\hline 0,45 & 135,0 & 317,1 & 47,1 & 139,6 & 62,5 & $-77,2$ & 6,0 & 15,7 \\
\hline 0,50 & 150,0 & 321,5 & 51,5 & 145,5 & 64,8 & $-80,8$ & 5,8 & 14,3 \\
\hline 0,55 & 165,0 & 325,1 & 55,1 & 151,2 & 66,9 & $-84,3$ & 5,5 & 13,1 \\
\hline 0,60 & 180,0 & 328,1 & 58,1 & 156,3 & 68,8 & $-87,5$ & 5,2 & 12,2 \\
\hline 0,65 & 195,0 & 330,6 & 60,6 & 160,5 & 70,2 & $-90,3$ & 4,9 & 11,3 \\
\hline 0,70 & 210,0 & 332,7 & 62,7 & 163,7 & 71,2 & $-92,5$ & 4,7 & 10,6 \\
\hline 0,75 & 225,0 & 334,6 & 64,6 & 165,7 & 71,7 & $-94,1$ & 4,4 & 10,1 \\
\hline 0,80 & 240,0 & 336,3 & 66,3 & 166,6 & 71,7 & $-95,0$ & 4,1 & 9,5 \\
\hline 0,85 & 255,0 & 337,7 & 67,7 & 166,4 & 71,1 & $-95,3$ & 3,8 & 9,1 \\
\hline 0,90 & 270,0 & 339,0 & 69,0 & 165,2 & 70,2 & $-95,0$ & 3,6 & 8,6 \\
\hline 0,95 & 285,0 & 340,1 & 70,1 & 163,3 & 69,0 & $-94,3$ & 3,3 & 8,2 \\
\hline 1,00 & 300,0 & 341,2 & 71,2 & 160,8 & 67,6 & $-93,3$ & 3,0 & 7,9 \\
\hline
\end{tabular}


Tabela 4.4 Principais dimensões das Pás do Distribuidor.

\begin{tabular}{|c|c|c|c|c|c|c|c|c|}
\hline $\begin{array}{c}\text { raio } \\
\text { adimensional } \\
\boldsymbol{X} \\
\boldsymbol{r} / \boldsymbol{R}_{\boldsymbol{R}} \\
\end{array}$ & $\begin{array}{c}\text { raio da } \\
\text { seção } \\
\boldsymbol{r} \\
\boldsymbol{m} \boldsymbol{m}\end{array}$ & $\begin{array}{l}\text { ângulo } \\
\text { do } \\
\text { passo } \\
\Phi \\
\text { graus } \\
\end{array}$ & $\begin{array}{c}\text { ângulo } \\
\text { da } \\
\text { corda } \\
\beta_{c o} \\
\text { graus } \\
\end{array}$ & $\begin{array}{l}\text { corda } \\
\text { do } \\
\text { perfil } \\
\boldsymbol{c} \\
\boldsymbol{m} \boldsymbol{m} \\
\end{array}$ & $\begin{array}{c}\text { distância BA } \\
\text { linha de ref } \\
\boldsymbol{c}_{B A} \\
\mathbf{m m}\end{array}$ & $\begin{array}{c}\text { distância } \\
\text { BF } \\
\text { linha de ref } \\
c_{B F} \\
m m \\
\end{array}$ & $\begin{array}{c}\text { espessura } \\
\text { máxima } \\
\boldsymbol{t}_{0} \\
\boldsymbol{m m} \\
\end{array}$ & $\begin{array}{c}\text { flecha da } \\
\text { linha } \\
\text { média } \\
\boldsymbol{f}_{\boldsymbol{o}} \\
\boldsymbol{m} \boldsymbol{m} \\
\end{array}$ \\
\hline 0,40 & 120,0 & 248,1 & 21,9 & 140,0 & $-70,0$ & 70,0 & 10,0 & 16,4 \\
\hline 0,45 & 135,0 & 250,4 & 19,6 & 140,0 & $-70,0$ & 70,0 & 10,0 & 15,3 \\
\hline 0,50 & 150,0 & 252,1 & 17,9 & 140,0 & $-70,0$ & 70,0 & 10,0 & 14,7 \\
\hline 0,55 & 165,0 & 253,7 & 16,3 & 140,0 & $-70,0$ & 70,0 & 10,0 & 13,7 \\
\hline 0,60 & 180,0 & 254,9 & 15,1 & 140,0 & $-70,0$ & 70,0 & 10,0 & 12,9 \\
\hline 0,65 & 195,0 & 256,0 & 14,0 & 140,0 & $-70,0$ & 70,0 & 10,0 & 12,4 \\
\hline 0,70 & 210,0 & 257,0 & 13,0 & 140,0 & $-70,0$ & 70,0 & 10,0 & 11,8 \\
\hline 0,75 & 225,0 & 257,7 & 12,3 & 140,0 & $-70,0$ & 70,0 & 10,0 & 11,5 \\
\hline 0,80 & 240,0 & 258,5 & 11,5 & 140,0 & $-70,0$ & 70,0 & 10,0 & 11,0 \\
\hline 0,85 & 255,0 & 259,1 & 10,9 & 140,0 & $-70,0$ & 70,0 & 10,0 & 10,6 \\
\hline 0,90 & 270,0 & 259,8 & 10,2 & 140,0 & $-70,0$ & 70,0 & 10,0 & 9,2 \\
\hline 0,95 & 285,0 & 260,2 & 9,8 & 140,0 & $-70,0$ & 70,0 & 10,0 & 10,1 \\
\hline 1,00 & 300,0 & 260,6 & 9,4 & 140,0 & $-70,0$ & 70,0 & 10,0 & 9,9 \\
\hline
\end{tabular}

A figura 4.5 mostra as pás do rotor e distribuidor fundidas confeccionadas com aço inoxidável 304 com tensão de escoamento de $755 \mathrm{~N} / \mathrm{mm}^{2}$ e densidade de $7900 \mathrm{~kg} / \mathrm{m}^{3}$.

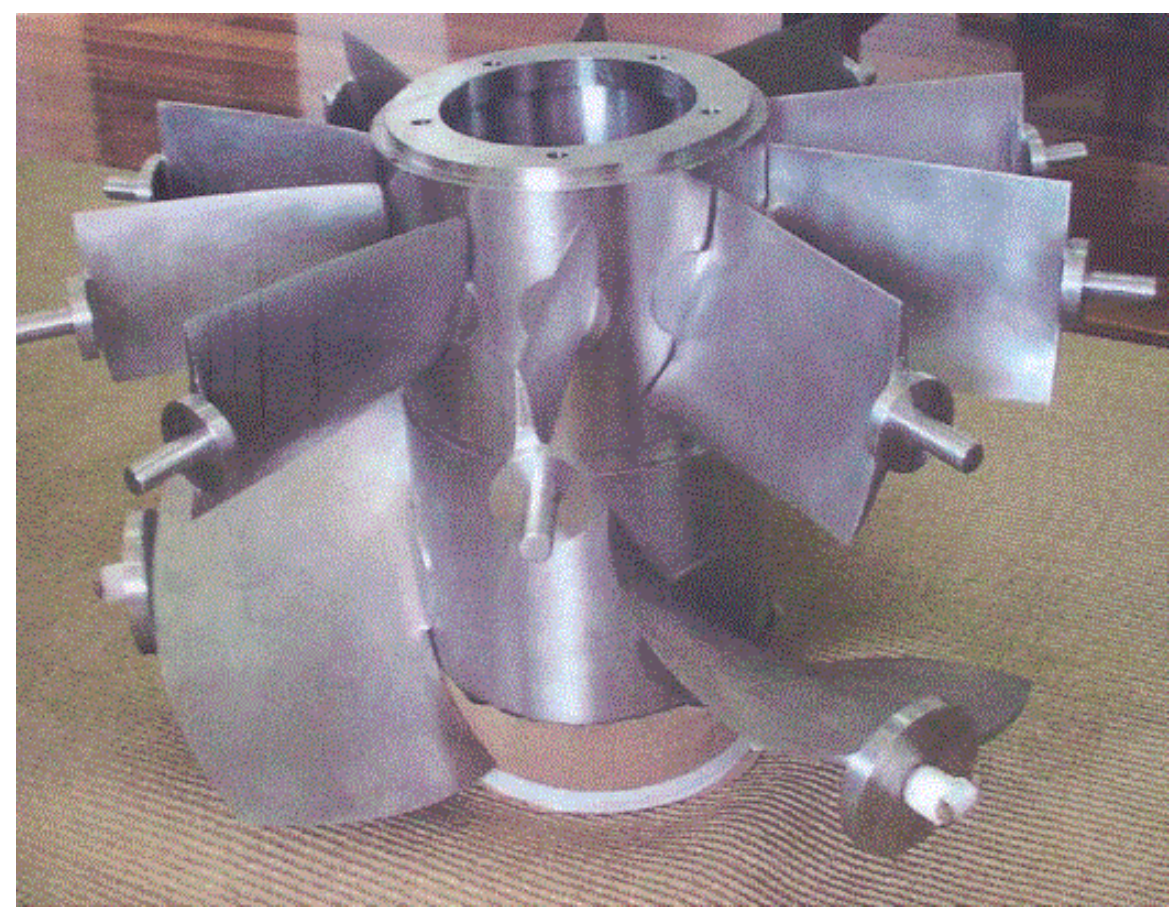

Figura 4.5 Pás do Rotor e Distribuidor Fundidas [Cortesia: Hydrel] 


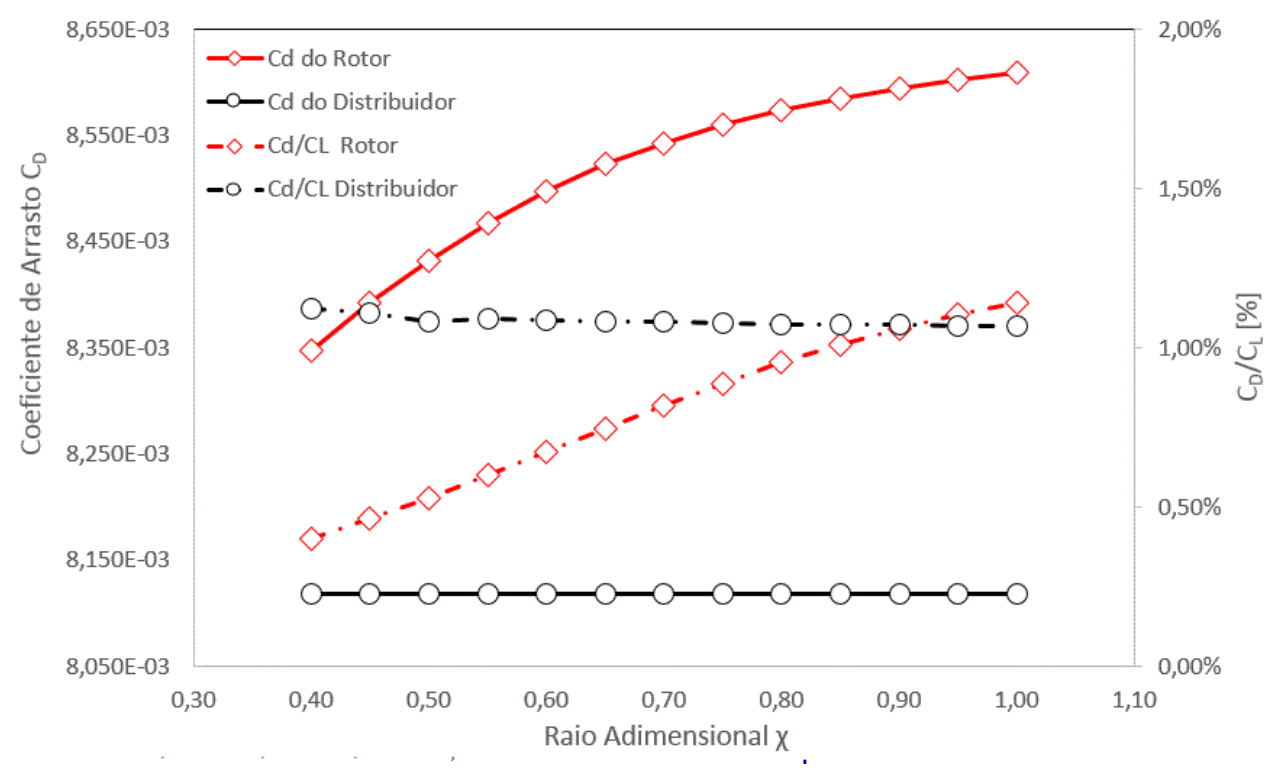

Figura 4.6 Coeficiente de Arrasto para os Perfis do Rotor e Distribuidor.

A figura 4.6 mostra os resultados do coeficiente de arrasto do rotor e distribuidor e bem como a sua relação com o coeficiente de sustentação no eixo secundário do gráfico. Notar que conforme mencionado na seção 2.5.1, a relação entre arrasto e sustentação é baixa para perfis tipo NACA 66 conforme podemos notar na figura 4.6.

Com a obtenção das geometrias do rotor e distribuidor podemos traçar os coeficientes de sustentação para as duas pás.

A figura 4.7 mostra a comparação dos coeficientes de sustentação para o perfil isolado e os perfis em cascata mostrando a influência da proximidade das pás, parâmetro $m$, na sustentação das pás.
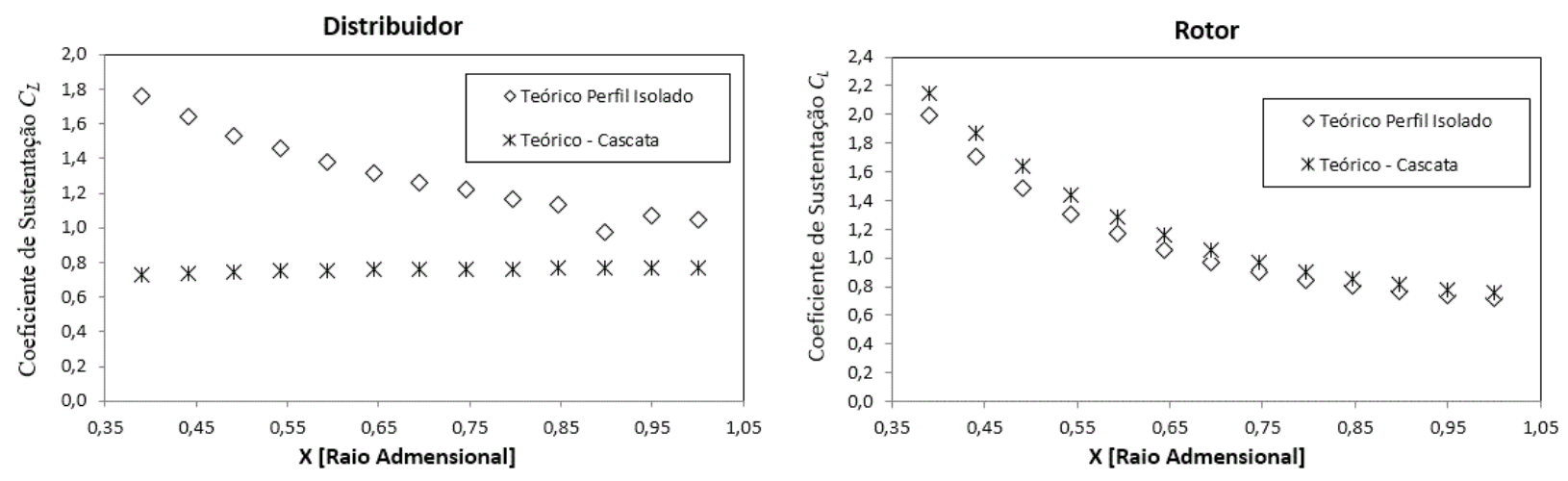

Figura 4.7 Comparação do Coeficiente de Sustentação - Perfis Isolados versus Perfis em Cascata

Quanto as pás do rotor, a figura 4.7 apresenta valores bem próximos de coeficiente de sustentação entre o perfil isolado e em cascata com a tendência dos valores em cascata serem ligeiramente maiores, principalmente para os perfis próximos ao cubo. 
Já para as pás do distribuidor vemos que a cascata afeta drasticamente os coeficientes de sustentação dos perfis, devido a maior proximidade dos perfis das pás. Lembramos que o coeficiente de sustentação tem papel importante no cálculo estrutural do distribuidor.

\subsection{MÉTODO DOS PAINÉIS}

O objetivo principal do emprego do método dos painéis neste trabalho foi comparar o coeficiente de sustentação obtido pelo método analítico. Com o método analítico empregado neste trabalho não é possível o cálculo das distribuições de pressão sobre o perfil, porém o método dos painéis de empregado com base em LEWIS (1991) nos fornece a distribuição do coeficiente de pressão em função da percentagem da corda \%c. Essa distribuição foi obtida para todos os perfis do rotor e distribuidor em estudo. A figura 4.8 mostra as distribuições de pressão obtida através do método da vorticidade superficial.

Segundo CARPENTER (2003) o coeficiente de sustentação pode ser obtido através do coeficiente de pressão pela expressão:

$$
C_{Z}=\oint_{\Pi} C_{P} d\left(\frac{x}{c}\right)
$$

Onde a integral de linha é calculada seguindo a direção anti-horária em torno do contorno $\Pi$ do perfil e $C_{z}$ é a componente de força perpendicular ao perfil. A análise desta expressão explica o fato de os perfis mais próximos ao cubo $(\chi \rightarrow 0,4)$ terem maiores valores de $|1-C p|$ e consequentemente maiores valores de $C_{L}$.

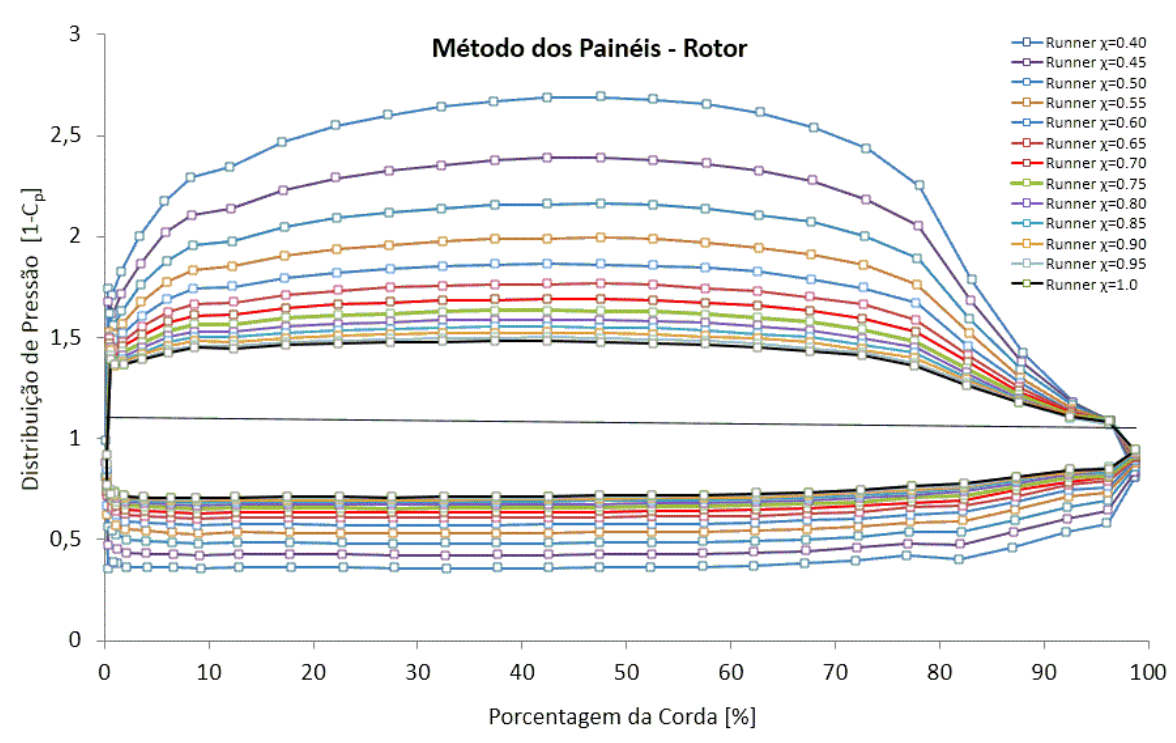

Figura 4.8 Distribuições de Pressão em função da corda - Perfis do Rotor 
A figura 4.9 mostra as distribuições de pressão para os perfis do distribuidor onde é posivel notar um maior agrupamento das curvas se comparado com as distribuições do rotor e isso pode ser explicado pela menor torção e menor corda que as pás do distribuidor tem em relação a do rotor.

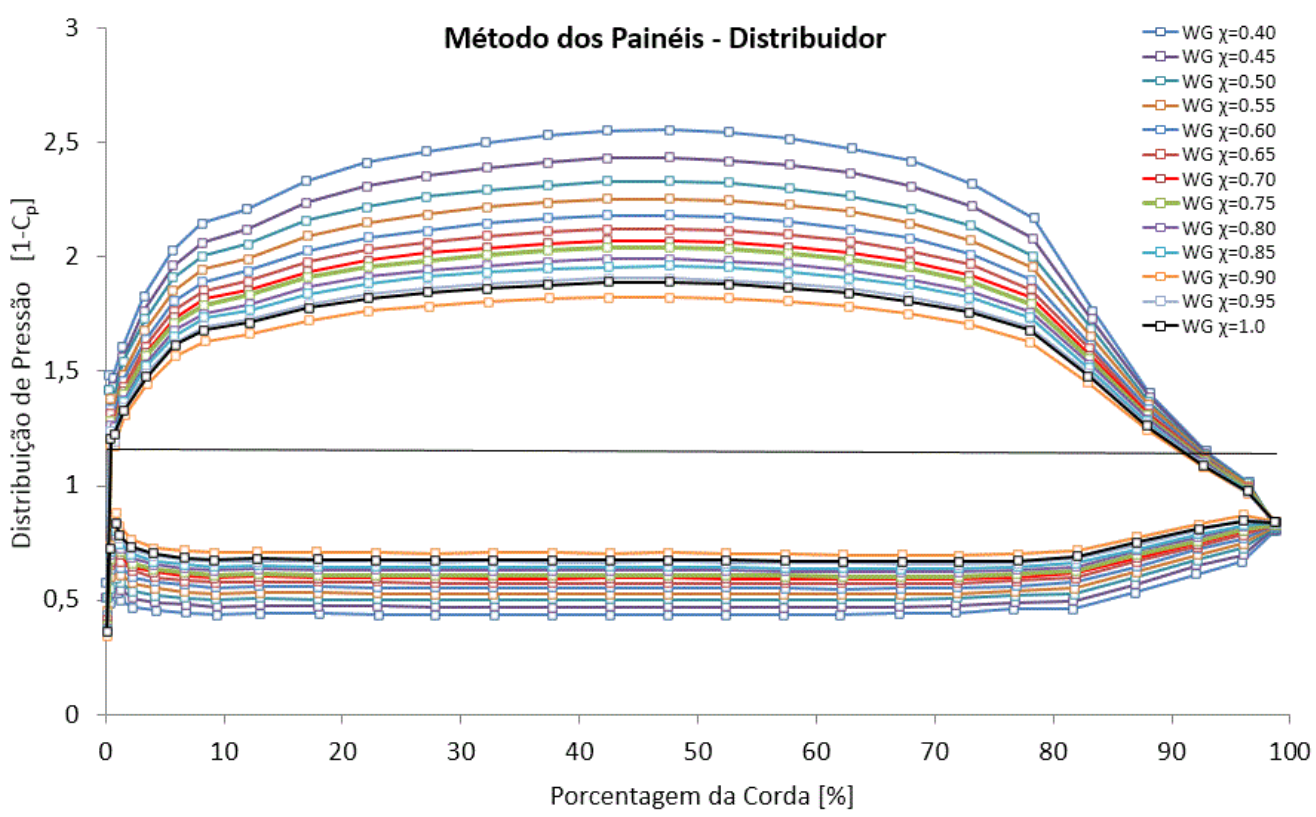

Figura 4.9 Distribuições de Pressão em função da corda - Perfis do Distribuidor

A figura 4.10 mostra o mesmo gráfico da figura 4.8, porém somente com os perfis das extremidades das pás $(\chi=0,4$ e $\chi=1,0)$ onde o dorso dos perfis (ou lado de sucção) são as curvas em azul e a face dos perfis (ou lado de pressão) são as curvas em amarelo. Aqui fica mais evidente a diferença de sustentação entre as extremidades.

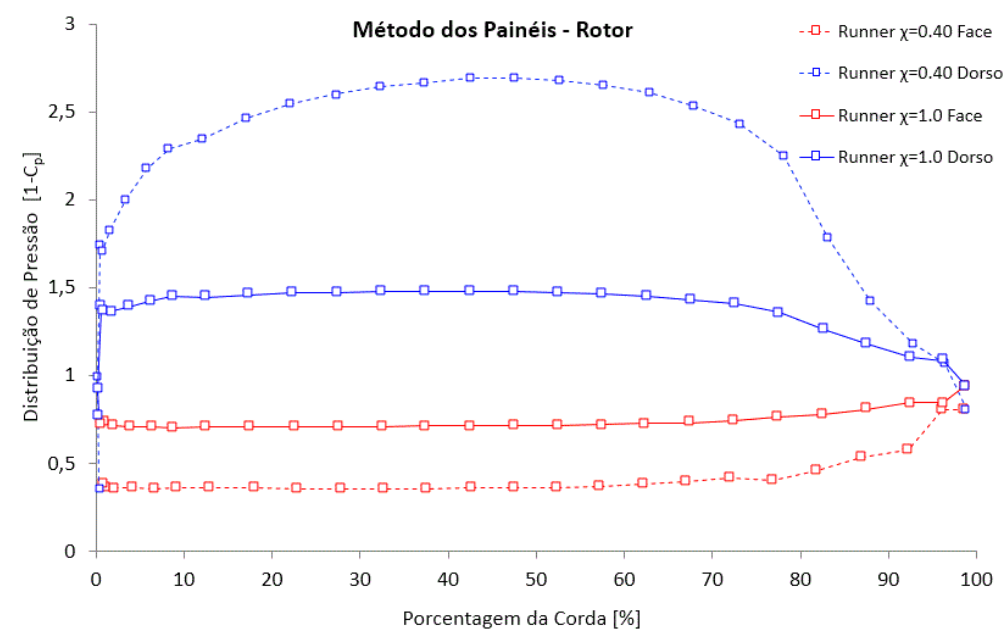

Figura 4.10 Distribuições de Pressão- Perfis do Rotor - Extremidades 
A figura 4.11 mostra o resultado dos coeficientes de sustentação para cada perfil do rotor em função do ângulo de ataque ou incidencia $\alpha_{i n c}$. O programa, rodado em Matlab com base no modelo de cálculo mostrado na seção 2.6 fornece resultados para angulos de ataque entre $-16^{\circ} \mathrm{e}+16^{\circ}$ para cada perfil.

Os valores de $\alpha_{i n c}$ obtidos no método analitico (ver tabela 3.6) foram inseridos no gráfico para cada raio adimensional e mostra a tendencia do coeficiente de sustentação obtido através do método dos painéis em função do raio adimensional $\chi$.

Notar os valores de $C_{L}$ são maiores conforme nos aproximamos do cubo do rotor e que não há mudança na inclinação das retas de uma seção para a outra, o que era esperado já que se trata do mesmo perfil NACA.

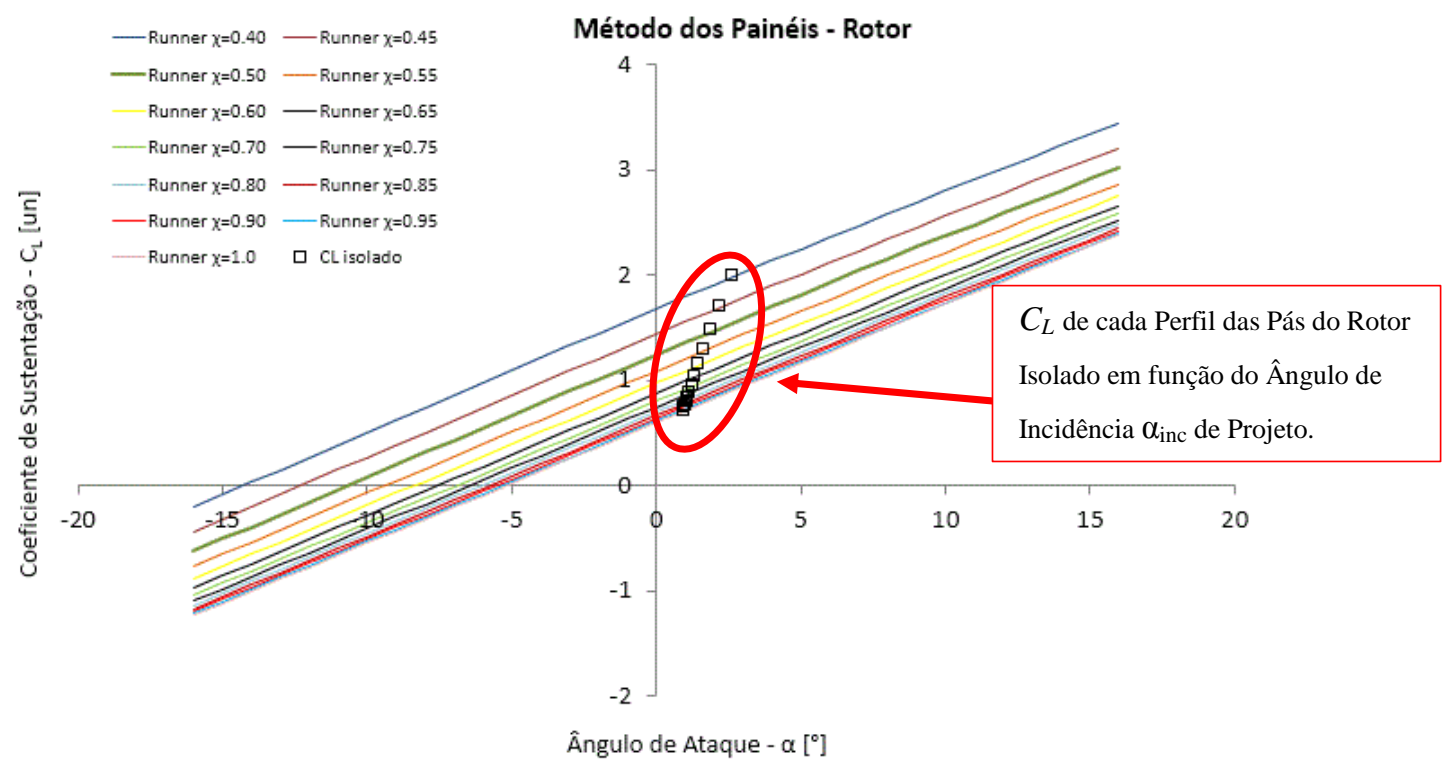

Figura 4.11 Coeficiente de Sustentação em função do ângulo de ataque - Perfil do Rotor Isolado.

O mesmo gráfico para o distribuidor está na figura 4.12. Notar que a inclinação das retas para os perfis do rotor e distribuidor devem ser e são idênticas já que o mesmo perfil NACA 66 foi usado nas duas geometrias. Como no caso do rotor os valores de $\alpha_{i n c}$ obtidos no método analitico (ver tabela 3.7) foram inseridos no gráfico para cada raio adimensional. 


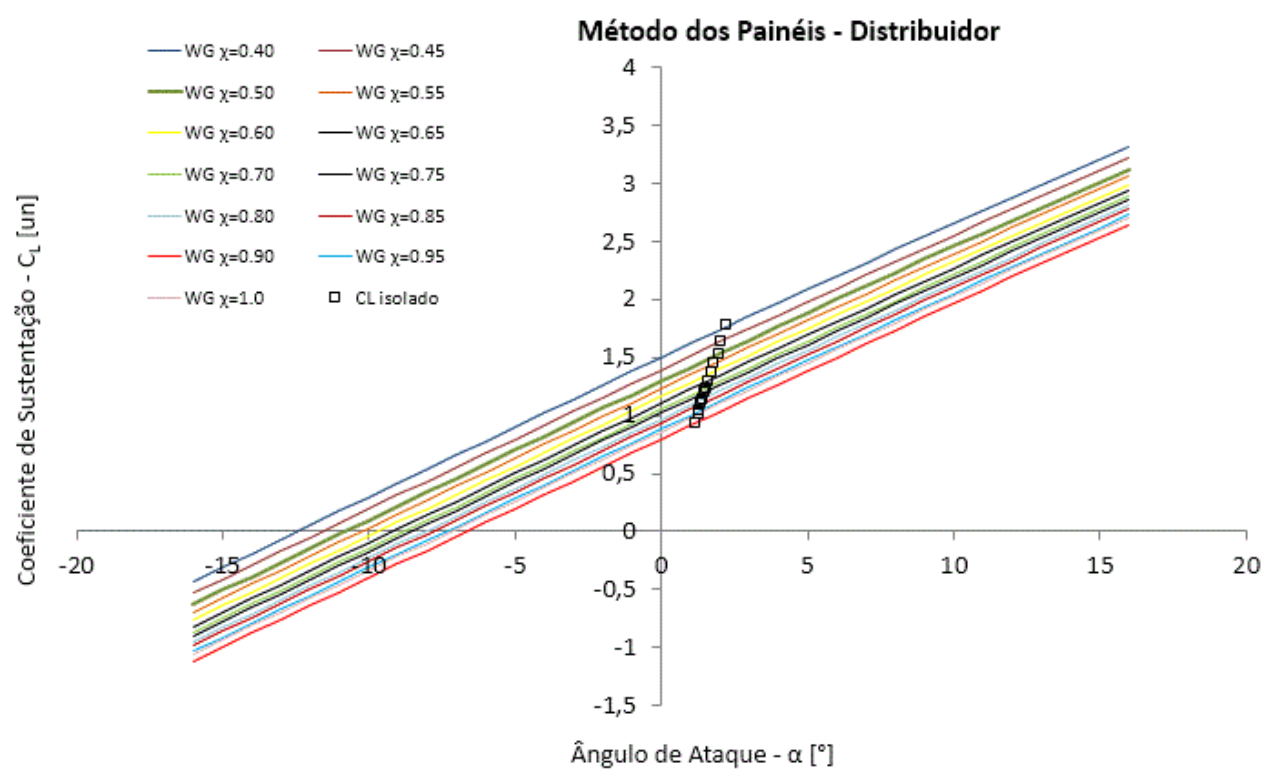

Figura 4.12 Coeficiente de Sustentação- Perfil do Distribuidor Isolado.

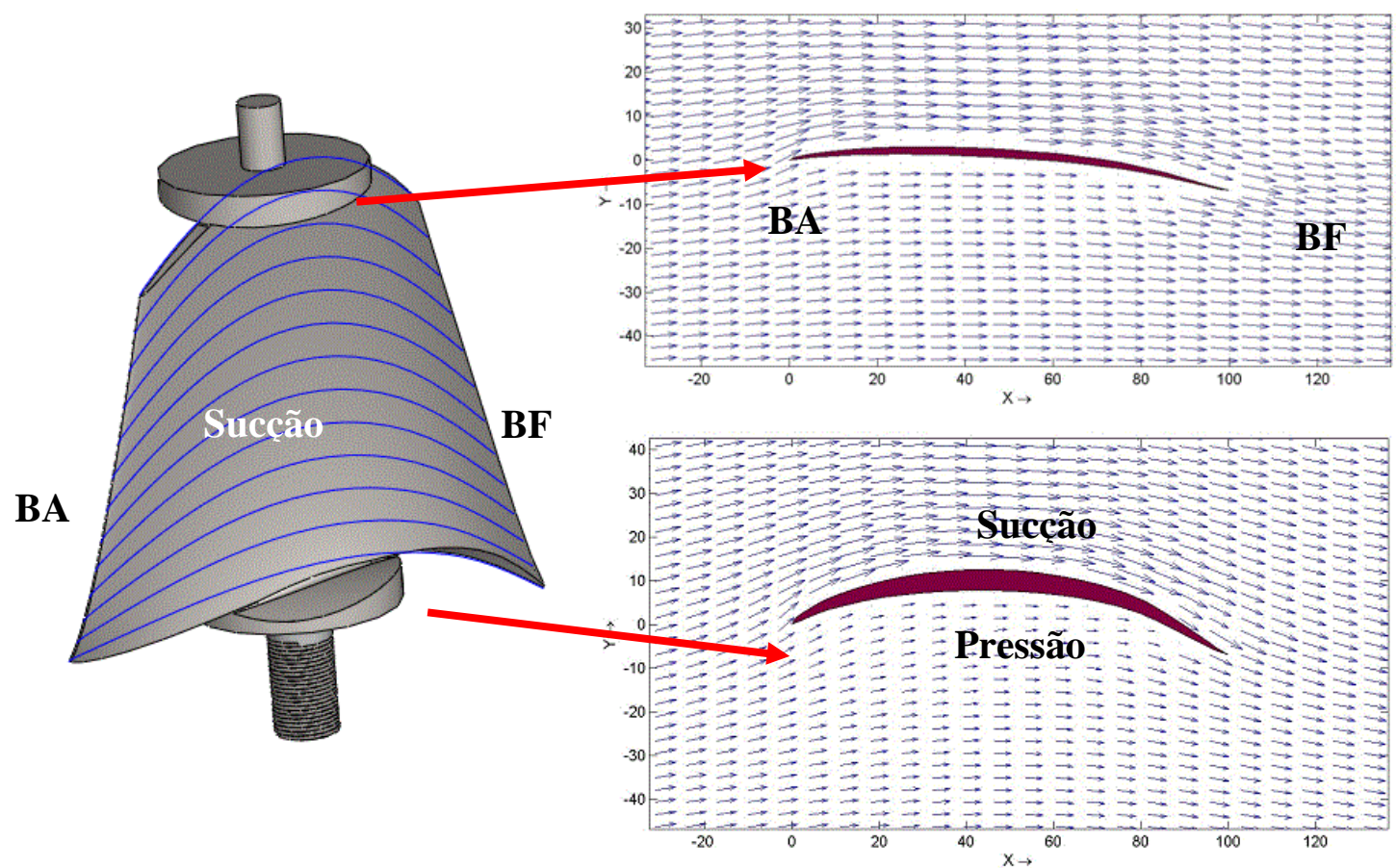

Figura 4.13 Vetores Velocidade para duas Seções Planificadas do Rotor

O métodos dos painéis foi executado utilizando o software Matlab e foi possível através de recursos internos reproduzir os vetores velocidade que cruzam os perfis como pode se visualizar na figura 4.13. É possível notar como os vetores tem tamanhos maiores no lado de sucção dos perfis bem como a diferença de espessura máxima entre os perfis. Fica nítido também a diferença entre os arqueamentos dos perfis (ver tabela 4.4 - Valores de $f_{0}$ ).

As siglas $\mathrm{BA}$ e $\mathrm{BF}$ na figura 4.13 significam bordo de ataque e bordo de fuga respectivamente. 
O ângulo de incidência para o perfil em $\chi=0,4$ é $\alpha_{i n c}=2,63^{\circ}$ e em $\chi=1,0$ é $\alpha_{i n c}=0,97^{\circ}$.

Como dito anteriormente, a ideia é usarmos o método dos painéis que é amplamente conhecido para verificar a teoria usada para o cálculo das pás, chamado de método analítico. Deve ser mencionado que o método dos painéis e o método analítico em estudo partem de métodos de escoamentos potenciais e por isso as soluções devem próximas.

A figura 4.14 mostra a comparação do coeficiente de sustentação $C_{L}$ entre o método dos painéis e método analítico para o rotor e distribuidor.
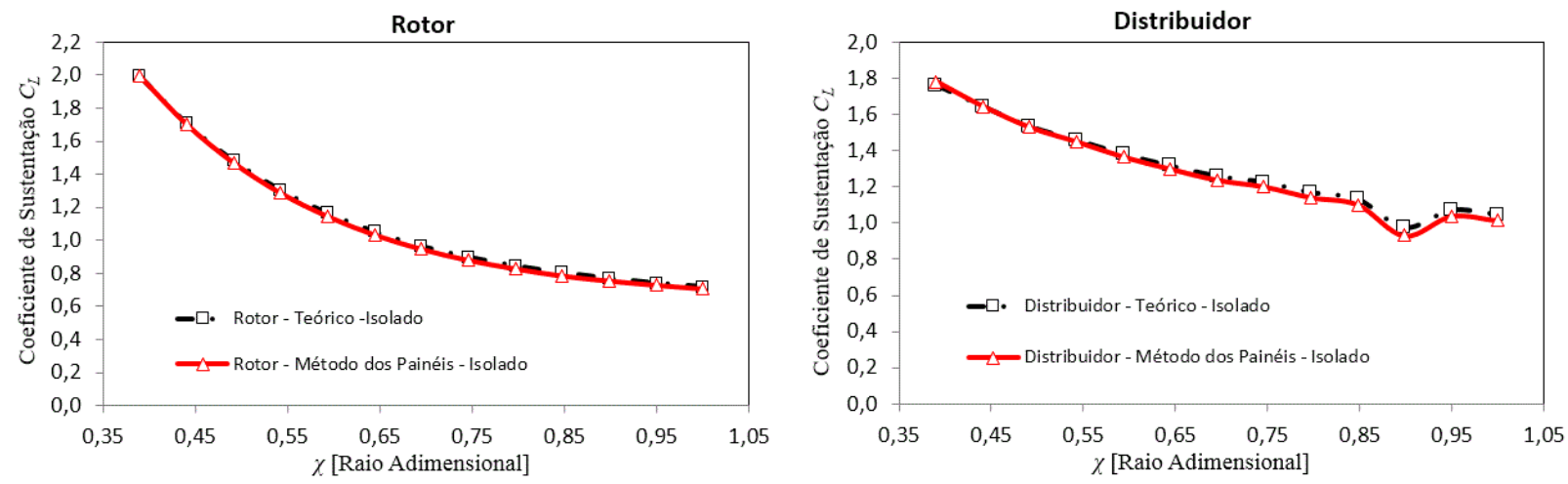

Figura 4.14 Comparação - Método dos Painéis versus Método Analítico (Teórico) - Perfil Isolado.

Mais uma vez podemos perceber para os dois casos a queda do coeficiente de sustentação conforme se chega a ponta da pá.

Existe conforme esperado uma boa conformidade entre os dois métodos, lembrando que estamos comparando o coeficiente de sustentação para o perfil isolado. Esta boa aderência entre os métodos é um bom indicativo da qualidade do projeto das superfícies já que a potência da turbina é obtida através do coeficiente de sustentação como vimos no capitulo 3.1.4.

A figura 4.15 mostra a comparação dos resultados para os perfis em cascata do rotor e distribuidor mostrando uma melhor aderência na comparação dos resultados para o rotor.
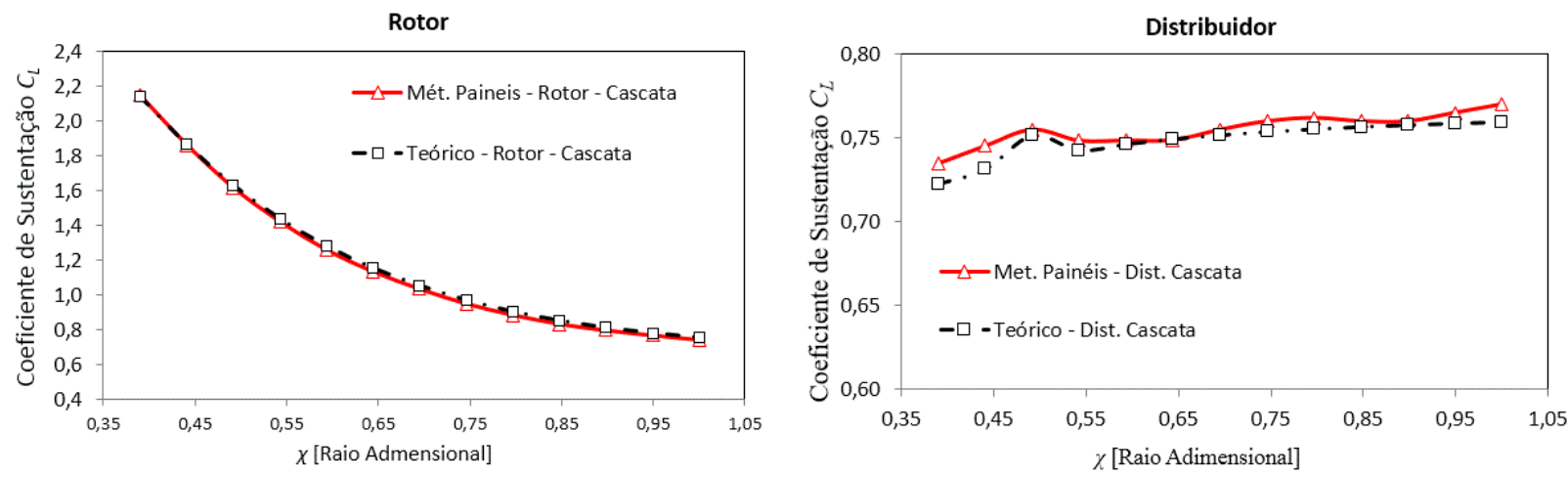

Figura 4.15 Comparação - Método dos Painéis versus Método Analítico (Teórico) - Perfis em Cascata 


\subsection{ENSAIOS DE CAMPO}

Os ensaios da máquina foram realizados nos dias 12 e 13 de junho de 2013 para três condições de carga. Para cada condição de carga houve a variação da abertura do distribuidor entre 0 a 100\% e medições de queda, vazão, potência e outras grandezas pertinentes foram realizadas.

Geralmente um ensaio de eficiência, segundo IEC 60041 (1991) se faz com uma única condição de carga para depois se comparar o resultado com o projeto ou ensaio de modelo, quando existe um. Neste caso, como não existe ensaio de modelo reduzido se resolveu ensaiar a máquina em várias condições possíveis de carga de modo que se possa adquirir um maior conhecimento sobre o comportamento hidráulico da máquina em várias condições.

O capitulo 3.2 apresentou as grandezas relevantes ao ensaio da turbina e como é o procedimento para obtenção dessas grandezas. Logo o objetivo aqui é somente apresentar os resultados pertinentes com discussões em relação a comparação entre o ensaio e o projeto.

\subsubsection{Localização dos Sensores}

Este item tem como objetivo mostrar os pontos medidos no ensaio da unidade geradora e algumas fotos da instalação como um todo. As explicações sobre qual sensor estão mostradas nas fotos estão nos quadros abaixo para melhor síntese e visualização.

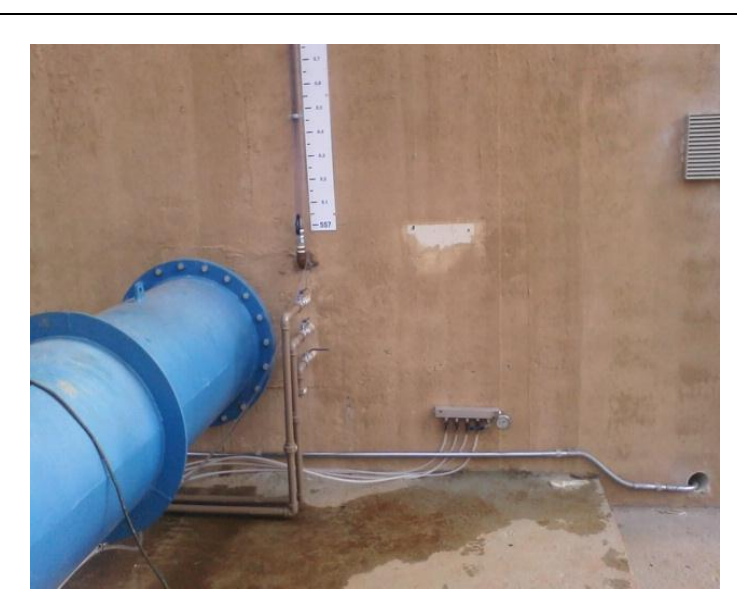

Foto 1. Medição do Nível de Montante e Pressão na Entrada da Turbina $\left(\mathrm{P}_{1}\right)$.

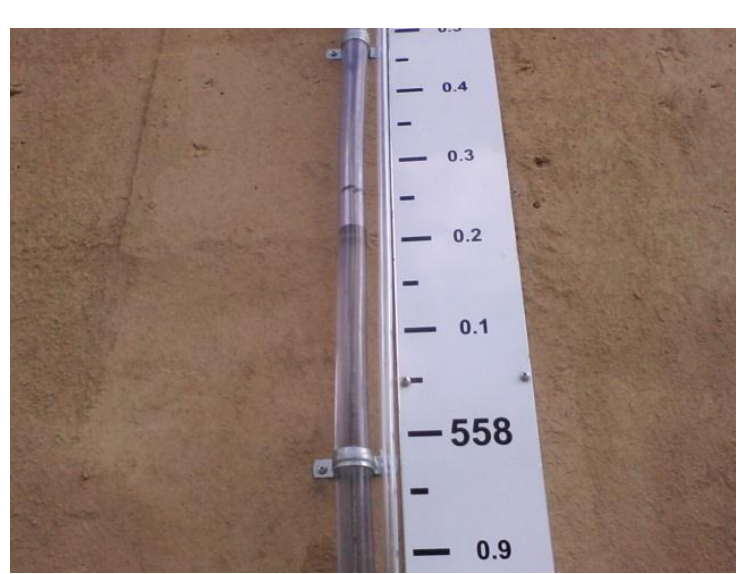

Foto 2. Medição do Nível de Montante e Pressão de Entrada ( $\left.\mathrm{P}_{1 \text { nível }}\right)$. 


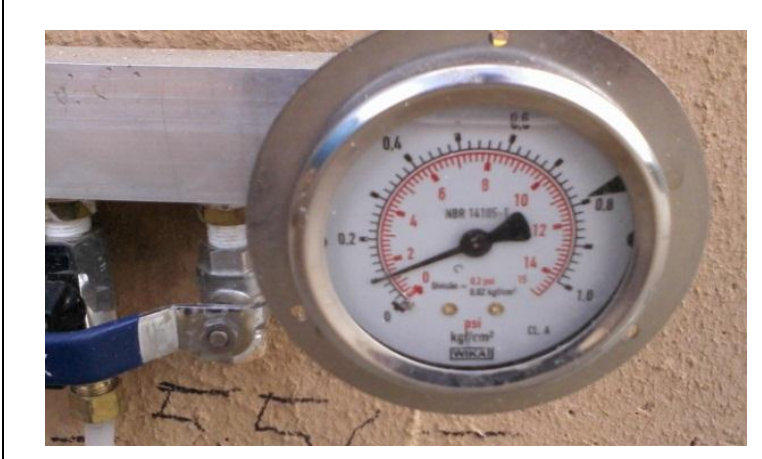

Foto 3. Manômetro para medição de P1 (0-1 bar).

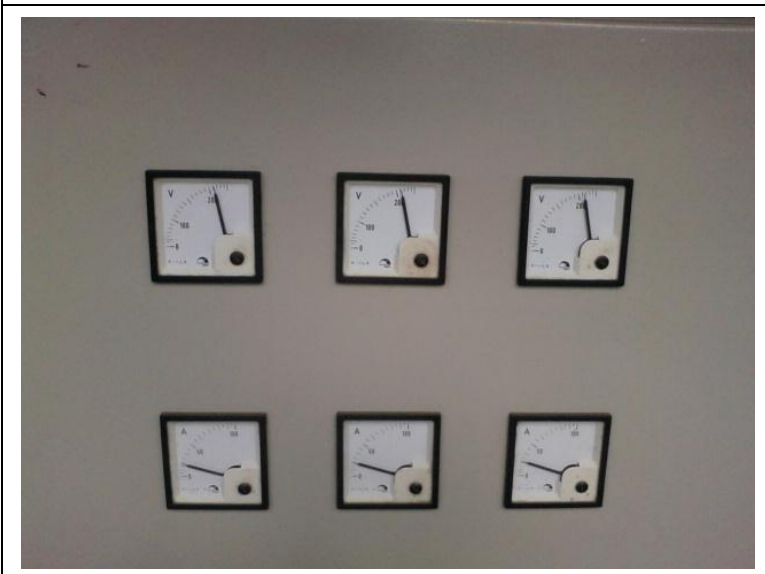

Foto 5. Medidor de tensão e corrente das três fases da unidade geradora.

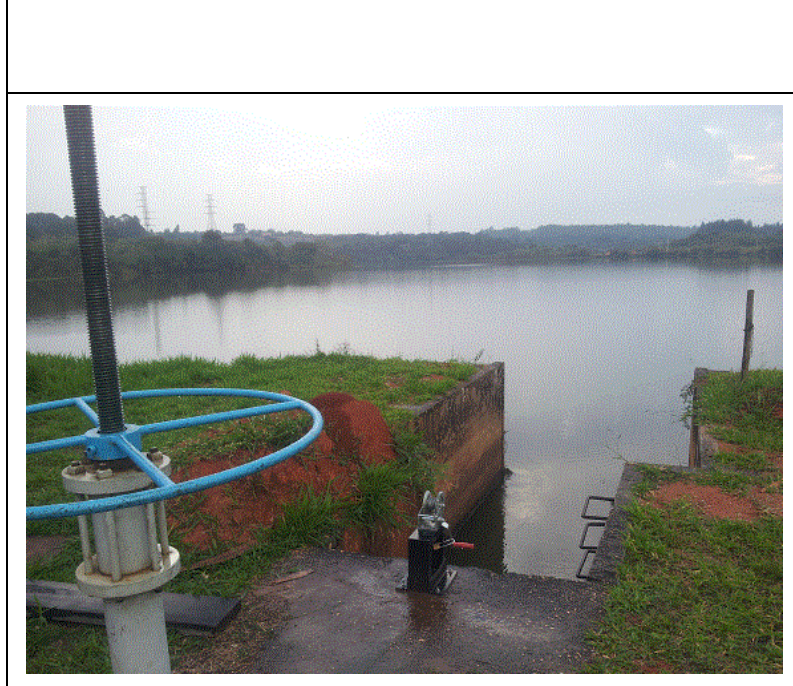

Foto 7. Reservatório do Rio Ipanema que abastece o tanque de Montante.

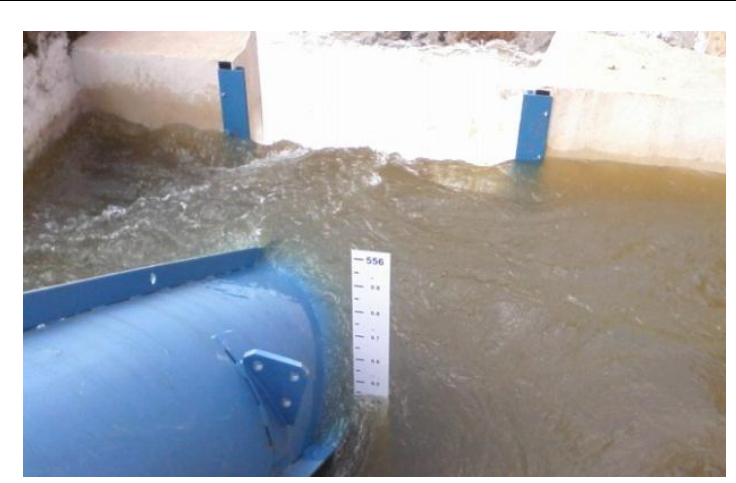

Foto 4. Nível de Jusante obtido através de

Régua de Nível com relação ao nível do mar.

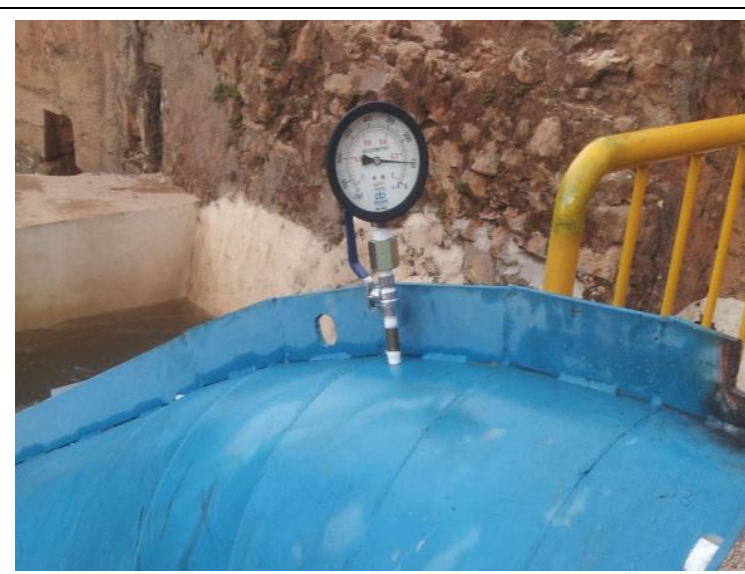

Foto 6. Vacuômetro (Faixa de -1 a 0 bar) para medição da Oscilação de Pressão no Tubo de Sucção

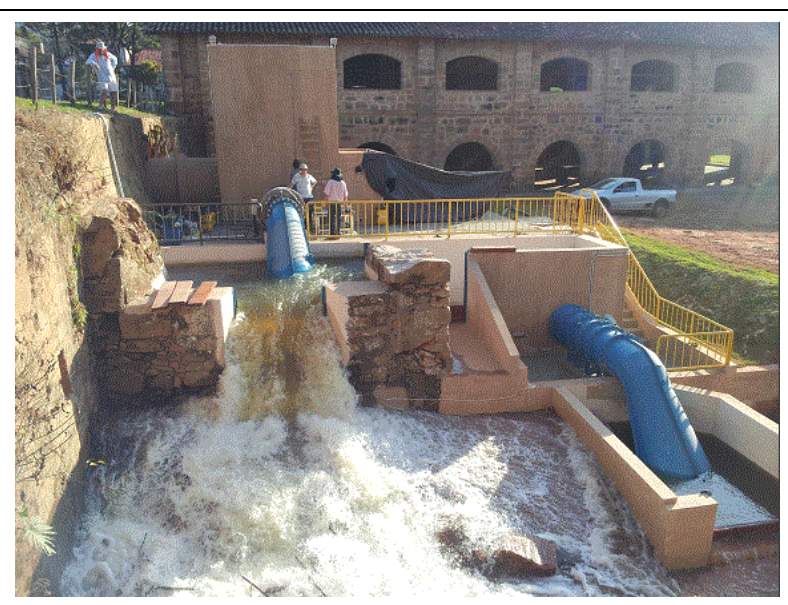

Foto 8. Vista Frontal da Máquina em Operação. 


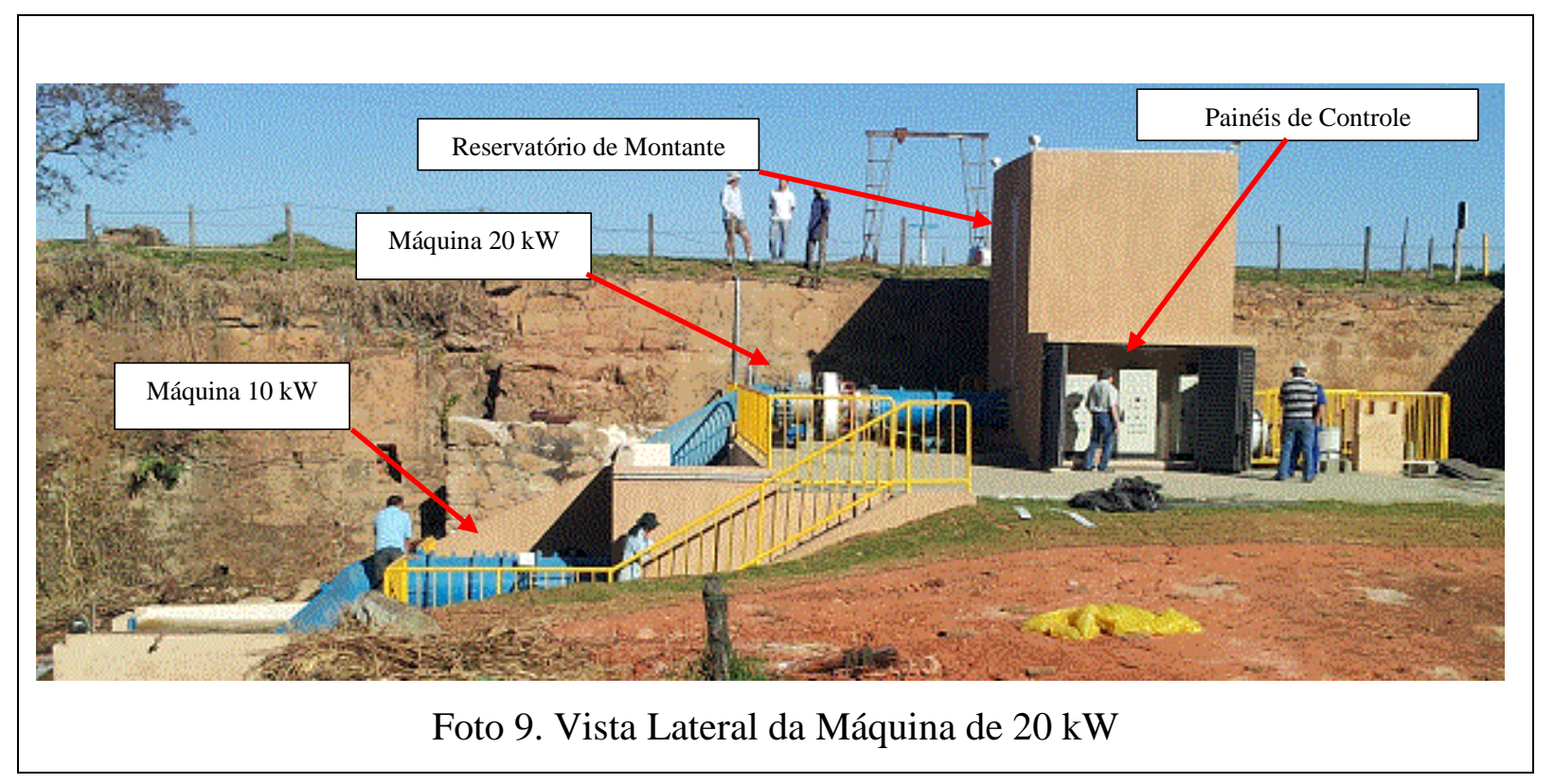

\subsubsection{Resultados do Ensaio}

O principal resultado deste ensaio é a comparação do ponto de projeto com o alcançado em campo. No entanto durante o ensaio complicações de operação, incertezas nas medições, erro na instalação dos equipamentos, perdas no escoamento não previstas e outros desvios podem resultar em um rendimento impreciso. Logo todos esses desvios devem ser levados em conta para que se possa "isolar" a turbina e que seu ponto possa ser comparado com certa precisão.

Também é objetivo do ensaio verificar o comportamento da turbina no maior numero de condições de carga possível para que a operação seja otimizada e qualquer tipo de instabilidade hidráulica e mecânica seja evitada, como por exemplo, oscilação de pressão e eixo em alguns pontos de medição.

Os resultados do ensaio estão, em sua maioria, em função da queda bruta $H_{g}$ e não da queda liquida $H_{l}$ como geralmente é feito em ensaios de rendimento. A razão para isso é totalmente operacional, devido a facilidade de se mensurar em campo rapidamente a diferença entre os níveis de montante e jusante.

A tabela 4.5 a seguir mostra a conversão para as três condições de carga com seus valores médios de queda medidos. 
Tabela 4.5 Quedas observadas no Ensaio da Máquina de 20 kW.

\begin{tabular}{c|c|c}
\hline Queda Líquida média & Queda Bruta média & Perda de Carga Média \\
\hline $2,68 \mathrm{~m}$ & $2,90 \mathrm{~m}$ & $0,22 \mathrm{~m}$ \\
\hline $2,90 \mathrm{~m}$ & $3,15 \mathrm{~m}$ & $0,25 \mathrm{~m}$ \\
\hline $3,29 \mathrm{~m}$ & $3,60 \mathrm{~m}$ & $0,31 \mathrm{~m}$ \\
\hline
\end{tabular}

Deve ser mencionado que o ensaio não foi realizado através de médias de séries temporais como é feito atualmente e que conferem à medição uma maior precisão dos dados medidos. Como o intuito do ensaio foi coletar dados sem grandes impactos financeiros na compra de sensores e sistemas de aquisição de dados o ensaio foi feito coletando dados manualmente, ou seja, um ponto de cada grandeza pertinente por faixa operativa depois que as condições para cada faixa fossem estabilizadas. Isso confere ao ensaio uma maior incerteza, porém não invalida o ensaio já que esse mesmo método foi amplamente utilizado para determinação das instalações mais antigas.

O comportamento da turbina pode ser verificado na figura 4.16 com a vazão e abertura do distribuidor. A condição de carga máxima medida (Queda bruta média $H g=3,60 \mathrm{~m}$ ) apresentou maiores valores de potência (Potência Máxima: 21,57kW).
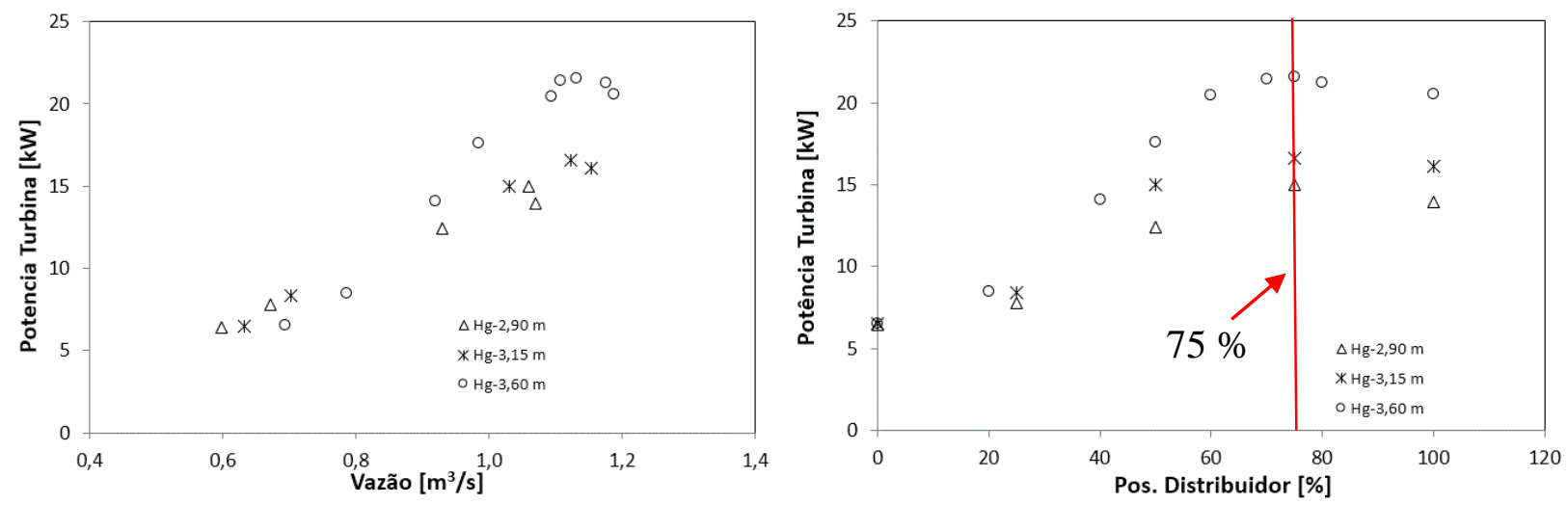

Figura 4.16 Comportamento da Potência da Turbina em função da vazão e posição do distribuidor.

A condição de projeto da máquina estabelece que para $75 \%$ de abertura do distribuidor a unidade ofereça potência máxima para a queda de projeto $\left(H_{g}=3,03 \mathrm{~m}\right)$, fato esse que pode ser constatado na figura 4.16 para as três condições de carga medidas. 
Devido a época do ano em que os ensaios foram realizados as condições de carga não foram as máximas possíveis para a instalação, na época de cheia acredita-se que a queda bruta possa ultrapassar os 4 metros e fica a oportunidade para verificação das condições de operação da máquina, já que se espera uma queda de rendimento devido a distância da queda líquida nominal.

A eficiência global da turbina $\eta_{G}$ envolve as perdas viscosas entre a entrada da turbina e a saída do tubo de sucção. A figura 4.16 mostra o seu comportamento em função da abertura do distribuidor a $a_{0}$. Podemos notar que embora há uma diferença de queda considerável entre as três condições de carga medidas, as curvas de rendimento não mostram essa disparidade com valores ligeiramente superiores para a curva de $\mathrm{Hg}=3,60$ metros.

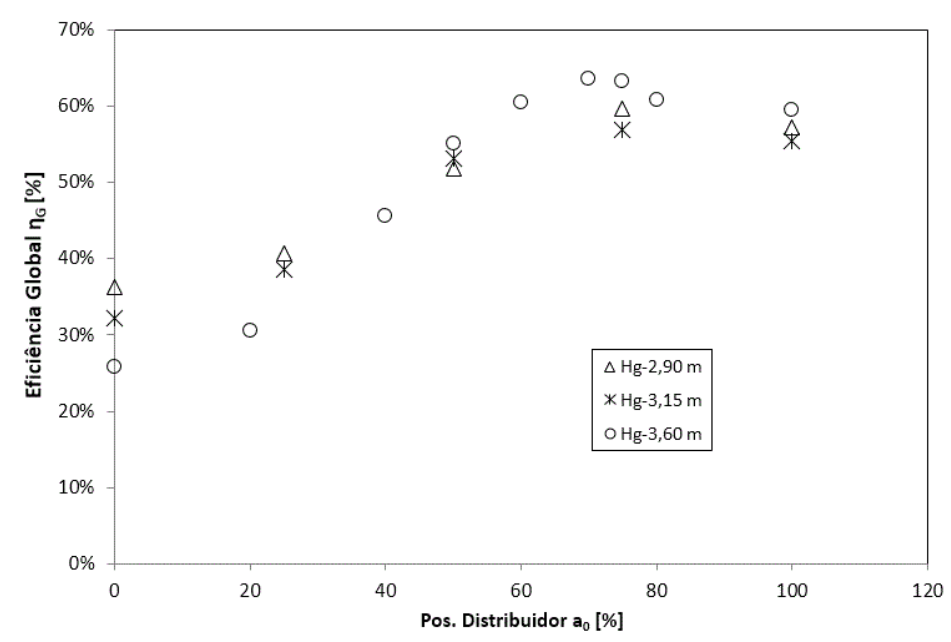

Figura 4.17 Eficiência Global da Turbina versus Abertura do Distribuidor.

A eficiência hidráulica do rotor $\eta_{H}$ é definida como a relação entre a energia útil no rotor e as perdas entre a entrada da turbina e saída do tubo de sucção, por isso tem seu valor superior a eficiência global $\eta_{G}$. Como as medições não envolvem os pontos entre a entrada e a saída do rotor, essa eficiência deve ser estimada para comparação com o projeto. De acordo com o projeto, para o ponto nominal ( $\mathrm{Hg}=3,03$ metros) a eficiência hidráulica do rotor é de $90 \%$ e esse valor foi alcançado no ensaio, ver figura 4.18 para as três quedas medidas se considerarmos um erro de medição em torno de $\pm 5 \%$. 


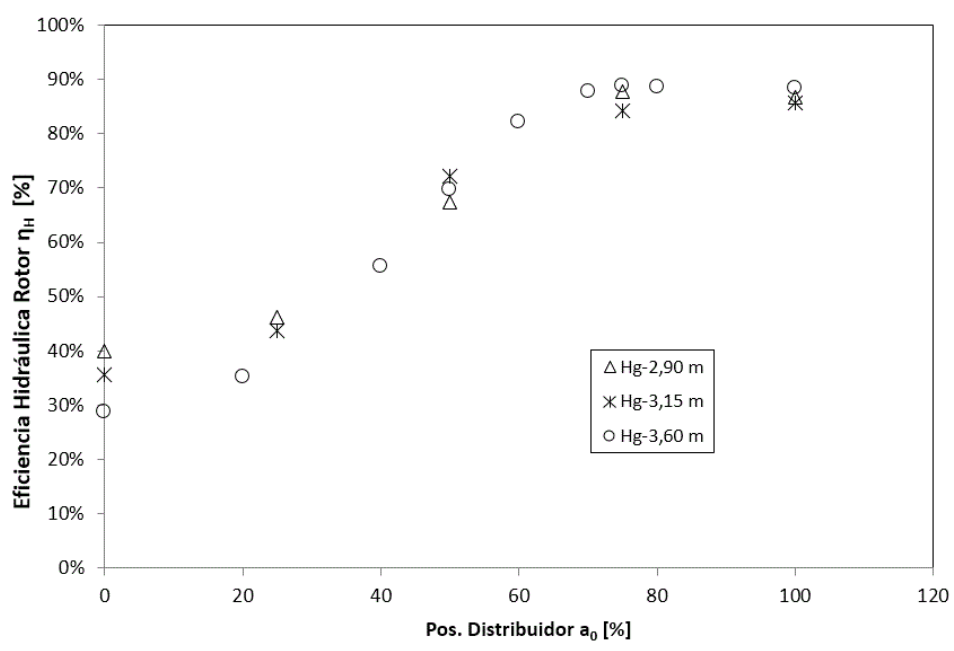

Figura 4.18 Eficiência Hidráulica do Rotor

Ao contrário da eficiência global a eficiência hidráulica do rotor foi obtida analiticamente de acordo com as perdas estimadas analiticamente descontando-as da queda liquida para cada ponto de medição.

A tabela 4.6 mostra as perdas estimadas para o ponto de eficiência ótima calculadas no circuito da turbina com dimensões mostradas no anexo 2 e com fatores de perda de carga retirados da referência IDELCHIK (1966) e logo abaixo a percentagem da queda total.

Tabela 4.6 Perdas no Circuito da Turbina - Maquina de $20 \mathrm{~kW}$

\begin{tabular}{cccc}
\hline $\begin{array}{c}\text { Perdas Viscosas no } \\
\text { Interior da Turbina }\end{array}$ & $\begin{array}{c}\text { Queda Útil } \\
\text { no Rotor }\end{array}$ & $\begin{array}{c}\text { Perdas no Tubo } \\
\text { de Sucção }\end{array}$ & Queda Total \\
$\Delta \mathrm{h}_{\text {viscosa }}$ & $\Delta \mathrm{h}_{\text {util }}$ & $\Delta \mathrm{h}_{\text {suç̧ão }}$ & $\Delta \mathrm{H}_{\text {total }}$ \\
\hline$[\mathrm{m}]$ & {$[\mathrm{m}]$} & {$[\mathrm{m}]$} & {$[\mathrm{m}]$} \\
\hline $4,574 \mathrm{E}-01$ & $2,268 \mathrm{E}+00$ & $3,00 \mathrm{E}-01$ & $3,026 \mathrm{E}+00$ \\
$15,12 \%$ & $74,96 \%$ & $9,92 \%$ & $100,00 \%$ \\
\hline \hline
\end{tabular}

O anexo 1 mostra os dados de medição das três condições de queda referente as figuras 4.16, 4.17 e 4.18 .

Para efeitos de comparação do projeto hidráulico da turbina com o ensaio de campo foi usado a eficiência global já que não é necessária nenhuma estimativa como a eficiência hidráulica do rotor. Para tal devemos converter a queda observada no ensaio mais próxima da queda liquida nominal de acordo com IEC 60041 (1991). 
As vazões e potências da turbina devem ser convertidas segundo as relações:

$$
\begin{aligned}
& Q_{r}=Q \cdot\left(\frac{H_{l}}{H_{n}}\right)^{1 / 2} \\
& P_{r}=P_{t} \cdot\left(\frac{H_{l}}{H_{n}}\right)^{1 / 2}
\end{aligned}
$$

Onde $Q_{r}$ e $P_{r}$ são as vazões e potências convertidas para a queda de referencia $H_{r}$, que é a queda nominal de projeto.

Tabela 4.7 Conversão dos dados de medição para a queda nominal de projeto $\mathrm{Hr}=2,57$ metros.

\begin{tabular}{c|c|c|c|c|c}
\hline $\begin{array}{c}\text { Vazão } \\
\mathrm{Q}\left[\mathrm{m}^{3} / \mathrm{s}\right]\end{array}$ & $\begin{array}{c}\text { Pot. Turbina } \\
\mathrm{P}_{\mathrm{t}}[\mathrm{kW}]\end{array}$ & $\begin{array}{c}\text { Vazão } \\
\mathrm{Q}_{\mathrm{r}}\left[\mathrm{m}^{3} / \mathrm{s}\right]\end{array}$ & $\begin{array}{c}\text { Pot. Turbina } \\
\mathrm{P}_{\mathrm{r}}[\mathrm{kW}]\end{array}$ & $\begin{array}{c}\text { Queda Líquida } \\
\mathrm{H}_{1}[\mathrm{~m}]\end{array}$ & $\begin{array}{c}\text { Eficiência Global } \\
\eta_{s}[\%]\end{array}$ \\
\hline 0,60 & 6,42 & 0,55 & 4,98 & 3,04 & 30,59 \\
\hline 0,67 & 7,80 & 0,63 & 6,40 & 2,93 & 35,67 \\
\hline 0,93 & 12,40 & 0,92 & 11,87 & 2,64 & 50,29 \\
\hline 1,06 & 14,98 & 1,09 & 16,26 & 2,43 & 63,01 \\
\hline 1,07 & 13,93 & 1,12 & 16,08 & 2,33 & 63,07 \\
\hline
\end{tabular}

O gráfico da figura 4.19 mostra os valores da tabela acima em comparação com o ponto de eficiência de projeto. E de acordo com a barra de erros a eficiência medida está de acordo com o projeto.

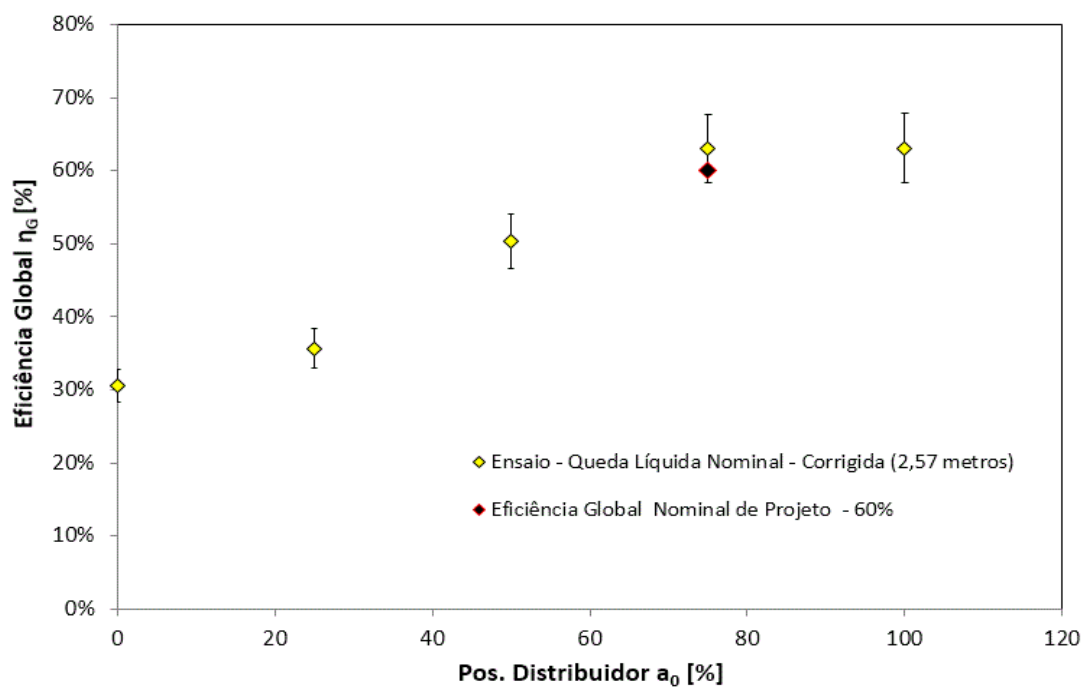

Figura 4.19 Eficiência Global - Comparação com Projeto. 


\section{CONCLUSÕES E RECOMENDAÇÕES}

Um método analítico para determinação de superfícies aplicado a seções de pás do distribuidor e do rotor de uma micro turbina hidráulica foi apresentado. A revisão bibliográfica apresentou os coeficiente e relações necessárias para a determinação das superfícies citando as referências pertinentes. O projeto de uma turbina hidrelétrica de $20 \mathrm{~kW}$ de potência nominal com queda líquida nominal de 2,57 metros e vazão de $1,15 \mathrm{~m}^{3} / \mathrm{s}$ foi utilizada como base do estudo.

A determinação de superfícies para este tipo de aplicação requer um estudo das velocidades de incidência para cada seção da geometria. As seções são posicionadas levando em conta a variação radial do escoamento e um critério de cavitação que leva em conta a velocidade tangencial às pás, que apresentou resultados satisfatórios.

Para comprovação e verificação do método analítico apresentado, um tipo de método dos painéis bidimensionais, o método de vorticidade superficial exposto em LEWIS (1991), foi utilizado mostrando boa aderência nas curvas do coeficiente de sustentação das pás, que é fator preponderante para a obtenção da potência da unidade geradora como apresentado no capitulo 3.2.3.

A parte experimental do trabalho foi realizada através de um ensaio de campo utilizando três condições de queda para as quais a performance da turbina foi testada em função da vazão e abertura do distribuidor, comparando os resultados com o que foi projetado analiticamente. Embora tenha sido um ensaio mais simples, sem equipamentos de medição modernos, o ensaio foi eficiente em determinar as principais características hidráulicas da máquina.

Desta forma o projeto das superfícies do rotor e distribuidor pode ser extrapolado para o projeto de turbinas axiais de potencias superiores à estudada já que houve boa concordância entre os resultados do cálculo analítico, o cálculo numérico pelo método da vorticidade e o ensaio de campo. 
Um ensaio adicional foi executado para verificação do efeito da admissão de ar pelo tubo de sucção em paralelo ao ensaio de rendimento como tentativa de solucionar as oscilações de pressão e ruídos que estavam presentes em praticamente toda a faixa operativa da máquina, ver Anexo 2. No comparativo da máquina com e sem admissão de ar podemos concluir que a admissão de ar ameniza substancialmente as oscilações de pressão e ruído como uma ligeira perda de rendimento próximo ao ponto ótimo. Logo como recomendação a unidade deve usar a admissão de ar pelo tubo de sucção em toda faixa operacional visando o aumento da vida útil da mesma.

A instalação utilizada na Fazenda Ipanema foi adaptada para receber a unidade geradora que já estava pronta com horas de operação no Centro Tecnológico da Hidráulica CTH-USP, e em decorrência foram observadas perdas no trecho de captação e saída da sucção maiores do que seriam em uma instalação projetada juntamente com a máquina, porém o objetivo para essa faixa de carga é o uso de instalações sem grandes impactos de obras civis em detrimento de possíveis perdas no escoamento.

Como recomendação para a continuidade do trabalho sugerem-se estudos levando em conta os efeitos viscosos do escoamento ao longo da turbina através de Dinâmica dos Fluidos Computacional (CFD), já que o método analítico e dos painéis são baseados em escoamentos incompressíveis e não-viscosos.

Outra recomendação é um estudo dinâmico da unidade para se conhecer melhor as flutuações de pressão e eixo presentes devido a instabilidades do escoamento, determinando restrições operativas ou soluções como por exemplo admissão de ar pela sucção que se mostrou muito eficiente nos ensaios.

Uma alternativa ao projeto do distribuidor com torção radial que está presente neste trabalho seria um projeto com velocidade tangencial constante que resulta em uma geometria sem torção no distribuidor. Neste caso teríamos uma velocidade axial variável com o raio após a passagem do escoamento pelo distribuidor e, em consequência as linhas de corrente não mais se situariam em cilindros concêntricos. No entanto um projeto de distribuidor sem torção necessita de um ajuste nos perfis do rotor, logo a decisão de usar esse tipo de geometria deve ser feita no projeto básico da máquina. É uma alternativa econômica já que a torção radial implica em pás confeccionadas a partir do processo de fundição que tem um custo maior se comparado a um processo de estampagem que pode ser usado em pás não torcidas radialmente. 


\section{LISTA DE REFERÊNCIAS}

ABBOTT, I. H. (1958). Theory of Wing Sections. New York: Dover Publications.

ALBUQUERQUE, R. B. (2006). Projeto de Turbinas Hidráulicas Axiais com Parametrização da Geometria, Equação de Equilíbrio Radial e Técnicas de Otimização. Itajubá: UNIFEI Tese de Mestrado.

BRESLIN, J. P. (1961). A Manual For Calculation Of Inception of Cavitation on Two And Three Dimensional Forms. New York: The Society od Naval Architects and Marine Engineers.

BROCKETT, T. (1966). Minimum pressure envelopes for modified NACA-66 sections with NACA a 1/4 0.8 camber and buships type I and II sections. Washington, D.C: DTMB.

CARPENTER, H. (2003). Aerodynamics for Engineering Students. Oxford: ButterworthHeinemann.

ELETROBRÁS. (1999). Diretrizes para Estudos e Projeto de Pequenas Centrais Hidrelétricas. Rio de Janeiro.

FERNANDO CASANOVA, C. A. (2010). Análisis experimental de la vibración en el tubo de aspiración de una turbina hidráulica Francis durante operación a diferentes niveles de potencia. Rev. Fac. Ing. Univ. Antioquia, pp. 90-98.

FERRO L.M.C, G. L. (2011). Design of the rotor blades of a mini hydraulic bulb-turbine. Renewable Energy, 1-9.

FOX R.W, M. A. (2006). Introdução a Mecânica dos Fluidos. London: Livros Técnicos e Científicos, Editora LTC.

GHOSE, J. (2004). Basic Ship Propulsion. New Delhi: Allied Publishers.

GOSTELOW, J. (1984). Cascade Aerodynamics. Sydney, Australia: Pergamon Press. 
HORLOCK, J. (1973). Axial Flow Compressors. London: Butterworks.

IDELCHIK, I. E. (1966). Handbook of Hydrauli Resistance. New York: Begell House.

INTERNATIONAL ELECTROTECHNICAL COMMISSION, I. 6. (1991). Field acceptance tests to determine the hydraulic performance of hydraulic turbines, storage pumps and pumpturbines. IEC 60041 International Standard. IEC.

JUSTINO, L. A. (2006). Estudos de Procedimentos de ensaios de Campo em Turbinas Hidráulicas para PCH. Itajubá: Unifei.

KRUPPA, C. F. (1969). High Speed Propellers Hydrodynamics and Design. Michigan: The University of Michigan.

LEWIS, R. (1991). Vortex Element Methods for Fluid Dynamic Analysis of Engineering Systems. New York: Cambridge.

MAGNOLI, M. V. (2005). Cálculo das velocidades críticas da linha de eixo de turbinas hidráulicas com ênfase no comportamento dinâmico do gerador. São Paulo: Tese de Mestrado - Escola Politécnica da USP.

NBR11374, A. (1990). Turbinas hidráulicas - Ensaio de campo. Rio de Janeiro: ABNT.

PROGRAM, HYDRAULIC ENERGY. (2004). Micro Hydropower Systems - A Buyer's Guide. Canada Gov.

RUPRECHT, A. (2000). Unsteady Flow Analysis in Hydraulic Turbomachinery. Charlotte: IAHR Symposium.

SABERSKY, R. H., \& ACOSTA, A. J. (1964). Fluid Flow, A First Course in Fluid Mechanics. Portlan: Prentice Hall.

SIMONE, G. (2000). Centrais e Aproveitamentos Hidrelétricos. São Paulo: Érica. 
SOUZA, Z. (1999). PCH de Baixa Queda. Grupo de Trabajo sobre Hidromecânica.

TWHAITES, B. (1987). Incompressible aerodynamics. Oxford: Dover.

VOITH. (2004). Voith Brochures. Heidenheim, Germany: Voith AG. 


\section{Anexo 1. Dados do Ensaio de Campo}

\begin{tabular}{|c|c|c|c|c|c|c|c|c|c|c|c|c|c|c|c|c|c|c|}
\hline Data & Hora & $\begin{array}{l}\text { Pos. } \\
\text { Distrib }\end{array}$ & $\begin{array}{c}\text { Nível } \\
\text { Montante }\end{array}$ & $\begin{array}{c}\text { Nível } \\
\text { Jusante }\end{array}$ & $\begin{array}{l}\text { Altura } \\
\text { Crista }\end{array}$ & $\begin{array}{l}\text { Pressão } \\
\text { Entrada }\end{array}$ & Rotação & $\begin{array}{l}\text { Potência } \\
\text { Gerador }\end{array}$ & $\begin{array}{l}\text { Potência } \\
\text { Turbina }\end{array}$ & Vazão & $\begin{array}{l}\text { Queda } \\
\text { Líquida }\end{array}$ & $\begin{array}{l}\text { Efic. } \\
\text { Global }\end{array}$ & $\begin{array}{l}\text { Eficiência } \\
\text { Hidráulica } \\
\text { Rotor }\end{array}$ & $\begin{array}{l}\text { Queda } \\
\text { Bruta } \\
\text { Média }\end{array}$ & $\begin{array}{l}\text { Queda } \\
\text { Bruta }\end{array}$ & $\begin{array}{l}\text { Perda } \\
\text { de } \\
\text { Carga }\end{array}$ & $\begin{array}{l}\text { Efic. } \\
\text { Gerador }\end{array}$ & $\begin{array}{c}\text { Perda } \\
\text { Eixo }\end{array}$ \\
\hline & & $\begin{array}{c}a_{0} \\
{[\%]}\end{array}$ & $\begin{array}{c}N_{M} \\
{[\mathrm{~m}]}\end{array}$ & $\begin{array}{c}N_{j} \\
{[\mathrm{~m}]}\end{array}$ & $\begin{array}{c}h \\
{[\mathrm{~m}]}\end{array}$ & $\begin{array}{c}P_{1} \\
{[\mathrm{~m}]}\end{array}$ & $\begin{array}{c}n \\
{[\mathrm{rpm}]}\end{array}$ & $\begin{array}{c}P_{e l} \\
{[\mathrm{~kW}]}\end{array}$ & $\begin{array}{c}P_{t} \\
{[\mathrm{~kW}]}\end{array}$ & $\begin{array}{c}Q \\
{\left[\mathrm{~m}^{3} / \mathrm{s}\right]}\end{array}$ & $\begin{array}{l}H_{\text {net }} \\
{[\mathrm{m}]}\end{array}$ & $\begin{array}{c}\eta_{G} \\
{[\%]}\end{array}$ & $\begin{array}{c}\eta_{H} \\
{[\%]}\end{array}$ & $\begin{array}{c}H_{g} \\
{[\mathrm{~m}]}\end{array}$ & $\begin{array}{c}H_{g} \\
{[\mathrm{~m}]}\end{array}$ & $\begin{array}{c}d P \\
{[\mathrm{~mm}]}\end{array}$ & $\begin{array}{c}\eta_{G} \\
{[\%]}\end{array}$ & $\begin{array}{c}P_{f} \\
{[\mathrm{~W}]}\end{array}$ \\
\hline $2 / 06 / 2013$ & $16: 05$ & 0 & 558,26 & 555,14 & 0,35 & 558,12 & 210,75 & 2,93 & 6,42 & 0,60 & 3,04 & $36,24 \%$ & $40,02 \%$ & & 3,13 & 81,95 & $45,92 \%$ & 44,53 \\
\hline $12 / 06 / 2013$ & $16: 10$ & 25 & 558,25 & 555,20 & 0,38 & 558,00 & 302,25 & 6,25 & 7,80 & 0,67 & 2,93 & $40,71 \%$ & $46,18 \%$ & & 3,05 & 118,63 & $80,70 \%$ & 60,85 \\
\hline $12 / 06 / 2013$ & $16: 16$ & 50 & 558,25 & 555,33 & 0,47 & 557,60 & 403,50 & 11,42 & 12,40 & 0,93 & 2,64 & $51,79 \%$ & $67,42 \%$ & 2,9 & 2,92 & 280,43 & $92,64 \%$ & 80,11 \\
\hline $12 / 06 / 2013$ & $16: 23$ & 75 & 558,20 & 555,39 & 0,51 & 557,27 & 439,50 & 13,50 & 14,98 & 1,06 & 2,43 & $59,67 \%$ & $87,74 \%$ & & 2,82 & 382,90 & $90,65 \%$ & 88,31 \\
\hline $12 / 06 / 2013$ & $16: 28$ & 100 & 558,17 & 555,45 & 0,51 & 557,00 & 423,00 & 12,63 & 13,93 & 1,07 & 2,33 & $57,30 \%$ & $86,67 \%$ & & 2,72 & 391,79 & $91,20 \%$ & 84,43 \\
\hline $3 / 06 / 2013$ & $11: 49$ & 0 & 558,3 & 554,93 & 0,36 & 558,13 & 215,25 & 3,15 & 6,50 & 0,63 & 3,28 & $32,23 \%$ & $35,65 \%$ & & 3,37 & 97,06 & $48,79 \%$ & 45,38 \\
\hline $3 / 06 / 2013$ & $11: 54$ & 25 & 558,29 & 554,98 & 0,39 & 557,95 & 321,00 & 7,29 & 8,37 & 0,70 & 3,18 & $38,50 \%$ & $43,64 \%$ & & 3,31 & 133,73 & $87,75 \%$ & 64,16 \\
\hline $13 / 06 / 2013$ & $11: 58$ & 50 & 558,24 & 555,08 & 0,50 & 557,48 & 435,75 & 13,50 & 14,98 & 1,03 & 2,81 & $53,20 \%$ & $72,21 \%$ & 3,15 & 3,16 & 357,55 & $90,65 \%$ & 87,41 \\
\hline $13 / 06 / 2013$ & $12: 02$ & 75 & 558,23 & 555,13 & 0,53 & 557,10 & 459,75 & 15,03 & 16,59 & 1,12 & 2,67 & $56,87 \%$ & $84,14 \%$ & & 3,11 & 434,68 & $91,09 \%$ & 93,38 \\
\hline $13 / 06 / 2013$ & $12: 11$ & 100 & 558,2 & 555,16 & 0,54 & 556,96 & 446,25 & 14,55 & 16,09 & 1,15 & 2,58 & $55,49 \%$ & $85,77 \%$ & & 3,05 & 463,80 & $90,94 \%$ & 89,96 \\
\hline $7 / 06 / 2013$ & $13: 12$ & 0 & 558,78 & 554,92 & 0,38 & 558,63 & 189,75 & 3,27 & 6,53 & 0,69 & 3,75 & $25,79 \%$ & $28,71 \%$ & & 3,86 & 116,53 & $50,34 \%$ & 40,54 \\
\hline $7 / 06 / 2013$ & $13: 17$ & 20 & 558,76 & 554,98 & 0,42 & 558,45 & 279,00 & 7,43 & 8,45 & 0,79 & 3,62 & $30,58 \%$ & $35,11 \%$ & & 3,78 & 169,65 & $88,52 \%$ & 56,78 \\
\hline $7 / 06 / 2013$ & $13: 23$ & 40 & 558,73 & 555,03 & 0,46 & 558,20 & 360,00 & 12,75 & 14,07 & 0,92 & 3,45 & $45,63 \%$ & $55,50 \%$ & & 3,71 & 259,45 & $91,09 \%$ & 71,33 \\
\hline $7 / 06 / 2013$ & $13: 27$ & 50 & 558,70 & 555,07 & 0,49 & 558,00 & 402,00 & 15,99 & 17,59 & 0,98 & 3,33 & $55,18 \%$ & $69,66 \%$ & & 3,63 & 308,80 & $91,34 \%$ & 79,79 \\
\hline $27 / 06 / 2013$ & $13: 33$ & 60 & 558,67 & 555,10 & 0,52 & 557,75 & 437,25 & 18,70 & 20,47 & 1,09 & 3,18 & $60,51 \%$ & $82,17 \%$ & 3,6 & 3,57 & 398,59 & $91,72 \%$ & 87,77 \\
\hline $7 / 06 / 2013$ & $13: 40$ & 70 & 558,65 & 555,12 & 0,52 & 557,60 & 450,00 & 19,60 & 21,45 & 1,11 & 3,12 & $63,64 \%$ & $87,69 \%$ & & 3,53 & 411,26 & $91,79 \%$ & 90,90 \\
\hline $27 / 06 / 2013$ & $13: 46$ & 75 & 558,65 & 555,13 & 0,53 & 557,50 & 439,50 & 19,72 & 21,57 & 1,13 & 3,09 & $63,31 \%$ & $88,88 \%$ & & 3,52 & 431,49 & $91,80 \%$ & 88,31 \\
\hline $27 / 06 / 2013$ & $13: 56$ & 80 & 558,65 & 555,13 & 0,55 & 557,47 & 446,25 & 19,43 & 21,26 & 1,18 & 3,05 & $60,81 \%$ & $88,56 \%$ & & 3,52 & 471,94 & $91,78 \%$ & 89,96 \\
\hline $27 / 06 / 2013$ & $13: 59$ & 100 & 558,63 & 555,16 & 0,55 & 557,35 & 436,50 & 18,78 & 20,56 & 1,19 & 2,99 & $59,56 \%$ & $88,31 \%$ & & 3,47 & 482,72 & $91,73 \%$ & 87,59 \\
\hline
\end{tabular}




\section{Anexo 2. Instalação (Dimensões em milímetros)}

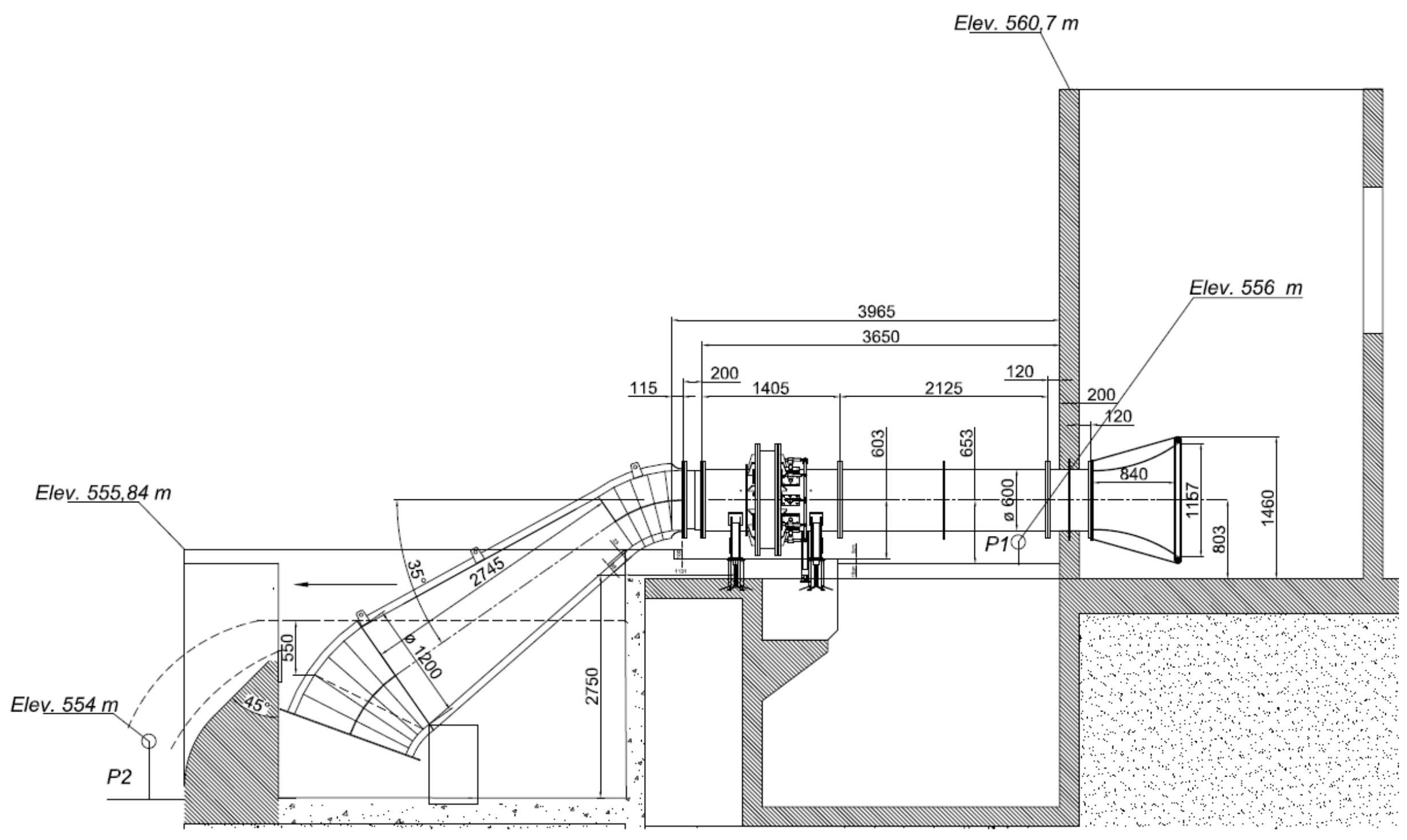




\section{Anexo 3. Ensaio de Aeração do Tubo de Sucção}

Durante os ensaios da turbina foi constatado um fortes instabilidades no interior da máquina devido a instabilidades no escoamento para praticamente toda a faixa operativa da unidade, com exceção do ponto de $100 \%$ de abertura do distribuidor. Segundo (RUPRECHT, 2000) existem dois grupos principais de problemas de instabilidades em escoamentos em turbo-máquinas. $\mathrm{O}$ primeiro grupo são escoamentos com instabilidades forçadas externamente, que podem ser causadas por condições instáveis na camada limite ou pela mudança na geometria com o tempo. Um exemplo disto é a iteração Distribuidor-Rotor presente neste trabalho. O segundo grupo são escoamentos com instabilidades auto excitadas, que são por exemplo: escoamentos turbulentos, vórtices de Von Karman ou vórtices com comportamento instável, onde a trança gerada no tubo de sucção se encaixa.

Segundo FERNANDO CASANOVA (2010) as pulsações de pressão na turbina aparecem devido aos vórtices de Von Karman nas pás do distribuidor e a trança (Vortex Rope) no tubo de sucção.

Esses dois grupos estão presentes em turbinas hidráulicas e geram além de ruído, oscilações de pressão e eixo na máquina diminuindo sua vida útil. Um dos modos de se avaliar essas instabilidades é a medição da oscilação de pressão no tubo de sucção. Esse é um parâmetro utilizado atualmente no contrato de grandes Usinas Hidrelétricas como garantia de desempenho e alvo de grandes discussões entre clientes e fornecedores de turbinas.

A figura A3.1 mostra a instalação de um vacuômetro na entrada do tubo de sucção para medição da oscilação de pressão.

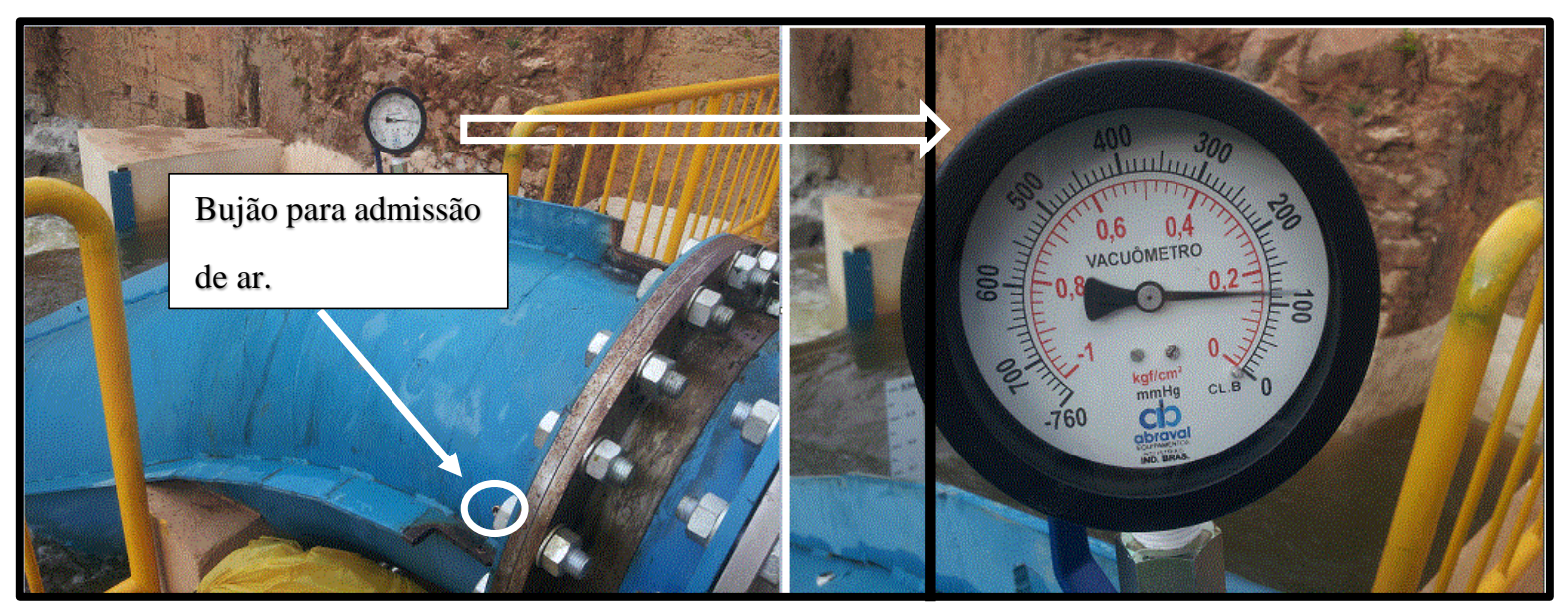

Figura A3.1. Vacuômetro 0 a -1 bar instalado na Entrada do Tubo de Sucção 
As medições foram feitas em conjunto com os ensaios da máquina, a figura A3.2 mostra os valores médios comparando o comportamento da máquina com e sem admissão de ar. Para aberturas abaixo a admissão de ar não se mostra eficiente, nesta faixa como a unidade geradora está bem longe do ponto ótimo. Para aberturas acima de $20 \%$ de abertura do distribuidor o efeito da injeção de ar fica nítido amenizando a pressão negativa na sucção.

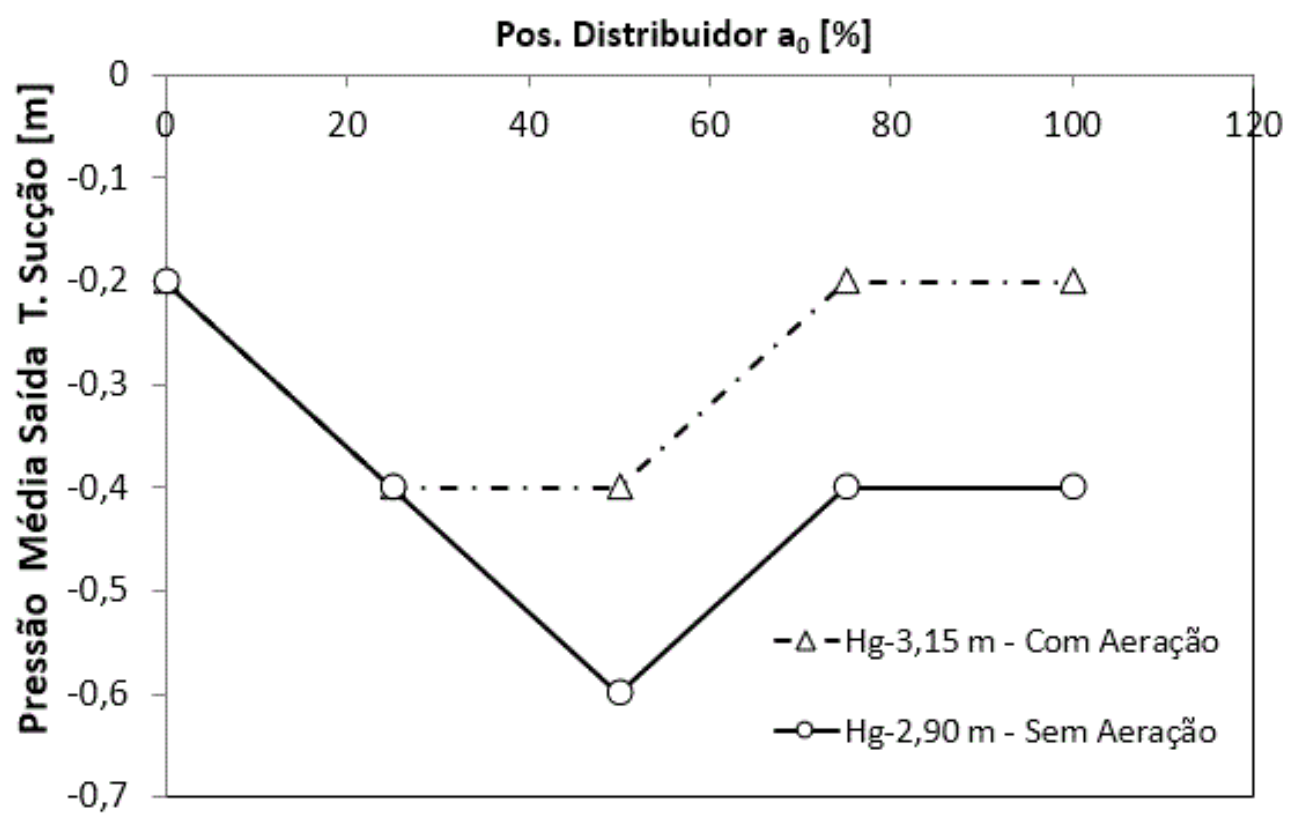

Figura A3.2. Pressões Médias na Saída da Sucção - Com e Sem Ar

A figura A3.3 mostra a oscilação de pressão para os mesmos pontos medidos mostrados na figura A3.3. Juntamente com a redução da oscilação de pressão com a admissão de ar foi perceptível a redução de ruído da máquina referente ao escoamento no interior da máquina. O nível de ruído externo a máquina devido a admissão de ar no tubo de sucção é alto, logo como recomendação o que pode ser feito ao invés da admissão direta de ar, a mesma pode ser feita através da instalação de um conjunto de tubos instalados radialmente ao tubo de sucção com a outra extremidade aberta para a atmosfera onde não há a circulação de pessoas e onde esse ruído possa ser isolado.

Na figura A3.3 foi inserida uma linha limite de oscilação de pressão de $10 \%$ da queda liquida nominal que mostra que uma restrição na faixa operativa da máquina pode ser adicionada a operação da unidade onde cargas parciais devem ser eliminadas e sempre com injeção de ar pelo tubo de sucção visando a extensão da vida útil da unidade. 


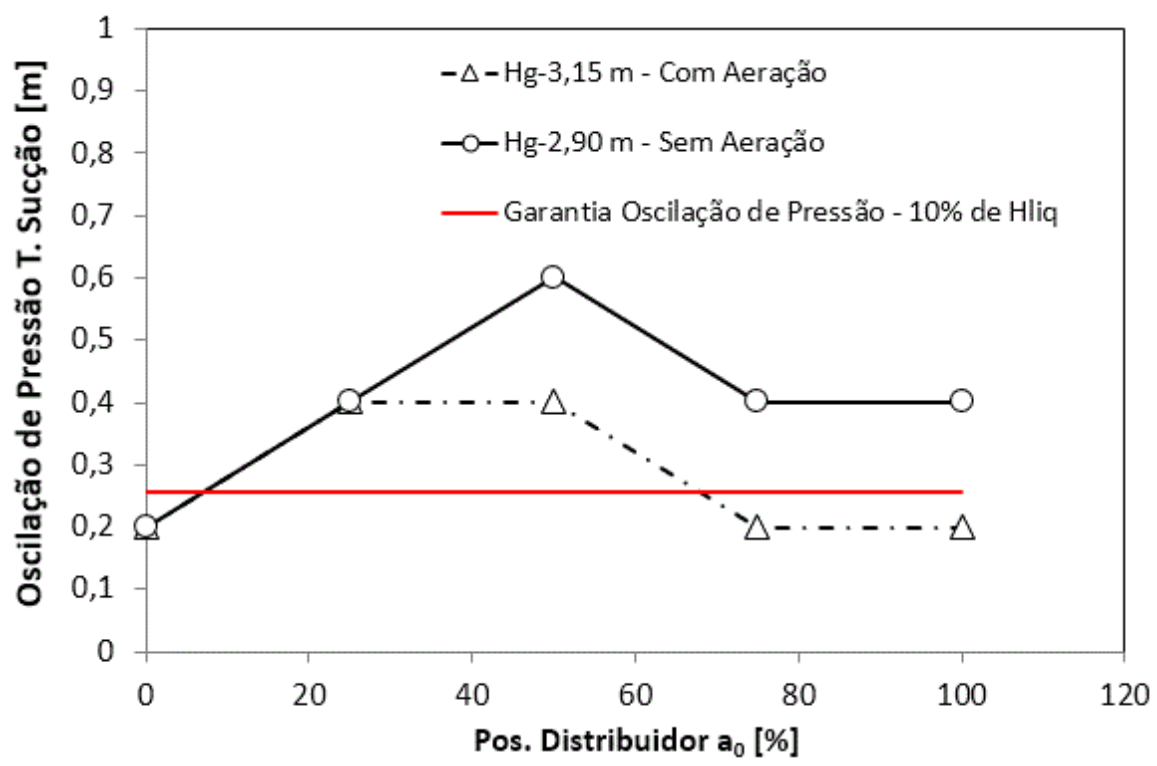

Figura A3.3. Oscilação de Pressão no Tubo de Sucção - Com e Sem Ar

A figura A3.4 mostra a análise da eficiência global da turbina com relação ao efeito da admissão de ar no tubo de sucção. Embora o efeito da injeção de ar seja mais perceptível na oscilação de pressão e na atenuação do ruído da máquina a eficiência é pouco afetada com uma ligeira tendência de piora da eficiência com a admissão de ar próximo do ponto ótimo de operação. Entretanto como se trata de uma micro central hidrelétrica a estabilidade e vida útil do equipamento deve prevalecer em detrimento de uma perda mínima de eficiência, logo a injeção de ar pelo tubo de sucção deve estar presente em toda a faixa operativa.

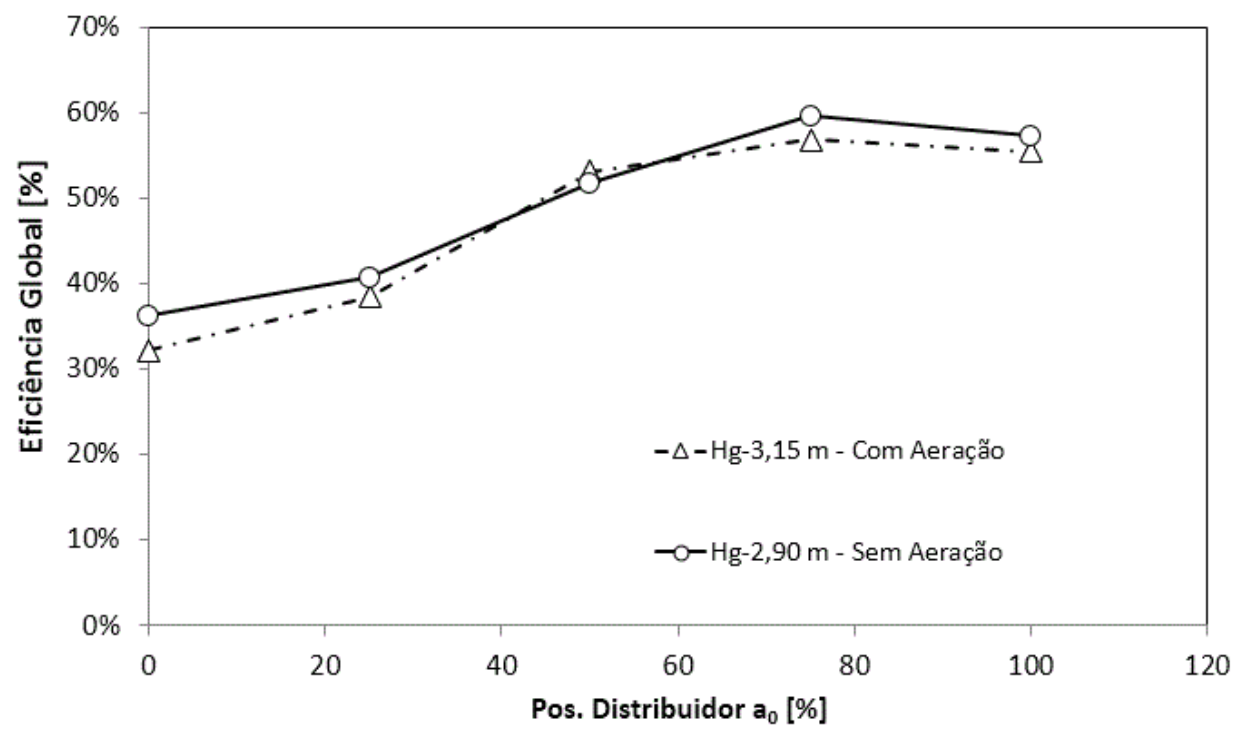

Figura A3.4. Oscilação de Pressão no Tubo de Sucção - Com e Sem Ar 